This item was submitted to Loughborough's Research Repository by the author.

Items in Figshare are protected by copyright, with all rights reserved, unless otherwise indicated.

\title{
A methodology for predicting company failure in the construction industry
}

PLEASE CITE THE PUBLISHED VERSION

PUBLISHER

(C) Adnan Fadhil Abidali

LICENCE

CC BY-NC-ND 4.0

\section{REPOSITORY RECORD}

Abidali, Adnan Fadhil. 2019. "A Methodology for Predicting Company Failure in the Construction Industry". figshare. https://hdl.handle.net/2134/7034. 
This item is held in Loughborough University's Institutional Repository (https://dspace.lboro.ac.uk/) and was harvested from the British Library's EThOS service (http://www.ethos.bl.uk/). It is made available under the following Creative Commons Licence conditions.

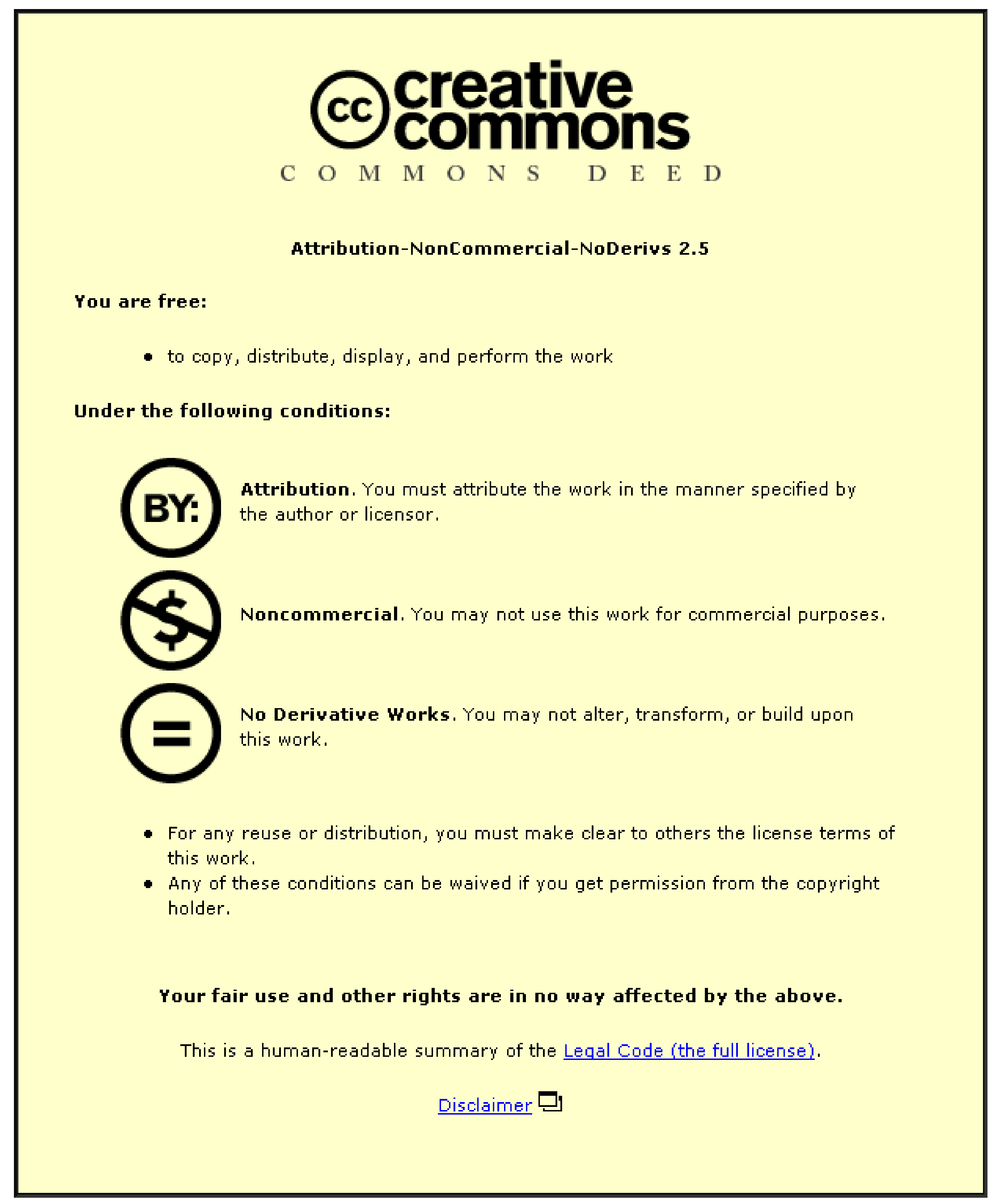

For the full text of this licence, please go to: http://creativecommons.org/licenses/by-nc-nd/2.5/ 
A METHODOLOGY FOR PREDICTING COMPANY FAILURE

IN THE CONSTRUCTION INDUSTRY

by

ADNAN FADHIL ABIDALI, BAE, MSC

A Doctoral Thesis submitted in partial fulfilment

of the requirements for the award of

Doctor of Philosophy

of the

Loughborough University of Technology

August 1990

- Adnan Fadhil Abidali 


\section{DEDICATION}

To the soul of my father FADHIL, a great father, who gave me inspiration and moral support

and

My Mother

* * * * * 


\section{DECLARATION}

No portion of the research referred to in this thesis has been submitted in support of an application for another degree or qualification at this or any other university or other institution of learning. 


\section{ACKNOWLEDGEMENIS}

I would like to extend my sincere thanks to all who gave generously of their knowledge, time and experlence during the preparation of this report.

Grateful thanks are extended to my Director of Research, Professor R MoCaffer for his guidance and support.

The author also wishes to thank Dr J Allen for his advice on computer programing.

Thanks are also due to all staff of the Computer Centre for their advice and valuable assistance.

The author also wishes to thank Mr $J$ Finnie for his advice on financial ratio analysis.

Thanks to Mr R M Addy, Senior Liquidator of Cork Gully, Chartered Acoountants, for his support in providing case studies relating to company failures in the construction industry.

Thanks are also due to all staff of the Landan Borough of Camden who gave their time during testing of the model. Special thanks are extended to Mr I Pardhanant for his valuable time spent on discussing the results and his enthusiasm to adopt the model at LBC.

Special thanks are expressed to the project supervisor, Professor F Harris for his guidance and encouragement who went beyond mere supervision of this study. His enthusiasm for the research provided a source of inspiration to the author.

The author also wishes to thank Mrs Janet Sinith for her help in typing the thesis.

Finally, to my family I extend my love, and to my wife I extend my sincere thanks for her encouragement and patience during the preparation of this report. 


\section{ABSTRACT}

This thesis develops the theory of failure prediction for UK construction companies. The research aims were directed towands an evaluation of several methods namely:

1. Multivariate discriminant analysis: This technique is widely employed in the commercial sector with much of the work concentrated on failed and healthy companies. Altman [8], Deakin [25], Taffler [11]. The different characteristics of two or more groups are analysed to create a model that best differentiates between them. The end result transforms these characteristics into a single varlable, normally called a z-score. \&

This method was particularly well demonstrated in this thesis by the successful prediction of failure of Rush and Tamkins plc three years before the recent announcement.

Secondly the multiple regression second version was enthusiastically employed by the Landan Boraugh of Camden for vetting oontractors on tender lists.

Generally the first model performed well on the data for quoted and unquoted companies, while the second was better for unquoted companies, particularly those private companies dealing with LBC.

2. Traditional financial ratios: The use of financial ratios to predict fallure is not new, Indeed Merwin [2] analysed 6 years trends of ratios for a number of failed and non-failed companies and found that three ratios were particularly sensitive predictors of failure. Further work was later reported by Beaver [3] and Pinches [6].

In this study, 31 financlal ratios were calculated and statistically examined as potential indicators. Three were found to be important at the following limits:

- current assets/current liabilities

- net assets/arrent liabilities

1.0

- pre-tax profit/payable interest

1.0

2.0

Ratios alone, however, were not sufficiently reliable to predict fatlure and the research concluded that it was essential to use at least two different methods before firm indications of failure of a suspect company can be substantiated.

3. The A-score method: The concept behind the A-score is based on the belief that if a company is in financial difficulty the reason generally relates to inadequate management ability and errors perpetrated earlier, the A-score is designed to address this aspect of failure prediction e.g. Argenti [7]. 
A questionnaire was devised and included 17 questions related to failure for both an "at risk" group classified as vulnerable, i.e. those scoring negatively by the $\mathrm{z}$-score model and a positively scoring "solvent" group.

The existence of managerial factors related to failure was investigated in the questionnaire using a multiple choice method. Both groups proved adequate for comparison purposes, and were therefore included in the A-score model.

The A-score for a company is obtained by adding the weight of all factors and errors together, and a cut-off value determined. The model was statistically verified by the t-test method at $1 \%$ significant level and further examined by the Willooxon (Rank Sum) tests null hypothesis rejected at $5 \%$ level of significance.

An attempt was also made to relate $\mathrm{A}$-score and $\mathrm{Z}$-score values, unfortunately statistical analysis indicated only $67.7 \%$ intercorrelation between A-score and $\mathrm{Z}$-score i.e. not very strong. However, the Z-score value of zero corresponded to an A-score cut-off value of about 50, these being critical values in both modes.

Finally, trend analysis was shown to be a suitable extra check in objective evaluation of company performance, and an improved method of systematically appraising contractors was produced. However, the developed models should only be used as part of an overall assessment of company stability. Any predictions should be interpreted with caution as the models require further testing on a broader range of companies. It is also important to appreciate that the use of such models to exclude companies from tender lists could accelerate or even cause failure. 
Dedication

Page No

Declaration

Acknowledgements

Abstract

iv

Contents

vi

List of Tables

xifi

List of Figures

xviii

CONTENTS

CHAPTER 1: GENERAL INTRODUCTION .......... 1

1.1 Introduction to Subject Matter ...... 1

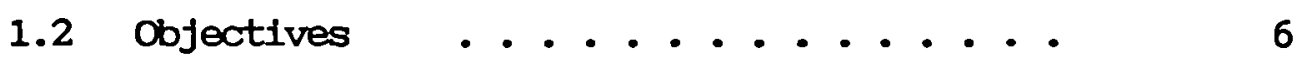

1.2.1 Secandary Objective ........ 7

1.3 Methodology ................. 7

1.4 Achlevements ................ 9

1.5 Organisation of the Thesis ....... 10

CHAPTER 2: REVIEW OF PREVIOUS STUDIES . . . . . . 14

2.1 General Introduction .......... 14

2.1.1 Introduction to Failure Prediction . 14

2.2 The Traditional Financial Ratios Method .. 14

2.2.1 Introduction .......... 14

2.2.2 Merwin's Study .......... 15

2.2.3 Beaver's Study .......... 16

2.2.4 Argenti's study .......... 17

2.2.5 Summary and Conclusions to Traditional Financial Ratios as Predictive Tools of Failure . . . . . . . 22

2.3 The z-Score Method .......... 24

2.3.1 Introduction .......... 24

2.3.2 Altman Z-score Model ....... . 26

2.3.3 Taffler z-score Model ........ 27

2.3.4 Mason and Harris Z-Score ..... 29

2.3.5 Other z-Score Models ....... . 30

2.3.6 Summary and Conclusions to Z-soore
Model Method .............. 30 
Page No

2.4 The A-Score Method $\ldots . . . . . . .34$

2.4 .1 Introduction ......... 34

2.4.2 Argenti A-Soore .......... 35

2.4.3 Conclusions to A-Soore ...... 37

2.5 Summary and Conclusions ........ 37

CHAPTER 3: THE TECHNIQUE OF DISCRIMINANT ANALYSIS . . 39

3.1 Introduction ............. 39

3.2 The General Concept of MDA ....... 41

3.3 The Mathematical Theory Behind MDA .... 43

3.4 Derivation of Computational Fonmula . . . . 47

3.5 Statistical Computer Package and its use . . 54

3.6 Summary and conclusions ........ 55

CHAPTER 4: DATA COLLECTION AND FORMATION OF THE DATA GROUPS ................. 60

4.1 Introduction ............ 60

4.2 Data Analysis ............. 61

4.3 Formation of the Data Groups ....... 62

4.3.1 The "Failed 11" and "Test Failed 11" Groups ............ 63

4.3.2 The "Non-Failed 20" Group ..... 65

4.3.3 The "Taken-Over 9" Group ..... 67

4.3.4 The "Continued 70" Group ..... 68

4.3.5 The "All 90" Group ........ . . . 69

4.4 Summary and Conclusions ........ 69

CHAPTER 5: THE DEVELOPED MODEL AND REGRESSION CHARACTERISTICS ............. 70

5.1 Introduction ............. 70

5.2 Financial Ratios used in the Analysis ... 70

5.3 Financial Ratios Calculations and Data Manipulation ......... 
Page No

5.3.1 Introduction ........... . 74

5.3.2 Computer Package (Adnan.For) . . . 74

5.4 Statistical Computer Package (SPSSX) . . . 75

5.4.1 Introduction .......... . 75

5.4.2 Statistical Computer Package . . . 75

5.5 Multiple Regression Models ....... 85

5.5 .1 Introduction .......... 85

5.5.2 The Regression Model ....... 85

5.5.3 Updated Mason Model ....... 86

5.6 Summary and Conclusions ......... 87

CHAPTER 6: THE RESULTANT MODEU . . . . . . . . 89

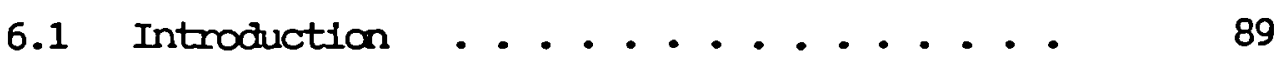

6.2 The Resultant Model ........... 89

6.3 The Constituent Variables ........ 90

6.4 The Relationship Between the Ratios .... 93

6.5 Contribution of Each Ratio to the Model . . 97

6.6 The Cut-Off Between Groups and Grey-Area . . 100

6.6.1 Introduction .......... 100

6.6.2 Mathematical Derivation of the cutOff Point .......... 101

6.6.3 Prior Probability and Misclassification Costs Estimates . . . . . 106

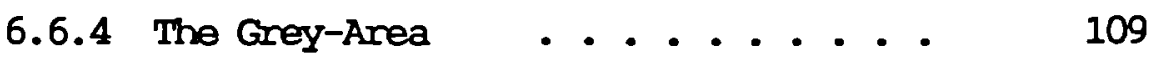

6.7 Summary and Conclusions ........ 110

CHAPTER 7: RESULTS FROM THE MODELS . . . . . . . 113

7.1 Introduction . . . . . . . . . . 113

7.2 Results Obtained fram the "Non-Failed 20" and "Failed 11" Groups ......... . 114

7.2.1 Introduction ......... 114

7.2.2 The Results of the "Non-Failed 20" and "Failed 11" Groups ....... 114 


\section{Page No}

7.2.3 Prior Year Z-Scores Analysis ....

7.3 Results Obtained from the "Taken-Over 9" Group . . . . . . . . . . . .

7.4 Results Obtained fram the "Non-Failed 20" and "Failed 11" Groups by Using Multiple Regression Model ........... 124 7.4.1 Introduction ........... 124

7.4.2 The Results of the "Non-Failed 20" and "Failed 11" Groups .......

7.4.3 The Grey-Area of the Multiple Regression Model ........ 127

7.4.4 Prior Year's Z-Score Analysis . . . 128

7.5 Results Obtained from the "Non-Failed 20" and "Failed 11" Groups by Updating Mason Model ...............

7.5.2 The Results ......... 129

7.6 Trends Analysis $\quad$. . . . . . . 133

7.6.1 Introduction ......... 133

7.6.2 The Analysis ......... 133

7.6.3 Conclusions ......... 144

7.7 Financial Ratios as a Means of Predicting Fallure ............. 146

7.7.1 Introduction ......... 146

7.7.2 The Critical Ratios ....... 147

7.7.3 Conclusions ......... 149

7.8 Summary and Conclusions ........ 153

CHAPTER 8: VALIDATION OF THE Z-MODELS AND FINANCIAL RATIOS AS A TOOL FOR PREDICTING FAILURE • . 156

8.1 Introduction . . . . . . . . . 156

8.2 Validation of Developed Model ....... 156

8.2.1 Introduction . . . . . . . . 156 
Page No

8.2.2 Results Obtained from the "Test Failed 11" and "Continued 70" Groups

8.2.3 Results Obtained from the "Test Failed 11" and "All Failed 22" Groups

8.2.4 Prior Years Z-Score Analysis for the "Test Failed 11" Group ... . . .

8.2.5 Results Obtained fram the "Test 70" and "Non-Failed 20" Groups .....

8.2.6 Prior Years Z-Score Analysis for the "Continued 70" and "Non-Falled 20" Groups .. . . . . . . . .

8.2.7 The Relationship Between Bankrupt and Z-Score Trend . . . . . . . 170

8.2.8 Prediction of Bankruptcy Using the Discriminant Model ....... . 172

8.3 Validation of Multiple Regression Model . . 176

8.3.1 Introduction .......... 176

8.3.2 Results Obtained from the "Test Failed 11" and "Test Continued 70" Groups ...........

8.3.3 Results Obtained from the "Test Failed 11" and "All Failed 22" Groups

8.3.4 Prior Years Z-Score Analysis from "Test Failed 11" Group ....... 181

8.3.5 Results Obtained fram the "Continued 70" and "Non-Failed 20" Groups ...

8.3.6 Prior Years Z-Score Analysis from "Continued 70" and "Non-Falled 20" Groups . . . . . . . . . 182

8.3.7 Validation of Model at London Borough of Camden .......... 183

8.4 Validation of Financial Ratios as a Tool for Predicting Fallure . . . . . . . . 
8.4.1 Introduction ..........

8.4.2 Results Obtained from "Test Falled

8.4.3 The Z-Scores Linked with Critical Financial Ratios as a Tool for Predicting Failure ........

8.5 Summary and conclusions ........

CHAPTER 9: MANAGERIAL FACTORS RELATED TO COMPANY FAILURE . . . . . . . . . . . . 194

9.1 Introduction . . . . . . . . . . 194

9.2 Particular Factors of Failure by a Case Study Approach . . . . . . . . . . 195

9.2.1 Introduction .......... . 195

9.2.2 Case study 1 . . . . . . . 196

9.2.3 Case Study 2 . . . . . . . . 196

9.2.4 Case study 3 ......... 197

9.2.5 Conclusions ......... 198

9.3 Management Defects and Management Mistakes . 199

9.3.1 Introduction . . . . . . . . 199

9.3.2 Management Defects ........ 199

9.3.3 Management Mistakes ......... 201

9.3.4 Conclusions ......... 203

9.4 Survey Related to Managerial Defects and Mistakes .. . . . . . . . . . 204

9.4.1 Introduction ........... 204

9.4.2 The Survey .......... 204

9.4.3 Results from the Survey ...... 206

9.4.4 Conclusions .......... 211

9.5 Summary and conclusions ......... 212 
Page No

CHAPTER 10: THE A-SCORES . . . . . . . . .

10.1 Introduction ............. 213

10.2 Formation of Data Groups . . . . . . 214

10.3 The Developed A-Score Model . . . . . 215

10.3.1 Weighted Results . . . . . . 218

10.3.2 Method of Scoring . . . . . . 218

10.3.3 Statistical Analysis ...... 219

10.4 Validation of Results from the "Test 14" Group .............. . 219

10.5 Relationship Between the A-Score and the Zscore ............. . . 220

10.6 Summary and Conclusions . . . . . . . 221

CHAPTER 11: DISOUSSION AND CONCLUSIONS ....... 223

11.1 Introduction ........... 223

11.2 The z-Scores ............ . . 224

11.3 The Traditional Ratios ......... 226

11.4 The A-Scores . . . . . . . . . 227

11.5 Research Findings ........... 228

11.6 Recommendations for Implementing the Research Findings in Vetting Construction Companies in Tender Lists ....... 232

11.7 Contributions of the Thesis to the Canstruction Industry ......... 236

11.8 Further Research ........... 236

References

APPENDIX A: 


\section{LIST OF TABLES}

Table No

Page No

1.1 Number of private contractors by activity

3

2.1 Results obtained from previous studies of the traditional financial ratios as predictive tool of failure

2.2 Ratios discriminating between failed and nonfailed companies in murtivariate studies

2.3 Companies with at risk z-score at the end of 1976. A summary of subsequent events

3.1 The results obtained from an illustrative example

3.2 ' ' values for the sample problem

4.1 A list of companies in the "failed 11" group

4.2 A list of companies in the "test failed 11" group

4.3 A list of companies in the "man-failed 20" group

4.4 A list of companies in the "take-over 9" group

4.5 A list of companies in the "continued 70" group 
$5.1 \quad$ Financial ratios employed in the analysis 72

5.2 Key to Table 5.1

6.1 The constituent ratios and financial aspect measurements

6.2 The within group correlation matrix

6.3 Description of ratios and financial aspects, measurements achieved by previous studies and this study

6.4 The percentage contribution of ratios to the discriminant model

6.5 Insolvencies in the construction industry

7.1 The results obtained from the "non-failed 20" group

7.2 Results obtained from the "failed 11" group

7.3 Classification of the "non-failed 20" and "failed 11" groups

7.4 Prior years classification of the "non-failed 20" group

7.5 Prior years classification of the "failed 11" group

7.6 Results obtained from the "take-over 9" group 
7.7 Prior years classification of the "take-over 9" group

7.8 Results obtained from the "non-failed 20" group by using multiple regression model [2]

7.9 Results obtained from the "fatled 11" group by using multiple regression model [2]

7.10 Prior years classification of the "non-failed 20" and "failed 11" groups by using multiple regression model

7.11 Results obtained from the "non-failed 20" group by using an updated Mason model [3]

7.12 Results obtained from the "failed 11" group by using an updated Mason model [3]

7.13 Prior years classification of the "non-failed 20" group by using an updated Masan model [3]

7.14 Prior years classification of the "failed 11" group by using an updated Mason model [3]

7.15 Discriminating variables inclusion in the three models

7.16 The results of the discriminating ratios obtained from the "non-failed 20" group

7.17 The results of the discriminant ratios obtained from the "failed-11" group 
7.18 Sumary of the results by using models 1, 2 and 3

8.1 Results obtained from the "test-failed 11" group

8.2 Results obtained from the "test continued 70" group

8.3 Classification of the "test failed 11" and "test continued 70" groups

8.4 Classification of the "test failed 11" group

8.5 Classification of the "all failed 22" group

8.6 Prior years classification of the "test falled 11" group

8.7 Prior years classification of the "continued 70" group

8.8 Prior years classification of the "all 90" group

8.9 Results obtained from the "test failed 11" group by using multiple regression model

8.10 Results obtained from the "continued 70" group by using multiple regression model

8.11 Classification of the "test failed 11" and "test continued 70" groups 
8.12 Classification of the "test falled 11" group

8.13 Classification of the "all failed $22^{n}$ group

8.14 Prior years classification of the "test failed 11" group

8.15 Prior years classification of the "all 90" group by using multiple regression model

8.16 The results of discriminating ratios obtained fram "test failed 11" group

8.17 The results of discriminating ratios obtained from the "classified as failed 17" group

8.18 The results of discriminating ratios obtained from the "classified as non-failed 73" group

9.1 The Z-score for the "at risk 7" group

9.2 The $\mathrm{Z}$-score for the "solvent $7^{n}$ grap

10.1 The A-score for the "at risk 7" group

10.3 


\section{LIST OF FIGURES}

Figure No

Page No

1.1 A number of insolvencies in the construction industry

1.2 Thesis layout diagram

3.1 The two group-one variable (univariate) diagram

3.2 The two groups-two variables diagram

5.1 A particular step in the stepwise method

5.2 A sumary of all the steps in the analysis

5.3 The final step in analysis at step 9

81

5.4 Unstandardised canonical discriminant function coefficients

5.5 The discriminant scores

6.1 The cut-off point between groups

6.2 The cut-off between "non-failed 20" and "failed 11" groups

7.1 Histogram of the "non-failed 20" and "failed 11 " Z-scores 
7.2 The "non-failed 20" and "failed 11" companies prior year z-score means obtained from the discriminant model [1]

7.3 The "non-failed 20" and "failed 11" companies prior year $\mathrm{Z}$-score means obtained from the multiple regression model [2]

7.4 The "non-failed 20" and "failed 11" companies prior year $\mathrm{z}$-score means obtained from the updated Mason model [3]

7.5 The trend of the means of profit after tax to net capital employed ratio in the "non-failed $20 "$ and "failed 11" companies

7.6 The trend of the means of current assets to net assets ratio in the "non-failed 20" and "failed 11" companies

7.7 The trend of the means of turnover to net assets ratio in the "non-failed 20 " and "failed 11" companies

7.8 The trend of the means of short term loans to earnings before tax ratio in the "non-failed 20" and "failed 11" companies

7.9 The trend of the tax trend in the "nonfailed" and "failed 11" companies

7.10 The trend of the profit after tax trend in the "non-failed 20" and "failed 11" companies 
7.11 The trend of the short term loan trend in the "non-failed 20" and "failed 11" companies

7.12 The trend of earnings before tax and interest to net capital employed ratio in the "nonfailed 20" and "failed 11" companies

7.13 The trend of debtors to current liabilities ratio in the "non-failed 20" and "failed 11" companies

7.14 The trend of current liabilities to net assets ratio in the "non-falled 20" and "failed 11" companies

7.15 The trend of interest to earnings before tax ratio in the "non-failed 20" and "failed 11" companies

8.1 The trend of prior year $\mathrm{z}$-soore means of the "continued 70" and "test failed 11" groups

8.2 Z-score distribution for the "all 90" group for 1984 with superimposed normal distribution

8.3 Z-score distribution for "all 90" group for 1985 with superimposed normal distribution

8.4 Z-score distribution for "all 90" group for 1986 with superimposed nonmal distribution

8.5 Z-score distribution for "all 90" group for 1987 with superimposed normal distribution 
8.6 Bankrupt trend in construction industry 171

8.7

Z-score trend for "all 90" group

171

11.1 A systematic appraisal of contractor diagram

234

11.2

Key to Figure 11.1

235

xxi 
GAAPTER 1

GENERAL INIRODUCTION

1.1 Introduction

1.2 Objectives

1.3 Methodology

1.4 Achievements

1.5 Organisation of the Thesis 


\section{CHAPTER 1}

\section{GENERAL INTRODUCTION}

\subsection{INTRODUCTION}

The number of construction company liquidations has been, perhaps surprisingly higher in recent years than in the low output years of 1977 and 1982. This could indicate that many which started up in the boom years have since failed due to inadequate finance and managerial skills.

Figure 1 plots the number of insolvencies in construction companies in England and Wales. It can be seen that during the period 1979-1985 an increase of insolvencies followed by a rapid decrease in 1985 probably starting with the boom in construction in 1986.

The fall in insolvencies in 1987 corresponds with the increase in output in 1987. A fall in overall demand always seems to be accompanied by a rise of insolvencies and vice versa.

It is clear that the number of firms becoming insolvent between the period of 1983-1986 was nearly twice as much as before.

Although the number of insolvencies went up however, there was a large entry of firms into the construction industry and many may not have possessed all the attributes required to ensure success.

There are also, fairly high numbers of insolvencies with compulsory and voluntary liquidations among construction companies accounting for around 13 웅 of all liquidations. 


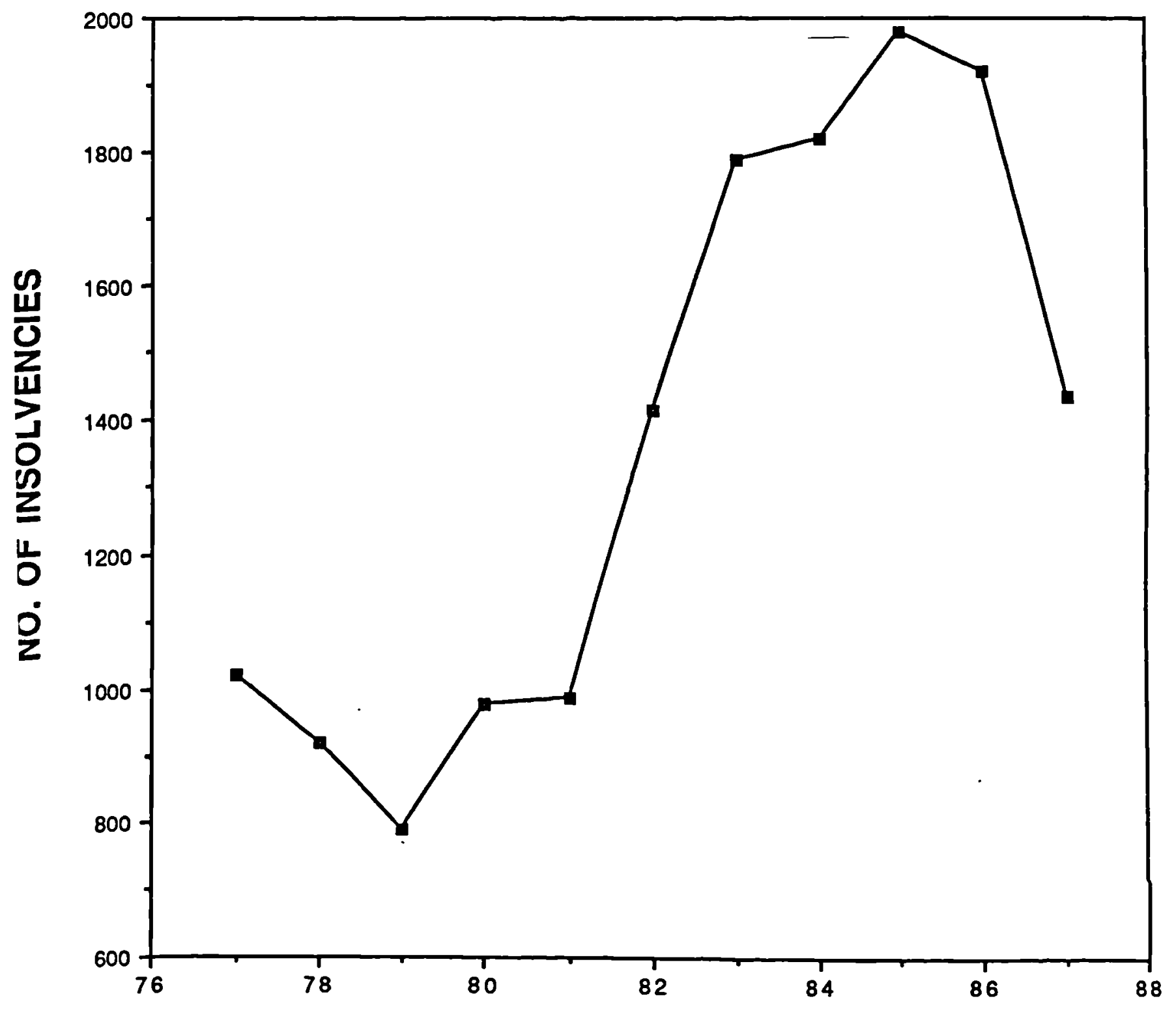

YEARS

FIGURE 1.1: THE TREND OF INSOLVENCIES IN THE CONSTRUCTION INDUSTRY 


\begin{tabular}{|c|c|c|c|}
\hline Activity & 1982 & 1987 & \& Increase \\
\hline 1 General builders & 57565 & 68947 & 19.8 \\
\hline $\begin{array}{l}2 \text { Building and Civil } \\
\text { Engineering Contractors }\end{array}$ & 3242 & 3917 & 20.8 \\
\hline 3 Civil Engineers & 2357 & 2946 & 25.0 \\
\hline 4 Plumbers & 13286 & 15207 & 14.5 \\
\hline 5 Carpenters \& Joiners & 9341 & 11741 & 25.7 \\
\hline 6 Painters & 14267 & 14898 & 4.9 \\
\hline 7 Roofers & 4469 & 6145 & 37.5 \\
\hline 8 Plasterers & 3590 & 4137 & 15.2 \\
\hline 9 Glaziers & 3036 & 4871 & 60.4 \\
\hline 10 Demolition Contractors & 523 & 634 & 21.5 \\
\hline 11 Scaffolding Specialists & 623 & 1081 & 73.5 \\
\hline $\begin{array}{l}12 \text { Reinforced Concrete } \\
\text { Specialists }\end{array}$ & 435 & 597 & 37.2 \\
\hline $\begin{array}{l}13 \text { Heating \& Ventilation } \\
\text { Engineers }\end{array}$ & 7469 & 8751 & 17.2 \\
\hline 14 Electrical Contractors & 13176 & 16402 & 24.5 \\
\hline $\begin{array}{l}15 \text { Asphalt \& Tar Spreaders } \\
\text { Plant Hires }\end{array}$ & 3260 & 3819 & 17.11 \\
\hline 16 Flooring Contractors & 1272 & 1495 & 17.5 \\
\hline 17 Construction Engineers & 1154 & 1756 & 52.2 \\
\hline 18 Insulating Specialists & 1076 & 1379 & 28.0 \\
\hline 19 Floor \& Wall Tilling & 963 & 1259 & 30.7 \\
\hline 20 Miscellaneous & 1866 & 3189 & 70.9 \\
\hline Total & 144395 & 175095 & 21.3 \\
\hline
\end{tabular}

TABLE 1.1: NUMBER OF PRIVATE CONIRACTORS BY ACTIVITY (Source: House and Construction Statistics (keynote)) 
Table 1.1 shows the number of private contractors by activity for the years 1982 and 1987, in which 45\% are single employee operations.

The rate of appearance and disappearance of small building firms in particular is high, with about 3000 new VAT registrations and roughly the same number of de-registrations each year. Therefore in this research it was decided to concentrate on general builders, building and civil engineering contractors or civil engineers who employ more than fifty employees medium-size to large companies and are also recorded in Company House. The companies are classified by numbers of employees, for example, small and medium companies, employing less tha $\mathbf{n} 50$ and 250 employees respectively, and over 250 for large companies [1].

Construction has always been a high risk business and clearly there is a need for an early warning system of bankruptcy. Furthermore potentlal company failures should be recognised at the earliest possible opportunity in order to minimise the costs to the public, especially as the majority of Govermment contracts are awarded to firms that appear on selected tendering lists. Also since under the Local Govermment Act 1988 reasans for rejecting potential contractors in competitive tendering need to be substantiated as necessary to set standard financial appraisal requirements.

In this context a London wide survey (see Appendix D) revealed that while the majority of authorities (24 out of 25) examine firm's financial accounts only eleven authorities prefer to see accounts for the last three years, a further eleven prefer to see the last two years and the remaining two base their appraisal on the most recent years results alone. 
Twenty authorities out of twenty five use ratio analysis to assess the financial appraisal which relies heavily upon an assessment of liquidity. Of the twenty authorities using ratios six use $\mathrm{z}$ - score analysis (mainly Altmans Z-Score developed in 1968 in the USA) to assess the solvency of potential contractors.

Furthermore, twenty two of the twenty five authorities impose same form of limit on the value of contracts which may be awarded.

In conclusion, the objectives behind the use of financial limits seem to be:

- Firms should not be encouraged to overtrade and consequent receivership.

- Firms should not be encouraged to become over-reliant on Council business.

- The council should not allow firms to became over-dependent upon a few contracts.

- There should be as wide a choice of firms as possible to ensure tenders are competitive and Councils get value for money.

- The use of financial limits based upon standard criteria ensure that applicants are treated fairly.

Obviously it would not be practicable under current circumstances to adopt a limit on the value of work, because of the impossibility of enforcement and monitoring adherence to the limits. 
Therefore, some other methods are needed which will give a quantitative indication of the solvency of companies.

This research work successfully developed several z-score models that were able to classify companies into solvent and insolvent groups, by giving each company a score related to its degree of solvency.

Until now, no other construction based system has been produced in the UK and the motivation for the development of a separate construction based system is that, in the UK, the characteristics of such firms differ from those of manufacturing concerns. The main difference being that civil engineering and construction companies practices are dominated by the contracting firm, with a contractor directly responsible to the client. The hypothesis of the thesis to prove that bankruptcy prediction for construction companies is both empirically feasible and theoretically explainable was largely achieved.

\subsection{OBJECTIVES}

1. To assist Local Authorities in the selection of an approved list of contractors for competitive tendering.

2. To provide bankers, lenders and investors with an early warning system of financial difficulty for construction companies.

3. To minimise the danger of corporate failure of companies making take-over bids of other companies possessing potential failure characteristics.

4. To develop a model able to predict the failure of companies in the construction incustry on a financial basis. 
5. To develop a model that is able to predict the fallure of compantes in the construction industry on a non-financial basis.

6. To investigate reasons for failure by using different methods of prediction before coming to a conclusion.

7. To develop a practical system that is able to classify companies into solvent and insolvent groups.

\subsubsection{Secondary Objectives}

1. To review the economic situation of the construction industry during the period of project.

2. To review the reasans for failure by case study method.

3. To review the previous studies of predicting failure in the construction industry and other sectors.

4. To develop a computer package for the calculation of financial ratios.

\subsection{METHODOIOGY}

The method which attermts to achieve the thesis objectives was made possible by using a cambination of two techniques, "Financial Ratio Analysis" and a statistical technique known as "Multivariate Discriminant Analysis". The object being to distinguish between two groups, namely "Solvent" and "Insolvent" firms by selecting fran a collection of "discriminating variables" measures which characterise the expected differences. 
The "discriminating variables" used to form the model are traditional financial ratios, calculated from The Canstruction Companies published balance sheets.

Because of complexities of calculation involving many different ratios for a large number of companies it was impractical to achieve this manually, because of time restrictions and precision of calculations.

Therefore, a computer program "ADNAN.FOR" was developed for the purpose. Questionnaires concerning companies and interviews of individuals were also incorporated. New data revisions were continuously made to collection methods and analysis techniques, also a second regression analysis model was developed and tested, and ultimately adopted in the selection of healthy contractors by Iandon Borough of Camden.

Further analysis was made of companies classified as potential fallures but not falling in the short term and the reasans for their survival considered.

A new tool "A-SOORES" was developed based on non-financial features which Identifies the items of failure extracted from case studies and company literature.

Questionnaires were also designed to achieve this goal followed by an evaluation of management deficiencies weighted for importance. 
Finally, a linkage between $\mathrm{Z}$-Scores and traditional ratios with AScores was developed to provide a practical system that is able to predict the failure of companies in the construction industry. In canclusion the research work proved how the developed system offers a contribution to failure prediction in the construction industry.

\subsection{ACHIEVEMENTS}

The research successfully achieved the following:

1. Faflure prediction based on financial features using financial ratios and Z-Scores as indicators of approaching fallure.

2. Failure prediction based on non-financial features which indicate failure long before the signs of financial difficulties.

3. Identification of the factors influencing failure in construction companies.

4. Identification of the mistakes companies made which may lead to failure.

Finally, a significant achievement was that the model was adopted by London Borough of Camden as an aid in the selection of healthy contractors.

To support this research existing models of predicting failure were reviewed and criticised. Also case studies of failed major construction companies were investigated and the reasons ascertained.

Furthemore, the research successfully developed a new system to aid Local Authorities in vetting construction oompanies in tender lists. 


\subsection{ORGANISATION OF THE THESIS}

Figure 2 illustrates the various steps taken in this research to achieve the stated objectives. These steps are presented in eleven chapters which are briefly described as a guide to the thesis.

Guide to The Thesis

Chapter 2: Presents a detailed literature review of previous studies relating to models for predicting the failure of a company. Methods for prediction of bankruptcy are also discussed.

Chapter 3: This chapter provides the background knowledge of "Multivariate Discriminant Analysis" and how the technique can be utilised to classify companies into "Solvent" and "Insolvent" groups.

Chapter 4: Presents the data collection and company groups used to establish the models including the data collected for testing the models.

Chapter 5: Presents a full description of the models together with the constituent variables, relationships between variables and contribution of each variable to the model, also included are the statistical techniques and computer packages used.

Chapter 6: Presents the resultant models including prior probability and misclassification estimation method, also cut-off value for the models are discussed. 
Chapter 7: Presents the results fram the models which support the "prediction" power of the technique and includes $\mathrm{Z}$ Scores, trends and financial ratios as tools for predicting fallure.

Chapter 8: Presents an attempt to validate the "MDA" technique and ascertain the capabilities of the model regarding discrimination between "solvent" and "insolvent" companies. Also validation of the regression model at London Borough of Camden is included. Finally validation of financial ratios as a tool of predicting failure is included.

Chapter 9: Presents non-financial features of failure and what they might indicate, management characteristics, management mistakes contributing to failure and not covered by any financial tool such as z-scores or financial ratios are illustrated, furthermore, a questionnaire was designed to identify the managerial factors related to failure.

Chapter 10: Presents a full description of the A-Scores model and method of scoring as a tool of predicting failure, the results are also described. Finally, relationships between the A-Scores and the Z-Soores are discussed.

Chapter 11: Presents conclusions drawn fram the research and how the developed system offers a contribution to the construction industry as an early warning system of failure and gives advice on corrective action to avoid failure. Also these findings are included altogether with recommendations for implementation in vetting construction companies for tender lists. 
The Appendices contain graphical presentations of the Z-Soores and tables of results obtained from individual companies.

A manual for use with the computer package ADNAN. FOR and an example of the programme application are included.

A manual for use with statistical computer package and sample of the output are also included.

A sample of the questionnaire and basic statistical tests is also contained in the appendices. 


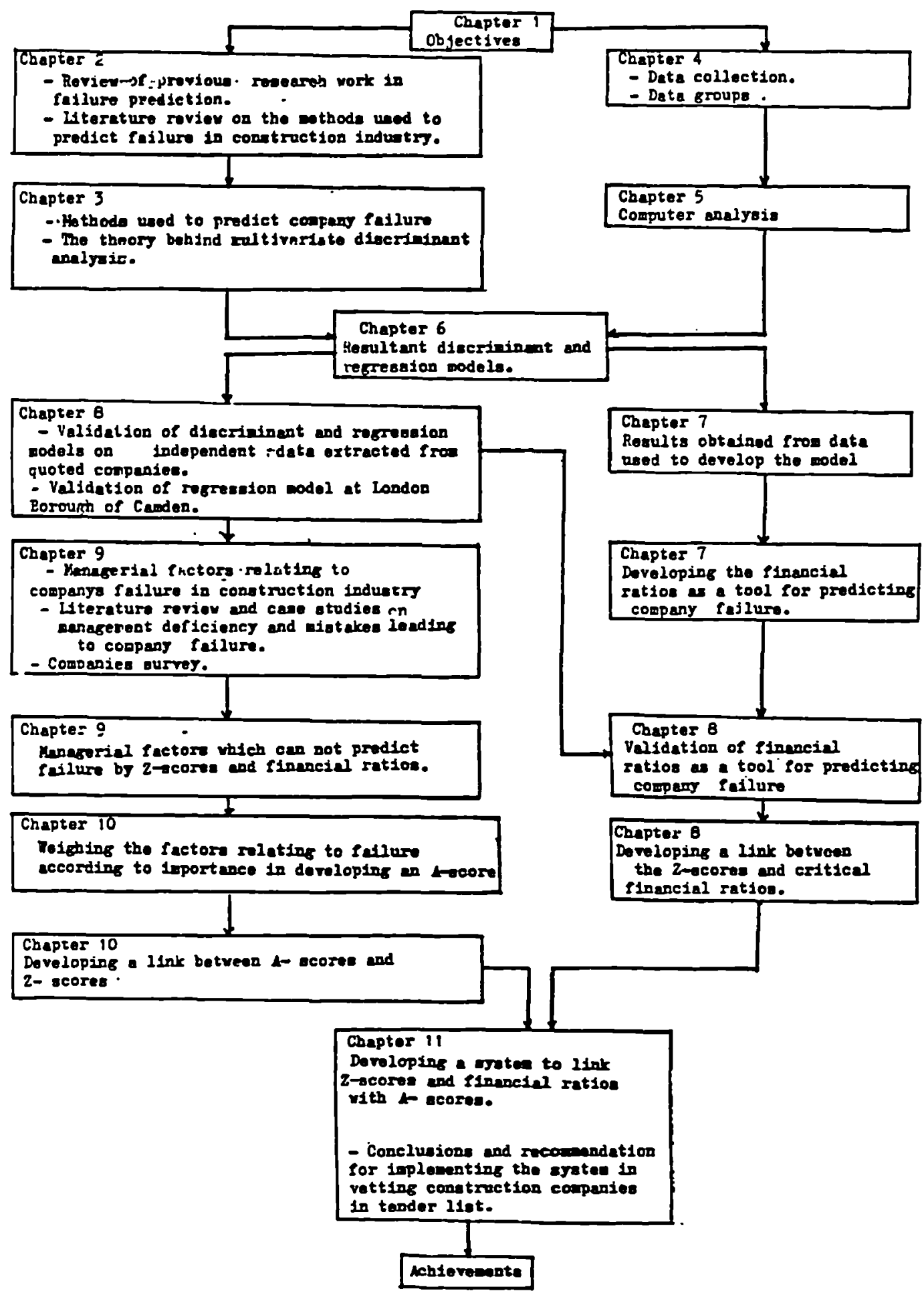

FIGURE 1.2: THESIS LAYOUT DIAGRAM 


\section{CHAPTER 2}

REVIEW OF PREVIOUS STUDIES

2.1 General Introduction

2.2 The Traditional Financial Ratios

2.3 The Z-Soore

2.4 Other Methods of Failure Prediction

2.5 Summary and Conclusions 


\section{CAAPTER 2}

\section{REVIEW OF PREVIOUS STUDIES}

\subsection{GENERAL INIRODUCTION}

Experience suggests that failure of a company may be defined as its having entered into receivership or voluntary or compulsory liquidation or having received government assistance. Previous studies proved that bankruptcy prediction is both empirically feasible and theoretically explainable, with much of a financial analyst's time spent intuitively making judgements, assessing likelihoods, forecasting etc.

\subsubsection{Introduction to Failure Prediction}

This chapter reviews the development of an operational method which has been used for the identification of companies in danger of failure.

Section 2.2 begins with the traditional financial ratios as a tool to predict company failure. Section 2.3 includes all the $\mathrm{z}$-score models. Section 2.4 deals with other methods of failure prediction. The final section briefly discusses the above methods, their weaknesses and advantages and utility.

\subsection{THE TRADITIONAL FINANCIAL RATIOS}

\subsubsection{Introduction}

The use of financial ratios to predict failure is not new. Ratios were first used in the USA in the late 1920s. 
In 1942 Merwin [2] also in the USA, analysed six years trends of ratios of a number of failed and non-failed companies. He found that three ratios were particularly sensitive predictors of fallure.

Other work was later carried out on the same subject by Beaver $[3,4,5]$ and Pinches [6].

Finally, John Argenti [7] compared the financial ratios of two companies which enfoyed approximately the same turnover and employed a similar volume of capital, ane of them cansidered successful and the other a troubled one. He concluded that ratios will not on their own, infallibly predict failure, his study is discussed in more detail in Section 2.2.4 because it relates to British industry and is considered the latest study in this field.

\subsubsection{Merwin's Study}

Merwin defined failure of a company "as those that had ceased filing tax returns". This definition includes not only bankrupt or economically unsuccessful firms but also those which had ceased operations voluntarily or changed their form of business organisation.

Merwin analysed a large number of financial ratios calculated from the financial data of a large sample of small corporations in five manufacturing industries [2]. The sample included continuing and discontinuing companies during the period 1926-1936 in the USA.

The following ratios were shown to be good discriminators between failed and non-failed companies are: 
1. Current ratio: 1.e. a ratio of current assets to current liabilities.

2. Net assets/total liabilities.

3. Working capital/total assets.

By comparing the industry mean ratios, Merwin found that the current ratios of the discontinued firms were lower than those of the continuing firms and moreover were shown to have declined three to five years prior to cessation of business.

Empirical studies in the USA have subsequently reinforced the view that the current ratio is a significant indicator of financial difficulties.

Merwin also highlighted higher debt in the failed campanies. Using the ratio of net asset to debt, he found that whereas only 26 percent of continuing firms had a ratio less than unity, in 65 percent of failed ones debt was greater than unity.

In over 70 percent of the failed firms the ratio of net assets to debt declined whilst in the continuing companies it remained fairly stable.

Also working capital/total assets ratios showed the ratio in failed firms, a year prior to bankruptcy was negative whilst in continuing firms positive.

\subsubsection{Beaver Study}

Beaver defined failure of a company "as those defaulting on interest payments, overdrawing their bank accounts or declaring bankruptcy". 
Beaver [3] analysed the ratios of 79 failed US firms in the period 1954-1964 and a corresponding number of non-failed firms.

The following ratios show there to be good discriminators between failed and non-failed companies:

1. Total liability/total assets (leverage ratio)

2. Net profit/total assets (profitability ratio)

3. Cash flow/total debt (liquidity ratio).

The mean of the total debt/total assets ratio of the continuing companies was 0.79 compared to 0.37 in the failed firms, one year before fallure. Also his study pointed to a sharp increase in the mean of the debt/total assets ratio of failed companies over the five years to failure. During the same period the means of the ratio remained unchanged in the continuing firms.

Also, in Beaver's study, the low net profit/total assets ratio proved to be one of the three major characteristics of failed firms. The mean of this ratio in the failed companies was substantially lower than that of the continuing firms period to fallure.

Cash flow/total debt ratio also showed that the mean of the ratio in the failed firms a year prior to bankruptcy was negative (less than 0.15 ), whereas in the continuing fims it was +0.45 .

\subsubsection{John Argenti Study}

John Argenti [7] analysed the main financial ratios as performance ratios as follows: 
1. The Acid Test Ratio on the Quick Ratio

Quick assets/current liabilities: this is considered the "ultimate test" by most financial specialists because it shows whether the company has sufficient cash to meet its immediate liabilities. Quick assets is defined as only current assets minus stock.

Current liabilities is any short-term liability including creditors and provisions, taxation dividends and overdraft. This ratio is considered to be one of the most important single failure prediction tools. Finance specialists traditionally like to see this ratio at or above 1 .

2. Current Ratio

$\frac{\text { current assets }}{\text { current liability }}$

This is the twin brother of the quick ratio but is a little stringent, a little less 'quick'. The only difference is that in this one stock, or inventory are included in current assets definition. Nevertheless the current ratio is much favoured. Financial specialists traditionally like to see the current ratio at 2 to 1.

\section{Capital Gearing 'Leverage' Debt/Equity}

Debt includes long-term debt and short tem. This definition includes all debt on which interest is payable, 1.e. debt means total borrowings. The ratio of 1 to 1 is high by British standards. 


\section{Inoome Gearing or "Interest Cover" Ratio}

\section{Profit before tax and interest} Interest

This is the amount of interest the company is committed to pay an its long- and short-term loans, as a ratio of its pre-tax profits. A company could quite happily carry on immense debts so lang as:
a) its profits were high
b) interest rates were low.

Results show that most companies with a ratio of 5 to 1 are in a comfortable situation.

\section{Stock Tumover Ratio $=$ Sales $/$ Stocks}

or

$$
\frac{\text { Stocks }}{\text { Sales }} 52
$$

This ratio measures how skilfully the company is controlling its stock (which includes inventory, work in progress etc) in relation to turnover. Conversely rising stocks and decrease of turnover leads to a tightening cash flow position.

(Argenti considers the numerator the cost of sale instead of turnover, and very often this ratio is expressed in weeks - 1.e. the number of weeks stocks at the current rate of turnover).

It might be dangerous if the ratio falls i.e. turnover falls and stocks rise, but it can also be dangerous if it rises under certain conditions. If turnover rises much faster than stocks this could 
indicate a condition known as "overtrading" where turnover expands but the company does not have the resources available to finance the expansion and runs out of cash.

\section{Debtors Ratio or "Collection Period"}

$$
\text { Sales/Debtors or } \frac{\text { Debtors }}{\text { Sales }} 52
$$

Most finance specialists like to see a collection period well below 6 or 7 weeks would be exceptionally good; 8 or 9 is common. More than 10 is beginning to look lax. Once again it depends an the nature of the business.

\section{Return on Capital}

\section{Profits before interest and tax Capital employed}

or

$$
\frac{\text { Earnings }}{\text { Shareholder }}
$$

These are most important ratios as measuring profitability, both of which indicate the overall return earned on all the capital employed including loans as well as equity. (Return on equity or shareholders capital). Capital employed is taken as the average capital employed in the year, return on capital, however measured is obviously the prime criterion by which any company's performance should be judged. No company can however contimue in existence for lang unless the return on the capital it employs exceeds the cost of borrowing. 


\section{Profit Margin Ratio}

\section{Profit and Loss \\ Sales}

The version proposed here is probably the simplest and widest because it compares trading profit and sales turnover.

An overall profit margin of 10 percent on sales turnover is good by most standards today. This ratio should be compared with the average of similar sectors.

Argenti concluded that a profit margin of 1 percent will almost always indicate trouble, however, some companies deliberately operate a highvolume, low-margin strategy and thrive for years on margins as low as a few percent.

Falling margins do not always spell approaching doom and could merely reflect a change in strategy, or the maturing of an industry (margins nomally fall as an industry matures) or simply that the company is growing. Thus, while there is mo fixed norm for this ratio, it is possible to come to a rational and useful conclusion for any given company in a given industry.

\section{Assets Turnover Ratio}

Sales

Capital enployed

The aim is to determine how effectively the company's assets are being employed. Argenti concluded that a company with expensive capital assets (either fixed or working) lying unused may be heading into danger. 


\subsubsection{Summary and Conclusions on Traditional Financial Ratios as Predictive Tools of Failure}

The table below gives the results of the financial ratios used as discriminators between failed and non-falled companies.

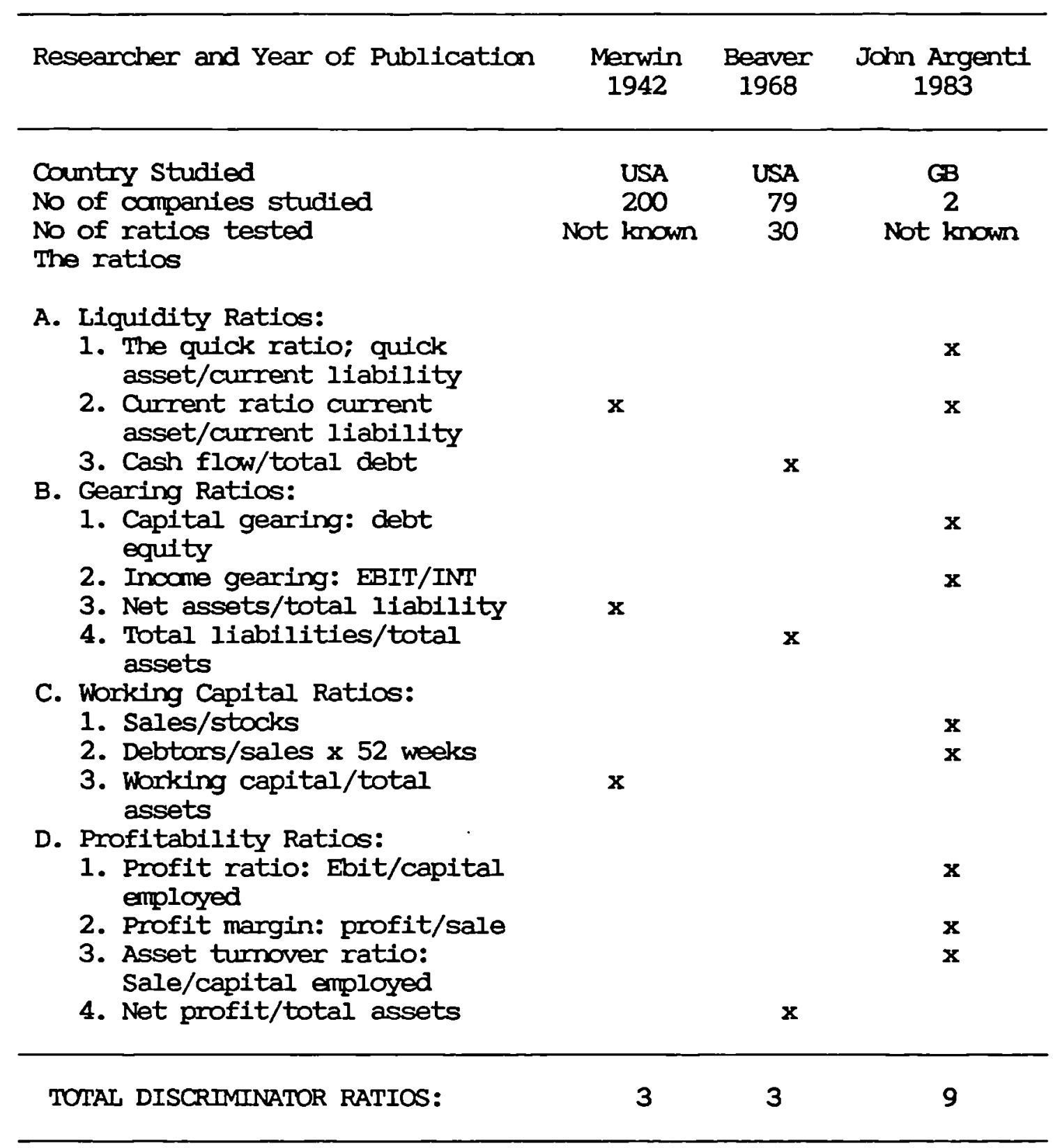

TABLE 2.1: RESULTS OBTAINED FROM PREVIOUS STUDIES OF TRADITIONAL RATIOS AS PREDICTIVE TOOLS OF FAILURE 
It is difficult to obtain a clear picture of the risk involved in an individual company from a study of the financial ratios.

It is not sufficient for the analyst to know the failed firm had lower ratios prior to bankruptcy, irrespective of whether this knowledge is the result of multivariate analysis. A firm may fail as a result of declining profits even if five years previously it had reported a relatively high profitability. Similarly a firm suffering temporary losses or low profits at a certain time may subsequently improve its records as a result of new investment, and the previous studies commonly conclude that:

1. One can be misled by relying on only one or two ratios.

2. One can be misled by comparing the same ratios between companies even in the same industry.

3. Using a small portfolio of key ratios may reflect the change in a company's financlal strength from one year to another.

Finally, predicting fallure by ratio methods is mainly performed on the basis of the dichotomous classification technique whereby the firms are arbitrarily divided into two groups and arranged (for each ratio) in ascending order. An 'optimal cut-off point' is chosen through trial and error as the demarcation line for failing, 1.e. any firm below it being categorised as a failed firm. The results are then compared with actual data to find the percentage of incorrect predictions. Often many trials are repeated before the optimal cut-off point is reached. This test is criticised because it decides the cutoff point after looking at the actual status of the firms whereas in a real situation the user of financial ratios has to make decisions without access to this information and of course the set of firms is 
different from that used in the original sample to decide the cut-off point. Thus predictions are always being made on a set of firms, other than the set from which the cut-off point was derived.

The percentage error is calculated between the predicted status, failed or non-failed, and the actual status. The ratio with the smallest percentage of misclassification is considered the best predictor of failure. Therefore, the ratio with the smallest error of misclassification is considered to be the best. In contrast, the MDA method does not suffer such a weakness, hence its interest to analysts.

\section{$2.3 \quad \mathrm{Z}-\mathrm{SOORE}$}

\subsubsection{Introduction}

It was shown in the previous section that the analysis of failed firms based an a consideration of single ratios may present a confused and unreliable indicator of financial difficulties.

The Z-score overcomes these difficulties. A company's z-score is calculated by adding together a number of ratios, each ratio having been weighted according to its usefulness. Because the z-score comes out as one single figure, it is possible to set ane simple pass mark above which a company may be considered safe, but below which it must be considered at risk of failure.

As the likely most appropriate statistical technique for Z-score Altman in 1968 chose multiple discriminant analysis (MDA) using financial ratios for failure prediction. 
A large number of $\mathrm{Z}$-score models now exist and although they all follow the concepts of the original one devised by Altman, they are all different.

It is not yet possible to estimate how acarrately and how far ahead each of these models can be expected to predict failure. However, there is a wide acceptance that the $\mathrm{z}$-score represents an important innovation, one that will surely play an increasingly useful role in failure prediction.

Because of the weakness of the financial ratios method described earlier, it is strongly recommended that in addition to examining the trends of the traditional ratios for any suspect company, the observer should also calculate the company's z-scores for the past few years. The calculations are simple to make and the result will either confirm the story told by the financial ratios or it will not.

In either case an extra dimension will have been added to the observer's knowledge. The various models so far developed are now described leading to the latest work described in this thesis.

Section 2.3.2 begins with Altman's z-score.

Section 2.3.3 includes a brief description of Taffler's model.

Section 2.3.4 covers the Mason and Harris' model.

Section 2.3.5 deals with the Castagra and Matolcsy model.

Section 2.3.6 includes Van Frederikstust model.

The final section briefly discusses the above models and draws conclusions. 


\subsubsection{Altman's Z-score}

Two samples of sixty-six US companies were chosen, half being failed firms during the period 1946-1965, the non-bankruptcy firms were chosen carefully on a stratified random basis [8] to match the failed ones.

All the non-bankrupt companies were still operating in 1966 and had assets between $\$ 1$ and $\$ 25$ million which corresponded to the size of the failed companies. This range of size eliminated the giant firms, as these rarely fail, and small firms for which data are usually not available. Twenty-two ratios were considered represented by liquidity, profitability, leverage, solvency and perfomance ratios.

Five variables were selected as providing the best combination of ratios for the prediction of bankruptcy and the final discriminant function is as follows:

$$
z=1.2 x_{1}+1.4 x_{2}+3.3 x_{3}+0.6 x_{4}+1.0 x_{5}
$$

$$
\begin{aligned}
& \mathrm{x}_{1}=\frac{\text { Working capital }}{\text { Total assets }} \\
& \mathrm{x}_{2}=\frac{\text { Retained eamings }}{\text { Total assets }} \\
& \mathrm{x}_{3}=\frac{\text { Profit before interest and tax }}{\text { Total assets }} \\
& \mathrm{x}_{4}=\frac{\text { Market capitalisation }}{\text { Book value of debts }} \\
& \mathrm{x}_{5}=\frac{\text { Sale }}{\text { Total assets }}
\end{aligned}
$$


As can be seen Altman's equation consists of five terms, each of which is a financial ratio and each ratio is given a weighting. Professor Altman developed a computer programme which detemined that it was this set of ratios with just these weightings, that best discriminated between failed and non-failed companies over quite a range of size and industry in the USA but not for retail, banks or railroads.

The definitions of financial terms are as follows:

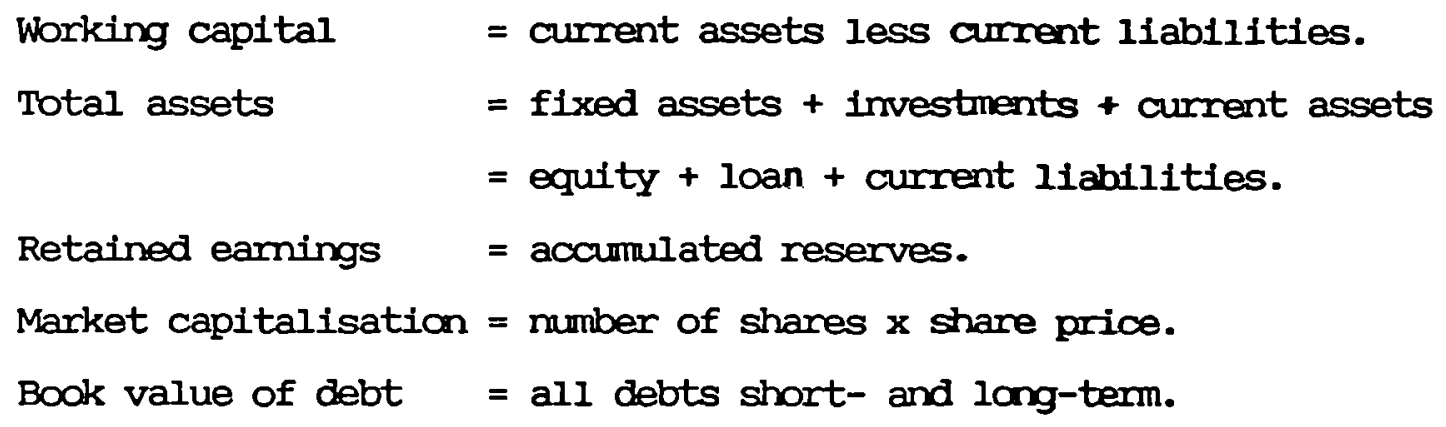

The pass mark for Altman's Z-score is 3. Companies scoring above that level should be safe while companies scoring below 1.8 will be classified as potential failures. Altman believes this equation can discriminate between "solvent" and failure candidates up to 2 or 3 years before the event.

Note: Altman added a ratio of market value as stown in term 4 in his model. It appears to be a more effective predictor of bankruptcy.

\subsubsection{Taffler's Z-Score}

Equal size samples of 46 failed and 46 financially sound (non-failed) manufacturing enterprises were used and a list of 80 financial ratios were employed in analysis. The model was originally developed in 1977 
[11]. Although Taffler has not published the detailed mathematical equation, he has stated that:

a) A 53 percent contribution to the model is made by the "profitability" measure:

\section{Profit before tax}

Average current liabilities

b) A 13 percent contribution is made by the "working capital" measure:

Current assets

Total liabilities

c) An 18 percent contribution comes from the "financial risk" measure:

\section{Current liabilities}

Total assets

d) A 15 percent contribution comes from the "liquidity" measure no credit interval 1.e. the number of days a company can finance its operations from its immediate assets if it can no langer generate revenue.

The Taffler model is valid for manufacturing companies, there is a further equation for distribution companies. The pass mark for Taffler's Z-score is zero. 


\subsubsection{Mason and Harris' z-score}

Equal size samples of 20 failed (which falled between 1970-1977) and 20 non-failed companies, construction compantes were used, and a list of 28 financial ratios was employed in analysis.

The model was published in 1979 [17] and contains six terms. It was originally designed for use in the construction industry. The equation contains slx terms as follows:

$$
\begin{aligned}
z=25.39 & -51.18 x_{1}+87.81 x_{2}-4.84 x_{3}-14.52 x_{4} \\
& -9.10 x_{5}-4.47 x_{6}
\end{aligned}
$$

where:

$$
\begin{aligned}
& \mathrm{x}_{1}=\frac{\text { Earnings before interest and tax }}{\text { Net assets }} \\
& \mathrm{x}_{2}=\frac{\text { Earnings before interest and tax }}{\text { Net capital employed }} \\
& \mathrm{x}_{3}=\frac{\text { Debtors }}{\text { Creditors }} \\
& \mathrm{x}_{4}=\frac{\text { Current liabilities }}{\text { Ourrent assets }} \\
& \mathrm{x}_{5}=\text { Log } 10 \text { days debtors } \\
& \mathrm{x}_{6}=\text { Trend debtors }
\end{aligned}
$$

The definitions of financial terms are as follows:

Net capital employed $=$ net assets + short term loan 
For net assets and net capital employed, the opening balance sheet figure is used in preference to closing sheet figure.

Short term loans are taken as being the loan and overdraft.

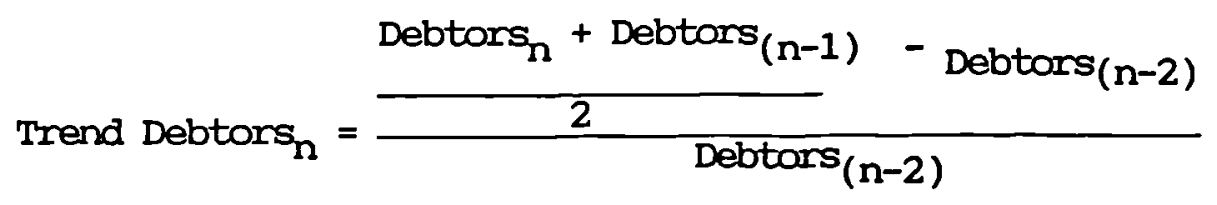

The calculation of days debtors is as follows:

$$
\text { Days Debtors }=\left\{\frac{\text { Debtors }(\text { opening })+\text { Debtors (closing) }}{\text { Turnover }}\right\} \times \frac{365}{2}
$$

The pass mark for Mason and Harris' z-score is 2.94. Companies scoring above that level should be safe while companies scoring \pm 2.94 within these limits cannot be confidently classified and can anly be considered as "vulnerable".

\subsubsection{Other 'Z-Score' Models}

- Castagna and Matolscy developed a model specifically designed for use in the Australian eoonomy.

- Van Frederikslust in the Netherlands.

- Marais in conjunction with the Bank of England.

- Altman himself are all actively engaged in the developing Z-score technology.

\subsubsection{Summary and Conclusions to 'z-Score' Model}

Table 2.2 gives the results of the $\mathrm{Z}$-score models which are used as discriminators between falled and non-failed companies: 
Generally, the Z-score approach is viewed as an extremely powerful financial analysis tool in finance and credit management areas where they are perhaps best placed of all to exploit the full potential of the methodology.

Generally academics are lagging behind practitioners in the creative application of the technique particularly for investment analysis. In particular, the approach does not suffer from methodological weakness leading to poor performance, because the $\mathrm{z}$-score model possesses true operational utility in practical applications.

One final statistical issue that is worthy of note here is raised in the recent paper of Mensah [18] [1984]. The author explores the degree of stationarity of bankruptcy models over time by comparing functions developed for different periods.

He concluded (page 391) on the basis of his evidence, that "bankruptcy prediction models are fundamentally non-stationary, at least insofar as the stability of the models' coefficients are concerned". Mensah, in fact, shows that distance in time from when a model is developed rather than state of the economy (recession, expansion) is more important in determining the propensity for structural shift.

Taffler concluded that "Any researcher in this area would agree that Z-score models need redevelopment when they grow old and tired". However, in contrast, the continuing efficiency of Altman's 1968 original z-score model demonstrates after almost 20 years when applied to US data (but not UK data) longevity appears to be a hall mark. Also some consideration needs to be given to the quality of a model in predicting failure well before bankruptcy. 


\begin{tabular}{lccc}
\hline Researcher and Year of Publication & Altman & Taffler & $\begin{array}{c}\text { Mason \& } \\
\text { Harris } \\
1978\end{array}$ \\
& 1968 & 1977 & UK \\
Country Studied & USA & UK & 40 \\
No of companies studied & 66 & 92 & 28 \\
No of ratios tested & 22 & 80 & Manufac- \\
Type of Industry & Muring & turing & Construc- \\
& Nan-retail & & \\
\hline
\end{tabular}

A. Liquidity Ratio

1. Current assets/total

liabilities

2. $\log _{10}$ days debtors

$\mathrm{X}$

$\mathrm{X}$

B. Gearing Ratios

1. Market capitalisation/

book value of debts $\mathrm{x}$

2. Current liabilities/ total assets

3. Current liabilities/ current assets

C. Working Capital Ratios

1. Working capital/total assets

$\mathrm{x}$

2. No credit interval

3. Debtors/creditors

4. Trend debtors

$\mathrm{X}$ $x$

$x$

$\mathrm{x}$

$\mathrm{x}$

D. Profitability Ratios

1. Retained earnings/total assets

2. Earnings before tax and interest/total assets

3. Sales/total assets

4. Earnings before tax and interest/current liability

5. Earnings before tax and interest/net assets

6. Earning before tax and interest/net capital employed

$\mathrm{x}$

$\mathbf{x}$

$\mathrm{X}$

TOTAL DISCRTMINATOR TERMS IN MODEL:

5

4

6

TABLE 2.2: RATIOS SHOWN TO DISCRIMINATE BETWEEN FAILED AND NON-FAILED COMPANIES IN PREVIOUS STUDIES 
Table 2.3 (taken from Taffler, 1984) summarises what happened in the six years subsequent to model development to 115 out of the 825 (14\%) listed industrial companies on EXSTAT at risk of financial distress as at the end of 1976. No fewer than 43\% had suffered financial distress in some sense and a further $29 \%$ were still at risk with less than 3 out of 10 appearing to have effected a pemanent recovery.

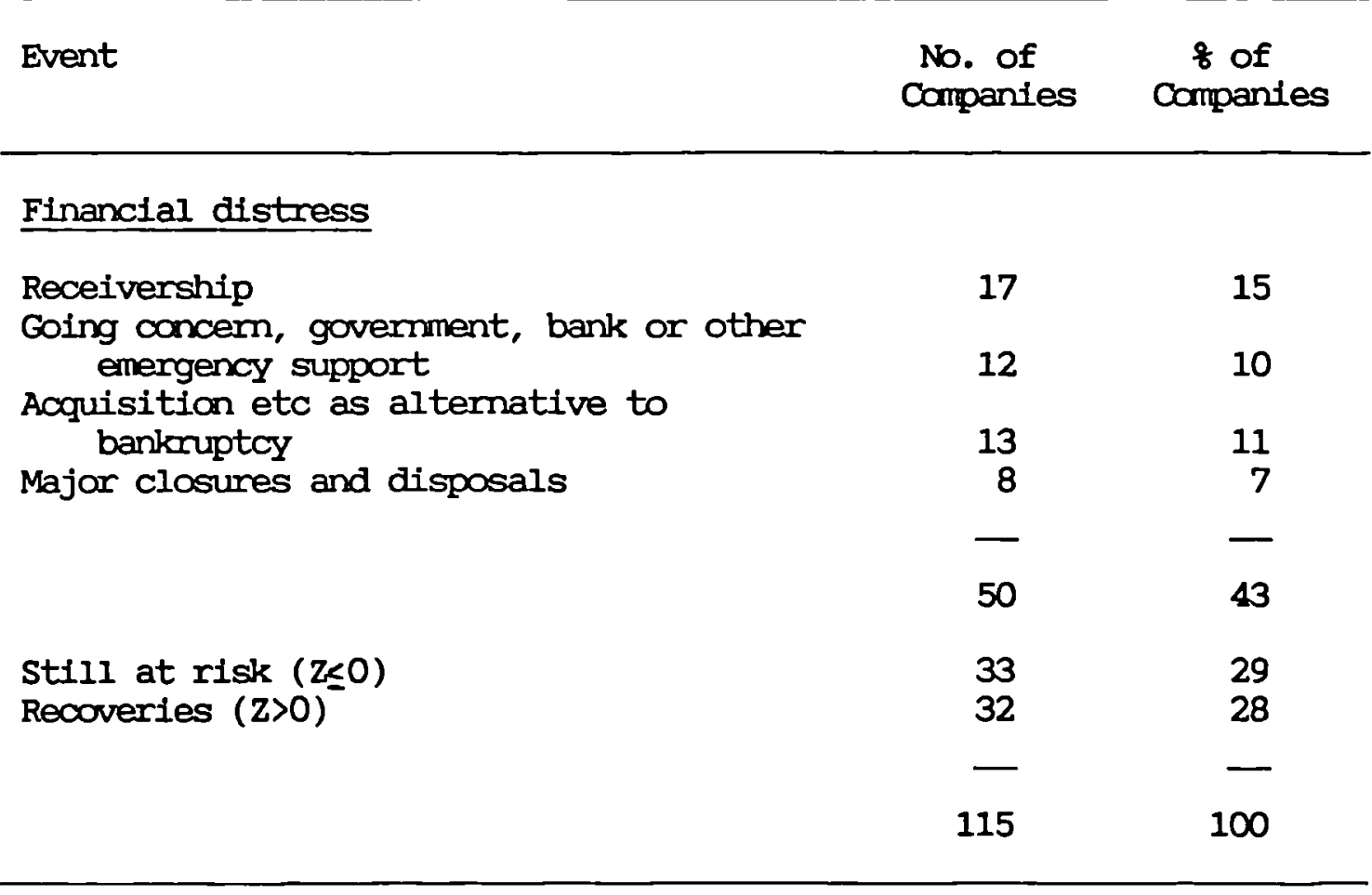

TABLE 2.3: COMPANIES WITH AT RISK Z-SOORES AT THE END OF 1976. A SUMMARY OF SUBSEQUENT EVENTS

Further, the writer tested Mason and Harris' model for companies predicted at risk in 1976 after 10 years. The result shows that 33\% failed, the others changed their names [17].

These statistics provide another useful benchmark for the potential utility of such techniques in practice. 
Finally we can conclude that:

1. Multivariate discriminant analysis (MDA) is an appropriate technique.

2. Multivariate discriminant analysis is completely free of methodological and statistical flows. Any problems are mainly due to the lack of in depth knowledge by business researchers of the statistical properties of discriminant analysis [Pinches, 1980, p429].

3. Discriminant functions are robust and can work well, and do so over quite a long period of time without requiring specification.

\subsection{OTHER METHODS OF FATLURE PREDICTION}

\subsubsection{Introduction}

There are essentially two methods of forecasting fallure, ane is to study the suspect company's finances, the other is to study its nonfinancial features.

The previous sections (2.2 and 2.3 ) have taught us to treat ratios and Z-scores with considerable respect. These finance-based tools suffer, however, from two major defects namely they:

- are dependent upon the availability of financial information

- may suffer from creative acoounting problems especially in small companies.

However, two statements can be made about the acoounts of failing companies. Firstly, the company may be late publishing accounts. Secandly the company may have practised "creative accounting". This section is concerned with the non-financial features of fallure. 
As a company fails it might display non-financial signs of deterioration [7] as well as financial ones. Argentl has illustrated a means of ascertaining the influence of the latter and this method is summarised because it is the latest development. However the model's predictive value has not been adequately tested in the field. In this thesis the writer has thus taken the initiative to test the model on construction companies data.

The last and final section briefly discusses the above method and gives guidance for further research work which is more fully described in Chapter 9.

\subsubsection{A-Score}

The concept behind an A-score developed for this research is based on the belief that if a company is in financial trouble, it is because of the management defects and errors that were perpetrated a long time previously, and that these defects and errors could have been corrected by a careful observer before - maybe lang before - the signs of financial distress became visible.

The lists of these non-financial indications include typically "bad management". The A-score is an attermt to:
a) make a list of those non-financial indications
b) rank the items in order of importance
c) place the items in sequence.

The A-score has been designed to introduce a measure of quantification of weighted scores according to importance in the failure process and can be produced as illustrated in the following example [7]. 
1. Autocrat

2. Chairman and Chief Executive (same persan)

3. Passive Board

4. Unbalanced skills

5. Weak Finance Director

6. Poor management depth

7. No budgetary control

8. No cash flow plan 3

9. No costing system 3

10. Poor response to change 15

Total for defects: 43

$\begin{array}{ll}\text { Pass mark for defects: } & 10\end{array}$

Mistakes

- High leverage 15

- Overtrading 15

- Big project 15

Total: $\quad 45$

$\begin{array}{ll}\text { Pass mark for mistakes } & 15\end{array}$

\section{Symptoms}

- Financial signs 4

- Creative acoounting 4

- Non-financial signs 3

- Terminal signs

Total for symptoms: $\underline{12}$

Overall maximm possible: $\quad \underline{100}$

Pass mark: $\quad 25$ 
Research conducted by Argenti [7] in the commercial sector found that companies scoring above 25 showed many of the signs which precede failure, whereas companies that are not at risk score below 25 overall pass mark.

While the observer may have insufficient reasons to make firm conclusions on failure, A-scores coupled with a close and very careful examination of the company's ratios and Z-scores, prediction becomes much more reliable.

\subsubsection{Conclusions to A-Soore}

The predictive value A-score has been explored in this research, but same doubt still remains regarding absolute reliability, nevertheless its power has been convincingly demonstrated.

\subsection{SUMMARY AND CONCLUSIONS}

Early methods illustrate fairly useful approaches to the subject of corporate collapse, but in the past decade researchers realised that failure does not occur suddenly. Failure takes years, therefore an evaluation of the strengths and weaknesses of financial and nonfinancial features of companies becomes necessary to obtain a sufficient early warning to take action.

There are several methods of observing the approach of fallure, firstly, financial ratios. We have noticed that companies with continuing problems will have:

a) a low or negative working capital

b) a high level of liabilities relative to total assets

c) low current assets to current liabilities 
but the deterioration of certain well-known ratios is not sufficient an indicator of company failure.

Secondly, the z-score technique for assessing corporate fallure appears to be a reliable technique for the commercial sector and could prove equally suited to the construction situation.

Thirdly A-scores show promise. While none of the above methods is completely accurate i.e. sometimes give false signals in certain circumstances, the use of a combination of these different methods has been demonstrated in this research to give fairly confldent predictions. 


\section{CHAPTER 3}

THE TECINIQUE OF MULTIVARIATE DISCRIMINANT ANALYSIS

\subsection{Introduction}

3.2 The General Concept of Multivariate Discriminant Analysis (MDA)

3.3 The Mathematical Theory Behind MDA

3.4 Derivation of Computational Formula

3.5 Statistical Computer Package and its Use

3.6 Sumary and Conclusions 


\section{CHAPTER 3}

THE TECHNIQUE OF MULTTVARIATE DISCRTMINANT ANALYSIS

\subsection{INTRODUCTION}

A problem that arises frequently in the social and behavioural sciences as well as in the biological sciences is that of classifying an object into one of a number of possible categories. Linear discriminant function analysis is a related approach for examining between-group differences on a set of measures. However, this approach focuses more on understanding between-group differences than on developing rules to classify units one population or another.

The discriminant analysis technique is a useful tool for the mechanistic assignment of observations from unknown groups or populations to one of two or more mutually exclusive groups or populations.

The related technique of linear discriminant function analysis involves finding one or more linear combinations of the original variables that maximise the between-group differences relative to within-group differences.

If there are more than two groups, then more than one discriminant function may be necessary to characterise group differences completely. In general, the number of discriminant functions necessary to characterise between group differences completely is equal to the number of groups minus one $(g-1)$. 
For two groups, then, there will be one discriminant function that will exhaust all between group differences, regardless of the number of variables.

Although (MDA) had been used in the Biological and Behavioural Sciences since 1930, it was not until the 1960s that MDA was used in conjunction with financial ratio analysis. The leading pioneer in this field at that time was Edward Altman [8] who developed several models using USA data, which he claimed could predict bankruptcy.

Several other researchers have done work in the same field over the past decade, the majority of them in the USA $[19,20,21]$.

It is surprising, however, that the anly extensive work to have been carried out in Britain is by Dr Richard Taffler at City University Business School $[11,12,13,14,15]$. The major part of his work has been conducted using UK based data and he has produced several predictive models for manufacturing companies.

In cooperation with the London stockbrokers, Laurence Prust and Company, he also produced separate models for various industries [22], one of these industries was the construction industry. In 1978 Mason and Harris also developed a model to predict bankruptcy for construction companies.

The next few sections of the thesis attempt to direct a path beginning with the simplest illustration of the general concept of MDA in Section 3.2. Section 3.3 illustrates the mathematical theory behind MDA, Section 3.4 presents derivation of computational formula with illustrative example, and section 3.5 deals with the statistical computer package and its use. The final section briefly discusses the application of linear discriminant analysis. 


\subsection{THE GENERAL CONCEPT OF MDA}

The objective of linear discriminant function analysis is to derive linear functions of the original variables that maximise between-group variation relative to within-group variation.

The mathematical objective of the analysis is to weight and linearly combine the discriminant variables in a function so that the groups are forced to be as statistically distinct as possible. For example, taking a number of variables and mathematically combining them in a discriminant function results in a relationship of the following form:

$$
z=c_{0}+c_{1} v_{1}+c_{2} v_{2}+\ldots+c_{n} v_{n}
$$

where: $\mathrm{z}=$ = the score on the discriminant function

$c_{1}$ to $c_{n}=$ the weighting coefficients

$\mathrm{C}_{0}=$ a constant

$v_{1}$ to $v_{n}=$ the discriminant variables.

The statistical theory of discriminant analysis assumes that the discriminant variables have a multivariate nomal distribution and that they have equal variance-covariance matrices within each group [Donald G Morrison [23] on "The Interpretation of Discriminant Analysis" Journal of Marketing, Vol 6, No 2, May 1969]. Covariance analysis is used for the purpose of increasing precision, however, the practical research worker and the theoretical statistician take different views of this case. The research worker sees it as an opportunity for introducing experimental controls in a nonexperimental field, and the statistician sees it as a reason for exercising the utmost caution and, often, as a sufficient reasan for 
refusing to carry out analysis of covariance at all [Introcuction to Multivariate Analysis, George H Dunteman, [29].

As has been shown in previous works, in practice these conditions are not always satisfied [0. Maurice Joy and John O. Tollefsan, [24] "On the Financial Applications of Discriminant Analysis", Journal of Marketing Research, Vol 6, No 2, May 1969, pp 156-163], but the technique has been found to be very robust which means the assumptions need not be strongly adhered to [Edward B. Deakin, [25] "Distribution of Financial Accounting Ratios: Some Empirical Evidence", the Accounting Review, Vol 51, No 1, January 1976, pp 90-96].

In the company bankruptcy situation we have two group cases where samples of solvent and failed firms are used to form the classificatory models. Once a set of variables has been found which provides satisfactory discrimination for the cases with known group membership, a classification function can then be derived which will permit the classification of new cases with unknown memberchips. The discriminant variables used to form the model are typical financial ratios, calculated from the companies published financial acoounts.

More recently some researchers have adopted a quadratic discriminant function (QDF) methodology in an attempt to overocme same perceived difficulties with (IDA) and currently conditional probability model formulations (Logit and Probit) are enjoying much attention (e.g. Zavgren, [26] 1985; Ohlson, 1989; Mensah, [18] 1984; Marais et al, 1980 and Zmijewski, [27] 1984). However the underlying model building approach does not differ significantly. 


\subsection{THE MATHEMATICAL THEORY BEFIND MDA}

Before discussing the multivariate situation, let us discuss a hypothetical univariate situation in which two possible categorles are involved and one measure is available an the object to be classifled.

Let us assume that these two populations are nomally distributed. From Figure 3.1 we can see that there is overlap in the two distributions and that any rule we use for classifying into one of these two categorles. The optimal classification rule in this situation is to classify the membership belanging to each group as shown in Figure 3.1. For example, if a soore is less than B then population 1 applies and if the score is greater than B the subject belangs to group 2. The reasan for choosing $B$ as the decision point is that it is the score that has the same relative frequency for each of the two populations. The mathematical theory behind MDA is complicated, but well documented $[28,29]$.

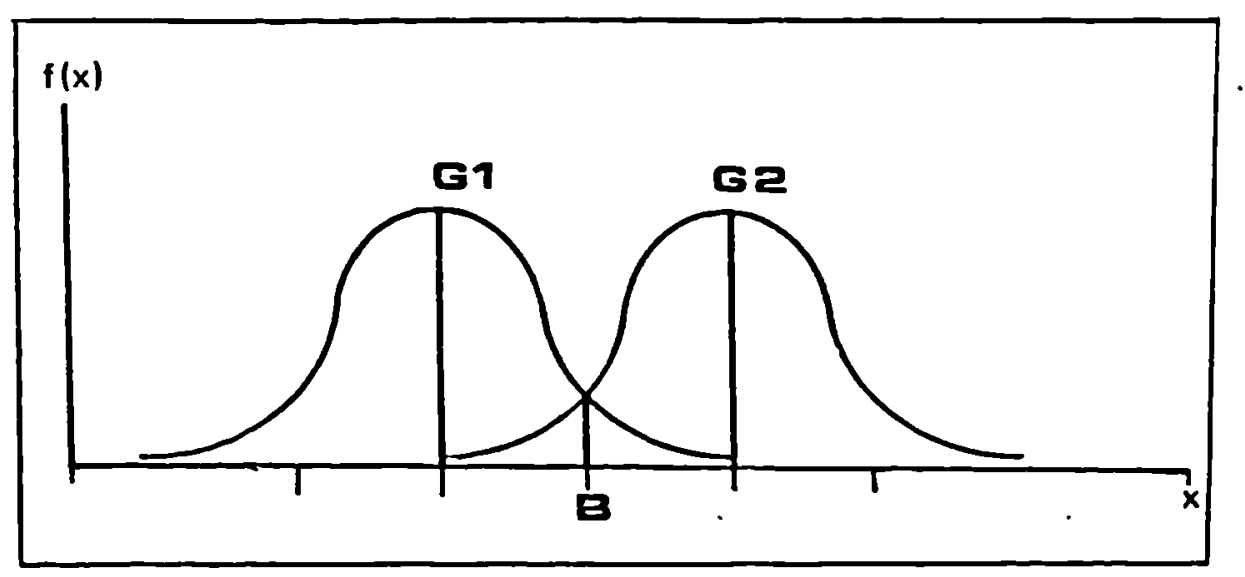

FIGURE 3.1: THE TWO GROUP-ONE VARIABLE 


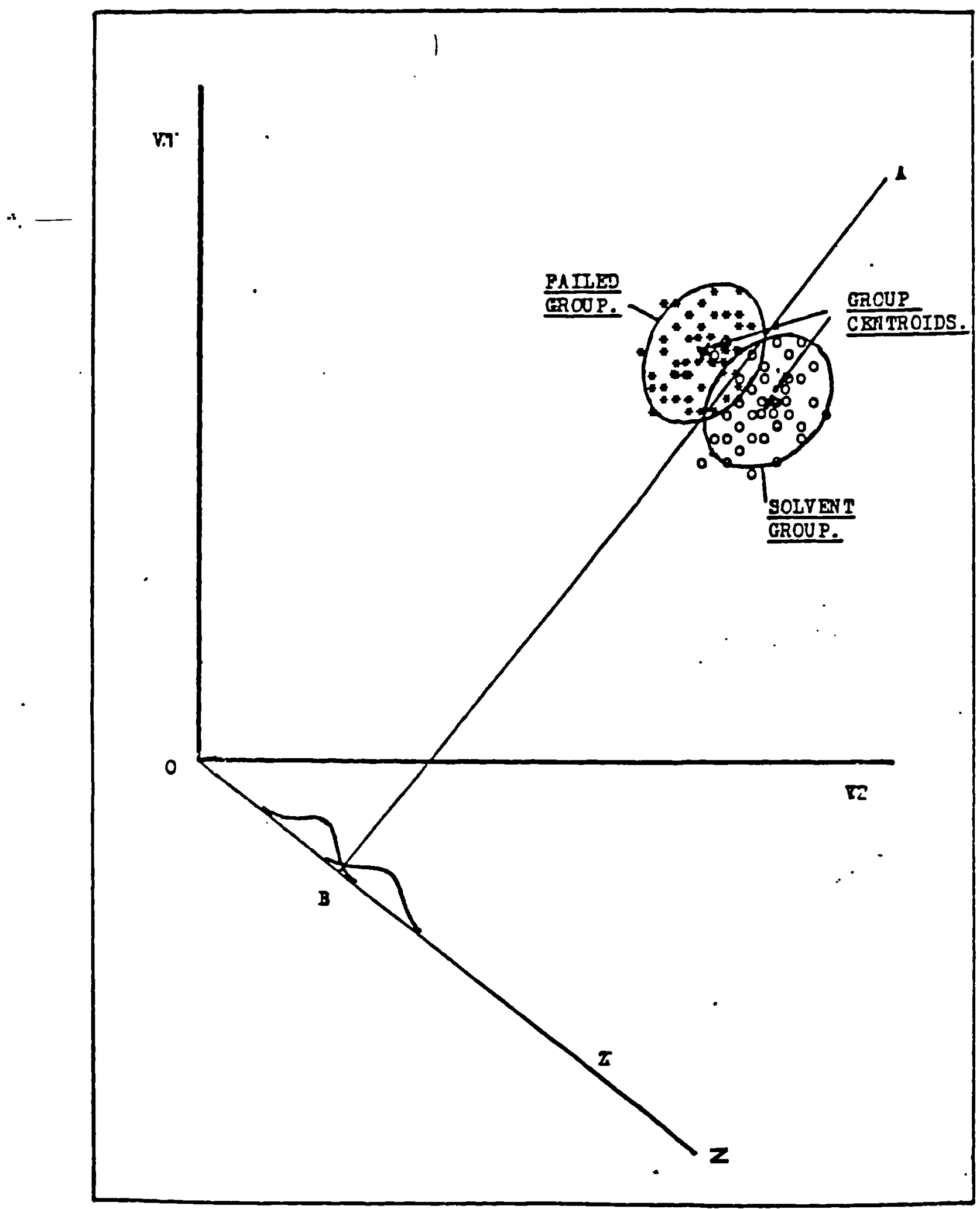

FIGURE 3.2: THE TWO GROUP-TWO VARIABLE DISCRIMINANT MODEL 
Further conceptualising the approaches to consider the case of the two group population with two discriminating variables $v_{1}$ and $v_{2}$. In the case of failed companies if we plot the values of $v_{1}$ and $v_{2}$ for the companies in the continuing and failed groups, we arrive at Figure 3.2 (see Cooley [28], pp 245).

Each ellipse on the diagram is the locus of points of equal density (or frequency) for a group. For example, each of these ellipses may define the regions within which say $95 \%$ of each set of observations lie. The two points at which these ellipses intersect define a straight line $A B$. If the second line $O Z$ is drawn perpendicular to $A B$ and the points in the two-dimensional space are projected onto $\mathrm{OZ}$ labelled Z-axis, the overlap between the two groups will be smaller than for any other line, that the points could be projected anto. This is the same as saying that the centroids of the two groups have been pushed as far apart as possible, thus giving maximum discrimination.

By projecting the groups onto a single axis, in this way, each company's set of variables is transformed into a single Z-score by vector algebra. The point $B$ then divides the discriminant axis into two regions, the solvent an ane side and the failed on the other. A company with a Z-score below B would then be assigned to membership of the failed population and vice versa for a Z-score above the B point. In this way company two-dimensional data is transformed into a single Z-score.

With more than two variables the concepts become too difficult to express visually. In this situation the intersection of the two groups changes from being a straight line, $A B$, to being a plane. The derivation of the discriminant coefficients is therefore done 
mathematically. In general terms, it requires solving the general eigenvector problem:

$$
\lambda \cdot W v=B v
$$

where: $B$ and $W$ are respectively the "between-" and "within-" groups sums of squares and cross products matrices [28]

is known as Wilks' Lambda

The most discriminating function is achieved by maximising the ratio $\mathrm{B} / \mathrm{W}$. This is another way of saying that we wish to make the "between groups variable differences" large in comparison to the "within groups differences".

This is where the theoretical importance of having equal variancecovariance matrices, for the two groups, enters into consideration. This can be highlighted if we refer back to Figure 3.2. If either the variances of $v_{1}$ and $v_{2}$ or the $v_{1} v_{2}$ covariance, were different for the two groups, the contours (ellipses) of the two groups would not be the same shape or orientation, and therefore AB would not appear as straight line. This can lead to errors giving a classification bias in the function.

In previous works the need for adherence to the "equal variancecovariance matrices" and "separately distributed multivariate populations" rules have been the subject of argument. Whilst Morrison [23] insists on adherence, Deakin [25] points out that:

"The ultimate test of a model lies not in adherence to certain data assumptions but rather in its adherence to its usefulness as a decision model". 
In this study it was felt that Deakin's viewpoint was quite valid and this was taken into consideration when investigating the distributions of the discriminating variables.

\subsection{DERIVATION OF COMPUTATIONAL FORMUA}

The mathematical derivation of the computational formula for the twovariables case is that developed by Paul [34] Lecturer at the University of Alabama, as follows. First define two groups, Group I and Group II and two variables, $x_{1}$ and $x_{2}$.

Let $x_{p i j}$ represent the value of $x_{p}$ for the $j$ th observation in the $i^{\text {th }}$ group,

where $\mathrm{p}=1,2$

$i=1,2$

$\mathrm{j}=1, \ldots \mathrm{n}_{\mathrm{i}}$ and

$n_{1}=$ the number of observations in $i^{\text {th }}$ group.

Let $\bar{x}_{\mathrm{p}} \mathrm{i}$ represent the mean value of $x_{p}$ for the $n i$ indivicuals in that group.

1. Define $z_{i j}=a_{1} x_{1 i j}+a_{2} x_{2 i j}$

2. Then $\bar{z}_{1}=a_{1} \bar{x}_{11}+a_{2} \bar{x}_{21}$

and $\bar{z}_{2}=a_{1} \bar{x}_{12}+a_{2} \bar{x}_{22}$

3. Let " $A$ " be the variation between groups, then $A=\left(\bar{z}_{1}-\bar{z}_{2}\right)^{2}$

Substituting 2 in 3 we obtain:

$$
A=\left[a_{1}\left(\bar{x}_{11}-\bar{x}_{12}\right)+a_{2}\left(\bar{x}_{21}-\bar{x}_{22}\right)\right]^{2}
$$


4. Let "B" be the variation within groups, then

$$
\begin{aligned}
B & =\sum_{i=1}^{2} \sum_{j=1}^{n i}\left(z_{i j}-\bar{z}_{i}\right)^{2} \\
& =\sum_{i=1}^{2} \sum_{j=1}^{n i}\left[a\left(x_{1 i j}-\bar{x}_{1 i}\right)+a_{2}\left(x_{2 i j}-\bar{x}_{2 i}\right)\right]^{2} \\
& =\sum_{i=1}^{2} \sum_{j=1}^{n i}\left[a_{1}^{2}\left(x_{1 i j}-\bar{x}_{1 i}\right)^{2}\right. \\
& +2 a_{1} a_{2}\left(x_{1 i j}-\bar{x}_{1 i}\right)\left(\bar{x}_{2 i j}-\bar{x}_{2 i}\right) \\
& \left.+a_{2}{ }^{2}\left(x_{2 i j}-\bar{x}_{2 i}\right)^{2}\right]
\end{aligned}
$$

5. $d p=\bar{x}_{1}-\bar{x}_{2} ; \quad d_{1}=\bar{x}_{11}-\bar{x}_{12} ; \quad d_{2}=\bar{x}_{21}-\bar{x}_{22}$

6. $s_{p q}=\sum_{i=1}^{2} \sum_{j=1}^{n i}\left(x_{p i j}-\bar{x}_{p i}\right)\left(x_{q i j}-\bar{x}_{q i}\right)$

$$
\mathrm{p}=1,2 ; \mathrm{q}=1,2 ; \quad \mathrm{s}_{\mathrm{pq}}=\mathrm{S}_{\mathrm{qP}}
$$

7. Substitute 5 in 3 to obtain:

$$
\begin{aligned}
A & =\left(a_{1} d_{1}+a_{2} d_{2}\right)^{2} \\
& =a_{1}^{2} d_{1}^{2}+2 a_{1} a_{2} d_{1} d_{2}+a_{2}^{2} d_{2}^{2} \\
& =a_{1} d_{1}\left(a_{1} d_{1}+a_{2} d_{2}\right)+a_{2} d_{2}\left(a_{1} d_{1}+a_{2} d_{2}\right)
\end{aligned}
$$

8. Substitute 6 in 4 to obtain:

$$
\begin{aligned}
B & =a_{1}^{2} s_{11}+2 a_{1} a_{2} s_{12}+a_{2}^{2} s_{22} \\
& =a_{1}\left(a_{1} s_{11}+a_{2} s_{12}\right)+a_{2}\left(a_{1} s_{12}+a_{2} s_{22}\right)
\end{aligned}
$$


9. $R=\frac{A}{B}$

The objective of the computation is to maximise the variation between groups relative to the variation within groups. The desired plane is therefore the plane for which $a_{1}$ and $a_{2}$ determine the maximum, thus

Set $\frac{\partial R}{\partial a_{1}}=0 \quad$ and $\quad \frac{\partial R}{\partial a_{2}}=0$

10. $\frac{\mathrm{a}_{\mathrm{R}}}{\partial \mathrm{a}_{1}}=\frac{\frac{\mathrm{B} \partial \mathrm{A}-\mathrm{A \partial B}}{\partial \mathrm{d} I-1}}{\mathrm{~B}^{2}}=0$

11. $\frac{B \partial A}{\partial a_{1}}=\frac{A \partial B}{\partial a_{1}}$

12. $\frac{\partial B}{\partial a_{1}}=\frac{B \partial A}{A \partial a_{1}}$

13. Similarly, $\frac{\partial B}{\partial a_{2}}=\frac{B \partial A}{A \partial a_{2}}$

วB $\quad \mathrm{B} \partial \mathrm{A}$

14. $\frac{\overline{\partial a_{1}}}{\partial \mathrm{B}}=\frac{\overline{\mathrm{A} \partial \mathrm{a}_{1}}}{\overline{\mathrm{B} \partial \mathrm{A}}}$

$\partial \mathrm{a}_{2} \quad \mathrm{~A}_{\partial} \mathrm{a}_{2}$

15. $\frac{\partial A}{\partial a_{1}} \cdot \frac{\partial B}{\partial a_{2}}=\frac{\partial B}{\partial a_{1}} \cdot \frac{\partial A}{\partial a_{2}}$ 
16. $\frac{\partial \mathrm{A}}{\partial \mathrm{d}_{i}}=2 \mathrm{a}_{1} \mathrm{~d}_{1}^{2}+2 \mathrm{a}_{2} \mathrm{~d}_{1} \mathrm{~d}_{2}$

$$
=2 d_{1}\left(a_{1} d_{1}+a_{2} d_{2}\right)
$$

17. $\frac{\partial A}{\partial a_{2}}=2 a_{1} d_{1} d_{2}+2 a_{2} d_{2}^{2}$

$$
=2 d_{2}\left(a_{1} d_{1}+a_{2} d_{2}\right)
$$

18. $\left.\frac{\partial B}{\partial a_{1}}=2 a_{1} s_{11}+a_{2} s_{12}\right)$

19. $\frac{\partial B}{\partial a_{2}}=2\left(a_{1} s_{12}+a_{2} s_{22}\right)$

Substitute 16 through 19 in 15 and obtain:

$$
\begin{aligned}
& 2 d_{1}\left(a_{1} d_{1}+a_{2} d_{2}\right) 2\left(a_{1} s_{12}+a_{2} s_{22}\right) \\
& =2 d_{2}\left(a_{1} d_{1}+a_{2} d_{2}\right) 2\left(a_{1} s_{11}+a_{2} s_{12}\right) \\
& a_{1} d_{1} s_{12}-a_{1} d_{2} s_{11}=a_{2} d_{2} s_{12}-a_{2} d_{1} s_{22} \\
& a_{1}\left(a_{1} s_{12}-d_{2} s_{11}\right)=a_{2}\left(d_{2} s_{12}-d_{1} s_{22}\right)
\end{aligned}
$$

20. Thus $\frac{a_{1}}{a_{2}}=\frac{d_{2} s_{12}-d_{1} s_{22}}{d_{1} s_{12}-d_{2} s_{11}}$

A set of simultaneous linear equations can also be derived in the following manner. From 12 


$$
\frac{\partial B}{\partial a_{1}}=\frac{B \partial A}{A \partial a_{1}} ; \text { note that } \frac{B}{A}=\frac{1}{R}
$$

21. Then $2\left(a_{1} s_{11}+a_{2} s_{12}\right)=\frac{1}{R} 2 d_{1}\left(a_{1} d_{1}+a_{2} d_{2}\right)$

22. Let $C=\frac{1}{R}\left(a_{1} a_{1}+a_{2} d_{2}\right)$

23. $a_{1} s_{11}+a_{2} s_{12}=c d_{1}$

24. Similarly $a_{1} s_{12}+a_{2} s_{22}=c a_{2}$

For the $a_{1}$ and $a_{2}$ case determined from equations 23 and 24 , and in which the unknown factor " $C$ " cancels out when the values for "a,s" are substituted in 9.

\section{Illustrative Example}

The simple problem is ane of classifying insects as to race on the basis of mean numbers of teeth in proximal combs and mean number of teeth in distal combs. The individual values are presentet in Table 3.1. The first group belongs to race $A$, and the second group to race B. There are eleven insects in the first group and twelve in the second. The equations to be solved are:

$$
\begin{aligned}
& s_{11} a_{1}+s_{12} a_{2}=d_{1} \\
& s_{12} a_{1}+s_{22} a_{2}=d_{2}
\end{aligned}
$$

where $\mathrm{x}_{1}=$ mean number of teeth on proximal comb

$\mathrm{x}_{2}=$ mean number of teeth on distal comb

$\cdot \bar{X}_{11}=6.46545$

$\overline{\mathrm{X}}_{: 21}=5.32364$ 


$$
\begin{aligned}
& \bar{x}_{12}=5.550 \\
& \bar{x}_{22}=4.72667 \\
& d_{1}=\bar{x}_{11}-\bar{x}_{12}=6.46545-5.55=0.91545 \\
& d_{2}=\bar{x}_{21}-\bar{x}_{22}=5.32364-4.72667=0.59697 \\
& s_{11}=\sum_{i=1}^{2} \sum_{j=1}^{n i}\left(x_{11 j}-\bar{x}_{11}\right)^{2}=2.67650 \\
& s_{12}=s_{21}=\sum_{i=1}^{2} \sum_{j=1}^{n i}\left(x_{11 j}-\bar{x}_{11}\right)\left(x_{21 j}-\bar{x}_{21}\right) \\
& s_{22}=\sum_{i=1}^{2} \sum_{j=1}^{n i}\left(x_{21 j}-\bar{x}_{21}\right)^{2}=1.75454
\end{aligned}
$$

Substituting the data frōm the sample gives:

$$
\begin{aligned}
& 2.675 a_{1}+1.2942 a_{2}=.91545 \\
& 1.294 a_{1}+1.754 a_{2}=.5967
\end{aligned}
$$

The solution $a_{1}=.27597$ and $a_{2}=.13671$.

The linear discriminant function is as follows:

$$
z=.2759 x_{1}+.1367 x_{2}
$$

The " $Z$ " values are listed in order of magnitude in Table 3.2. The mean of the " $\mathrm{Z}$ " values in the first group is 2.5118 and the standard deviation is 0.09372 . The mean of the $\mathrm{z}$ values in the second group is 2.17754 and standard deviation is 0.14966 .

\section{Statistical Test}

The F-ratio indicates a significant difference between the two groups. The tabular value of $F$ is 5.85 with degree of freedam $\mathrm{DF}_{1}=2$ and $\mathrm{DF}_{2}$ $=20$ at the 18 significance level. The computed value of "F" is 19.18. 
The F-ratio is the ratio between two variances and is used to test for homogeneity of variances and equivalence of two groups.

A value of "F" larger than the tabular value for the degrees of freedom in the numerator $\left(D_{1}\right)$ and the degrees of freedom in the denominator $\left(\mathrm{DF}_{2}\right)$ at an indicated level of significance leads to the rejection of the hypothesis that the two groups are samples fram the same population with a confidence level of 18 level of significance. An increase in differences between the means of the variables or decrease in the variability of the variables improves the ability of discriminant function to differentiate between groups.

\begin{tabular}{rcccc}
\hline No & \multicolumn{2}{c}{ Race A } & \multicolumn{2}{c}{ Race B } \\
\hline & $x_{1}$ & $x_{2}$ & $x_{1}$ & $x_{2}$ \\
\hline 1 & 6.36 & 5.24 & 6.0 & 4.88 \\
2 & 5.92 & 5.12 & 5.60 & 4.69 \\
3 & 5.92 & 5.36 & 5.64 & 4.96 \\
4 & 6.44 & 5.64 & 5.76 & 4.80 \\
5 & 6.4 & 5.16 & 5.96 & 5.08 \\
6 & 6.56 & 5.56 & 5.72 & 5.04 \\
7 & 6.64 & 5.36 & 5.64 & 4.96 \\
8 & 6.68 & 4.96 & 5.44 & 4.88 \\
9 & 6.72 & 5.48 & 5.04 & 4.44 \\
10 & 6.76 & 5.6 & 4.56 & 4.04 \\
11 & 6.72 & 5.08 & 5.48 & 4.2 \\
12 & - & - & 5.76 & 4.8 \\
& & & & \\
\hline
\end{tabular}

TABLE 3.1: DATA FOR SAMPLE PROBLEM 


\begin{tabular}{rcrr}
\hline Rank & $\begin{array}{c}\text { First Group } \\
\text { Values }\end{array}$ & $\begin{array}{c}\text { Second Group } \\
\text { Values }\end{array}$ & $\begin{array}{c}\text { First Group } \\
\text { Item No }\end{array}$ \\
\hline 1 & 2.63085 & & 10 \\
2 & 2.60341 & & 9 \\
3 & 2.57020 & & 7 \\
4 & 2.56493 & & 11 \\
5 & 2.54873 & & 8 \\
6 & 2.54082 & & 5 \\
7 & 2.52128 & & 1 \\
8 & 2.47137 & & \\
9 & 2.47127 & 2.33902 & \\
10 & 2.36626 & & \\
11 & & 2.32272 & \\
12 & 2.33345 & 2.26733 & \\
13 & & 2.24556 & \\
14 & & 2.24556 & \\
15 & & 2.23432 & \\
16 & & 2.23432 & \\
17 & & 2.17953 & \\
18 & & 2.16819 & \\
19 & & 2.08627 & \\
20 & & 1.99767 & \\
21 & & 1.81054 & \\
22 & & & \\
23 & & & \\
& & & \\
\end{tabular}

TABLE 3.2: "Z" VALUES FOR THE SAMPLE PROBLEM

\subsection{STATISTICAL COMPUTER PACKAGE AND ITS USE}

There are a number of software packages that can be used to conduct a linear discriminant function analysis. The most popular package, is probably SPSS, this package produces the following key outputs: the standardised coefficients for each discriminant function, the centroids of the groups in the discriminant function space, and the multivariate test to determine statistical significance of successive discriminant functions. 
The discriminant analysis performed for this research work was done using the (SPSS version 10) subprogram 'DISCRIMINANT' through the Computer Centre at Loughborough University. For this research the most interesting facility of the Discriminant program was the several "stepwise methods" which enabled reduction of the number of discriminating variables in the "function" fram the original 31 to 7. Later the writer reduced the number to 5 using the Minitab computer package.

Since we need to select the variables which discriminate most, the stepwise procedure available in the program was of advantage. The program begins by selecting the single best-discriminating variable according to a user-determined criterion.

Several criteria are available to the user but in our case the criterion is the "overall multivariate F-ratio for the test of differences among the group centroids".

The variable which maximises the F-ratio also minimises "Wilks Lamdba" a measure of group discrimination. The test takes into consideration the differences between the group centroids and the cohesion within the groups. The Wilks Lambda mentioned here is the same measure that appeared in equation (2) in Section 3.3.

\subsection{SUMMARY AND CONCLUSIONS}

Discriminant analysis is utilised to classify individuals into one of two or more classes by means of an index number called z-score. The purpose of the computation is to maximise the difference between means of the groups relative to the variance of the groups. A cut-off point "Z-score" is established in the two groups, for example, a company 
with a z-score above the cut-off point $B$ would be assigned to membership of the non-failed population and vice versa for a $\mathrm{Z}$-score below the B point.

The analysis of failed firms based on the consideration of single ratios may present a confused and unreliable indicator of financial difficulties. In contrast the statistical technique MDA attempts to derive a linear combination of these ratios which will best discriminate between the groups. Also the model will have to indicate which ratios are the most important indicators predicting failure, what weight should be attached to each ratio and how to establish them objectively. Thus the advantages of MDA may be summed up as follows:

a) Considers an entire profile of characteristics common to the relevant firms and their inter-relationship;

b) Reduces the analysts space dimensionality 1.e. from the number of different independent variables to $(g-1)$ dimensions where $(g)$ equals the number of original a priori groups. The discriminant function of the form $z=v_{1} x_{1}+G_{2} x_{2}+\ldots v_{n} x_{n}$ transforms indivicual variable values to a single discriminant score of $\mathrm{Z}$ value which is then used to classify the object.

c) MDA results of multicollinearity sometimes yield an overall small group of ratios [29].

d) The primary advantage of MDA is in dealing with classification problems, one sees the entire variables profile rather than individual ratios. 
Problems that might arise if the basic assumptions of MDA related to the main statistical issues are not met, embrace the following:

a) Multivariate normality is an important assumption [Pinches, [6] 1980, pp 431-433] although in sample-based research it is the presence of extreme observations (outliners) rather than the general shape of the multivariate distribution that is the key. Techniques are available to handle such problems in practice (e.g. Taffler, 1982]. Nonetheless concerns over the distributional form, inter alla, led to the adoption of conditional probability model formulations (Logit, Probit) in a number of cases [e.g. Ohlson, [30] 1980] which do not depend on independent variable distributional assumptions.

b) A multicollinearity problem could ocarr because of the high intercorrelation among the variables. Researchers have found difficulties in handling multicollinearity problems, in certain cases tending to overfit models. This led to serious sample bias and poor performance on out of sample data [as illustrated by Mensah, [18] 1984, pp 392-3] despite theoretical arguments this should not be so [e.g. Eisenbeis, [31] 1977 but see Pinches, [6] 1980]. In addition varlable coefficients may be highly unstable between different samples. Some researchers circumvent multicollinearity problems by transforming the original variables to principal components since they are uncorrelated. This transformation does not help much, however, if we are interested in the effects of the original variables (Dunteman [29] pp 177).

c) Other key issues that are commonly not addressed relate to the need to incorporate prior probability estimates of population membership into the discriminant function and also differential 
misclassification costs [Pinches, [6] 1980]. Such issues are typically ignored leading to serious errors in interpretation [e.g. see the discussion in Taffler, [12] 1982, p351 and poor out of sample performance [e.g. see Taffler, [14] 1984].

(One of the perceived benefits of a conditional probability approach is the lack of need to specify prior probabilities).

There is no reason to believe, for example, that there are equal numbers of potential failure and solvent companies in the population.

d) Finally, in all studies researchers have viewed continuing companies as possessing distinct characteristics from their failed companies. This is clearly incorrect as many presently live companies possess financial profiles similar to failed ones [Taffler, [12] 1982].

The statistical problems that can arise are not taken to acoount for the non-failed group of such firms before developing the statistical model.

This research work will try to avoid the conceptual and methodological weaknesses which appeared in previous studies since potentially the Zscore model has very convincing statistical and associated evidence that a properly developed model, based on its track record in practice, has strong ex-ante predictability and high operational utility. However, any researcher in this area would agree that Zscore models need redevelogment when they grow "old and tired" [see Mensah (18) pp 391]. 
We may conclude finally that, in practice, at least most concerns regarding the statistical underpinning of the traditional linear discriminant model z-score approach are unfounded. For good reasons such discriminant functions are robust and can work well and do so over quite a long period of time without requiring respecification. 


\title{
CHAPTER 4
}

DATA COLLECTION AND FORMATION OF THE DATA GROUPS

\author{
4.1 Introduction \\ 4.2 Data Analysis \\ 4.3 Formation of Data Groups \\ 4.4 Summary and Conclusions
}




\section{CHAPTER 4}

\section{DATA COLLECTION AND FORMATION OF THE DATA GROUPS}

\subsection{INIRODUCTION}

This section is concerned with the data oollection, data sources, data analysis and formation of the data groups used to develop and verify the discriminant model for construction companies.

The data analysed in this report was obtained mainly from the following sources;

1. Extel Statistical Services Ltd (Extel)

2. Companies Registration Offices (CRO)

3. Published data on the Business Ratio Reports.

Extel cards were used for the following reasans:

- Extel cards have very reliable data

- Sufficient financial information is included on Extel cards

- Discrepancies in data presentation from different sources are considerably reduced.

Extel cards were mainly limited to public companies while the Companies Registration office was suitable for private companies. Same adjustments were needed to allow for "creative" accounting of some small companies. 


\subsection{DATA ANALYSIS}

Both failed and non-failed companies were selected on a randam basis. Some exceptions were allowed, however, in the non-failed group, for example, well known companies were included to increase the discriminating power of the model and decrease the misclassifications of non-failed companies as "failed". This point was first recognised by Altman and Loris [10] and Taffler [11] and Masan [17].

Financlal data used for both groups were the latest ones available. The data for failed companies were obtained for the period 1978 and 1986 and included the data for the last three years before fallure. Failure being defined as voluntary or compulsory liquidation, entry into receivership but excluding oompanies re-organised for financial reasons like taken over companies. These were treated as a separate group. Some researchers have included taken over companies as failed, e.g. Mason [17]. Such inclusions decrease the discriminatory power of the model. Furthermore, including data from the last six years before failure also decreases discriminating power generally because the last three years is considered to be the most critical period.

In this research data for the non-failed group is mainly concentrated on the four years prior to failure and included 1986. Some further points of note are:

- Altman [8] initially matched his "failed" and "non-failed" groups by industry and company size.

- Taffler [11] initially constructed models without matching compantes by incustry and company size or financial year 
Mason [17] limited his study to the construction industry and avoided matching company size and financial year considerations. This study adopted the Mason approach for two reasons:

Firstly, empirical evidence indicates that financial ratios are uncorrelated with company size [3]. Indeed the use of ratio transforms removes the company size dimension. Also, a construction campany generally depends on secondary sub-contractors which sometimes facilitates expansion of business activity acoording to the market situation.

A similar argument applies to matching by financial year for both groups, i.e. for non-failed companies some can be selected on their historical performance and past reputation as being regular and well known, typically public compantes. Small companies cannot be selected on this basis because:

- they are not well-known 1.e. background information is imamplete.

- most were formed in boan periods where entry to construction work was freely available without qualification of past experience.

Clearly therefore small companies do not provide a good standard and would not be representative of a non-failed group.

\subsection{FORMATION OF DATA GROUPS}

Six groups of companies were used in this study as follows:

1. Failed 11 group

2. Non-failed 20 group

3. Taken-over 9 group 
4. Test "Continued 70" group

5. Test "failed 11" group

6. All 90 group.

The "Failed 11" and "Non-failed 20" groups were used to establish the model and the remaining groups used to verify and validate the model adequacy.

\subsubsection{The "Failed 11" and "Test 11" Groups}

The bankrupt set of companies from which the model was derived consisted of companies which failed between 1978 through to 1986, a period of 8 years, while the verification and validation groups included companies fatling up to 1988.

There was a general problem in obtaining the required information for a large number of failed companies caused mainly by a lack of information or change of company name and after take-overs etc. These were generally excluded from the model.

Thus finally only 22 companies could be found which met the "failed" criteria from which a "Failed 11" group were used to derive the model and "Test 11" used for verification purposes.

A list of companies included in these two groups can be seen in Tables 4.1 and 4.2 . 


\begin{tabular}{|c|c|c|}
\hline Company & $\begin{array}{l}\text { Date of Last } \\
\text { Published } \\
\text { Accounts }\end{array}$ & $\begin{array}{l}\text { Reasons for } \\
\text { Conclusion as Failed }\end{array}$ \\
\hline Beechwood Group plc & 30.6 .83 & Receiver appointed 1985 \\
\hline Cocksedge Holdings plc & 22.11 .84 & Receiver appointed 1985 \\
\hline Crouch Group plc & 24.8 .83 & Receiver appointed 1984 \\
\hline David Charles Ltd & 5.11 .75 & Voluntary liquidation 1977 \\
\hline James H Dennis plc & 1.9 .83 & Receiver appointed 1984 \\
\hline Mears Bros Ltd & 7.2 .78 & Voluntary ilquidation 1979 \\
\hline Milbury plc & 19.7 .84 & Compulsory liquidation 1985 \\
\hline $\begin{array}{l}\text { Modern Enginoering of } \\
\text { Bristol (Holdings) plc }\end{array}$ & 7.6 .83 & Receiver appointed 1985 \\
\hline $\begin{array}{l}\text { Moss Engineering Group } \\
\text { plc }\end{array}$ & 1.12 .81 & Receiver appointed 1983 \\
\hline $\begin{array}{l}\text { Southem Construction } \\
\text { Ltd }\end{array}$ & 29.5 .79 & Receiver appointed 1982 \\
\hline S W Fanmer & 31.3 .86 & Receiver appointed 1986 \\
\hline
\end{tabular}

TABLE 4.1: COMPANIES IN THE "FAILED 11" GROUP

A.C. and K. Builders Ltd

Allied Construction Itd

Bowmate Construction Itd

Bright Brook Builders Ltd

Comber Construction Ltd

Pevland Construction Ltd

Sphinx Bullding Construction Ltd

Staines Construction Ltd

Stevens and Sons Building Ltd

Stott Mills Building Ltd

Stream Star Construction Ltd
31.3 .1986

31.3.1986

31.3 .1986

31.3.1985

31.3.1986

31.3.1982

31.3.1985

31.3.1985

31.3 .1983

31.3.1986

31.3.1985

TABLE 4.2: COMPANIES IN THE "TEST FATIED 11" GROUP 


\subsection{2 "Non-failed 20" Group}

The "non-failed 20" group and "Failed 11" group used data extracted from Extel in order to reduce the discrepancy in data presentation in cases using different information sources and to increase the discriminant power of the model.

However it is stressed that the model was constructed without matching companies by size, or financial years. The non-fallure was defined as continuing in business for at least four years and also had to have continued in operation for two years after the focal year of 1986.

The selection criterion adopted for the "non-failed 20" group, resulted in not all the members of the "non-failed" 20 identified being selected on a random basis. In this way an increase in the discriminating power of the model together with a decrease in the misclassifications of the "non-failed" companies as failed was achieved, principally by making assessments of solvency on a qualitative ratio analysis basis.

Accounts used for the "non-failed" group covered the pertod of 19821986. A list of companies in this group can be seen in Table 4.3. 


\begin{tabular}{ll}
\hline \multicolumn{1}{c}{ Company } & Date of Published Accounts \\
\hline Aberdeen Construction Group plc & July 1987 \\
Barratt Development plc & November 1986 \\
Benlox Holdings plc & July 1987 \\
Benbailly Construction plc & December 1986 \\
C H Beazer Holdings plc & December 1986 \\
BIoC plc & May 1987 \\
Brown and Jackson plc & August 1987 \\
Bryant Holdings plc & November 1986 \\
Boulton and Paul plc & October 1987 \\
M J Geeson Group plc & January 1987 \\
George Winpey plc & July 1987 \\
Henry Boot and Sons plc & June 1987 \\
A Monk and Company plc & August 1985 \\
Newarthill plc & June 1987 \\
Rush and Tompkins Group plc & August 1986 \\
Taylor Woodrow plc & July 1987 \\
Tanmac plc & June 1987 \\
Tilbury Group plc & July 1987 \\
Turriff Corporation plc & June 1987 \\
Wilson Connolly Holdings plc & May 1987 \\
\hline
\end{tabular}

TABLE 4.3: COMPANIES IN THE "NON-FAILED 20" GROUP 


\subsubsection{The "Taken-over 9" Group}

Some attempt was also made to discriminate with a further group namely a "taken-over 9" group together with the "failed 11" group and "non-failed 20" group, see Chapter 6. Little was achieved and this group was ultimately combined to form part of the verification process. It should also be noted that previous studies included in their definition of failure reorganisation for financial reasons, such as take-over companies. These were excluded in this research work to increase the power of discrimination. A list of this group can be seen in Table 4.4.

Company

Date of Published Accounts

Braithwaite Group plc

4.7.1985

C H Pearce and Sons plc

21.10.1985

Fairclough Construction Group plc

15.4.1982

Glossop plc

6.7 .1983

Marchwill plc

8.3.1983

Mitchell Cotts Group Ltd

11.11 .981

Richard Costain Ltd

25.5.1978

Robert Adlard plc

14.5 .1986

Rowlinsan Construction plc

27.6 .1983

TABLE 4.4: COMPANIES IN THE "TAKEN-OVER 9" GROUP 


\subsubsection{The "Test Continued 70" Group}

The companies in the "Test 70" group which were used to verify the model were selected randomly from different sources. These companies consisted mainly of construction and civil engineering companies.

The complete list of companies in this group can be seen in Table 4.5.

Company Company

Bellway Builders Itd

Bryant Construction Ltd

Bovis Construction Ltd Charrwood Construction Ltd

Daltan Construction Ltd

Danbury Construction Ltd

Davoo Construction Ltd

Gargan Construction Ltd

Tarmac Homes Midlands

Tarrock Construction Ltd

Tarmac Construction Ltd

CBI Construction Ltd

Charles Gray Builders

Haymills Holdings Ltd

Ogilvie Holdings Ltd

Eve Construction plc

Alfred McAlpine Construction

R J McLeod Construction

Shepherd Building Group

Reema Construction Ltd

Andrew Scott Ltd

Simons Construction Ltd

Whittaker Ellis Bullders Ltd

Amec plc

Amoo Industrial Holdings plc

Costain Group plc

Robert M Douglas plc

Galliford plc

Higgs and Hill plc

Johnstan Group plc

John Laing plc

Walter Lawrence plc

F J C Lilley plc

Y J Lovell Holdings plc

John Mowlem and Company
Sunley Holdings plc

John E Wiltshire plc

Baboock Construction Ltd

Balfour Beatty Ltd

Peter Birse Holdings

Bowmer and Kirkland Ltd

A F Budge Construction Ltd

Cementation Construction Ltd

Croudace Holdings Ltd

Hollandsche Betan Ltd

$J$ M Jones and Sons Ltd

Kyle Stewart Ltd

James Longley and co Ltd

R Mansell Ltd

May Gurney Holdings Ltd

The Miller Group Ltd

Norwest Holst Ltd

Seddon Group Ltd

G Percy Tretham Ltd

Trollope \& Colls Construc. Ltd

Wates Construction Ltd

Willett Ltd

Willmott Dixan Holdings Itd

City of Aberdeen Ass. Ltd

Condor Group plc

Consolidated Term Invest. Ltd

Dencora plc

Dean and Bowes Group Ltd

Duntan Group plc

Exeter Building \& Constr. Ltd

London and $\mathrm{Clyde}$ Holdings Ltd

MoLaughlin and Harvey Ltd

Gilbert House Investments Ltd

Bellway plc

John Elliott Group plc

TABLE 4.5: COMPANIES IN THE "CONTINUED 70" GROUP 


\subsubsection{The "All 90 Non-Failed" Group}

In trying to detemine the proportion of companies "at risk" in the total population of quoted companies, the combined population of the "non-failed 20" group and the "test continued 70 " group called the "all 90 non-falled" group, was also considered. These can be seen in Tables 4.3 and 4.5 .

\subsection{SUMMARY AND CONCLUSIONS}

The statistical problems that arise if care is not exercised before developing the model can lead to poor model performance. For example, all previous researchers viewed continuing companies as possessing different characteristics from their failed counterparts. This conclusion would appear to be dubious as many presently active companies possess financial profiles similar to failed companies and may in due course fail.

This research therefore adopted companies for the "nan-failed" group as those appearing to be solvent, but not necessarily healthy companies. Thus not all the members of this group were selected on a random basis. The companies in the "failed" group were those which had entered into receivership, voluntary liquidation, winding up by order of the court. Thus companies with name changes or those that had been reorganised for financial reasons such as taken-over companies were excluded and considered as a separate group.

In summary the best problems for discriminant analysis appear to be those in which the group definitions are distinct and non-overlapping, also efforts made to avoid arbitrary grouping. 
CARPTER 5

THE DEVEIOPED MODEL AND REGRESSION CHARACTERISTICS

5.1 Introduction

5.2 Financial Ratios used in the analysis

5.3 Financial Ratios Calculations and Data Manipulation

5.4 Statistical Computer Package

5.5 Regression Analysis for Predicting Bankruptcy

5.6 Summary and Conclusions 


\section{CHAPTER 5}

THE DEVELOPED MODEL AND REGRESSION CHAPACTERISTICS

\subsection{INTRODUCTION}

This section describes the development of an operational model for the identification of UK construction companies in danger of failure. The model was developed using a combination of two techniques, Financial Ratio Analysis and a statistical technique known as "Multivariate Discriminant Analysis".

All aspects of the model's development are described, from the financial ratios analysis, through to the computer analysis, including a short description of the computer package used to calculate the financial ratios, and computer package "SPSS X" involved in developing the model.

\subsection{FINANCIAL RATIOS USED IN THE ANALYSIS}

Altman selected 22 financial ratios in forming his model. Taffler claimed 80 financial ratios in foming his model. Mason and Harris selected 28 different variables including 23 conventional ratios and 5 trend measures.

Laurence, Prust and Company reported 500 ratios in forming their construction model.

The first model attenpted in this research considered 82 different variables and was not successful because of the sensitivity of some growth ratios [see Appendix A ]. As a consequence of these trials 
variable selection became very important, and their effectiveness either in previous studies and their popularity in the literature was one of the criteria adopted to guide the author.

In this manner a total of 31 different variables were subsequently adopted consisting of 24 conventional financial ratios and seven trend measures all computed from balance sheet information contained on the "Extel cards". These varlables are shown in Tables 5.1 and 5.2 where several aspects of company structure are portrayed.

Furthermore empirical studies $[39,40]$ in various oountries showed that firms operating in different industrial sectors tend to have different financial ratios. This obliged the author to relate the firm being examined to the ratios existing in its particular industry.

Also previous research by Deakin [25] indicated that financial ratios very rarely fit a normal distribution. However, the population of companies within a particular industry exhibited more normal distribution than a population of companies from several industries.

Since this research concerned the construction industry only problems of non-nomality were able to be removed.

In addition the distribution was smoothed by averaging the acoounts of "failed" and "non-failed" companies for the last three and four years respectively. Nevertheless, strict adherence to the rules of normality had to same extent to be disreganded in view of Deakin's conclusion [25] i.e. "probability statements fram a model based on financial ratios may be subject to question because of the distributions characteristics. A user may thus be better off with a 


\begin{tabular}{|c|c|c|}
\hline No & Variable Description & Financial structure \\
\hline $\begin{array}{l}1 . \\
2 . \\
3 . \\
4 . \\
5 . \\
6 . \\
7 .\end{array}$ & $\begin{array}{l}\mathrm{EBIT} / \mathrm{NA} \\
\mathrm{EBIT} / \mathrm{EITY} \\
\mathrm{EBIT} / \mathrm{CL} \\
\mathrm{EBIT} / \mathrm{NCE} \\
\mathrm{EBIT} / \mathrm{TU} \\
\mathrm{PAT} / \mathrm{NCE} \\
\mathrm{PAT} / \mathrm{EQITY}\end{array}$ & PROFITABILITY \\
\hline $\begin{array}{l}8 . \\
9 . \\
10 . \\
11 . \\
12 .\end{array}$ & $\begin{array}{l}\text { FA/EQITY } \\
\text { LA/CL } \\
\text { WC/NCE } \\
\text { DR/CL } \\
\text { INT/EBIT }\end{array}$ & WORKING CAPITAL \\
\hline $\begin{array}{l}13 . \\
14 . \\
15 . \\
15 . \\
16 . \\
17 . \\
18 . \\
19 .\end{array}$ & $\begin{array}{l}\mathrm{CL} / \mathrm{NA} \\
\mathrm{CL} / \mathrm{NCE} \\
\mathrm{DEBIT} / \mathrm{NCE} \\
\mathrm{CA} / \mathrm{CL} \\
\mathrm{CA} / \mathrm{CL} \\
\mathrm{CA} / \mathrm{NA} \\
\mathrm{CA} / \mathrm{EQITY} \\
\mathrm{CA} / \mathrm{NCE}\end{array}$ & $\begin{array}{l}\text { FINANCIAL } \\
\text { LEVERAGE }\end{array}$ \\
\hline $\begin{array}{l}20 . \\
21 \\
22 .\end{array}$ & $\begin{array}{l}\mathrm{LA} / \mathrm{NA} \\
\mathrm{LA} / \mathrm{EQITY} \\
\mathrm{LOg}_{10} \text { (DAYS-DEBTORS) }\end{array}$ & LIQUIDITY \\
\hline 23. & TV/NA & ACTIVITY \\
\hline 24. & $\mathrm{STL} / \mathrm{EBIT}$ & LIQUIDITY \\
\hline $\begin{array}{l}25 . \\
26 . \\
27 . \\
28 . \\
29 . \\
30 . \\
31 .\end{array}$ & $\begin{array}{l}\text { TAX-TREND } \\
\text { PAT-TREND } \\
\text { DR-TREND } \\
\text { CRD-TREND } \\
\text { INT-TREND } \\
\text { STL-TREND } \\
\text { LA-TREND }\end{array}$ & $\begin{array}{l}\text { TREND } \\
\text { MEASUREMENT }\end{array}$ \\
\hline
\end{tabular}

TABLE 5.1: FINANCIAL RATIOS EMPLOYED IN THE ANALYSIS 


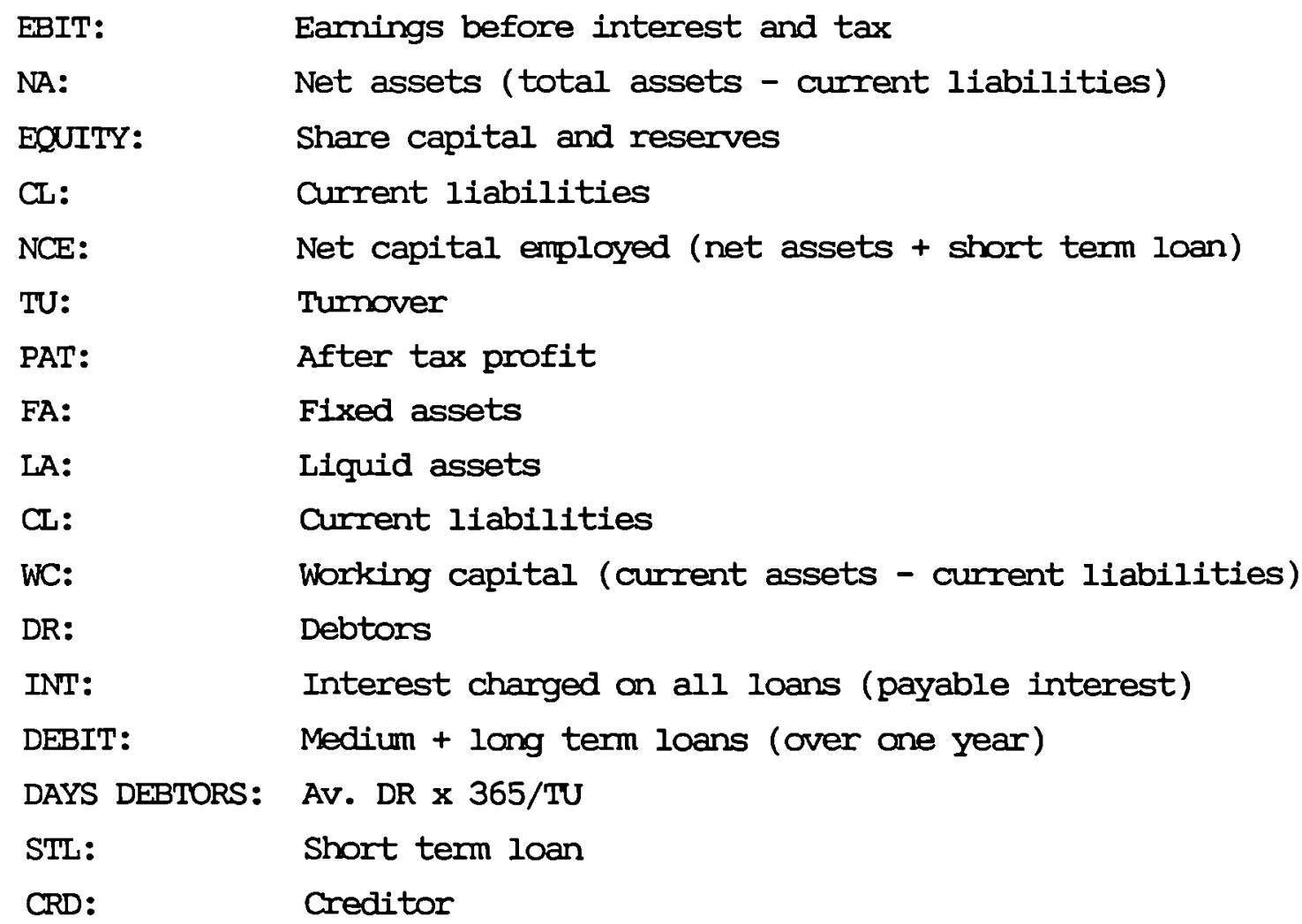

The trend ratios are calculated on the basis of the following formula:

$$
T_{n}=\frac{\left\{\frac{P_{n}+P_{n-1}}{2}\right\}-P_{n-2}}{\text { ABS. }\left(P_{n-2}\right)}
$$

where: $T_{n}$ is the trend ratio for year $n$

The P's are the balance sheet figures for years $n, n-1$ and $n-2$ of the trend being computed, e.g. Creditors, Tax etc.

Note: The denominator is taken as the absolute value, i.e. the sign is ignored.

TABLE 5.2: KEY TO TABLE 5.1 
rough estimate than no estimate at all". However, as the model was developed, the more discriminant ratios appeared to be those which displayed near normal distributions.

\subsection{FINANCIAL RATIOS CALOULATIONS AND DATA MANIPULATION}

\subsubsection{Introduction}

one major difficulty in the calculation of financial ratios, concerns the large number needed in developing and testing the model. A computer package was thus developed to speed up the process and precision analysis in the form of a Fortran programme, ADNAN.FOR, which included:

- The User Manual

- The Programe Documentation

See Appendix A.

\subsubsection{Computer Package ADNAN. FOR}

ADNAN.FOR is a computer programme written in the programing language FORTRAN 77 for use on a PC-IBM, core space required $(169,646)$ bytes. The computer programme was written and developed for specific use in the calculations required for the research.

The User Manual sets out how the programme may be used to perform the calculations and the Programme Documentation section allows the programme to be understood.

The programe calculates, from 18 pieces of financlal information obtained from company financial reports, a series of financial ratios and measured 46 in all relevant to this study. 
The programe is in two parts:

- the 18 pieces of financial information are read by the computer and printed out for checking

- the programme calculates the 46 financial ratios and measures of performance for a six year period as a maximum. The programme asks the user the required number of years and name of file for output.

Also, the programe calculates the financial ratio means over the required period, and prints the trend and change in growth ratios for the 18 pieces of data together with the means of the results. See Appendix A.

\subsection{STATISTICAL COMPUTER PACKAGE}

\subsubsection{Introduction}

Altman [8] appears to be the leading pioneer in applying the multivariate discriminant analysis technique for financial ratios as evidenced in his general equity models using (USA) data claiming bankruptcy prediction capabilities.

Subsequently several other researchers published in the same field. Indeed the technique is now considered to be a most reliable predictive tool. This research builds on this evidence and uses the particular computer package (SPSS X) available at the Computer Centre at Loughborough University of Technology for the analysis process.

\subsubsection{Statistical Computer Package (SPSS X)}

The programme was originally produced at chicago University, but is now a commercial product belonging to SPSS Inc of Chicago. It has powerful multivariate procedures for discriminant analysis. The original 82 variables were initially reduced to 31 and subsequently to a smaller, more easily handled 7. This was achieved by an 
interactive process whereby the programme selects the variables which discriminate most using the stepwise procedure i.e. the best discriminating varlable is selected according to user-determined criteria.

Several criteria are available to the user but in our case the principal criterton was "Wilks Lambda", as mentioned in equation (2) in Section 3.3. The method establishes the "F-ratio" and tests differences among group centroids, whereby the varlable maximising the F-ratio also minimises "Wilks Lambda", thereby measuring group discrimination.

The test takes into consideration the differences between the group centroids and the cohesion within the groups. Once the best discriminating variable has been found using the selection rule "minimise Wilks Lambda", the programme continues by pairing this variable with each of the other varlables in tum and computing wilks Lambda again.

The new varlable which, in conjunction with the initial variable gives a lower Wilks Lambda, is then selected as the second variable to enter the function.

These two variables are then combined with each of the remaining variables to form triplets, which are again evaluated on the criterion. The triplet with the lowest Wilks Lambda value detenines the third variable to be selected for the function.

This procechure of locating the next variable that would yield the least Wilks Lambda score gives the variables already selected. This continues until all the variables are selected. 
As variables are selected for inclusion some already in the function may lose their discriminating power. This occurs because the information that contained group differences is now better defined by some combination of the other included variables. Such varlables thus become redundant and are therefore removed from the equation. As a consequence, at the beginning of each step each of the previously selected variables is tested to determine if it still makes a sufficlent contribution to the discrimination. If any are eligible for removal, the least useful is eliminated. Nevertheless a variable removed at one step may re-enter at a later step if it satisfies the least Wilks Lambda at that stage.

So, by eliminating the poor discriminators, a small number of variables accounting for most of the discrimination are eventually determined. This result is an optimal, rather than a maximal solution. The assumption being that the stepwise procedure is an efficient way of approximately locating the best set of discriminating variables. In this research variables were ultimately identified as being powerful discriminators.

Figure 5.1 shows one particular step in the stepwise method. As can be seen, at step 5, for example, 5 variables were entered into the equation, together with remaining variables waiting to enter. The "F to enter" is the value of the "F-ratio" needed to give access to the equation. "F to remove" is the value of the "F-ratio" of that variable when entering the equation. It can be seen from this example that variable 23 was included in the equation at this step.

The variable with the highest "F to enter" will be the next to enter the equation, provided the "F to enter" value is greater than the minimum stipulated. In this case it will be variable 26 . 
Figure 5.2 shows a summary of all the steps in the particular analysis. The information here shows the variables entered or removed at each step, and shows that variable 12 which entered at step 3 was removed at step 9.

Figure 5.3 illustrates the final step of analysis at the value of the "F to remove" and also the value of "Wilks Lambda". Both the "F to remove" and the "Wilks Lambda" values are indications of how much each varlable contributes to the discrimination where it may be observed that 7 variables give good discrimination, at a "Wilks Lambda" of 0.175. The variables adding most to discrimination are those with the highest "F to remove" values.

The programme also calculates the "standardised" and "unstandardised" discrimination function coefficients. The "unstandardised" coefficients are the most useful when multiplied by the raw values of the associated variables to arrive at "discriminant $\mathrm{z}$-score".

The programme further calculates the "discriminant function evaluated at group means (group centroids)". See Figure 5.4 for unstandardized coefficients.

In order to use the model as a classification tool, the discriminant function coefficients have to be adjusted by calculating the mean value of discriminant function coefficient for two groups and multiplying throughout by two ignoring the sign.

As an extra check, the programme tests the adeguacy of the derived discriminant function. By classifying the cases used to derive the function in the first place and comparing the predicted group membership with the actual group membership, it empirically measures the success of the discrimination by observing the proportion of correctly classified. 


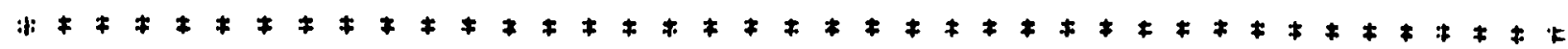

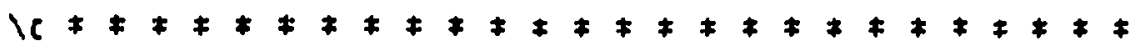

AI STEF 5, V2J HAS INCLUDED IN THE ANALYSIS.

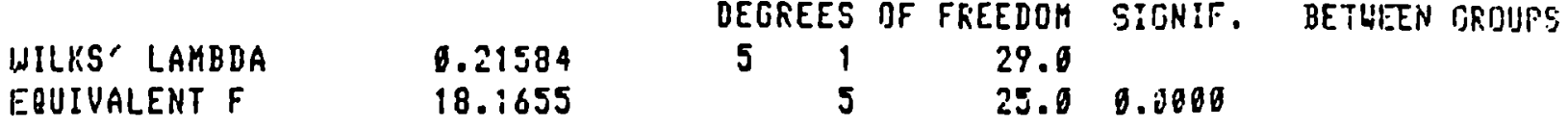

VARIABLES IN THE ANALYSIS AFTER STEP I

\begin{tabular}{|c|c|c|c|}
\hline VAR I ABLE & TOLERANCE & F TO REHOVE & HILKS' LAKBD \\
\hline U6 & 0.7391182 & 18.359 & 0.37434 \\
\hline V12 & 0.7750358 & 10.117 & 0.36318 \\
\hline v17 & 0.4613530 & 22.483 & 0.40995 \\
\hline U23 & 0.4833676 & 4.4916 & 0.25383 \\
\hline v25 & 0.7099661 & 9.4367 & 9.29731 \\
\hline
\end{tabular}

VARIARLLES NOT IN THE ANALYSIS AFTER STEF

5

MINIHUK

VARIABLE TOLERANCE TOLERAHCE F TO ENTER HILIS' LAME::

\begin{tabular}{|c|c|c|c|c|}
\hline vi & 0.1624146 & $0.1624 i 48$ & 1.8039 & 0.20975 \\
\hline$v_{2}$ & 0.3136713 & 0.3136713 & $0.86703 E-01$ & $9.2152=$ \\
\hline V3 & 0.3806102 & 0.3493684 & .34391 & 0.21279 \\
\hline U1 & 0.7955813 & 0.4604161 & $0.11050 E-81$ & $0.2157=$ \\
\hline US & 0.2347246 & 0.2347246 & .27893 & 0.21336 \\
\hline U7 & 9.1832967 & 0.1832067 & $0.23031 E-03$ & $0.2153=$ \\
\hline U8 & 8.8222385 & 0.4537366 & $0.46010 E-01$ & $0.2154 ?$ \\
\hline ve & 0.9045114 & $0.425 \div 22 i$ & 1.5414 & $0.2929 ;$ \\
\hline U10 & 0.8997728 & 0.4502239 & $0.12391 E-01$ & $9.2157 \%$ \\
\hline U1: & 0.7568934 & 0.4613444 & .47651 & $0.2116=$ \\
\hline W13 & 9.5104290 & 0.3739778 & 1.9383 & $9.2060=$ \\
\hline$v i 4$ & 0.5289365 & 0.3717586 & .15397 & $0.2 i 44 \div$ \\
\hline U15 & 0.8667331 & 0.4297505 & $0.16095 E-03$ & $6.2958=$ \\
\hline Wit & 0.4778423 & 0.4351789 & $0.48 i: 9 E-63$ & $0.2158=$ \\
\hline V18 & 0.5911871 & 0.3124255 & $0.21271 E-01$ & 0.21565 \\
\hline v19. & 0.3161685 & 0.3161385 & $0.26953 E-01$ & 0.21560 \\
\hline V20 & 0.7993289 & 0.4278886 & .27434 & 0.213451 \\
\hline v21 & 0.7842791 & 0.3921431 & $0.35405 E-01$ & $0.2155=$ \\
\hline v22 & 0.9299162 & 0.4513463 & .79972 & 0.20838 \\
\hline V24 & 0.1964195 & 9.1902891 & .12793 & 0.21465 \\
\hline V26 & 0.5981619 & 0.3136296 & 5.5418 & 0.17535 \\
\hline U27 & 0.9581067 & 0.4613283 & .15811 & 0.21443 \\
\hline V28 & 0.7964755 & 0.4472866 & .20464 & $0.2149 i$ \\
\hline U29 & 0.8785336 & 0.4613127 & .42074 & $0.2121=$ \\
\hline v30 & 0.8329811 & 0.9611340 & 2.7659 & $0.1935=$ \\
\hline V31 & 0.9338558 & 0.4576507 & $0.14736 E-03$ & 0.2158 \\
\hline
\end{tabular}

111429 MAY 88 COMPErison of Propitatle and Insolvent Cunanies 16

PAGE

FIGURE 5.1: ONE PARTICULAR. STEP IN STEPWISE METHOD 
r LE - DR TOLERANCE OR UIN INSIJFFICIENT FOR FURTHER COMPIJTATION. Il1: TAY 88 COMfarison of fropitable and Insolvent Companies ic

FASE 15

Loughtorough University Honeywell $68 / 89$ Multics

SUMMARY TABLE

\begin{tabular}{|c|c|c|c|c|c|c|}
\hline & \multicolumn{2}{|c|}{ ACTION } & VARS & HILKS" & & \\
\hline SIEF & :1-ERED & REHOVED & IN & LAMBDA & SIG. & LABEL \\
\hline 1 & $\neg$ & & 1 & .66258 & .0906 & \\
\hline 2 & .: & & 2 & .47336 & .0000 & \\
\hline 3 & . ? & & 3 & .35881 & .1900 & \\
\hline 4 & $\therefore$ & & 4 & .2538 .7 & .0089 & \\
\hline 5 & $\therefore$ & & 5 & .21584 & .0090 & \\
\hline 6 & $\therefore 2$ & & 6 & .175 .35 & .0090 & \\
\hline 7 & $\therefore 3$ & & 7 & .15087 & .6940 & \\
\hline 8 & $\therefore 2$ & & 8 & .13503 & .0909 & \\
\hline 9 & & V12 & 7 & .13517 & .0000 & \\
\hline
\end{tabular}

CAMDNICAL MISCRIMINANT FIJNCTIONS

FUNCT::= EIGENUALUE

ICAMB:: CHI-SRUARED

FERCENT OF CUMULATIVE VARIANCE FERCENT D.F. SIGHIFICANCE
1069 :
51.631
6.39813
99.06
0.0000
109.00
$0.9279627=$
13
109.06

10.00
CANONICAL : AFTER

CORRELATION : FUHCTION WILKS: L

:

0.1351

FIGURE 5.2: THE SUMMARY OF ALI THE STEPS IN THE STEPWISE METHOD 


\begin{tabular}{|c|c|c|c|c|}
\hline & & DEGREES & OF FREEDOM & SIGNIF. \\
\hline ILKS' L="I:HA & 0.13517 & 1 & 29.0 & \\
\hline & 29.0224 & 7 & 23.0 & 0.0000 \\
\hline
\end{tabular}

VARIABLES IN THE ANALYSIS AFTER STEF

9

\begin{tabular}{|c|c|c|c|}
\hline $\begin{array}{l}\text { UARIABLE } \\
\text { U6 } \\
\text { V17 }\end{array}$ & 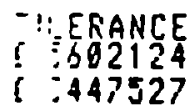 & $\begin{array}{l}F \text { TI REMOVE } \\
29.295 \\
29.648\end{array}$ & $\begin{array}{c}\text { HILKS } \\
9.369397 \\
.30941\end{array}$ \\
\hline U23 & (:829541 & 16.182 & 0.23627 \\
\hline U24 & f 2434945 & 13.928 & 0.21793 \\
\hline$\sqrt{25}$ & f : $: 113777$ & 19.161 & 0.24773 \\
\hline U26 & f $: 479918$ & 8.5112 & 0.18519 \\
\hline V30 & 13915605 & 6.8454 & 0.17549 \\
\hline
\end{tabular}

VARIABLES NOT IN THE ANAI.YST!S AFTER STEP

\begin{tabular}{|c|c|c|c|c|}
\hline VARIABLE & i__ERANCE & $\begin{array}{l}\text { MINIMUH } \\
\text { TOLERANCE }\end{array}$ & F TO ENTER & 'ULLKS' LAMBDA \\
\hline $\begin{array}{l}v_{1} \\
v_{2}\end{array}$ & $\begin{array}{l}\text { f. } 546896 \\
\text { F.:-903695 }\end{array}$ & $\begin{array}{l}0.1546806 \\
0.2366829\end{array}$ & $\begin{array}{l}.46462 \\
.32642 E-93\end{array}$ & $\begin{array}{l}0.13237 \\
0.13517\end{array}$ \\
\hline U3 & f.:\$26145 & 0.2643240 & .80408 & 6.13940 \\
\hline U4 & $f .5303164$ & 0.2795612 & .45811 & 0.13246 \\
\hline V5 & 6.:270301 & 0.1956506 & .50261 & 6.13215 \\
\hline Q & เ. . 247145 & 0.1747145 & .13911 & $0.13+32$ \\
\hline 48 & P. $\equiv 336324$ & 0.2810149 & $0.49684 E-01$ & 0.1348 .5 \\
\hline V9 & E.: $: 767617$ & 0.2801188 & .69835 & 0.13136 \\
\hline V19 & f. $\equiv 359510$ & 0.2828644 & $0.85963 E-01$ & $0.134,54$ \\
\hline V11 & $8.5: 90130$ & 0.2795873 & .28684 & 9.13347 \\
\hline V12 & E. 395183 & 0.1491418 & $0.23381 E-01$ & 0.13563 \\
\hline U13 & $2 .=297389$ & 0.2194048 & .49203 & 0.13221 \\
\hline $\begin{array}{l}414 \\
416\end{array}$ & 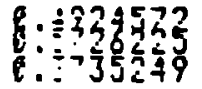 & $\begin{array}{l}8: 2395659 \\
0: 2652759\end{array}$ & 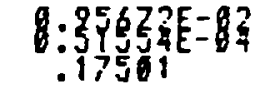 & $\begin{array}{l}9: 13593 \\
0.134: 39\end{array}$ \\
\hline U18 & 6.5\$15379 & 0.2417479 & .11248 & 0.13448 \\
\hline$v 19$ & $9 .: 171498$ & 0.2593306 & $0.45041 E-01$ & 0.134 .93 \\
\hline U20 &.-387956 & 0.2726227 & .12648 & $0.13 .4 \div 3$ \\
\hline V21 & $0 .-220602$ & 0.2716736 & .11060 & 0.13449 \\
\hline V22 & $0 . \vdots 527341$ & 0.2793084 & .68119 & $9.131: 1$ \\
\hline V27 & 0.9494892 & 0.2826655 & $0.69288 \mathrm{E}-02$ & $0.135: 3$ \\
\hline V28 & a. $-i 82636$ & 9.2748877 & $9.13368 E-61$ & 0.13597 \\
\hline $\mathbf{U}_{29}$ & 0.30426 .50 & 9.2795671 & .44794 & $0.132=?$ \\
\hline U31 & $0 .=175661$ & 0.2792637 & $0.67571 E-01$ & 0.13475 \\
\hline
\end{tabular}

F LEVEL OR TL:ERANCE OR VIN INSUFFICIENT FOR F: :-HER COFPUTATION.

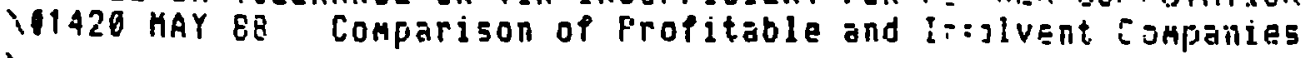

FIGURE 5.3: SHOWS THE FINAL STEP OF ANALYSIS IN THE STEPWISE METHOD 


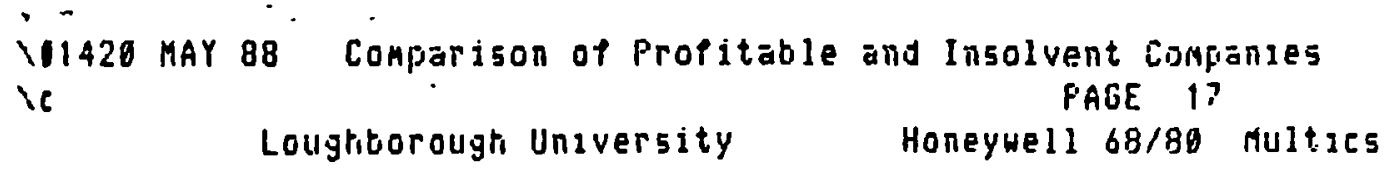

UNSTANDARDIZED CANONICAL DISCRIMINANT FUNCTION COEFFICIENTS

FURC 1

$\begin{array}{lr}\text { U6 } & -16.66449 \\ \text { U17 } & 2.848277 \\ \text { U23 } & -.4894365 \\ \text { U24 } & .2345166 \\ \text { U25 } & -.6957342 \\ \text { U26 } & .6957439 \\ \text { U36 } & .5972381 \\ \text { (CONSTANT) } & -2.854138\end{array}$

-..AGUHCAL DISCRIMINANT FUNCTIONS EVALUATED aT GROUP MEANS :ODUF CENTROTIS) GROUP FUNC 1 
Y1420 MAY 88 Comparison of Frofitable and Insolvent Companies

ie PAGE 18

Loughtorough University Honeyuell $68 / 8 g$ Multics

$\begin{array}{lllll}\text { CASE HIS } & \text { ACTUAL } & \text { HIGHEST FROBABILITY } & \text { 2ND HIGHEST } & \text { UISCRIM } \\ \text { ICINANT } & & & & \\ \text { SEQNUH VAL SEL GROUP } & \text { GRDUP P(D/G) F(G/D) } & \text { GROUP P(G/D) } & \text { SCORES }\end{array}$

ic...

$\begin{array}{ll}1 & 1 \\ 2 & 1 \\ 3 & 1 \\ 4 & 1 \\ 5 & 1 \\ 6 & 1 \\ 7 & 1 \\ 8 & 1 \\ 9 & 1 \\ 19 & 1 \\ 11 & 1 \\ 12 & 1 \\ 13 & 1 \\ 14 & 1 \\ 15 & 1 \\ 16 & 1 \\ 17 & 1 \\ 18 & 1 \\ 19 & 1 \\ 20 & 1 \\ 21 & 2 \\ 22 & 2 \\ 23 & 2 \\ 24 & 2 \\ 25 & 2 \\ 26 & 2 \\ 27 & 2 \\ 28 & 2 \\ 29 & 2 \\ 30 & 2 \\ 31 & 2\end{array}$

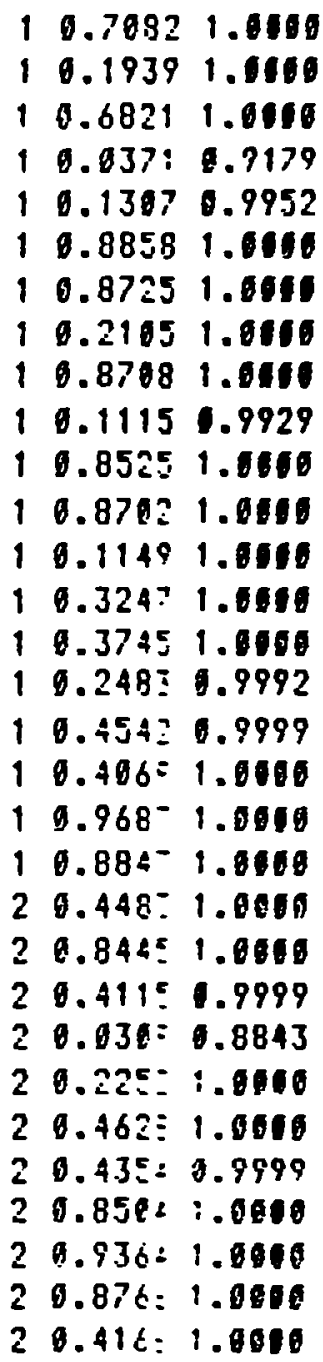

$20.0000-1.4401$

$20.0000 \quad-3.1135$

$20.0000 \quad-2.2246$

$20.9821 \quad 0.2799$

$20.6948 \quad-6.3930$

$29.0000-1.9579$

$20.0000 \quad-1.97+9$

$20.0000-3.0666$

$20.0000 \quad-1.6517$

$20.0071-0.2229$

$20.0000-1.6284$

$20.0600-1.9778$

$20.0000 \quad-3.3910$

$20.0006 \quad-2.7992$

$20.0000 \quad-2.7024$

$20.0608 \quad-9.6598$

$20.0601 \quad-1.06 .50$

$20.0600 \quad-2.6437$

$20.0000 \quad-1.7752$

$20.0000-1.3574$

$10.0000 \quad 4.0570$

$10.0000 \quad 3.4950$

$10.0001 \quad 2.4775$

$10.1157 \quad 1.1400$

$10.0009 \quad 4.5116$

$10.0000 \quad 4.0330$

$10.009: \quad 2.5139$

$10.0000 \quad 3.1102$

$10.0009 \quad 3.3787$

10.00003 .4541

10.00004 .1112

CLASSIFICATION PROCESSING SUMMARY

31 CASES HERE PROCESSED.

- CASES UERE EXCLUDED FOR HISSIHS ' OUT-OF-RANGE GROUP CODES.

- CASES HAD AT LEAST UME HIJSIME : 'RRIMIHETIHG VARIABLE.

7 narra curne unrn ran naturen nutr.u-

FIGURE 5.5: THE DISCRIMINANT CORES 
Classification is achieved by using classification functions, ane for each group. These functions are derived from the pooled within groups covariance matrix and the centroids of the discriminating variables.

The resulting classification coefficients are to be multiplied by the raw variable values, summed together, and added onto a constant. The classification function for one group would appear as:

$$
c_{1}=c_{i 1} v_{1}+c_{12} v_{2}+\ldots+c_{i n} v_{n}+c_{i 0}
$$

where $C_{1} \quad$ is the classification soore for group 1

$c_{11} \ldots C_{\text {in }}$ are the classification coefficients

$\mathrm{C}_{10}$ is the constant

$v_{1} \ldots v_{n}$ are the raw values of the discriminant variables

There is always a separate equation for each group. Similarly, classification functions for group 2 appear as:

$$
c_{2}=c_{j} v_{1}+c_{j} v_{2}+\ldots+c_{j n} v_{n}+c_{j 0} \ldots
$$

Thus in this research each case has two soores. The case would be classified into the group for which it had the highest score, see Figure 5.5 .

Under the assumptions of multivariate normal distributions the classification scores can be converted into probabilities of group membership. The rules of assigning a case to the group for which it has the highest score is then equivalent to assigning the case to the group for which it has the greatest probability of membership. 
Figure 5.5 shows the highest probability with discriminant scores. Further results of computer print outs are shown in Appendix"..

\subsection{REGRESSION ANALYSIS FOR PREDICTING BANKRUPTCY}

\subsubsection{Introduction}

Two further predicting models were developed in the form of regression techniques, less complicated than the discriminant models, as follows.

The first was developed from the same financial ratios of "failed" and "non-falled" groups which applied in the discriminant model described in the previous section. The dependent variables were calculated from the same Z-score as the developed model. This procedure further reduced the number of discriminant variables from 7 to 5 .

The second model was also developed from the same financial ratios but used the dependent variables calculated from the Mason and Harris' model published in 1979, updated for operational use.

\subsubsection{The Multiple Regression Model 1}

A simple regression analysis between $\mathrm{Z}$-scores calculated from the developed model and financlal ratios, of "failed 11" and "non-failed 20" groups, was carried out. After using the stepwise technique available in the Minitab programme, the following results were obtained (by taking the value of $\mathrm{z}$-scores fram discriminant scores and converting the sign) $(+)$ to $(-)$ :

$$
z=2.81-2.84 c_{17}+15.3 c_{6}-2.08 c_{12}+.581 c_{25}+.282 c_{23}
$$


where: $C_{17}$ - as a ratio of current assets to net assets

$\mathrm{C}_{6}$ - as a ratio of earning after tax and interest to net capital enployed

$\mathrm{C}_{12}$ - as a ratio of interest to earning before tax and interest

$C_{25}=$ Tax trend: $\frac{\frac{T_{n}+T(n-1)}{2}-T(n-2)}{T(n-2)}$

$C_{23}$ - as ratio of turnover to net assets.

See Appendix C.

\subsubsection{The Regression Model 2}

A second regression analysis was performed between $\mathrm{Z}$-values calculated from Mason's model and financial ratios of "non-failed 20" groups. Again after using the stepwise technique the following results were obtained:

$$
z=3.47+74.5 c_{4}-14.7 c_{11}+3.37 c_{26}-5.17 c_{13}
$$

where: $C_{4}$ is ratio of earnings before tax and interest to net capital employed

$\mathrm{C}_{11}$ is a ratio of debtor to current liabilities

$\mathrm{C}_{13}$ is a ratio of current liabilities to net assets

$C_{26}:$ Earnings after tax trend

See Appendix C. 


\subsection{DISCUSSION}

The multivariate methodology used in this research is based upon the following goals:

1. The variables used should be multivariate nomal distributed.

The solution suggested in the previous studies is that the data should be tansformed on a univariate basis to improve univariate nomality and this should have the desired effect of increasing the probability of multivariate normality.

2. The individual varlable should measure different financlal characteristics.

Correlation between variables has been tested in a way that any ratio which is highly correlated with other ratios that describe similar aspects of the company's financial structure should be discretised as a result when the correlation between variables was 0.7 or more. One of them was selected for inclusion in the analysis. In this way the large number of variables was reduced fram 82 to 31 .

Despite arguments that multicollinearity is not important in LDA (e.g. Eisenbeis, 1977 [31]) it was considered for the purpose of this study to be appropriate to limit the variables to measure different financial structures.

3. A stepwise linear discriminant package SPSS-X was utilised and after many runs the model developed. 
The procedure presented here is based on the unstandardised coefficient. They are most useful when their values are multiplied by the raw values of the associated variables to arrive at a"discriminant z-score" taking into account that the function has to be multiplied by twice the mean of classification scores for each group as an adjustment factor.

The "standardised coefficlents" which are related to weight of regression analysis were rejected and not taken into acoount. Instead the "inter-correlations in the variables set" were used to form the model. "Standardised Coefficients" however are still accepted in some literature [36] and further discussion will follow in a later section.

Two additional predictive models were developed during the research based an the multiple regression technique, aimed at recucing the number of discriminant variables in the final model and also to update the Mason model to fit the changes in economy after ten years of operational use.

Finally, the use of multiple regression should not be considered as a substitute for IDA and should be viewed as a method for unravelling the complexities of LDA. 


\section{CHAPTER 6}

THE RESULTANT MODEL
6.1 Introduction
6.2 The Resultant Model
6.3 The Constituent Variables
6.4 The Relationships between the Ratios
6.5 Contribution of Each Ratio to the Model
6.6 The Cut-off Between Groups and Grey-Area
6.7 Summary and Conclusions 


\section{CAAPTER 6}

THE RESULTANT MODEL

\subsection{INTRODUCTION}

This section includes a description of the discriminant model, and its constituent variables, together with the relationship between the ratios and contribution of each ratio to the model. The cut-off value for the model is also included.

The final prediction model produced in the research is made up of seven variables, measuring five distinct aspects of a company's financial structure. Good discrimination between "solvent" and "failed" companies was evident. Considerable effort was made to reduce the number of discriminating variables in the function fram seven to same smaller, more easily handled, say five variables, using regression techniques.

\subsection{THE RESULTANT MODEL}

The following seven variable linear function resulted:

$$
\mathrm{z}=\mathrm{c}_{0}+\mathrm{C}_{6} \mathrm{v}_{6}+\mathrm{c}_{17} \mathrm{~V}_{17}+\mathrm{c}_{23} \mathrm{~V}_{23}+\mathrm{c}_{24} \mathrm{~V}_{24}+\mathrm{c}_{25} \mathrm{~V}_{25}+\mathrm{c}_{26} \mathrm{~V}_{26}+\mathrm{c}_{30} \mathrm{~V}_{30}
$$

where $c_{0}, c_{6}, c_{17}, c_{23}, c_{24}, c_{25}, c_{26}, c_{30}$ denotes the coefficients.

$v_{6}, v_{17}, v_{23}, v_{24}, v_{25}, v_{26}, v_{30}$ denotes the discriminant variables. 


$$
\begin{aligned}
& c_{0}=14.6 \\
& c_{6}=82 \\
& c_{17}=-14.5 \\
& c_{23}=2.5 \\
& c_{24}=-1.2 \\
& c_{25}=3.55 \\
& c_{26}=-3.55 \\
& c_{30}=-3
\end{aligned}
$$

The modle is:

$$
\begin{aligned}
\mathrm{z}=14.6 & +82 \mathrm{v}_{6}-14.5 \mathrm{v}_{17}+2.5 \mathrm{v}_{23}-1.2 \mathrm{v}_{24} \\
& +3.55 \mathrm{v}_{25}-3.55 \mathrm{v}_{26}-3 \mathrm{v}_{30}
\end{aligned}
$$

\subsection{THE CONSTITUENT VARTABLES}

The constituent variables in the developed model are as follows:

1. $v_{6}$ : Ratio of earnings after tax and interest charge to net capital employed.

This is a profitability measure, and takes into account all the net assets plus the short term loan which is used to finance the company. The net capital employed may be defined as fixed assets plus working capital, and is often used for (ROCE) in published accounts. i.e. return on capital employed (ROCE)

This ratio is a valuable guide to the profitability of the companies. The values appear positive in solvent companies and tend towards the negative in failed companies. 
2. $V_{17}$ : Ratio of current assets to net assets:

This is a financial leverage measure. Failed fims consistently have less current assets including cash than non-failed fims. However, some failed firms also have a high ratio since net assets decrease continuously leading to an increase in this ratio. The ability of a firm to meet its short-term financial obligations without having to liquidate its long-term assets is an important factor in the consideration of lenders, the extreme case of such an inability is bankruptcy.

3. $v_{23}$ : Ratio of turnover to net assets

This ratio is ane measure of how well a company has used its productive capacity which is usually considered in failed firms rather than solvent companies, due to lack of response to market situation. However, some failed firms also have high ratios. An experimental ratio may be that for increasing turnover/net assets accompanied by decline in net assets. Also same failed companies may be increasing turnover by overtrading, a usual phenomenon in failed companies.

4. $v_{24}$ : Ratio of short term loan to earnings before tax and interest charges

Short term loans are taken as being the loan and overdrafts appearing in the company's current liabilities statement. It shows the relative safety of short-term loans compared to earnings before tax and interest charges. This ratio is one measure of a cotpany's liquidity. 
5. $\mathrm{V}_{25}:$ Tax trend

The tax trend tends towards the negative in failed companies. As a company becomes "better off" the trend increases, becoming negative in failed companies. In the author's case tax is a portion of profit paid to the Govermment, thus when a company does not achieve profitability, no tax is paid.

6. $v_{26}$ : Earnings after tax trend

The earnings after tax trend tends towards the negative in failed companies. Again as a company becomes "better off" the trend increases, becoming negative in the failed companies.

7. $v_{30}$ : Short term loan trend

The short term loan trend has the advantage of measuring the liquidity over several years. The majority of construction companies are dependent on short-term loans. In practice longterm nature, for example, the bank overdraft which a firm obtains or the credit extended to it by its trade creditors, will be available to the company without any further negotiation, unless drastic changes occur in the company or in the general economy. Generally, failed companies are highly dependent on short-term loans more than non-failed firms. As a company becomes "worse off" the trend increases, reaching crisis level before the collapse. 
Table 6.1 shows the constituent ratios and financial aspect measurements.

\begin{tabular}{rll}
\hline Ratio No & Description of Ratio & \multicolumn{1}{c}{$\begin{array}{c}\text { Finanical Aspect } \\
\text { Measurement }\end{array}$} \\
\hline 6 & PAT/NCE & PROFITABILITY \\
17 & CA/NA & FINANCIAL LEVERAGE \\
23 & TURN/NA & ACTIVITY/ASSETS TURNONER \\
24 & STL/EBIT & LIQUIDITY \\
25 & TAX-TREND ) \\
26 & PAT-TREND ) & TREND MEASUREMENT \\
30 & STL-TREND $)$ & \\
& & \\
\hline
\end{tabular}

TABLE 6.1: THE CONSTITUENT RATIOS IN THE MODEL

\subsection{THE RELATIONSHUIPS BETWEEN THE RATIOS}

As mentioned previously, the resultant model consists of seven discriminant variables measuring four financial aspects. The profitability measures were found to contribute much to the discrimination followed by the financial leverage measure, asset turnover and liquidity measure. The last three discriminators representing the trend measures are the least discriminant of the variables.

It seems that trend measurement was significant and confirmed in this research, when the trend measurements were included. By comparing the resultant model with previous studies, the author concludes that the 
profitability measure contributes the most because a firm earning profit almost never fails. Also it may be concluded that inclusion of TURN/NA ratio in the author's model produced similar results to Altman, using the numerator of the ratio, turnover. The major difference from all other models was its measures of profit after tax and interest omitted elsewhere. Taffler [11] stipulated that only ratios measuring different aspects should be in the same model. These restrictions were postulated to reduce the likelihood of sample bias being present in the model construction. Not all previous works, however, have agreed with these views [19][21]. Indeed Masan included two ratios measuring a similar dimension and, therefore, these two ratios are highly correlated.

The author-derived model contained several measures of trends apparently without detrimental effects. Table 6.2 shows the correlation matrix of the constituent variables.

It is interesting to note the lack of correlation between the variable set used to form the model since the purpose of this kind of study is to limit the variables to measure different financial structures. 


\begin{tabular}{llllllll}
\hline & PAT/NCE & CA/NA & TURN/NA & STL/EBIT TAX- & PAT- & $\begin{array}{c}\text { STL- } \\
\text { TREND }\end{array}$ \\
\hline PATEND & & & & & & \\
\hline CA/NA & 1.0 & & & & & & \\
\hline TURN/NA & -0.1858 & 0.5950 & 1.0 & & & & \\
\hline STL/EBIT & -0.0261 & -0.1759 & -0.2075 & 1.0 & & & \\
\hline TAX-TREND & -0.1461 & 0.2572 & 0.1206 & 0.2221 & 1.0 & & \\
\hline PAT-TREND & -0.1117 & 0.0340 & 0.4180 & 0.0316 & 0.2356 & 1.0 & \\
\hline STL-TREND & 0.2399 & 0.1034 & 0.0399 & -0.0886 & 0.0489 & -0.0193 & 1.0 \\
\hline
\end{tabular}

TABLE 6.2: POOLED WITHIN-GROUP CORREIATION MATRIX 


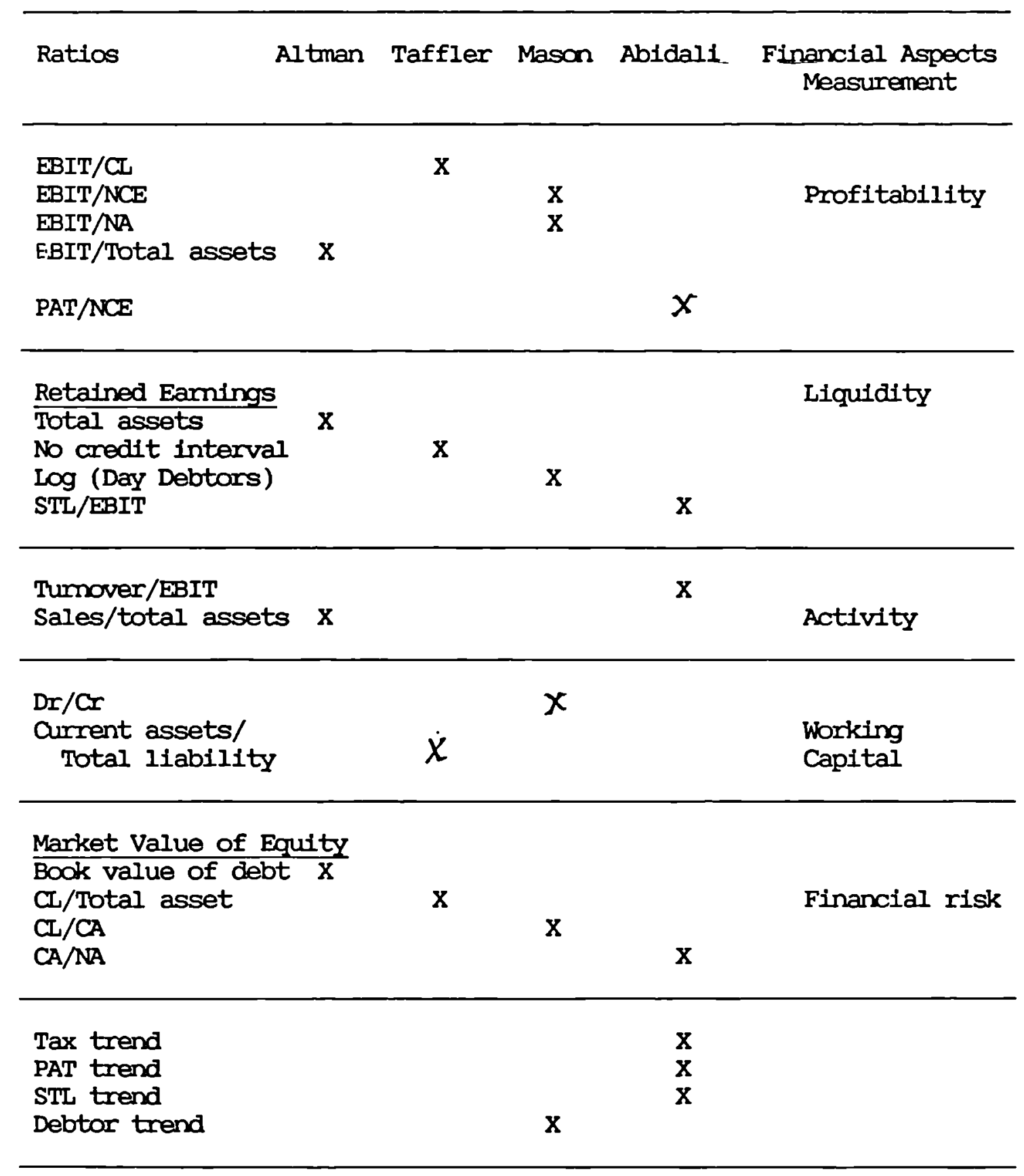

TABLE 6.3: SHOWS THE DESCRIPTION OF RATIOS AND FINANCIAL ASPECTS MEASUREMENTS ACHIEVED BY PREVIOUS STUDIES AND THIS STUDY 


\subsection{CONIRIBUTION OF EACH RATIO TO THE MODET}

There are three methods to measure the contribution that a ratio makes to the overall discriminating power of the model as follows:

1. Standardise coefficients:

This is a conventional method measuring the standardised coefficient, as weights of constituents, of the model. The main disadvantage concerns not taking into account the "intercorrelations" in the variable set used to form the model [11]. The value of using "standardised coefficients" however, is still accepted in some literature [36].

2. Mosteller and Wallace's Method [35]:

This mdel measures relative discriminant power as follows:

$$
R_{j}=\frac{c_{j}\left(\bar{x}_{j 1}-\bar{x}_{j 2}\right)}{\sum_{i=1}^{n} c_{i}\left(\bar{x}_{i 1}-\bar{x}_{i 2}\right)}
$$

where: $R_{j}=$ the relative proportion of discrimination that variable $f$ accounts for

$\bar{x}_{j 1}=$ the mean value of variable $j$ for group 1

$\bar{x}_{j 2}=$ the mean value of variable $j$ for group 2

$\mathrm{C}_{\mathrm{j}}=$ the standardised coefficient of variable $\mathrm{j}$

$\mathrm{n}=$ the total number of variables in the model

There has been much debate on this approach which was adopted by Taffler using the $C_{j}$ 's signed (+ or - ), with $R_{j}$ 's not summed to 1. 
Others believe that in practice the $c_{j}\left(\bar{x}_{j 1}-\bar{x}_{j 2}\right)$ 's must all have the same sign and if they do not, due to multioollinearity, then it is not possible to interpret the associated variables in any meaningful way. This concept was valuably demonstrated by Mason [17], where the variables measuring profitability showed high correlation. On this evidence, the relative contributions of the different variables, using the Mosteller and Wallace method, are questionable.

Similar conclusions can thus be made on why Taffler made the restriction that only ratios measuring different aspects should be in the same model.

3. Conditional deletion:

Qualitatively measures method of the additional contribution of each variable to the discriminant function with the other variables included, resulting in a ranking of the constituent variables, fram $F$ to inter of remove values. Altman adopted this method.

The results for the three methods are shown in Table 6.4. 


\begin{tabular}{lccc}
\hline & $\begin{array}{l}\text { Using standardised } \\
\text { coefficients method }\end{array}$ & $\begin{array}{c}\text { Using Mosteller \& } \\
\text { Wallace method }\end{array}$ & $\begin{array}{c}\text { Conditional } \\
\text { deletion method } \\
\text { F-value ranking) }\end{array}$ \\
\hline $\mathrm{V}_{6}$ PAT/NCE & 15 & 9 & $2(29.295)$ \\
\hline $\mathrm{V}_{17}$ CA/NA & 20 & 11 & $1(29.648)$ \\
\hline $\mathrm{V}_{23}$ TURN/NA & 19 & 15 & $4(16.182)$ \\
\hline$V_{24}$ STL/EBIT & 12 & 40 & $5(13.928)$ \\
\hline$V_{25}$ TAX TREND & 14 & 15 & $3(19.161)$ \\
\hline$V_{26}$ PAT TREND & 11 & 8 & $6(8.5112)$ \\
\hline$V_{30}$ STL TREND & 9 & 2 & $7(6.845)$ \\
\hline
\end{tabular}

TABLE 6.4: SHOWS CONTRIBUTION OF RATIOS TO MODEL

Both Taffler [11] in his multivariate study, and Beaver [3] in his univariate study conclude that short term liquidity is less important in determining a firm's solvency than permanent aspects. It appears Altman's method of using conditional deletion is more convincing than Taffler's method in measuring the contribution of each variable to discriminant function. Furthermore, the standardised coefficients are used when the variables are standardised to a mean of zero and a standard deviation of one, which is impossible in financial ratios. Therefore, the unstandardised coefficient method seems more reliable. However, the magnitude of the unstandardised coefficients is not a good index of relative importance when the variables differ in the units in which they are measured. Nevertheless variables with large coefficients are thought to contribute more to the overall discriminant function (see pp 91 [36]). 


\subsection{THE CUT-OFF BETWEEN GROUPS AND GREY-AREA}

\subsubsection{Introduction}

The aim of this section is to determine the cut-off between groups in order to mintmise the total number of misclassifications by locating the Z-value for which the company cannot be classified as belonging to failed or solvent groups. The overlap between the distribution of " $\mathrm{Z}$ " values for both failed and non-failed groups where misclassification can occur. In this region two types of error occur, namely type I errors, are defined as misclassification of "failed" company as "nonfailed", and type II errors as misclassifications of "non-failed" as failed. Ignoring the cut-off between groups gives rise to serious errors in interpreting the results from application of a derived discriminant function, for example, Altman and Eisenbeis [33] show that when the prior probabilities are arbitrarily set to 0.01 and 0.99 for a bankrupt and non-bankrupt firm respectively, then the type I error (misclassification of a bankrupt as a non-bankrupt occurs).

Experience with the Tisshaw (1976) [37] model for the analysis of privately owned manufacturing companies in practical application provides a low type I error rate but a wide number of type II errors.

Taffler (1982) suggested for privately owned manufacturing and construction enterprises a cut-off point of $(-1.6)$, though in one of his previous studies in 1976 he suggested a zero cut-off point.

Altman (1968) suggested a cut-off point of -2.99. The procedure which was adopted in this study to determine the cut-off point was based on two methods:

- mathematical methods

- prior probabilities and misclassification costs estimation method. 
After determining the cut-off point, furthermore, there will be a need - to set "grey area" limits in order to minimise the total number of misclassifications.

\subsubsection{Mathematical Derivation of the Cut-off Point}

The mathematical derivation of the computational formula of the cutoff point for the two groups, presented here, was developed by Paul [34]. In onder to set the cut-off point mathematically it is possible to determine the desired value if the distributions of " $\mathrm{Z}$ " values are known on the assumption that the distributions are nomal, the cut-off point which minimises the total number of misclassifications is found by locating the " $\mathrm{Z}$ " value for which the ordinates are equal. The area of misclassification is the sum of the integrals of the two density functions evaluated from the cut-off point to positive infinity for the distribution having lesser mean and from negative in infinity to cut-off point for the distribution having the greater value as shown in Figure 6.1.

This area can be minimised by setting the first derivative of the function so is defined equal to zero, and solving for the cut-off point. The derivative of the definite integral above is the difference between the two density functions at the cut-off point, the computations are as follows:

$u_{1}=$ mean of the first group

$\mu_{2}=$ mean of the second group

$\sigma_{1}=$ standard deviation of the first group

$\sigma_{2}=$ standard deviation of the second group

$\mathrm{z}_{\mathrm{C}}=$ cut-off point " $\mathrm{Z}$ " value.

as shown in Figure 6.1. 


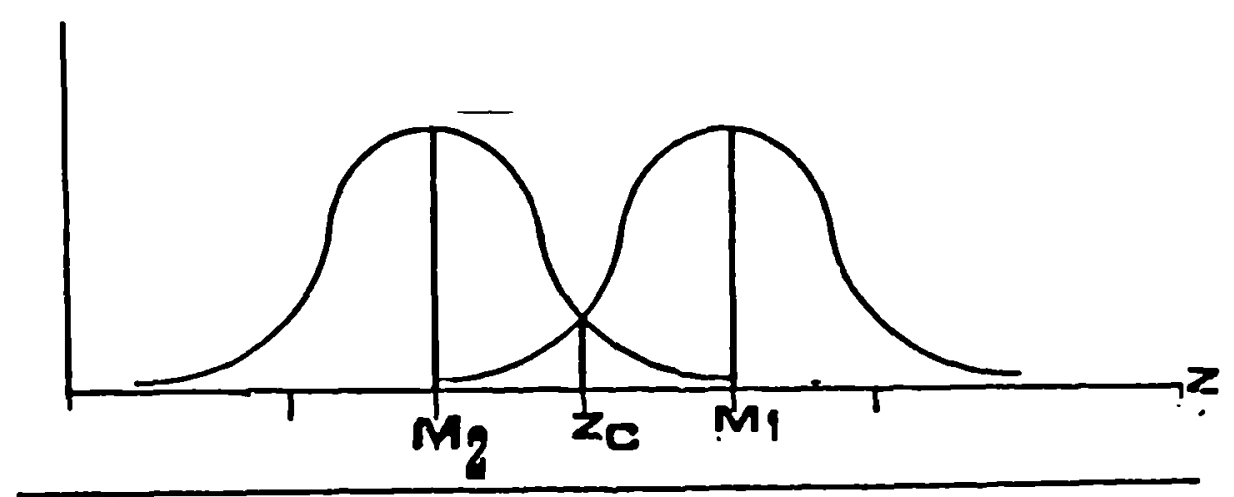

FIQURE 6.1

1. $\frac{1}{\sqrt{2 \pi \cdot \sigma_{1}}} e^{-1 / 2\left(\frac{z_{c}-u_{1}}{\sigma 1}\right)^{2}}-\frac{1}{\sqrt{ } 2 \pi \cdot \sigma_{2}} \cdot e^{-1 / 2\left(\frac{z_{c}-u_{2}}{\sigma_{2}}\right)^{2}}=0$

2. $\sigma_{2} \cdot e^{1 / 2} 2^{\left(\frac{z_{c}-\mu_{2}}{\sigma_{2}}\right)^{2}}=\sigma_{1} \cdot e^{1 / 22^{\left(\frac{z_{c}-\mu_{1}}{\sigma_{1}}\right)^{2}}}$

3. By logarithiming both sides:

$\log \sigma_{2}+\frac{1}{2}\left(\frac{z_{c}-u_{2}}{\sigma_{2}}\right)^{2}=\log \sigma_{1}+\frac{1}{2}\left(\frac{z_{c}-u_{1}}{\sigma_{1}}\right)^{2}$

4. $\log \sigma_{1}-\log \sigma_{2}=\frac{z_{c}{ }^{2}-2 z_{c} u_{2}+u_{2}{ }^{2}}{4 \sigma_{2}^{2}}-\frac{z_{c}^{2}-2 z_{c} u_{1}+u_{1}{ }^{2}}{4 \sigma_{1}{ }^{2}}$

5. $\left(\frac{1}{4 \sigma_{2}^{2}}-\frac{1}{4 \sigma_{1}^{2}}\right) z_{c}^{2}+\left(\frac{u_{1}}{2 \sigma_{1}^{2}}-\frac{u_{2}}{2 \sigma_{2}^{2}}\right) z_{c}+$

$$
+\left(\frac{u_{2}^{2}}{4 \sigma_{2}^{2}}-\frac{u_{1}^{2}}{4 \sigma_{1}^{2}}-\log \sigma_{1}+\log \sigma_{2}\right)=0
$$

This equation can be solved by use of the quadratic formula. 
where:

$$
\begin{aligned}
& \mathrm{a}=\left(\frac{1}{4 \sigma_{2}^{2}}-\frac{1}{4 \sigma_{1}^{2}}\right) \\
& \mathrm{b}=\left(\frac{u_{1}}{2 \sigma_{1}^{2}}-\frac{u_{2}}{2 \sigma_{2}{ }^{2}}\right) \\
& \mathrm{c}=\left(\frac{u_{2}^{2}}{4 \sigma_{2}^{2}}-\frac{u_{1}^{2}}{4 \sigma_{1}^{2}}-\log \sigma_{1}+\log \sigma_{2}\right)
\end{aligned}
$$

To determine $\mathbf{z}_{\mathbf{C}}$ :

$$
z_{c}=\frac{-b \pm \sqrt{b^{2}-4 a c}}{2 a}
$$

A graphical representation of the distribution of " $\mathrm{Z}$ " values actually computed for the individuals in the sample problem is made in Graph 6.2 .

The range of " $\mathrm{Z}$ " values is divided into segments of 3 units, and the frequency indicated on the graph is the number of " $\mathrm{Z}$ " values failing within a particular segment.

The histograms closely resemble the superimposed normal curves as shown in Figure 6.2 which represent the distribution of " $\mathrm{Z}$ " values based on the assumption that the population are nommal, and that the samples means and standard deviation are the population means and standard deviations (see Appendix E). 
There is only a very slight overlap in the " $Z$ " value over two graphs and the $F$ ratio indicates a significant difference between the two groups. Statistical test is shown in Appendix E.

The determine the cut-off point mathematically, by applying the formula:

$$
\begin{aligned}
& \left(\frac{1}{4 \sigma_{2}^{2}}-\frac{1}{4 \sigma_{1}^{2}}\right) z_{c}^{2}+\left(\frac{u_{1}}{2 \sigma_{1}^{2}}-\frac{u_{2}}{2 \sigma_{2}^{2}}\right) z_{c}+ \\
& +\left(\frac{u_{2}^{2}}{4 \sigma_{2}^{2}}-\frac{u_{1}^{2}}{4 \sigma_{1}^{2}}-\log \sigma_{1}+\log \sigma_{2}\right)=0
\end{aligned}
$$

where

$$
\begin{aligned}
& a=\left(\frac{1}{4 \sigma_{2}^{2}}-\frac{1}{4 \sigma_{1}^{2}}\right) \\
& b=\left(\frac{u_{1}}{2 \sigma_{1}^{2}}-\frac{u_{2}}{2 \sigma_{2}^{2}}\right) \\
& c=\left(\frac{u_{2}^{2}}{4 \sigma_{2}^{2}}-\frac{u_{1}^{2}}{4 \sigma_{1}^{2}}-\log \sigma_{1}+\log \sigma_{2}\right) \\
& z_{c}=\frac{-b \pm \sqrt{b^{2}-4 a c}}{2 a} \\
& u_{1}=9.60 \\
& \sigma_{1}=6.324 \\
& u_{2}=-14.3
\end{aligned}
$$




$$
\begin{aligned}
a & =0.00042 \\
b & =0.11977+.1908=0.310 \\
c & =\frac{204.5}{150}-\frac{91.5}{159.7}-0.8+0.7869=0.777 \\
& =1.3633-0.5729-.80+0.7869=0.777
\end{aligned}
$$

Therefore $\mathrm{z}_{\mathrm{c}}=-3.48$.

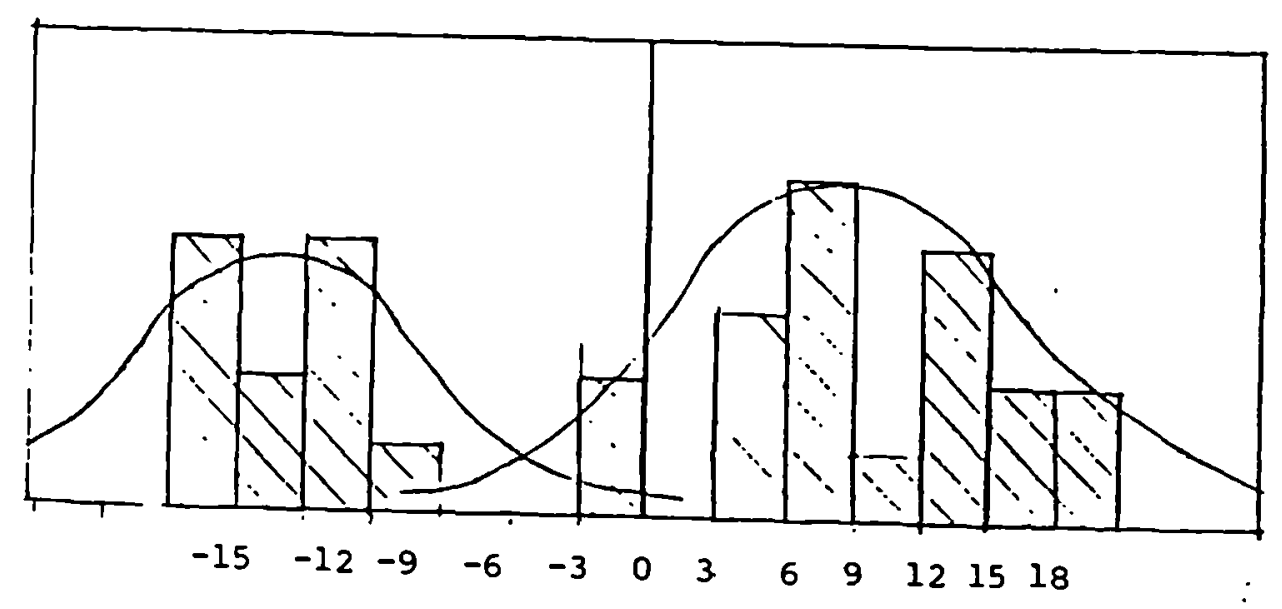

FIGURE 6.2: THE CUT-OFF BETWEEN "NON-FAILED 20" AND "FAILED 11" GROUPS 


\subsubsection{Prior Probability and Misclassification Costs Estimation Method} Previous studies discussed these issues. Tollefson [24] and Morrison [23], Pincher (1980), Taffler $(1982,1984)$ all concluded that ignoring such 1ssues leading to serious errors in interpreting the results from application of a derived discriminant function.

The classification procedure used in this study takes into acoount differential prior probability estimates and misclassification costs in determining an appropriate cut off.

The assigment functions used are those used in many previous studies and are of the form:

$$
P(g)=\frac{e^{z}}{e^{z}+L} \quad \text { and } \quad P(f)=\frac{e^{-z}}{e^{-z}+\frac{1}{L}}
$$

where: $P(g)=$ probability with which the company under investigation should be classed as resembling the "non-failed 20" group

$$
\begin{aligned}
P(f)= & \text { probability with which the company under investigation } \\
& \text { should be considered to resemble the "failed } 1 \text { '1" group } \\
L & =\text { the 'likelihood' or 'probability-oost' ratio } \\
& =\text { odds ratio } \times \text { costs ratio } \\
& =\frac{P 2}{P 1} \times \frac{C_{21}}{C_{12}}
\end{aligned}
$$


where P1 and P2 are the prior probability estimates (failed:solvent).

$\mathrm{C}_{12}$ and $\mathrm{C}_{21}$ are the estimated costs of misclassification of a "solvent" firm" as "insolvent" and vice versa respectively (type I:type II errors).

In the two groups linear discriminant model that if $f_{1}(x)$ and $f_{2}(x)$ are the multivariate normal distributed probability density functions for the "solvent" and "insolvent" populations and the conventional equality of dispersion matrices assumption holds then

$$
\frac{f_{1}(x)}{f_{2}(x)}=e^{z}
$$

By applying Bayesian fonmla, if $\mathrm{H}_{1}$ represents the statement that a firm belongs to the "solvent" population and $\mathrm{H}_{2}$ that it belangs to the "insolvent" population then the posterior probability $\mathrm{p}\left(\mathrm{H}_{1} / \mathrm{X}\right)$ taking into acoount differential prior probabilities and misclassification costs is given by

$$
\begin{aligned}
p\left(H_{1} / X\right) & =\frac{P_{1} C_{12} p\left(X / H_{1}\right)}{P_{1} C \cdot 12^{p}\left(X / H_{1}\right)+P_{2} C_{21} P\left(X / H_{2}\right)} \\
& =\frac{P_{1} C_{12} f_{1}(X)}{P_{1} C_{12} f_{1}(X)+P_{2} C_{21} f_{2}(X)}
\end{aligned}
$$

Therefore $p(g)=\frac{e^{z}}{e^{z}+L}$ 
and

$$
\mathrm{p}\left(\mathrm{H}_{2} / \mathrm{X}\right)=1-\mathrm{p}\left(\mathrm{H}_{1} / \mathrm{X}\right)
$$

Therefore $p(f)=\frac{e^{-z}}{e^{-z}+\frac{1}{L}}$

In practice the prior odds ratio can be gained from statistical evidence, but the misclassification costs ratio is more difficult to estimate and is generally reached through subjective estimation. The costs ratio used in previous work has varied but has generally been of the same magnitude. Laurence, Prust and Company and Taffler [12] in their studies used a cost ratio of $40 / 1$ and Altman [9] in ane of his studies suggested a ratio of $35 / 1$.

The prior odds ratio has been approximated using the information in Table 6.5.

\begin{tabular}{lccc}
\hline Year & $\begin{array}{c}\text { Approx No of } \\
\text { Insolvencies (A) }\end{array}$ & $\begin{array}{c}\text { Approx No of Finms } \\
\text { in the Industry (B) }\end{array}$ & A/B \\
\hline 1982 & 1422 & 63169 & $1 / 44$ \\
1986 & 1914 & 75810 & $1 / 39$ \\
\hline
\end{tabular}

TABLE 6.5: SHOWS THE INSOLVENCIES IN THE CONSTRUCTION INDUSTRY

The average ratio for two years is approximately $1 / 41.5$. If we considered a "costs ratio" of 40:1 as used in previous studies, we arrive at a "probability-cost" ratio $L$ of unity, the same as concluded by Mason [17]. In this study the cut-off point is specified as the point where there is equal probability of belonging to the "failed" and "non-failed" groups or equal numbers of potential failures and solvent companies in the population. That is to say: 


$$
P(g)=P(f)=508
$$

and from

$$
P(g)=\frac{e}{e^{z}+L}
$$

where $\mathrm{L}=1.0$.

We arrive at a cut-off point of $\mathrm{z}=0$. This is a mathematical proof for Z-model based on prior probability and misclassification costs. By comparing this result with the mathematical approach it seems too cautious in determining the cut-off value from -3.48 to zero.

Therefore, any company having a positive $\mathrm{z}$-soore an the model will have a higher probability of membership of the "non-failed" group than the "failed" group and will be classified as "non-failed". Similarly, a negative $\mathrm{Z}$-score will classify a company as "failed".

\subsubsection{Grey-Area}

Previous studies specified "grey-areas" for example Altman [8] and Mason [17]. This 'area' is one within which an accurate classification of a company is not possible, 1.e. the overlap region where misclassification can occur. This is to say that the difference between the probabilities of group membership $D=P(g)-P(f)$ is small.

Some advocates of this system appear to be too cautious in setting their "grey-area" limits. Their limits were set at $P(g)=958$ and $P(f)$ $=95 \%$. However these limits mean that companies confidently classified in a particular group have to have odds of 19 to 1 or more of belonging to that group.

These odds seem very restrictive and odds of 10 to 1 or 5 to 1 might be more appropriate. Laurence, Prust and $C O$ [22] in one of their studies used an "odd ratio" 1:10 and commented "this will of course 
vary over time with economic situation". Therefore, it needs subjective estimation based on the econamic envirament. Furthermore the "grey-area" limits should be set by users of the model.

This study set two probabilities at 958. The limits are calculated using the same function used in calculating the cut-off value:

$$
P(g)=\frac{e^{z}}{z^{z}+1} \quad \text { and } \quad P(g)=\frac{e^{-z}}{e^{-z}+1}
$$

By putting $P(g)=95 \%$ and $P(f)=95 \%$ the "grey-area" limits are \pm 2.94 .

\subsection{SUMMARY AND CONCLUSIONS}

The results from applying the linear discriminant analysis technique produced a linear discriminant model made up of seven varlables, measuring five distinct aspects of a company's financlal structure, namely profitability, liquidity, activity, financial leverage and three trend measurements, as shown in Table 6.1.

The computed F-statistic for the overall model was 40.5 and tabular ratio was 5.42 where degree of freedoms were 2 and 29 at the 18 significance level. Therefore it has been concluded that the ability of the discriminant model to differentiate between groups is good (see Appendix E).

Two issues should thus considered. Firstly, the influence of each variable in a model. Previous studies suggested a number of methods which were attempted to determine the relative importance of Individual variables. Five such methods were considered by Eisenbeis, 
Gilbert, and Avery [32]. A sixth method had been suggested by Mosteller and Wallace [35] and Joy and Tollefson [24]. Therefore the selection of methods which were used in this research study were based on their credibility among the model builders. Three methods were employed in this research programme as shown in Table 6.4. It was concluded that the F-deletion method was suitable for discriminant analysis.

As can be seen from the results (see Table 6.4) both profits after tax trend and short term loan trend are the least discriminant of the variables, while tax-trend is relatively more important than the other trends. Whereas the profit after tax as a ratio to net capital employed and current assets as a ratio to net assets are consistently good discriminators. Short term loans as a ratio to pre-tax profit is less important compared to other fundamental aspects of company financial structure such as profitability and financial leverage ratios.

The second issue to be considered is the cut-off and grey-area of the model. Two approaches were undertaken in determining the cut-off between two groups, as demonstrated in section 6.6.

Clearly it was concluded that the mathematical approach Indicated validation of the technique. The cut-off value of the distribution of Z-values for both the "non-failed 20" and "failed 11" groups as shown in Figure 6.2 are approximately equal to the calculated value of the cut-off point derived from this equation $\mathrm{z}_{\mathrm{C}}=-3.48$. The $\mathrm{z}$-value is that a company cannot be classified to belong to a failed or solvent group. This is the critical approach to the classification of a company, in order to use the model for operational classification purposes. 
It is necessary to specify "grey-areas". The "area" within which an accurate classification of a company is not possible, the overlap region in the original sample where misclassifications can occur. As shown in Figure 6.2 there is anly a very slight overlap in the "Z" value over two distributions, in this region two types of error can occur. Type I errors, defined as misclassification of falled company as non-failed and type II errors, defined as misclassification of nonfalled companies as failed.

By considering prior probability and misclassification costs estimates arriving to cut-off zero-value, this was reached through subjective estimation and grey-area limits of \pm 2.94 . Thus any corpany having a Z-score within these limits cannot be canfidently classified and can only be considered "vulnerable"

The Lachenbruch U-test errors indicated no type I errors and two type II errors for both models within these limits. This is a clear indication of the success in the selection of the limits. The type II errors were not considered to be misclassifications. As the sample of "non-failed" firms was not restricted to healthy firms, one would expect to find a few weak fims in the "non-failed" sample and it is these firms that have been assigned low $\mathrm{z}$-scores.

Finally, the existence of such a "grey-area" does not detract from the usefulness of the IDA method, it simply obliges the analyst to make further and more detailed analysis of the firm in this range of $z-$ scores. 


\section{CHAPTER 7}

RESULTS OBTARNED FORM THE MODETS

\subsection{Introduction}

7.2 Results Obtained from the "Non-Failed 20" and "Failed 11" Groups

7.3 Results Obtained from the "Taken-Over 9" Group

7.4 Results Obtained from the "Non-Failed 20" and "Failed 11" Groups by Using an Alternative Regression Model

7.5 Results Obtained fram the "Non-Failed 20" and "Failed 11 " Group by Using an Updated Mason Model

7.6 Trend Analysis

7.7 Financial Ratios as a Means of Predicting Failure

7.8 Sumary and Conclusions 
GAPPTER 7

RESULTS FROM THE MODETS

\subsection{INTRODUCTION}

The model was verified using the data described in section 7.2, and includes the results obtained from the "Non-failed 20" and "Failed 11" groups.

The model also deals with prior year Z-score analysis for both "Nonfailed 20" and "Failed 11" groups, and briefly illustrates the characteristics of both groups.

Section 7.3 includes the results obtained fram the failed and nonfailed group by using the alternative regression model.

Section 7.4 includes the results obtained from the failed and nonfailed groups by updating Mason's model.

Section 7.5 illustrates the trend analysis for all groups.

Section 7.6 explains the use of financial ratios as a means of predicting failure.

The final section briefly discusses the results and summarises results in graphical and tabular form.

A comprehensive listing of results for all the companies used in the study appears in Appendix D. 


\subsection{RESUltS OBTAINED FROM THE "NON-FAILED 20" AND "FAILED 11" GROUPS}

\subsubsection{Introduction}

The model was first examined with the data used to form the model in order to check the performance of each company added to the model itself. This procedure was carried out for two reasons: firstly, to identify the companies in danger of failure. Secondly, because of the difficulty in obtaining financial information suitable to explore such a model.

The following summarises the results.

\subsubsection{The Results of "Non-Failed 20" and "Failed 11" Groups} The results obtained from the "non-failed 20" and "failed 11" groups used to form the model are shown in Tables 7.1 and 7.2 and further portrayed in histogram form in Figure 7.1 .

Ignoring the 'grey area' developed in Section 6.6 and using the cutoff as a classification boundary, we can see that 18 out of 20 in solvent area and all companies in the failed-11 group were correctly classified respectively.

However taking into acoount the 'grey area' limit ( \pm 2.94 ) we reach the situation, shown in Table 7.3 where $90 \%$ were correctly classified with confidence in the "non-failed group" and $10 \%$ classified as 'vulnerable' 1008 of "failed 11" group were correctly classified. Na misclassification existed in both groups. 


\begin{tabular}{|c|c|c|c|c|c|}
\hline & 1983 & 1984 & 1985 & 1986 & Mean \\
\hline Aberdeen Canst Itd & 15.5 & 12.8 & 14.8 & 10.0 & 13.27 \\
\hline Barratt Develogment & 1.19 & 4.28 & -14.3 & 13.19 & 3.59 \\
\hline Benlox Holdings plc & 18.14 & 4.15 & 26.0 & 11.4 & 14.9 \\
\hline Benbailly Const plc & 22.0 & 12.3 & 21.0 & 2.84 & 14.53 \\
\hline C H Beazer Holds & 6.8 & 11.0 & 5.9 & 1.96 & 6.4 \\
\hline BI@C plc & 7.7 & 4.8 & 7.4 & 8.8 & 7.1 \\
\hline Brown and Jackson & 4.3 & 4.5 & 2.5 & 2.8 & 3.52 \\
\hline Bryant Holdings & 10.3 & 7.5 & 5.7 & 4.8 & 7.07 \\
\hline Boultan \& Paul plc & 15.9 & 23.4 & 15.3 & 18.3 & 18.22 \\
\hline M J Geeson Group & 18.24 & 32.0 & 18.0 & 13.5 & 20.4 \\
\hline George Wimpey plc & 7.1 & 5.0 & 4.8 & 8.4 & 6.32 \\
\hline Henry Boot and Sans & 4.5 & 4.6 & -11.2 & -5.3 & -1.85 \\
\hline A Monk Co Ltd & 14.6 & 17.8 & 20.0 & 6.58 & 14.74 \\
\hline Newarthill plc & 12.0 & 8.6 & 7.4 & 5.0 & 8.25 \\
\hline Rush \& Tompkins & 1.38 & .28 & 1.8 & -3.7 & -0.06 \\
\hline Taylor woodrow & 6.3 & 8.3 & 15.8 & 12.8 & 10.8 \\
\hline Tarmac plc & 20.4 & 11.2 & 19.8 & 19.7 & 17.7 \\
\hline Tilbury Group plc & 10.5 & -2.0 & 3.0 & 9.2 & 5.17 \\
\hline Turriff Corp plc & 6.0 & -2.3 & 6.9 & 16.7 & 6.8 \\
\hline Wilson connolly & 23.6 & 12.4 & 11.5 & 14.9 & 15.6 \\
\hline Averages: & 11.34 & 9.0 & 9.10 & 8.59 & 9.6 \\
\hline
\end{tabular}

TABLE 7.1: RESULTS OBTAINED FROM THE "NON-FAIIED 20" GROUP 


\begin{tabular}{|c|c|c|c|c|}
\hline \multirow[b]{2}{*}{ Failed Companies } & \multicolumn{3}{|c|}{ Years Prior to Failure } & \multirow{2}{*}{ Mean } \\
\hline & -3 & -2 & Last year & \\
\hline Beech wood Group plc & -1.07 & -1.5 & -9.8 & -4.1 \\
\hline Cockseage plc & -35 & +2.3 & -35.5 & -22.6 \\
\hline David Charles Ltd & -18.7 & -9.7 & -25 & -18.8 \\
\hline Crouch Group plc & -6.4 & -9.5 & -14.5 & -10.13 \\
\hline James H Dennis plc & -6 & -1 & -19.4 & -8.8 \\
\hline Mears Bros Ltd & -7.7 & -6.8 & -34 & -16 \\
\hline Milbury plc & -17.7 & -26 & -11.4 & -18.3 \\
\hline Modern Engineering Bristol & -11 & -20 & -33 & -21.3 \\
\hline Moss Engineering Group & -11 & -13 & -30 & -18 \\
\hline Southern Construction & +1 & -12 & -12.8 & -7.66 \\
\hline S W Farmer & +7.3 & -27 & -14.6 & -11.5 \\
\hline Averages: & -9.66 & -11.5 & -21.6 & -14.3 \\
\hline
\end{tabular}

TABLE 7.2: RESULTS OBTAINED FROM THE "FAIIED 11" GROUP 


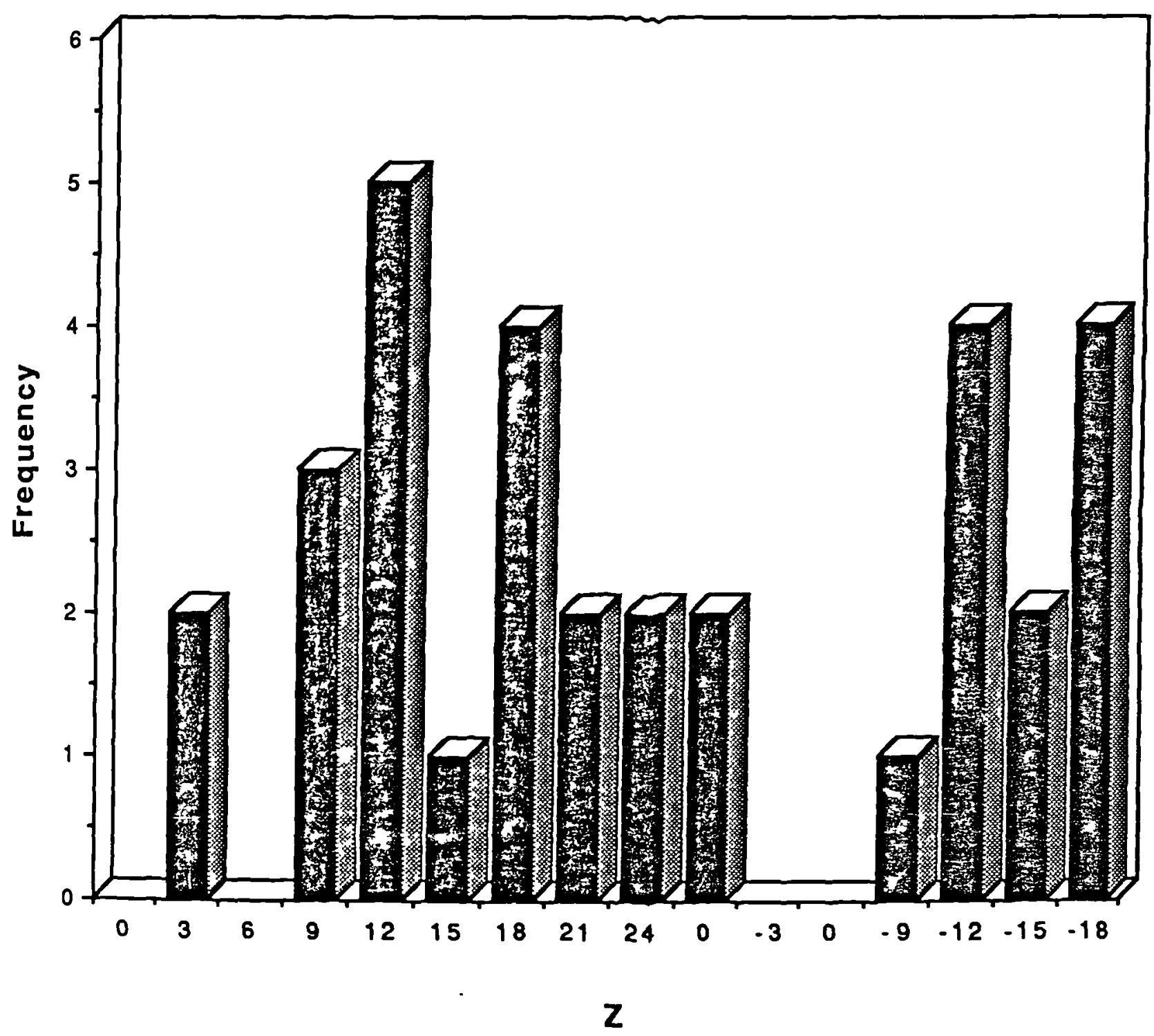

FIGURE 7.1: HISTOGRAM OF THE "NON-FAIIED 20" AND "FAILED 11" GROUPS 
The results indicate that the model is discriminating between failed and non-failed well in spite of the high risk of the construction business.

\begin{tabular}{|l|c|c|c|}
\hline \multirow{2}{*}{ Groups } & \multicolumn{3}{|c|}{ Classified as } \\
\cline { 2 - 4 } & Falled & Vulnerable & "Non-failed" \\
\hline "Failed 11" Group & $11(100)$ & - & - \\
"Non-failed 20" Group & - & $2(10)$ & $18(90)$ \\
\hline
\end{tabular}

TABLE 7.3: CLASSIFICATION OF THE "NON-FAILED 20" AND "FAILED 11" GROUPS

(Figures in brackets are percentages of total groups)

\subsubsection{Prior Year Z-Score Analysis}

Perhaps the most significant way in which to view the prior year's analysis is to plot the average-scores for the different groups for prior years. This plot can be seen in Figure 7.2.

We can see that although the "non-failed 20" group's mean Z-score varies from year to year, it is constantly above the 'grey area'. The "failed 11" group, on the other hand, is generally below the 'grey area' This is a clear indication of the discriminating power of the model.

The trend in the mean $\mathrm{z}$-scores reflects economic changes in the construction industry from year to year with a downward trend during the period 1982-1986. 


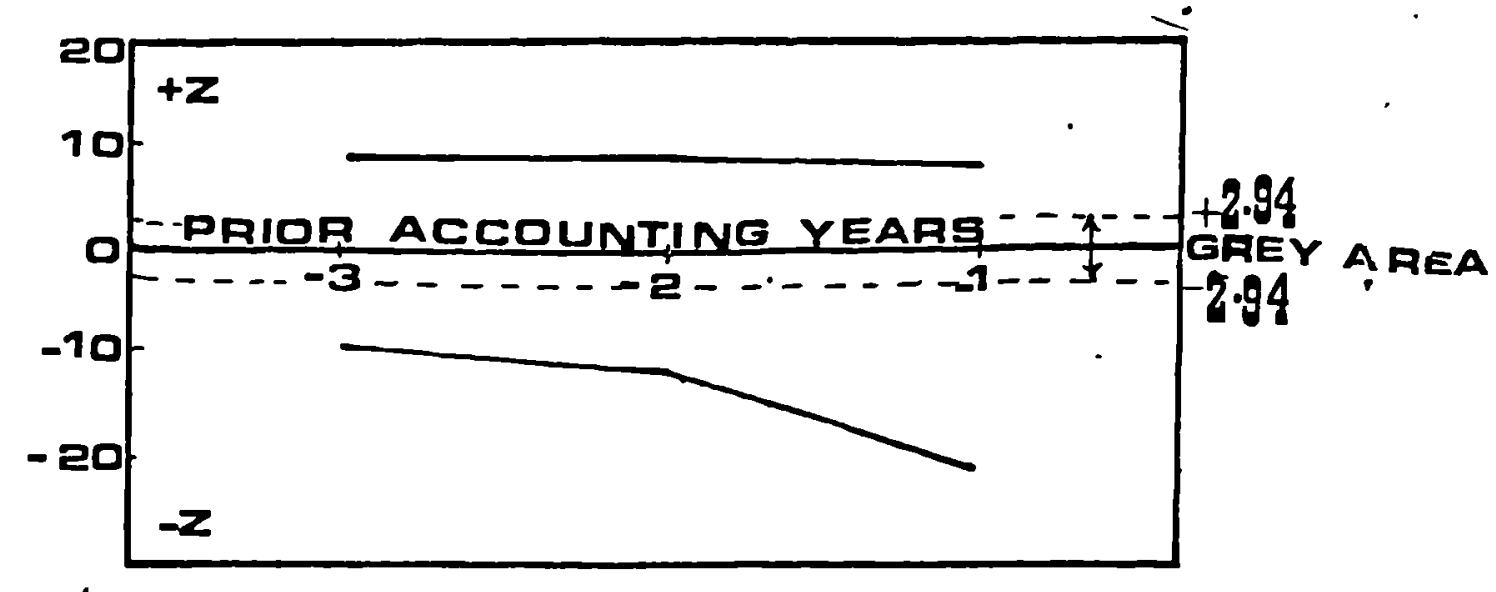

FIGURE 7.2: THE "NON-FAILED 20". AND "FAILED 11" COMPANIES PRIOR YEAR Z-SCORE MEANS OBTAINED FROM THE DISCRIMINANT MODEL [₹]

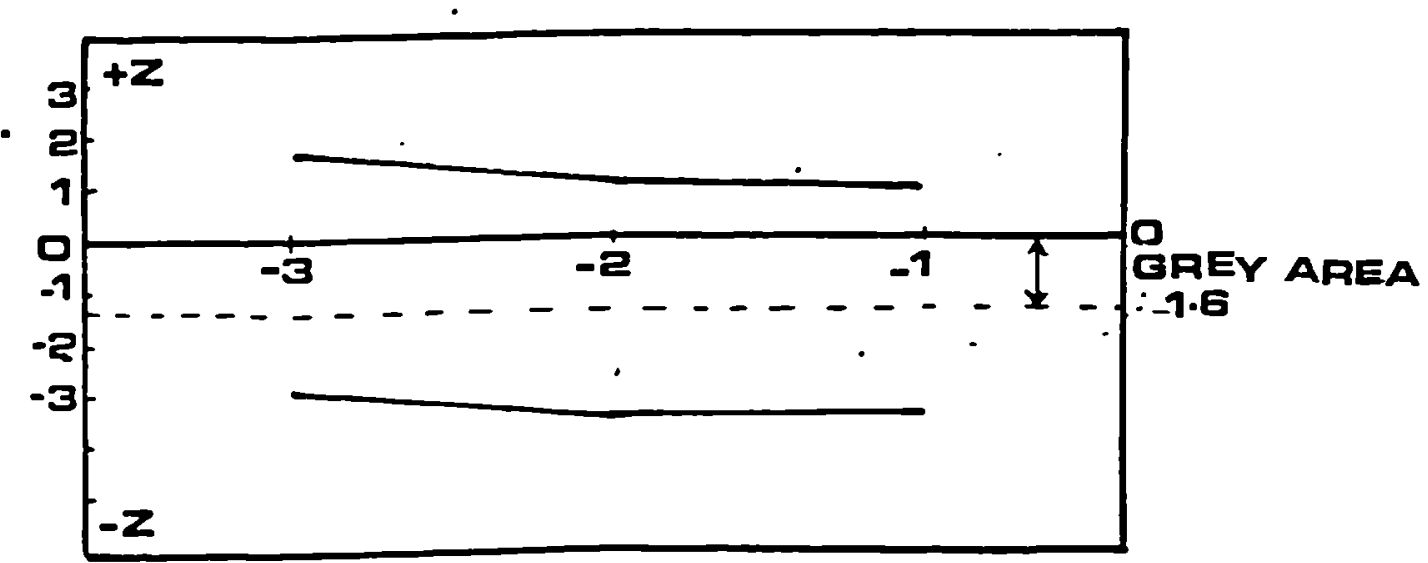

FIGURE 7.3: THE "NON-FAILED 20" AND "FAILED 11" COMPANIES PRIOR YEAR Z-SCORE MEANS OBTAINED FROM THE MULTIPLE REGRESSION MODEL [2]

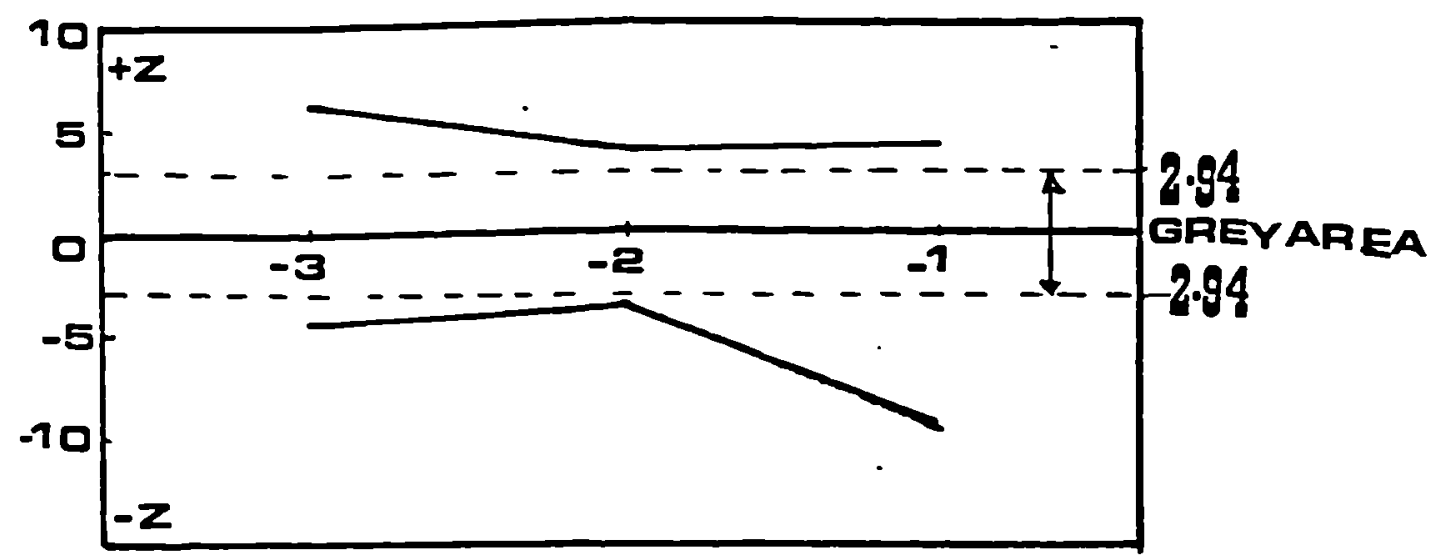

FIGURE 7.4: THE "NON-FAILED 20" AND "FAILED 11" COMPANIES PRIOR YEAR Z-SCORE OBTAINED FROM THE UPDATED MASON MODEL [3] 
Table 7.4 shows the model classifies 758 of the "non-failed" group as "solvent" at year 4. Furthermore, taking 'grey area' limits (+2.94) improves the model classification by $15 \%$ and gives some indication of discriminating power of the model, although the "non-failed 20" group mean $\mathrm{Z}$-score varies from year to year.

Table 7.4 shows prior years classification of the "non-falled 20" group (figures in brackets are percentages of total groups).

\begin{tabular}{|l|c|c|c|c|}
\hline Years & 1983 & 1984 & 1985 & 1986 \\
\hline $\begin{array}{l}\text { Solvent } \\
\text { Failnerable }\end{array}$ & $\begin{array}{r}19(95) \\
1 \\
(5)\end{array}$ & $\begin{array}{r}17(85) \\
3(15)\end{array}$ & $\begin{array}{r}16(80) \\
2(10) \\
2(10)\end{array}$ & $\begin{array}{r}15(75) \\
3(15) \\
2(10)\end{array}$ \\
\hline Total: & 20 & 20 & 20 & 20 \\
\hline Average Z-score: & 11.34 & 9.0 & 9.1 & 8.59 \\
\hline
\end{tabular}

TABLE 7.4

Table 7.5 shows prior years classification of the "failed 11" group.

\begin{tabular}{|l|c|c|c|}
\hline \multirow{2}{*}{ Classification } & \multicolumn{3}{|c|}{ Accounting year prior to company failure } \\
\cline { 2 - 4 } & -3 & -2 & Last year \\
\cline { 2 - 4 } & $\begin{array}{l}1(9) \\
2(18) \\
8(73)\end{array}$ & $\begin{array}{l}3(27) \\
8(73)\end{array}$ & $\begin{array}{c}- \\
\text { Solvent } \\
\text { Failed }\end{array}$ \\
\hline Total: & 11 & 11 & 11 \\
\hline Average Z-score & -9.66 & -11.5 & -21.6 \\
\hline
\end{tabular}

TABLE 7.5 
The Z-score fell below the cut-off level in the last year for two out of 20 companies. These companies were as follows:

1. Henry Boot and Sans.

2. Rush and Tankins Group plc.

We can thus conclude that a single $z$-score for a particular period may be insufficient to predict failure and a company's continuing dependence on its capability.

Table 7.5 shows how well the model behaved with data in the year prior to fallure. It would be useful to consider how far in advance of failure a firm starts to resemble previous bankrupts.

The results appear good with the model classifying $73 \%$ of the group as failed up to three years prior to failure.

The Z-score trends curring the period 1982-1986 for the "non-falled 20" firms and the last three years before failure of the "failed 11" firms appear in Appendix D. 


\subsection{RESULTS FROM THE "TAKEN-OVER 9" GROUP}

The results obtained from the "taken-over 9" group are shown in Table 7.6 and prior years classification of the "taken over 9" group as shown in Table 7.7 below.

\begin{tabular}{|l|c|c|c|c|}
\hline TAKEN-OVER OOMPANIES & -4 & -3 & -2 & Last Year \\
& & & & \\
\hline & 16.6 & 13 & 11.67 & -14 \\
Braithwaite Group plc & 14.8 & 6.27 & 32 & 5.6 \\
C Pearce and Sons plc & 13.6 & 17.9 & 14.7 & 22 \\
Fairclough Construction & 2.2 & 2.0 & -2.7 & 2.4 \\
Glossop plc & 8 & -23 & -33 & -7 \\
Marchwiel plc & 13.2 & -7.2 & 10.7 & 7.5 \\
Mitchell Construction & 17 & 14.3 & 17.6 & 15 \\
Richard Construction & 17 & 12.9 & 17.6 & 16.9 \\
Roberts Adlard plc & 3.8 & 6.9 & 4.1 & 0.7 \\
Rowlinson Construction & & & & \\
\hline
\end{tabular}

TABLE 7.6: RESULTS OBTAINED FROM THE "TAKEN OVER 9" GROUP

\begin{tabular}{|l|c|c|c|c|}
\hline \multirow{2}{*}{ Classified as } & \multicolumn{4}{|c|}{ Acoounting year prior to conpany take-over } \\
\cline { 2 - 5 } & -3 & -2 & -1 & Last year \\
\hline $\begin{array}{l}\text { Solvent } \\
\text { Wulnerable } \\
\text { Failed }\end{array}$ & $\begin{array}{l}8(89) \\
1(11)\end{array}$ & $\begin{array}{c}7(78) \\
-\end{array}$ & $\begin{array}{l}7(78) \\
1(11) \\
1(11)\end{array}$ & $\begin{array}{l}5(56) \\
2(22) \\
2(22)\end{array}$ \\
\hline Total: & $-2(22)$ & 9 & 9 & 9 \\
\hline Average Z-score & 11.8 & 6.7 & 8 & 5.45 \\
\hline
\end{tabular}

TABLE 7.7: PRIOR YEARS CLASSIFICATION OF THE TAKE OVER 9" GROUP (Figures in brackets are percentages of total groups) 
The "taken-over" group have $\mathrm{z}$-scores ranging between "failed" and "non-failed", indicating that there were no financial features identifying the taken-over company. Also the results indicate that:

2 out of 9 companies were considered failed at last year 2 out of 9 companies were considered vulnerable.

The remaining five companies positively soored, but their $\mathrm{Z}$-score deteriorated from year to year. Similarly the z-score approach can be used to anlayse merger activity (e.g. Taffler, 1985 [16]). 


\subsection{RESULTS OBTAINED FROM THE "NON-FAILED 20" AND "FAILED 11" GROUPS BY USING AN ALTERENATIVE REGRESSION MODEL}

\subsubsection{Introduction}

The alternative model (see Section 5.5.2) was developed from the original $\mathrm{z}$ model (see section 6.2) using a regression technique and was tested with data used to form the model. The results are sumarised below.

\subsubsection{The Results of "Non-Failed 20" and "Failed 11" Groups}

The results obtained from the "non-failed 20" and "failed 11" groups are given in Tables 7.8 and 7.9. By using the cut-off point $z=0$ as the classification boundary it can be seen that all 11 failed companies were correctly classified, and 17 out of 20 non-failed companies were correctly classified.

The model thus seems to be discriminating between solvent and insolvent groups well. For the "failed 11" group the result appears good with the model classifying 1008 correctly. Table 7.10 shows the classification of the "non-failed 20" and "failed 11" groups using the multiple regression model. 


\begin{tabular}{|c|c|c|c|c|c|}
\hline & 1983 & 1984 & 1985 & 1986 & Mean \\
\hline Aberdeen Const Ltd & 2.96 & 2.39 & 2.3 & 1.44 & 2.272 \\
\hline Barratt Development & 1.8 & .77 & -.5 & 1.118 & 0.797 \\
\hline Benlox Holdings plc & 3.78 & 2.4 & 5.7 & .36 & 3.06 \\
\hline Benbailly Const plc & 11.7 & -.82 & -8.3 & -5.8 & -.800 \\
\hline C H Beazer Holds & 1.433 & 4.5 & .86 & .386 & 1.794 \\
\hline BIOC plc & .67 & .427 & -5.22 & +.685 & -.83 \\
\hline Brown and Jacksan & -.63 & 5.18 & 3.08 & 2.10 & 2.43 \\
\hline Bryan Holdings & 1.68 & 1.237 & 2.02 & .63 & 1.39 \\
\hline Boulton \& Paul plc & 2.98 & 2.53 & 2.24 & 2.84 & 2.64 \\
\hline M J Geeson Group & 4.011 & 1.668 & 1.362 & 3.42 & 2.6 \\
\hline George Wimpey plc & .391 & -.34 & .967 & .508 & 0.38 \\
\hline Henry Boot and Sons & 1.22 & 2.92 & 3.33 & -1.2 & 1.567 \\
\hline A Monk Co Ltd & 2.68 & 1.548 & -.41 & .242 & 1.013 \\
\hline Newarthill plc & 2.4 & 1.837 & 1.218 & .71 & 1.54 \\
\hline Rush \& Tompkins & -.296 & -.165 & -.18 & -1.81 & -.61 \\
\hline Taylor Woodrow & 1.922 & 1.27 & 2.3 & 4.02 & 2.38 \\
\hline Tanmac plc & 3.33 & 2.185 & 2.76 & 2.99 & 2.813 \\
\hline Tilbury Group plc & 2.53 & 2.61 & 1.255 & .8 & 1.79 \\
\hline Turriff Corp plc & .048 & -.728 & .0238 & 1.79 & 0.283 \\
\hline Wilson Connolly & 4.77 & 2.42 & 2.26 & 3.66 & 3.27 \\
\hline Averages: & 2.47 & 1.72 & 1.1 & 0.878 & 1.4969 \\
\hline
\end{tabular}

TABLE 7.8: THE RESULTS OBTAINED FROM THE "NON-FAILED 20" GROUP BY USING AN ALTERNATIVE MUTTIPLE REGRESSION MODET 


\begin{tabular}{|l|c|c|c|}
\hline \multicolumn{3}{|c|}{ Year Prior to Failure } \\
\hline Failed Companies & -2 & -1 & Last year \\
& & & \\
Beech Wood Group plc & & & -1.82 \\
Cocksedge plc & -2.85 & -1.27 & -3.17 \\
David Charles Ltd & -.94 & -9.13 & -5.18 \\
Crouch Group plc & -1.7 & -3.55 & -657 \\
James H Dennis plc & -2.15 & -.62 & -.76 \\
Mears Bros Ltd & -6.7 & -1.1 & -53 \\
Milbury plc & -4.11 & -5.3 \\
Modern Engineering Bristol & -6.7 & -4.73 & -2.16 \\
Moss Engineering Group & -4.36 & -3.68 & -5.7 \\
Southern Construction & -.75 & -.187 & -.87 \\
S W Farmer & +.83 & -9.34 & -6.4 \\
& -2.816 & -3.27 & -4.012 \\
\hline Averages: & & & \\
\hline
\end{tabular}

TABLE 7.9: RESULTS OBTAINED FROM THE "FAILED 11" GROUP BY USING AN ALTERNATIVE MUTIPLE REGRESSION MODEL

\begin{tabular}{|l|c|c|c|}
\hline \multirow{2}{*}{ Group } & \multicolumn{3}{|c|}{ Classified as } \\
\cline { 2 - 4 } & Failed & Vulnerable & Non-failed \\
\hline "Failed 11" Group & $9(82)$ & $\begin{array}{l}2(18) \\
9(45)\end{array}$ & 11 (55) \\
\hline "Non-fatled 20" Group & - & 9 & \\
\hline
\end{tabular}

TABLE 7.10: CLASSIFICATION OF THE "NON-FAILED 20" AND "FAILED 11" BY USING MULTIPLE REGRESSION MODEL

By taking the grey-area between -1.60 to zero, $82 \%$ are correctly classified as failed, 55 are correctly classified as non-failed and $45 \%$ classified as vulnerable. The results do not appear as good as the 908 result of the "non-failed 20" group used to form the discriminant model. 
For the "non-failed 20" group, three companies scored negatively in the last year and these were:

3 - Rush and Tomkins Group plc

1 - Benbailly Construction plc

2 - Henry Boot and Sons plc.

\subsubsection{The "Grey" Area of the Multiple Regression Model}

The previous section has set a cut-off point $z=0$ as the classification boundary, which divides the discriminant space into solvent and insolvent area.

This section attempts to develop the "grey-area" for the multiple regression model in order to use the model for operational classification purposes. This "area" is one within which an accurate classification of a company is not possible. An optimal line is chosen through trial and error on the demarcation line for failing, 1.e. any firm below it being classified as a failed company. The results are then compared with actual data to find the percentage of incorrect prediction.

The ratio with the smallest percentage of misclassification is considered the best predictor of failure. In our case, it was found to be the $(-1.6)$ threshold. Therefore, any company with a z-score less than -1.6 was classified as failed whilst those firms with $Z$-scores between zero and -1.6 were oonsidered as vulnerable, so any company having a Z-score within these limits cannot be confidently classified.

Finally, those firms, with a z-score greater than zero (i.e. positive scoring) may be assumed to lie in the solvent zone and can be confidently classified as "non-failed". 


\subsubsection{Prior Year z-Score Analysis}

Figure 7.3 shows that the mean $\mathrm{Z}$-score of the "non-failed" group varies from year to year but is constantly above the cut-off limit 1.e. the cut-off limit zero.

A comparison of the mean values of $Z$-scores for the "non-failed" group for both models during the period 1982-1986 reveals 11.34, 9, 9.10, 8.59 and $2.47,1.72,1.1, .876$ respectively which again varies from year to year but were constantly higher than the cut-off limit. Applying both models for the last three years before failure produced $-9.66,-11.5,-21.6$ and $-2.93,-3.4,-3.155$ respectively.

The trend of Z-scores in both models appears similar, see Figure 7.3. Indeed for 10 out of 11 companies of the "failed 11" group their Zscores in the three years prior to failure scored negatively. one company in particular, namely southern Construction Ltd, had a Zscore in the three years prior to fallure deteriorating from to.83 to -6.4. Thus it was classified as failed in its secand year prior to failure, although it was apparent from the rate of decrease of its $\mathrm{Z}-$ score that it was failing.

An exception was the Crouch Group plc, classified as failing in its last year prior to failure, in spite of increasing the rate of $\mathrm{z}$ score. However looking at reasons for failure reveals that in spite of the company's turnover increasing rapidly, severe losses had occurred since April 1983 due to poor trading on contracts obtained at tight margins during a period of recession (see case study in Appendix D). This is an occurrence which is impossible to forecast. Therefore it may be concluded that any company overtrading in its business may produce a misleading z-score. 
7.5 RESUlts OBTAINED FROM THE "NON-FaILED 20" AND "Failed 11" GROUPS BY UPDATING MASON'S MODEL

\subsubsection{Introduction}

The updating of Mason's model (see Section 5.5.3) was developed from data collected during this research work combined with Z-scores from Mason's original model for 1976 and also that data obtained for the regression technique. The developed model (see Section 6.2) was tested using the same data used to form the model itself. The following sumarlses the results.

\subsubsection{The Result}

The results obtained from the "non-failed 20" and "failed 11" groups are given in Tables 7.11 and 7.12.

Ignoring the 'grey area' and using the cut-off as a classification boundary it can be seen that 16 out of 20 in the solvent area, 2 out of 11 of the "failed 11" group were also in the solvent area and only 9 of this group were correctly classified.

Figure 7.4 shows that the mean Z-score of both non-failed and failed groups varies from year to year. However for the non-failed group is constantly above the classification boundary ( \pm 2.94 ), while for the failed group the mean Z-score at the second year before fatlure lies inside the classification boundary, but decreases dramatically at the year of failure. 


\begin{tabular}{|c|c|c|c|c|c|}
\hline & 1983 & 1984 & 1985 & 1986 & Mean \\
\hline Aberdeen Const Ltd & 3.85 & 2.47 & 1.72 & 2.04 & 2.52 \\
\hline Barratt Development & 10.0 & 2.7 & -6.0 & 5.17 & 2.96 \\
\hline Benlox Holdings plc & -7.1 & 1.65 & -6.7 & -6.6 & -4.68 \\
\hline Benbailly Const plc & 3.8 & 5.2 & -5.4 & -6.6 & -2.55 \\
\hline C н Beazer Holdings & .72 & 9.7 & 8.7 & 6.27 & 6.3 \\
\hline BICC plc & 2.07 & -0.9 & 2.62 & 3.47 & 2.017 \\
\hline Brown and Jackson & -.3 & -5.3 & 1.14 & -1.14 & -1.4 \\
\hline Bryant Holdings & 11.7 & 11.2 & 9.8 & 9.3 & 10.5 \\
\hline Boulton and Paul plc & 5.3 & 14.5 & 6.9 & 7.4 & 8.52 \\
\hline M J Geeson Group & 5.3 & 9.4 & 9.4 & 11.2 & 8.8 \\
\hline George Wimpey plc & -.3 & -.33 & -.2 & 4.14 & .827 \\
\hline Henry Boot and Sons & 1.73 & .9 & 11.5 & -4.2 & 2.48 \\
\hline A Monk Co Ltd & 5.9 & 14.0 & 4.4 & -.06 & 6.0 \\
\hline Newarthill plc & 6.85 & 8.4 & 2.62 & 3.38 & 5.3 \\
\hline Rush and Tompleins Group plc & 7.4 & .86 & .44 & -2.8 & 1.47 \\
\hline Taylor Woodrow & 8.5 & 8.4 & 10.7 & 10.26 & 9.47 \\
\hline Tarmac plc & 4.57 & 12.6 & 7.0 & 8.15 & 8.08 \\
\hline Tilbury Group plc & 5.12 & 8.4 & 1.98 & 1.37 & 4.2 \\
\hline Turriff Corp plc & 7.0 & -8.3 & -9.9 & .74 & -2.6 \\
\hline Wilsan Cannolly Holdings & 13.9 & 15.0 & 17.2 & 20.4 & 16.6 \\
\hline Averages: & 4.8 & 5.56 & 3.4 & 3.6 & \\
\hline
\end{tabular}

TABLE 7.11: RESULTS OBTAINED FROM THE "NON-FAILED 20" GROUP BY USING AN UPDATED MASON MODEL 


\begin{tabular}{|l|c|c|c|c|}
\hline \multirow{2}{*}{} & \multicolumn{3}{|c|}{ Year Prior to Failure } \\
\cline { 2 - 5 } Failed Companies & -3 & -2 & $\begin{array}{c}\text { Last } \\
\text { Year }\end{array}$ & Mean \\
& & & & \\
\hline & & & -4.1 & -6.63 \\
Beech Wood Group plc & -7.2 & -5.6 & -9.0 & +2.73 \\
Cocksedge plc & 2.9 & 14.3 & -3.45 & -3.38 \\
David Charles plc & -0.57 & -0.57 & -9.4 & -5.93 \\
Crouch Group plc & -1.2 & -7.2 & -4.26 & -6.9 \\
James H Dennis plc & -11.6 & -2.0 & -4.6 & -1.93 \\
Mears Bros Ltd & -5.5 & 4.3 & -0.55 & -3.68 \\
Milbury plc & -3.4 & -4.1 & -2.94 \\
Modem Engineering Bristol & -9.7 & -.0 .4 & +1.27 & -4.93 \\
Moss Engineering Group plc & -.19 & -4.2 & -10.9 & -4.9 \\
Southern Construction Ltd & 2.6 & -22.0 & -32.0 & -17.1 \\
S W Farmer plc & -6.1 & 1.8 & -6.5 & +0.73 \\
& & & & \\
\hline Means: & -3.63 & -2.33 & -7.6 & \\
\hline
\end{tabular}

TABLE 7.12: RESULTS OBTAINED FROM THE "FAILED 11" GROUP BY USING AN UPDATED MASON MODEL [3]

Table 7.13 shows the model classifying 708 of the "non-failed" as solvent up to four years prior to failure, but decreases to $55 \%$ in the last year. Taking the grey-area limit of \pm 2.94 considered very high in this model 15\% are misclassified 1.e. 3 out of 20 companies are predicted as failed that do not fail.

\begin{tabular}{|l|c|c|c|c|}
\hline Years & 1983 & 1984 & 1985 & 1986 \\
\hline $\begin{array}{l}\text { Solvent } \\
\text { Vulnerable } \\
\text { Failed }\end{array}$ & $\begin{array}{r}14(70) \\
5(25) \\
1(5)\end{array}$ & $\begin{array}{r}11(55) \\
2(35)\end{array}$ & $\begin{array}{r}9(45) \\
7(35)\end{array}$ & $\begin{array}{r}11(55) \\
6(30) \\
3(15)\end{array}$ \\
\hline Total: & 20 & 20 & 20 & 20 \\
\hline Average Z-scores: & 4.8 & 5.56 & 3.4 & 3.6 \\
\hline
\end{tabular}

TABLE 7.13: SHOWS PRIOR YEARS CLASSIFICATION OF THE "NON-FAILED" GROUP BY USING AN UPDATED MASON MODEL [3] 


\begin{tabular}{|l|c|c|c|}
\hline & -2 & -1 & Last Year \\
\hline $\begin{array}{l}\text { Solvent } \\
\text { Vulnerable }\end{array}$ & $5(45)$ & $\begin{array}{l}1(9) \\
4(36) \\
5(45)\end{array}$ & $\begin{array}{l}- \\
2(18) \\
(82)\end{array}$ \\
\hline Total: & 11 & 11 & 11 \\
\hline Average Z-score & -3.63 & -2.33 & -7.6 \\
\hline
\end{tabular}

TABLE 7.14: SHOWS PRIOR YEARS CTASSIFICATION OF THE "FAILED 11" GROP BY USING AN UPDATED MASON MODEL [3] 


\subsection{TREND ANALYSIS}

\subsubsection{Introduction}

This section attempts to show the trend analysis for discriminating variables for the three $\mathrm{Z}$-models developed in this study. The attenpts were made for non-failed and failed groups and 11 graphs were plotted to show the trend for two groups over four years.

\subsubsection{Trend Analysis}

The discriminating variables included in three $\mathrm{Z}$-models are shown in Table 7.15 and a graphical representation of the trends of discriminating variables is made in Graphs 7.5 to 7.15 .

\begin{tabular}{rlccc}
\hline & Financial Ratios & Model 1 & Model 2 & Model 3 \\
\hline 1 & PAT/NCE & $\mathrm{X}$ & $\mathrm{X}$ & \\
2 & EBIT/NCE & & & $\mathrm{X}$ \\
3 & CA/NA & $\mathrm{X}$ & $\mathrm{X}$ & \\
4 & CL/NA & & & $\mathrm{X}$ \\
5 & TURN/NA & $\mathrm{X}$ & $\mathrm{X}$ & \\
6 & STL/EBIT & $\mathrm{X}$ & & \\
7 & INT/EBIT & & $\mathrm{X}$ & \\
8 & DR/CL & & & $\mathrm{X}$ \\
9 & TAX-TREND & $\mathrm{X}$ & $\mathrm{X}$ & \\
10 & PAT-TREND & $\mathrm{X}$ & & $\mathrm{X}$ \\
11 & STL-TREND & $\mathrm{x}$ & & \\
& & & & \\
\hline
\end{tabular}

TABLE 7.15: SHOWS DISCRIMINATING VARIABLES INCLUSION IN THE THREE MODELS 
The method of analysis required the arithmetic means of varlables to be used in the calculation, these being the average of one year's data for all the companies in a group. It is obvious that when the data of many companies are grouped together to produce an aggregate, the results are in many respects an improvement on the financial data. The following is thus a brief description of non-failed and failed groups trend analysis.

Figure 7.5 profit after tax to net capital employed trend ratio. The trend for "non-falled" companies varies slightly from year to year, and shows a drop in the first year followed by a slight rise in the next year, then another slight drop in the last year. While for the failed group a drastic drop from year to year occurs, thereby reflecting the losses in profit over the period for failed companies which varies between +78 to -198 , while for "mon-failed" companies the average ratio varies between 7.78 to 9.48 .

Figure 7.6 current assets to net assets trend ratio. The trend for "non-failed" companies varies slightly from year to year, and shows a drop in the first year followed by a slight rise for the last year of the study. While the graph of failed companies fluctuates widely reflecting instability of current assets in failed companies. Also the increase in current assets to net assets does not reflect the strength of the company since net assets decreasing continuously lead to an increase in this ratio. The average ratio in the "non-failed" companies varies between 1.23 to 1.14, while in the failed group varies between 1.24 to 2.10 . 
Figure 7.7 tumover to net assets trend ratio. The trend for "nonfailed" companies varies slightly from year to year, and shows a rise in the first year followed by a slight drop, then a rise in the last year. The failed group indicates the dramatic rise in the ratio is not real since a drastic decrease in net assets should increase the ratio, 1.e. some failed companies may be increasing tum-over by overtrading, a usual phenomenon in failed companies.

The average ratios in non-failed companies varies between 3.19 to 3.3 , while in the failed group increases drastically from 1.94 to 4.3 in the year of failure. The graph also shows there is no ordering of the groups.

Figure 7.8 short term loans to earning before tax ratio. The trend for the "non-failed" group varies from year to year for the first two years increase, followed by a drop, while for the failed group a sharp rising trend is evident, so reflecting the dependence of a failed company on short term loans. The ratio varles between 1.18 to 1.49 in solvent companies while in the failed group it varies between 4.08 to 5.62 .

Figure 7.9 Tax trend. The graphs for both groups followed a very consistent pattern. Both graphs showed tax trends for solvent groups higher than the failed group, with the failed group sharply decreasing in trend, and varying between +1.2 to -.58 .

Figure 7.10 Profit after tax trend. Although the trend for this "nonfailed" group fell from year to year, it was positive, while the trend for the failed group was sharper and varied between +.25 to -.44 . The "non-failed" companies varied between .538 to .148. The negative values reflect the losses made by the failed company. 
Figure 7.11 Short term loan trend. The trend for the "non-failed" group varies from year to year for the first two years and the fell, followed by a rise. For the "failed" group the rise was constant to a crisis level. The trend varied for non-failed and failed groups from doubled every year in the failed group, reflecting high dependence of failed companies on short term loans. Also the two graphs differ from each other.

Figure 7.12 Earnings before tax and interest to net capital employed ratio. The trend for both failed and non-failed groups varies from year to year. The two graphs differ from each other, reflecting the rising profits and growth for the "non-failed" group. The ratio varies between .10 to .117, while for the failed gram it varies between 0.077 to .069 . In conclusion falled companies may make losses after paying interest and the costs of short term loans.

Figure 7.13 Debtors to current liability ratio. The trend for solvent companies showed a fall in the first year followed by a rise for the last two years, while for the failed group there was constant deterioration, reflecting an increase of current liabilities, when debtors reduced facilities to the failed company.

The two graphs differ from each other reflecting rising debtor facilities to solvent companies.

Figure 7.14 ourrent liability to net assets ratio. The trend for the "non-failed" group varied from year to year and fell in the first year, followed by a slight rise, while for failed companies the ratio rose constantly to crisis level 1.52. The nan-falled group varied between 0.85 to 0.73 ; also the two graphs differ from each other. 
Figure 7.15 Interest to earnings before tax and interest ratio. The trend for solvent companies showed a slight rise in the first year, followed by a decline for failed companies, with a slight drop followed by a sharp increase, thus reflecting the high interest paid by failed companies. Also the two graphs differ from each other. 


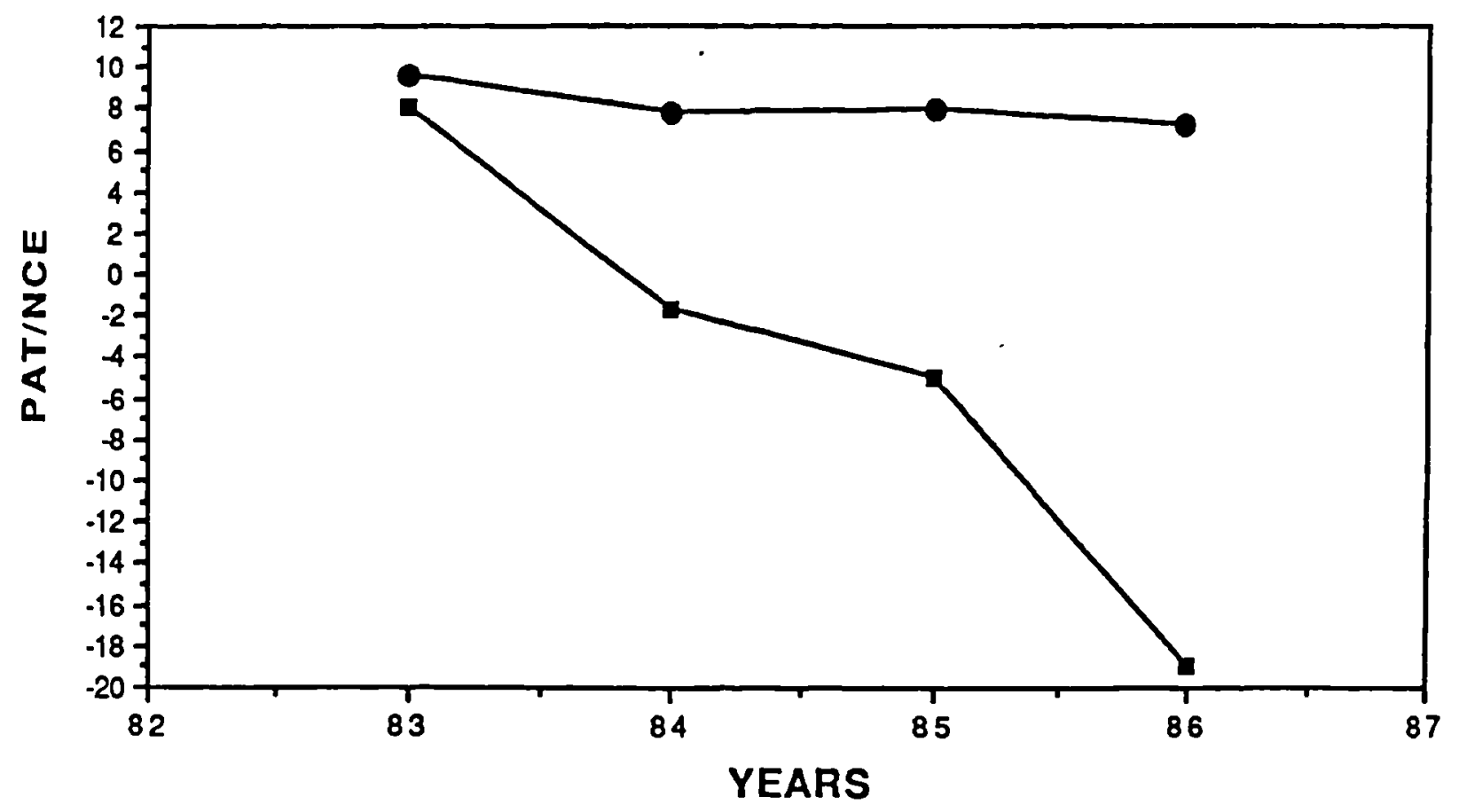

FIGURE 7.5: THE TREND OF THE MEANS OF PROFIT AFTER TAX TO NET CAPITAL EMPLOYED RATIOS

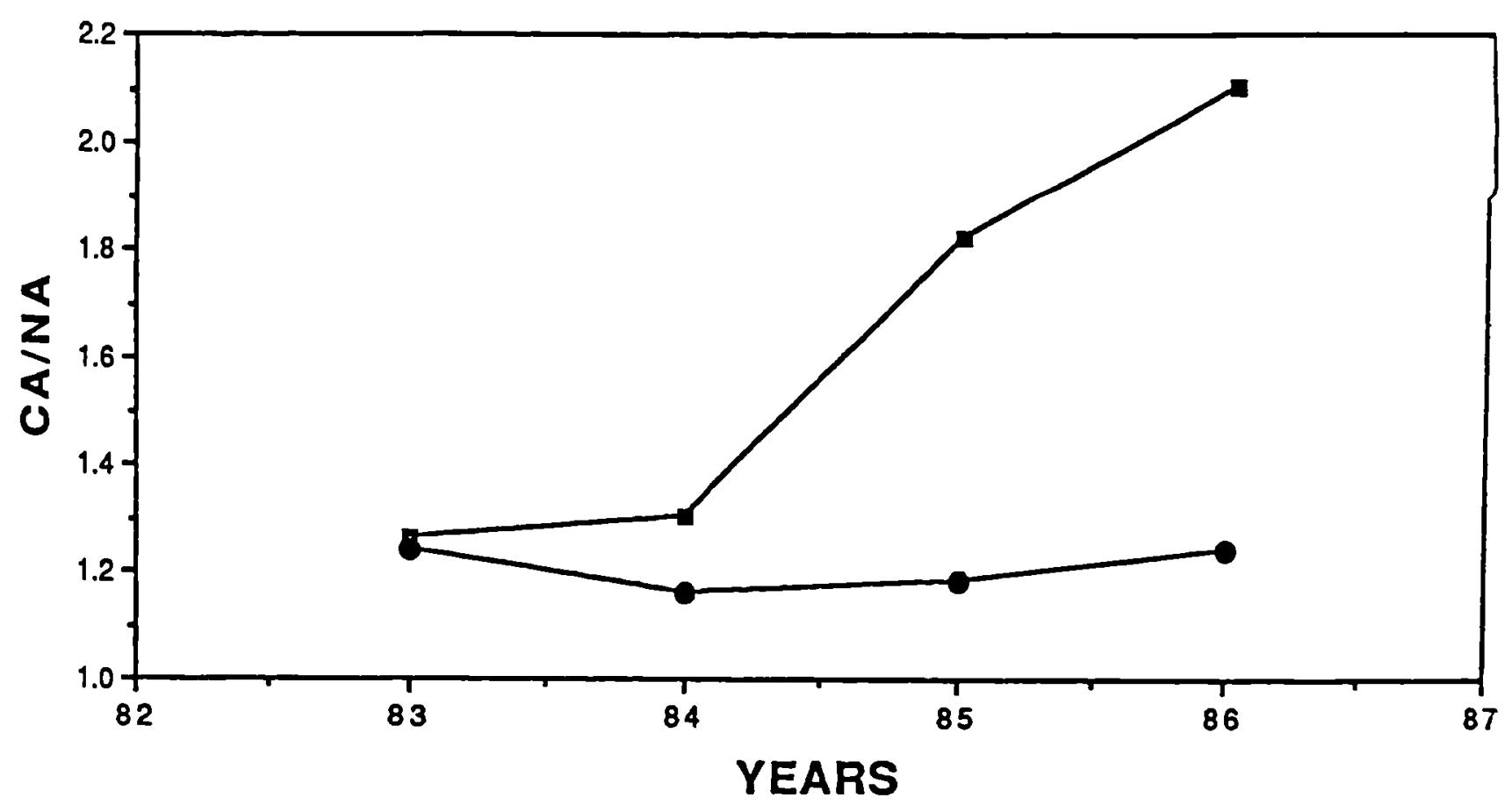

EIGURE 7.6: THE TREND OF THE MEANS OF CURRENT ASSETS TO NET ASSETS RATIOS 


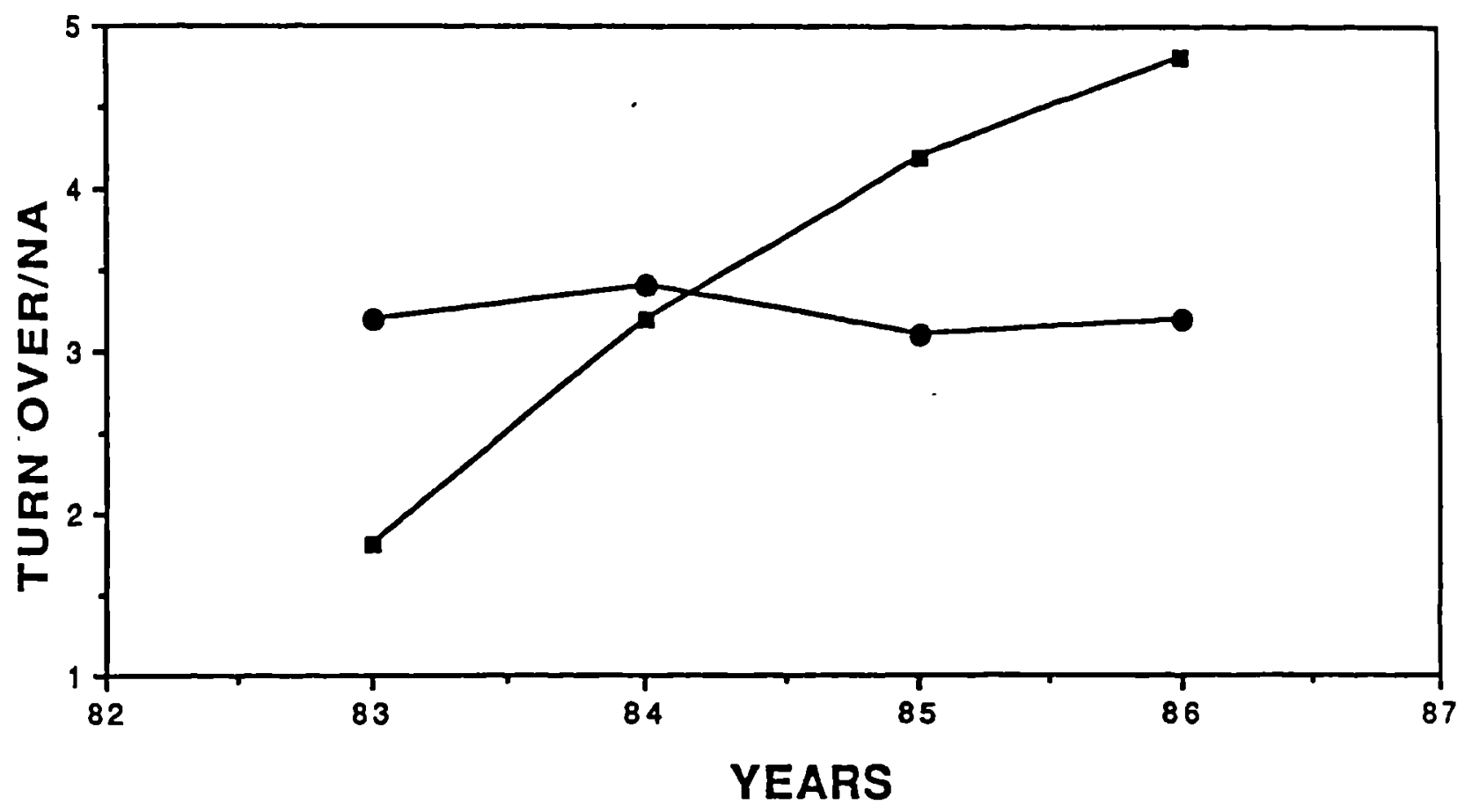

FIGURE 7.7: THE TREND OF THE MEANS OF TURNOVER TO NET ASSETS RATIOS

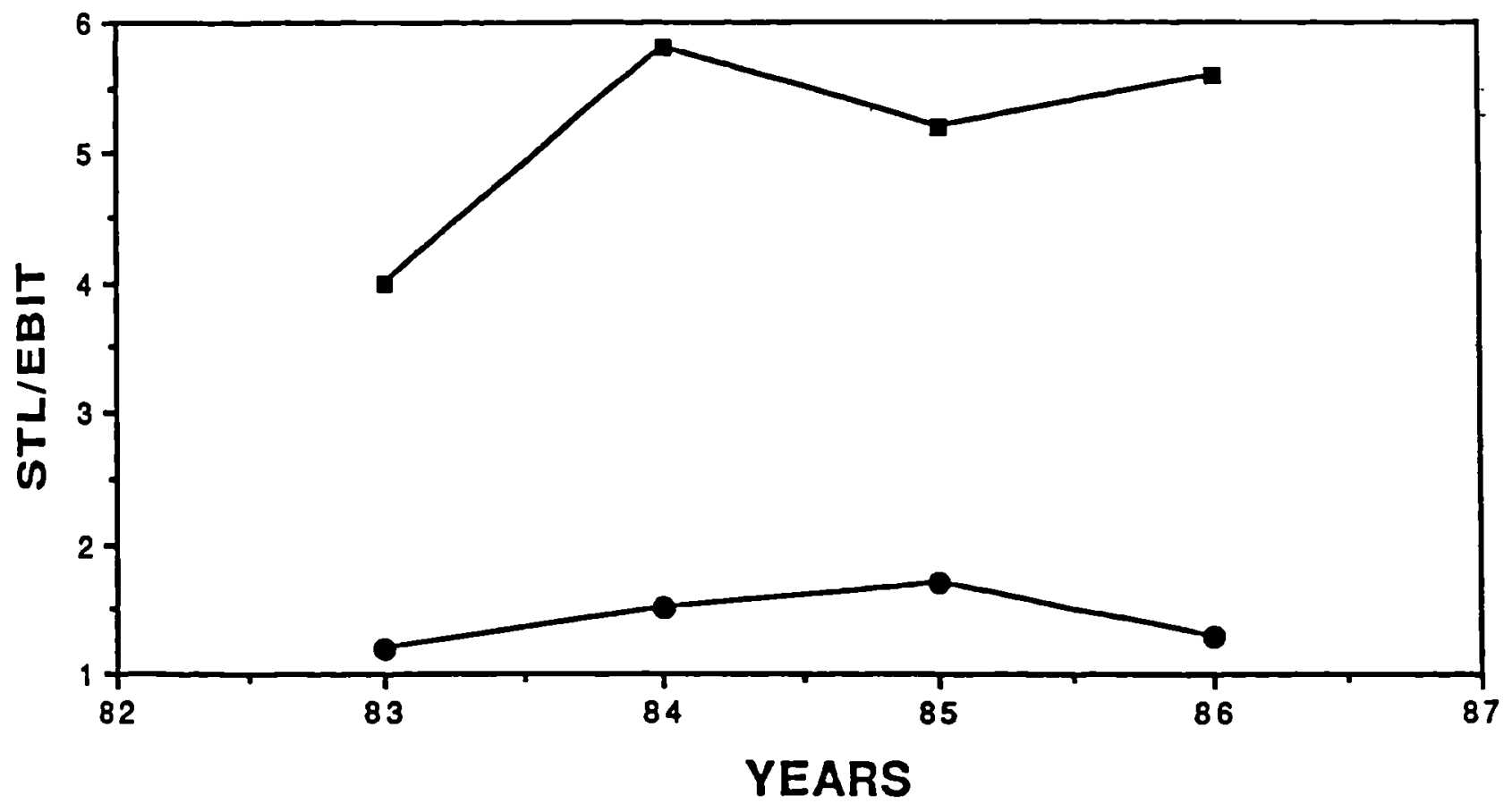

FIGURE 7.8: THE TREND OF THE MEANS OF SHORT TERM LOANS TO EARNINGS BEFORE TAX AND INTEREST RATIOS 


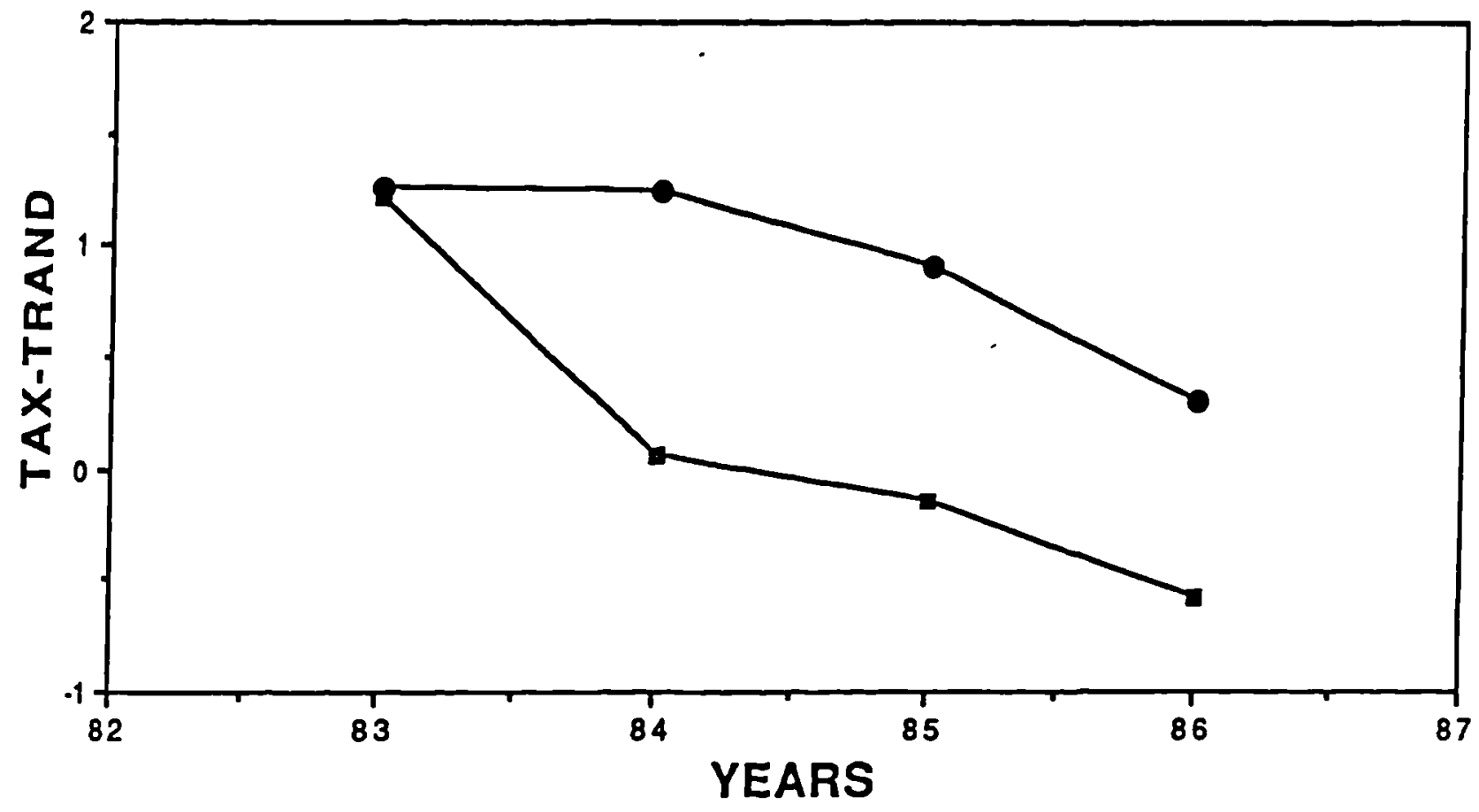

FIGURE $7.9:$ THE TAX TREND

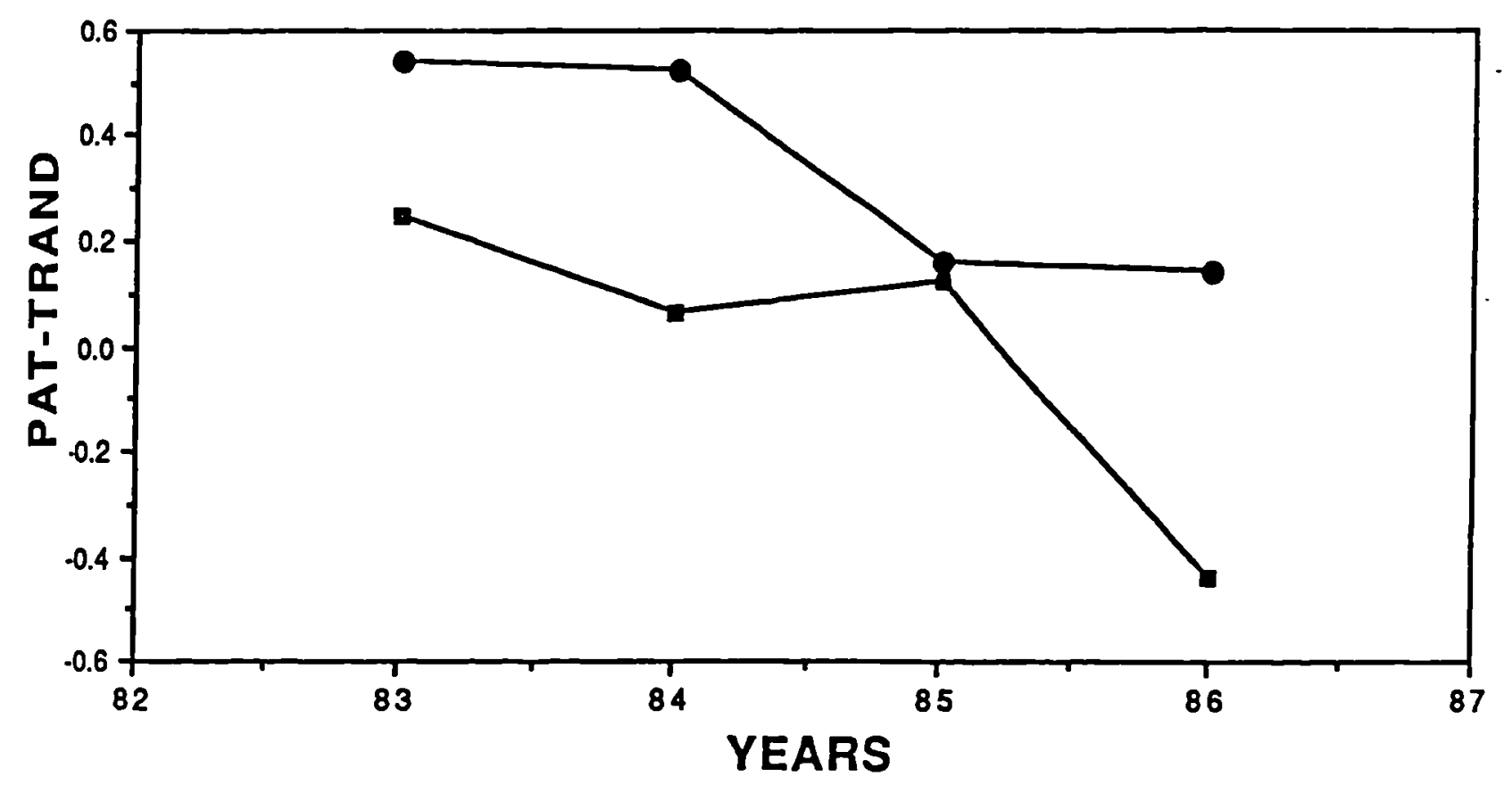

FIGURE 7.10: THE PROFIT AFTER TAX TREND 


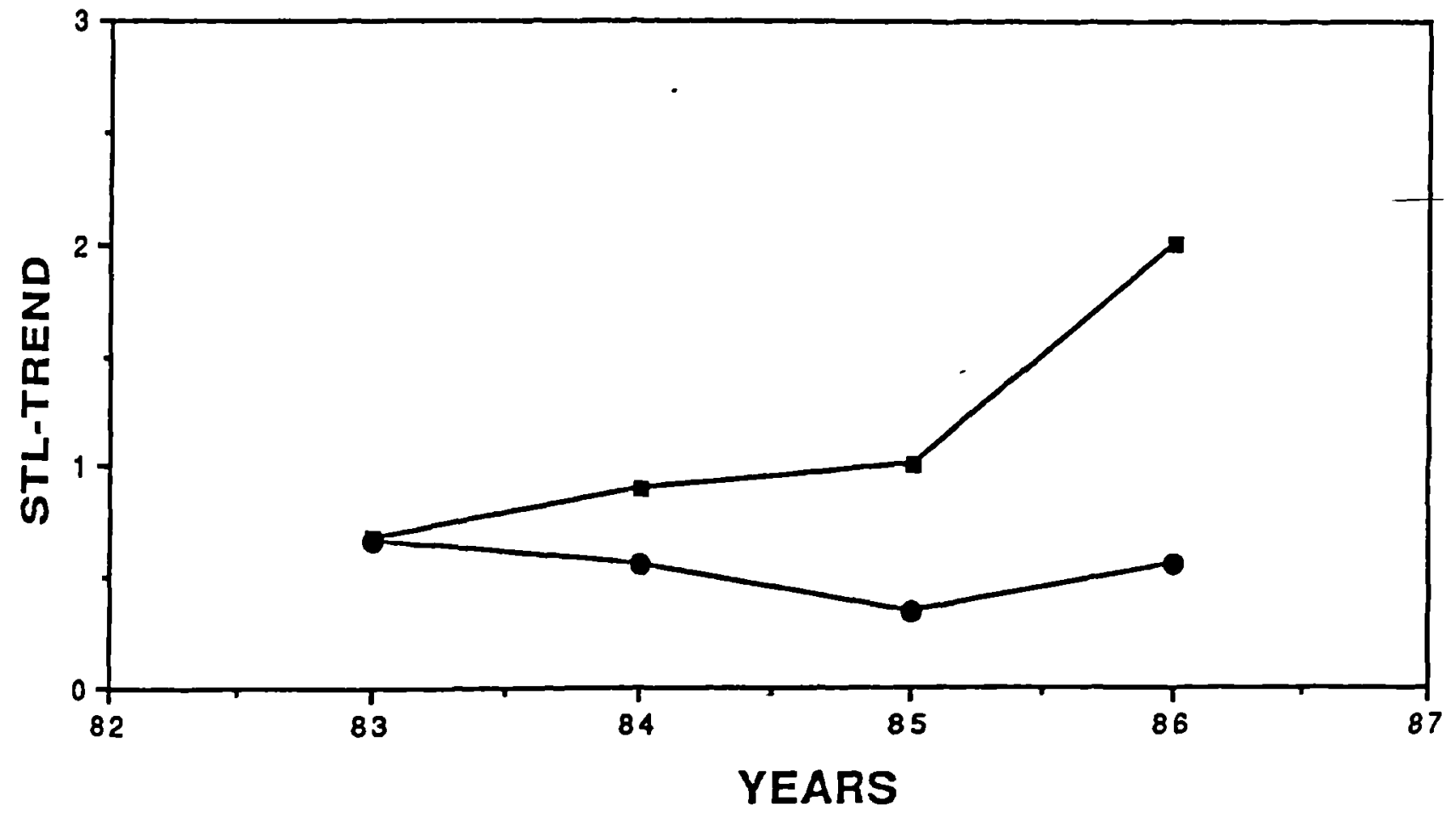

FIGURE 7.11: THE SHORT TERM LOAN TREND

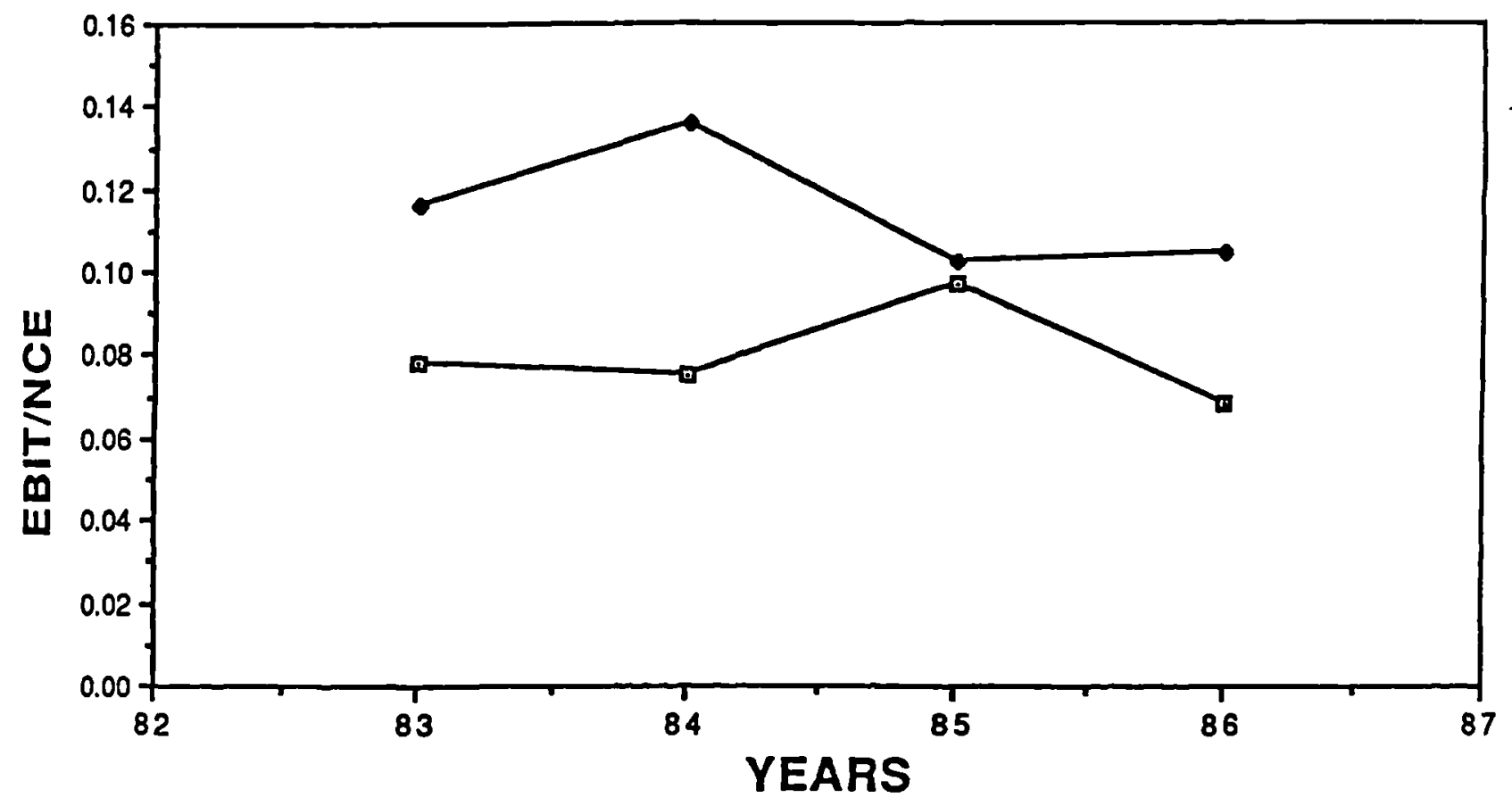

FIGURE 7.12: THE TREND OF THE MEANS OF EARNINGS BEFORE TAX AND INTEREST TO NET CAPITAL EMPLOYED RATIOS 


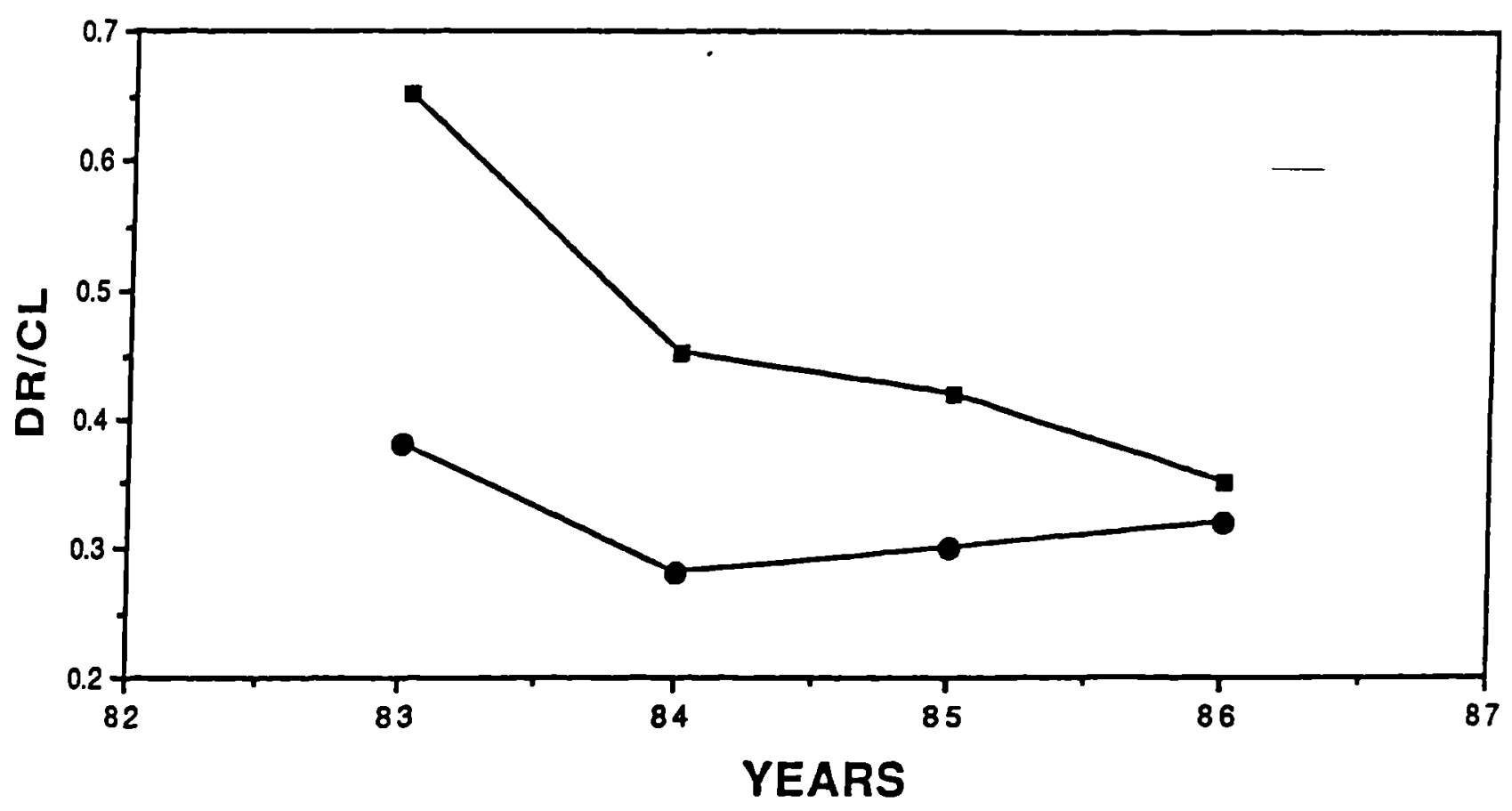

FIGURE 7.13: THE TREND OF THE MEANS OF DEBTORS TO CURRENT LIABILITIES RATIOS

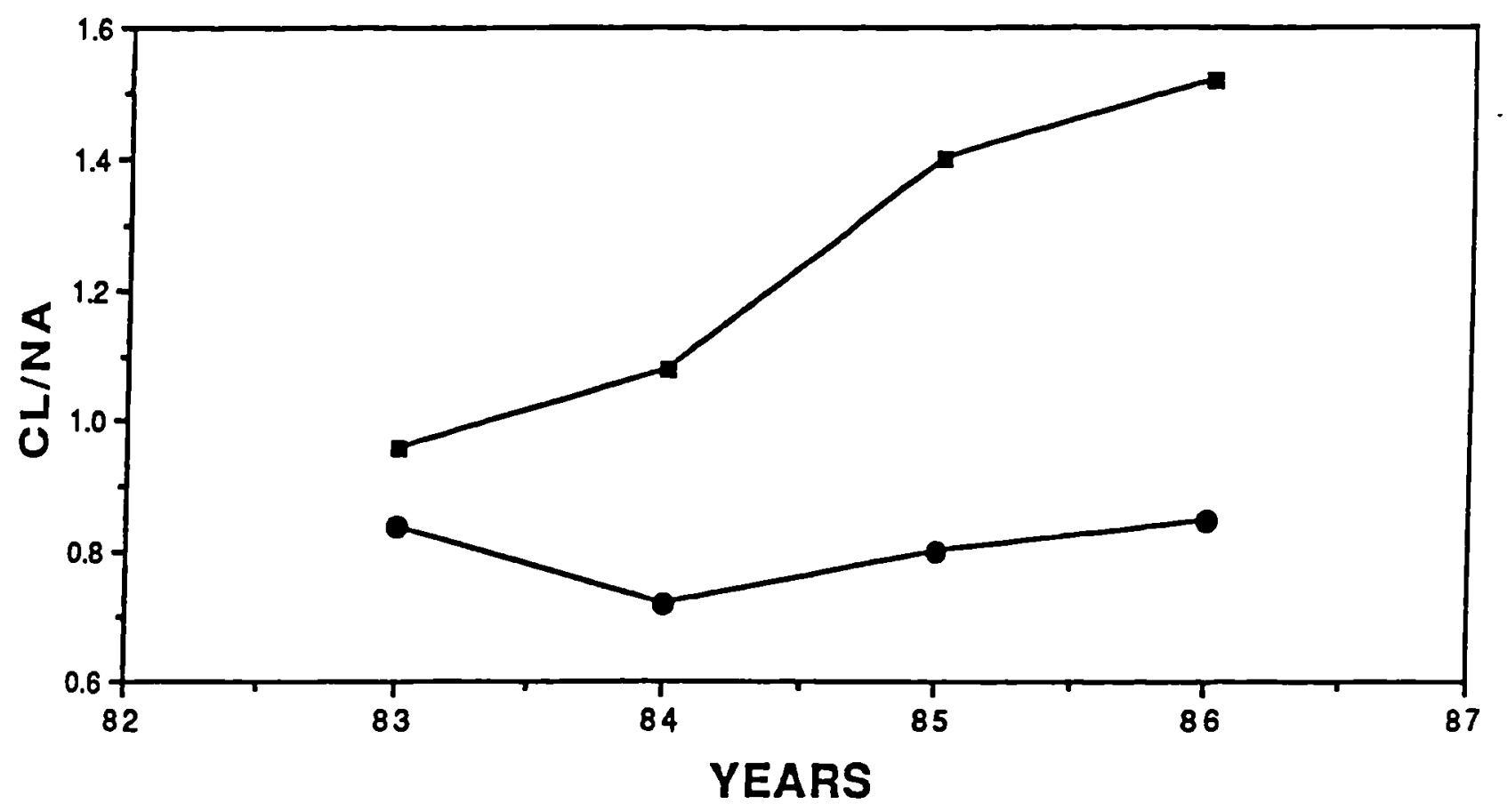

FIFURE 7.14: THE TREND OF TEH MEANS OF CURRENT LIABILITIES TO NET ASSETS RATIOS 


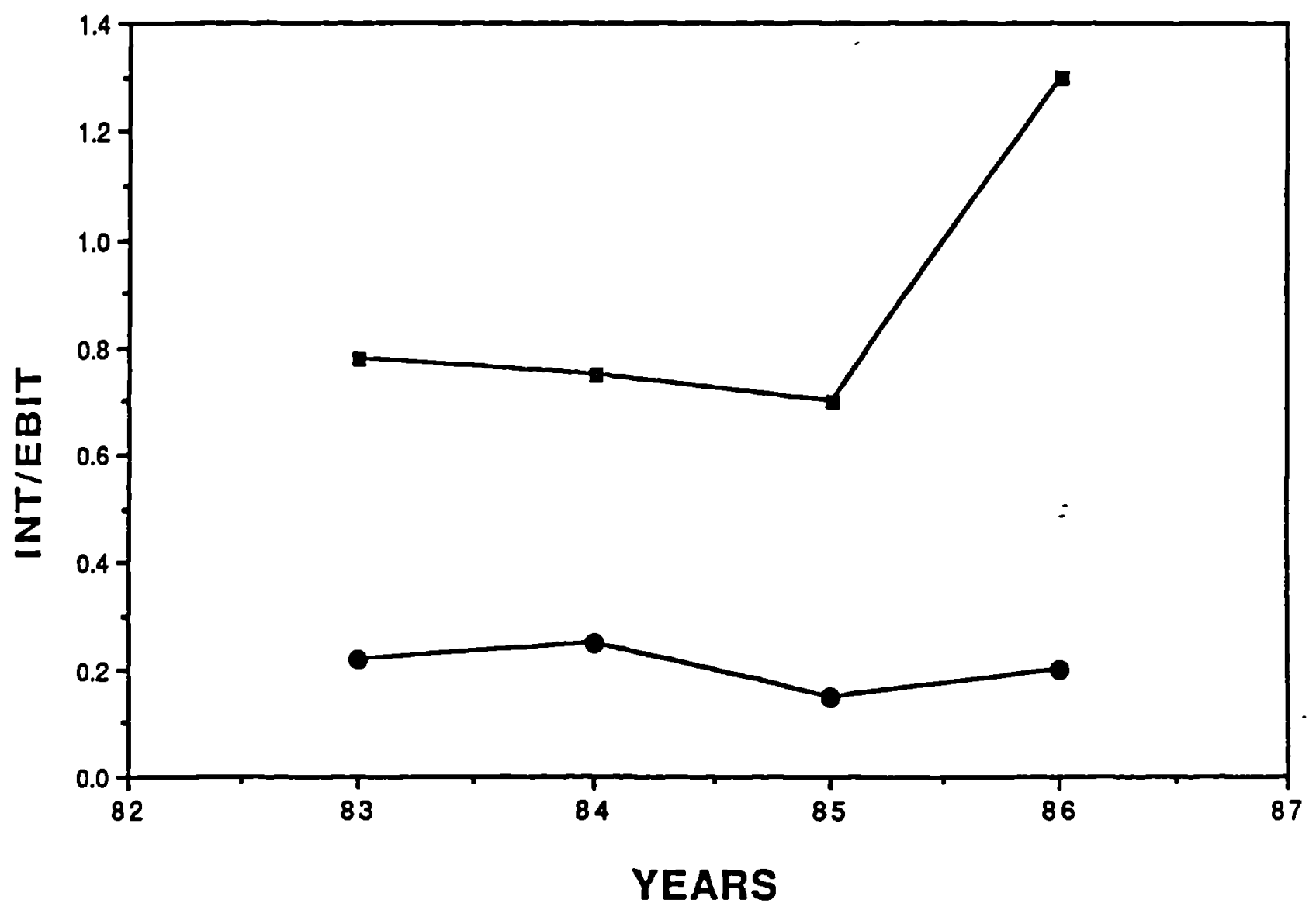

FIGURE 7.15: THE TREND OF THE MEANS OF PAYABLE INTEREST TO EARNINGS BEFORE TAX AND INTEREST RATIOS

Legend:

The trend of the "Failed 11" group

The trend of the "Non-failed 20" Group 


\subsubsection{Conclusions}

The analysis of trends leads to the conclusions:

- The trend in profitability for solvent companies is always positive, while for the failed group it declines sharply and becomes negative in the year of failure. See Figures 7.5, 7.10 and 7.12 .

- The trend in current assets for both groups is positive and rises, but the net assets in the failed groups always decline and fluctuate widely, thus reflecting instability of current assets in failed groups. See Figure 7.6.

- The trend in tum-over is not significant since failed cormanies may increase their tum-over by overtrading and which cannot be predicted by statistical tools. See Figure 7.7.

- The trend in gearing ratios is very significant for identifying the failed company when the trend in net assets gearing rises constantly to crisis level. In contrast solvent groups are generally stable. See Figure 7.14.

- The trend in incame gearing for failed groups rises sharply to crisis level at the year of failure, while for the solvent group it is stable. See Figure 7.15.

- The short term loan trend for the failed group rises sharply, while for the solvent group it is stable. See Figure 7.11. 
- The trend in liquidity for the failed companies always falls for the last four years before failure, reflecting that debtors decrease theirfacilities to the failed company when current liabilities are increasing constantly. Solvent companies are considered stable. See Figure 7.13.

- The trend in tax for solvent companies is always positive while for the failed group it declines sharply and becomes negative for the last two years before failure. See Figure 7.9. 


\subsection{FINANCIAL RATIOS AS A MEANS OF PREDICTING FAILURE}

\subsubsection{Introduction}

Initially ratios measuring liquidity and gearing were considered for the following reasons:

1. Liquidity ratios predict failure better than non-liquidity assets ratios for the period of one or two years to fatlure, whereas the non-liquidity ratios perform better prediction in long periods prior to bankruptcy. Beaver [5] in a later study returned to a more detailed analysis of the liquidity ratios and their potential as forecasters of failure.

2. Gearing ratios show the extent to which a firm depends on borrowed funds. The greater the use of gearing, the greater the inability of the firm to withstand sudden changes in market conditions and so the higher the probability of its failure as in the construction companies. The data shows that prior to bankruptcy failed firms operate with a higher degree of gearing than the contimuing companies.

3. Ratios predicting failure in long periods to bankruptcy such as profitability ratio are not included since its inclusion in the discriminant model.

In this section various ratios are calculated for samples of the "failed 11" and "non-failed 20" companies, and the mean values were compared for two groups. 
The ratios of the failed firms were consistently lower than those of the "non-failed" companies. Furthenmore in most cases the ratios declined several years prior to bankruptcy or failure. In particular three ratios were sensitive predictors of failure in the short term.

\subsubsection{The Three Financial Ratios}

The most discriminating financial ratios among 31 ratios tested were:

1. ourrent ratio: this current ratio indicates to what extent short term assets are adequate to settle short-term liabilities.

The study indicates that the current ratios of failed companies are consistently lower than those of continuing firms. The mean ratios for failed and non-failed groups were 1.16 and 1.66 respectively. A ratio lower than 1.5 is worrying on the grounds of liquidity. In the manufacturing industry the current ratio limit much favoured is about 2 to 1 (Argenti), while this study suggests that $1: 1.5$ is the more likely ultimate limit for construction firms.

Surprisingly the quick ratio was not significant, reflecting work in progress as being easily convertible to cash in the construction industry. Current ratios of discontinued firms were lower than those of the contimuing firms and moreover declined three years prior to cessation of business.

2. Net assets to current liabilities ratio: Current liabilities include creditors, bills pay back, overdrafts, provisions and amounts such as corporation tax payable within ane year. Net assets is the sum of fixed assets, intangible assets and total current assets less current liabilities. 
Using the ratio of net worth to debt, i.e. net worth equals shareholders, funds less intangible assets, the mean of net assets/current liabilities ratio of continuing companies is 1.76 as compared to 0.81 in the failed fims.

The study revealed that 4 out of 20 of the continuing firms had a ratio less than unity, while 7 out of 11 of the failed firms current liabilities were greater than net assets over two years to failure, and eventually all the failed companies had a ratio of less than 1.0 in the last year of failure.

In $65 \%$ of the falled firms the ratio of net assets/current liabilities declined whilst in the continuing firms it remained fairly stable. The conclusion being that a ratio of less than 1.0 places the company in danger of failure. Similarly, by comparison in over $70 \%$ of the failed firms in Merwin's [q] sample, the ratio of net worth to debt declined, whilst in the continuing corporations it remained fairly stable.

The increasing reliance on borrowed funds over a relatively lang period as substantiated by Beaver's study [3] is shown by the sharp increase in the mean of the debt/assets ratio of the falled companies over the five years prior to failure. During the same period the means of the ratio remained unchanged in the continuing firms.

3. Income gearing or "interest cover": This is the amount of interest the company is committed to pay on its lang and short term loans as a ratio of its pre-tax profits. The mean of pre-tax profit/interest ratio of continuing companies is 4.7 as compared to 1.44 in the failed firms. 
Nine out of 11 of the failed companies had a ratio of less than 2.0 in the last year of failure. The ratio is considered to be one of the most important single failure predictors in the year of failure. Therefore, we can conclude that a ratio less than 2.0 places the company in danger of failure.

\subsubsection{Sumary and Conclusians}

Additional to discriminating variables in $\mathrm{z}$-models the following financial ratios are considered the important failure predictors.

- Current assets/current liabilities

- Net assets/current liabilities

- Pre-tax profit/interest

A comparison of the mean ratios for both the failed and non-failed groups concludes that the current ratio of failed companies is lower than the "non-failed" group. The mean ratios for the failed and "nonfailed" groups were 1.16 and 1.66 respectively. Also the current ratio in the failed group deteriorates three years prior to failure. Also 10 out of 11 of the failed companies have ratios less than 1.5 in the last year of fallure and the mean of the ratio when less than 1.5 and which has deteriorated over at least two years may be considered as a failure sign.

The mean ratios for both the failed and non-failed groups, indicates that the net assets/current liabilities ratio of the failed group is lower than the "non-falled" group. Seven out of 11 of the failed group had a ratio less than unity and the mean of the ratio is less than unity and deteriorating over at least three years may be considered as a failure sign. 
A comparison of the mean ratios for both failed and non-falled groups shows that the pre-tax profit/interest paid of failed group is lower than 2.0 in 908 of cases, 1.e. the mean of the ratio when below 2.0 in a single year may be a sign of failure.

A summary of results for the nan-failed and failed groups is shown in Tables 7.16 and 7.17 . 


\begin{tabular}{|c|c|c|c|c|c|c|c|c|c|}
\hline \multirow{2}{*}{$\begin{array}{l}\text { Ratios } \\
\text { Non-failed Co }\end{array}$} & \multicolumn{3}{|c|}{ CA/CL } & \multicolumn{3}{|c|}{$\mathrm{NA} / \mathrm{CL}$} & \multicolumn{3}{|c|}{ EBIT/INT } \\
\hline & 84 & 85 & 86 & 84 & 85 & 86 & 84 & 85 & 86 \\
\hline Aberdeen Canst Ltd & 0.98 & 1.1 & 1.05 & 1.05 & 2.1 & 1.8 & 4.5 & 2.1 & 1.58 \\
\hline Barratt Development & 1.8 & 2.5 & 2.7 & 1.28 & 2.0 & 2.59 & 2.9 & 3.8 & 3.3 \\
\hline Benlax Holdings plc & 1.17 & 1.2 & 1.8 & 1.4 & 1.33 & 1.1 & 9.4 & 6.8 & 5.37 \\
\hline Benbailly Const plc & 1.6 & 1.6 & 1.6 & 1.02 & 0.77 & 0.99 & 3.0 & 0.71 & 0.58 \\
\hline C H Beazer Holds & 2.3 & 2.8 & 1.88 & 1.7 & 2.2 & 1.55 & 4.7 & 5.6 & 3.3 \\
\hline BICC plc & 1.36 & 1.38 & 1.3 & 0.93 & 0.96 & 0.90 & 5.8 & 5.0 & 8.3 \\
\hline Brown and Jackson & 2.5 & 2.3 & 3.1 & 2.0 & 1.8 & 2.8 & 3.8 & 5.1 & 3.7 \\
\hline Bryan Holdings & 1.6 & 1.56 & 1.68 & 1.28 & 1.18 & 1.4 & 10.0 & 10.0 & 5.8 \\
\hline Boultan \& Paul plc & 2.7 & 2.5 & 2.5 & 2.7 & 2.2 & 2.5 & 26.0 & 25.0 & 25.0 \\
\hline M J Geeson Group & 1.06 & 1.14 & 1.12 & 0.83 & 1.08 & 1.11 & 2.7 & 4.0 & 5.0 \\
\hline George Winpey plc & 1.66 & 1.8 & 1.66 & 1.42 & 1.5 & 1.5 & 2.2 & 2.3 & 3.2 \\
\hline Henry Boot and Sons & 1.4 & 0.9 & 0.96 & 1.0 & 0.5 & 0.45 & 4.0 & 4.8 & 1.13 \\
\hline A Monk $\infty$ Ltd & 1.6 & 1.6 & 1.6 & 1.02 & 0.9 & 1.0 & 2.0 & 1.8 & 2.1 \\
\hline Newarthill plc & 1.6 & 1.33 & 1.5 & 2.3 & 1.7 & 1.58 & 6.2 & 5.0 & 3.4 \\
\hline Rush \& Tampkins & 1.4 & 1.16 & 1.8 & 1.88 & 1.42 & 0.8 & 1.09 & 1.17 & 0.88 \\
\hline Taylor Woodrow & 1.5 & 1.4 & 1.22 & 2.1 & 2.2 & 2.1 & 7.3 & 10.0 & 11.9 \\
\hline Tarmac plc & 1.17 & 1.4 & 1.5 & 1.25 & 1.56 & 1.56 & 6.4 & 5.7 & 7.5 \\
\hline Tilbury Group ple & 1.3 & 1.44 & 1.58 & 1.3 & 1.23 & 1.03 & 33.0 & 33.0 & 33.0 \\
\hline Turriff Corp plc & 1.25 & 1.16 & 1.12 & 0.6 & 0.56 & 0.7 & 3.3 & 3.8 & 11.0 \\
\hline Wilson connolly & 3.4 & 3.5 & 3.5 & 3.5 & 3.4 & 3.3 & 52.0 & 52.0 & 52.0 \\
\hline Means & 1.66 & 1.68 & 1.72 & 1.57 & 1.54 & 1.52 & 4.6 & 4.5 & 4.5 \\
\hline
\end{tabular}

TABLE 7.16: THE RESULTS OF THE DISCRIMINATOR RATIOS OBTAINED FROM THE "NONFAILED 20" GROUP IN UNIVARIATE ANALYSIS 


\begin{tabular}{|c|c|c|c|c|c|c|c|c|c|}
\hline Ratios & \multicolumn{3}{|c|}{$\mathrm{CA} / \mathrm{CL}$} & \multicolumn{3}{|c|}{$\mathrm{NA} / \mathrm{Cl}$} & \multicolumn{3}{|c|}{$\mathrm{EBIT} / \mathrm{INT}$} \\
\hline Failed Companies & -3 & -2 & -1 & -3 & -2 & -1 & -3 & -2 & -1 \\
\hline Beech Wood Group plc & 1.6 & 1.56 & 1.25 & $\mid 1.59$ & 1.49 & 0.93 & 1.07 & $|0.55|$ & 1.08 \\
\hline Cocksedge plc & 0.5 & 0.5 & 0.5 & 0.5 & 0.54 & 0.43 & 1.9 & 6.2 & 1.13 \\
\hline David Charles plc & 1.77 & 1.9 & 1.5 & 1.12 & 1.3 & 0.98 & 0.2 & 3.7 & 1.03 \\
\hline Crouch Group plc & 0.59 & 0.52 & 0.66 & 1.06 & 1.28 & 0.9 & 1.37 & 0.9 & 2.0 \\
\hline James H Dennis plc & 1.2 & 0.88 & 0.95 & 1.7 & 0.8 & 0.56 & 1.8 & 0.25 & 0.5 \\
\hline Mears Bros Ltd & 1.25 & 1.2 & 1.3 & 0.54 & 0.75 & 0.75 & 0.74 & 2.9 & 0.4 \\
\hline Milbury plc & 1.3 & 1.49 & 1.25 & 0.6 & 0.64 & 0.7 & 0.58 & 0.4 & 1.16 \\
\hline Modern Eng Bristol plc & 1.4 & 1.2 & 1.07 & 1.6 & 0.8 & 0.52 & 0.58 & 0 & 0 \\
\hline Moss Eng Group plc & 1.47 & 1.28 & 1.1 & 1.05 & 0.73 & 0.6 & 4.4 & 1.3 & 0.75 \\
\hline Southem Construction Ltd & 1.49 & 0.85 & 0.85 & 1.2 & 0.25 & 0.29 & 4.3 & 0 & 0 \\
\hline S W Farmer plc & 1.4 & 1.44 & 1.25 & 0.5 & 0.55 & 0.33 & 2.5 & 3.2 & 0.9 \\
\hline Means: & 1.26 & 1.16 & 1.06 & 0.99 & 0.83 & 0.63 & 1.79 & 1.78 & 0.76 \\
\hline
\end{tabular}

TABLE 7.17: THE RESULTS OF PREDICTING RATIOS OBTAINED FROM THE "FALLED 11" GROUP IN UNIVARIATE ANALYSIS

Note The year indicates years before failure:

- CA/CL: Gurrent assets/ current liabilities

- NA/CL: Net assets/current liabilities

- EBIT/INT: Eamings before interest and tax/interest 


\subsection{SUMMARY AND CONCLUSIONS}

The results obtained from the "non-failed 20" and "failed 11" groups using the developed model (1), regression model (2), updated Mason model (3) and using the cut-off as a classification boundary and ignoring 'grey area' developed in section 6.6 are shown in Table 7.18:

\begin{tabular}{|c|c|c|c|c|c|c|}
\hline \multirow{2}{*}{ Groups } & \multicolumn{2}{|c|}{ Model 1} & \multicolumn{2}{|c|}{ Model 2} & \multicolumn{2}{|c|}{ Model 3} \\
\hline & $(-) \mathrm{Z}$ & $(+) Z$ & $-\mathbf{z}$ & $+\mathrm{Z}$ & $(-) \mathrm{z}$ & $+z$ \\
\hline "Falled 11" Group & $11(100)$ & - & $11(100)$ & - & $9(82)$ & $2(18)$ \\
\hline $\begin{array}{l}\text { "Non-failed 20" } \\
\text { Group }\end{array}$ & $2(10)$ & $18(90)$ & $3(15)$ & $17(85)$ & $4(20)$ & $16\left(80^{\circ}\right)$ \\
\hline
\end{tabular}

TABLE 7.18

Both models 1 and 2 1008 correctly classified the failed group, while model 3 had a lower discriminating power i.e..82 8 .

For the "non-failed" group both models 1 and 2908 and $85 \%$ correctly classified, while model 3 had a lower discriminating power of $80 \%$.

Models 1 and 2 discriminate better than model 3. However taking into account the 'grey area' limit $( \pm 2.94)$ for model 1 and cut off point zero for model 2, because it has been developed by regression technique, it must be observed that all companies in the "failed 11" group were correctly classified, while 85\% were correctly classified in the "nonfailed" group with $15 \%$ classified as vulnerable. No misclassifications in both groups. 
For the failed group the mean values of $\mathrm{Z}$-score by applying both models for the last three years before failure were: $-9.66,-11.25,-21.6$ and $-2.93,-3.40,-3.15$ respectively. Ten out of 11 companies of the "failed 11" group scored negatively in the three years prior to fallure reflecting the discriminating power of both models.

The following ratios are considered an ultimate test of a company's solvency if their values decrease to limits as calculated:

- Current assets/current liabilities $\geq 1.5$

- Net assets/current liabilities $\geq 1.0$

- Pre-tax profit/interest $\quad \geq 2.0$

Also the study suggests that while the traditional financlal ratios are most useful tools, tried and tested, these cannot by themselves give a reliable overall picture of performance of a company and only pinpoint particular areas of concern, ratios cannot on their own predict fallure, they only arouse anxiety. Z-scores also are not foolproof, and may be influenced by the economy (e.g. a rise in interest rates would cause a deterioration in all companies gearing).

Finally, Rush and Tompkins plc announced its failure in April 1990, therefore further investigations were made and it was found that the zscores for the period 1987-1989 were -1, -4, -16 respectively. Clearly the Z-score declined continuously and declined sharply at least one year before failure. Therefore it was concluded that the average length of time between the company registering an at risk z-score on 31 March 1986 and the recent announcement was four years. 
Additional to the $\mathrm{z}$-model prediction, the three financial ratios which are developed in Section 7.7 also successfully predicted the same. Table 7.16 shows that the current ratio, net assets/current liability ratio and pretax profit/interest ratio were lower than the solvency limits $(1.5,1.0$ and 2.0 respectively). Furthermore these ratios deteriorated in 1986 when the company registered an at risk z-score.

Thus it is essential to use at least two different methods of prediction before coming to a conclusion relating to a suspect company. 


\title{
CAAPTER 8
}

VALIDATION OF THE Z-MODETS AND FINANCIAL RATIOS

\section{AS A TOOL FOR PREDICTING FAIUURE}

\author{
8.1 Introduction \\ 8.2 Validation of Developed Model \\ 8.3 Validation of Multiple Regression Model \\ 8.4 Validation of Financial Ratios as a Tool for Predicting Failure \\ 8.5 Summary and Conclusion
}




\section{CHAPTER 8}

VALIDATION OF THE Z-MODETS AND FINANCIAL RATIOS AS A TOOL

\section{FOR PREDICTING FATLURE}

\subsection{INTRODUCTION}

This chapter presents the procedure taken to validate the developed model and regression model, however the Masan model was excluded due to the high percentage of misclassification errors. Results of the validation were obtained with independent data such as "Test failed $11 "$ and "Test Contimued 70" groups.

Section 8.2 includes validation of the developed discriminant analysis model.

Section 8.3 includes validation of an alternative regression technique model and also includes validation of the model in the London Borough of Camden.

Section 8.4 presents validation of the three financial ratios as tools for predicting failure.

The final section briefly discusses the validation of the model linked with critical financial ratios as a tool for predicting failure. A summary of the results is also included.

\subsection{VALIDATION OF DEVELOPED MODET}

\subsubsection{Introduction}

This section deals with validation of the developed MDA model using independent data, being appropriate to check the model with data as follows: 
- The "Test falled 11" group with a "failed 11" new group called the "All failed 22" group.

- A "Continued 70" group with the "non-failed 20" group used to develop the model itself, so forming a new group called the "All non-failed 90" group.

This procedure was adopted for two reasons: firstly, to analyse the prior year Z-score for both failed and non-failed groups. Secondly to determine the proportion of companies "at risk" in the population of continued companies. The combined population of "non-failed 20" and "continued 70" groups called the "All non-failed 90" group needs to be considered.

\subsubsection{Results from the "Test Failed 11" and "Continued 70" Groups} The results obtained from the independent data for "Test failed 11" and "Continued 70" groups as shown in Tables 8.1 and 8.2 and taking into account the 'grey area' \pm 2.94 produces results as shown in Table 8.3: 


\begin{tabular}{|l|c|c|c|}
\hline \multicolumn{1}{|c|}{ Companies } & -3 & -2 & Last Year \\
\hline 1. A.C. \& K. Builders Ltd & -41 & -29 & -42 \\
2. Allied Construction Ltd & -28 & -10 & -18 \\
3. Bowmate Construction Ltd & +7.0 & -7.9 & -14 \\
4. Bright Brook Builders Ltd & +9.7 & +13.5 & -31 \\
5. Comber Construction Ltd & -4 & -13.6 & -67 \\
6. Pevland Construction Ltd & - & - & -20 \\
7. Sphinx Building Const. Ltd & +20 & -72 & -19 \\
8. Stevens \& Sons Building Ltd & +19.6 & -24 & -19 \\
9. Staines Construction Ltd & +37 & -32 & -35 \\
10. Stottmilis Build. Ltd & -1.6 & -31 & -132 \\
11. Stream Star Const. Ltd & -2 & -34 & -35 \\
\hline
\end{tabular}

TABLE 8.1: RESULTS OBTAINED FROM THE "TEST FAILED 11" GROUP 


\begin{tabular}{|c|c|c|c|c|}
\hline Companies__ & 1984 & 1985 & 1986 & 1987 \\
\hline $\begin{array}{l}\text { Amec plc } \\
\text { Amoo Indus Hold plc } \\
\text { Babcock Cont Ltd } \\
\text { Balfour Beatty Ltd } \\
\text { Bellway Builders Ltd } \\
\text { Peter Birse Hold } \\
\text { Bowmer \& Kirkland Ltd } \\
\text { Bryant Const Ltd } \\
\text { Bovis Const Ltd } \\
\text { A F Budge Cont Ltd } \\
\text { CBI Canst Ltd } \\
\text { Cementation Const Ltd } \\
\text { Charles Davies } \\
\text { Charles Gray Blds } \\
\text { Charnwood Const Ltd } \\
\text { City of Aberdeen Ass } \\
\text { Conder Group plc } \\
\text { Consolidated Term Inv } \\
\text { Costain Group plc } \\
\text { Croudace Hold Ltd } \\
\text { Dalton Const Ltd } \\
\text { Danbury Const Ltd } \\
\text { Davoo Const Ltd } \\
\text { Dencora plc } \\
\text { Dean \& Bowes Group } \\
\text { Robert M Douglas plc } \\
\text { Dunton Group plc } \\
\text { John Elliott plc } \\
\text { Eve Canst plc } \\
\text { Exeter Bdg \& Const } \\
\text { Galliford plc } \\
\text { Gargan Const Ltd } \\
\text { Gilbert House Invest } \\
\text { Haymills Holds Ltd } \\
\text { Higgs \& Hill plc } \\
\text { Hollandsche Betan } \\
\text { Johnston Group plc } \\
\text { John Laing plc } \\
\text { J M Janes \& Sons } \\
\text { Kyle Stewart Ltd } \\
\text { Walter Lawrence plc } \\
\text { F J C Lilley plc } \\
\text { Londan \& Clyde Hold } \\
\text { James Longley \& Co } \\
\text { Y J Lovell Hold plc }\end{array}$ & $\begin{array}{c}17.2 \\
-1.0 \\
-14.0 \\
-2.5 \\
-8.4 \\
-36.0 \\
16.9 \\
-38.0 \\
+80.0 \\
14.2 \\
54.0 \\
2.1 \\
- \\
-21.0 \\
6.77 \\
7.3 \\
- \\
- \\
8.8 \\
13.6 \\
-.58 \\
12.0 \\
31.7 \\
- \\
- \\
-2.0 \\
- \\
- \\
- \\
1.3 \\
9.4 \\
26.0 \\
24.0 \\
13.0 \\
3.24 \\
- \\
2.6 \\
4.2 \\
- \\
- \\
54.0 \\
-4.4 \\
10.7 \\
- \\
-3.0\end{array}$ & 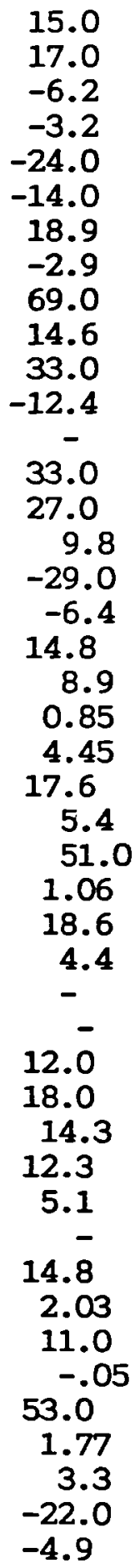 & $\begin{array}{c}15.0 \\
-2.90 \\
-8.0 \\
-6.7 \\
-8.3 \\
17.9 \\
-3.0 \\
-9.5 \\
- \\
15.7 \\
14.4 \\
4.5 \\
-17.0 \\
- \\
- \\
9.0 \\
11.5 \\
47.0 \\
-6.61 \\
15.0 \\
10.9 \\
-3\end{array}$ & $\begin{array}{c}1.65 \\
- \\
- \\
2.135 \\
- \\
9.9 \\
15.0 \\
- \\
38.3 \\
- \\
-23.0 \\
- \\
- \\
- \\
- \\
- \\
-5.6 \\
- \\
9.3 \\
- \\
- \\
- \\
53.0 \\
16.9 \\
- \\
-2.0 \\
9.7 \\
13.0 \\
9.0 \\
33.0 \\
- \\
15.1 \\
22.4 \\
- \\
16.37 \\
-.25 \\
-7.6 \\
34.0 \\
8.2 \\
2.09 \\
- \\
62.8\end{array}$ \\
\hline
\end{tabular}




\begin{tabular}{|c|c|c|c|c|}
\hline Companies & 1984 & 1985 & 1986 & 1987 \\
\hline $\begin{array}{l}\text { Alfred MaAlpine Con } \\
\text { MaLaughlin \& Harvey } \\
\text { R J McLeod Cont } \\
\text { R Mansell Ltd } \\
\text { May Gurney Holds Ltd } \\
\text { The Miller Group Ltd } \\
\text { John Mowlem \& Co } \\
\text { Norwest Holst Ltd } \\
\text { Ogilvie Holds Ltd } \\
\text { Reema Const Ltd } \\
\text { Andrew Scott (Civ) } \\
\text { Seddon Group Itd } \\
\text { Shepherd Bldg Group } \\
\text { Simons Const Ltd } \\
\text { Sunley Hold plc } \\
\text { Tarmac Const Ltd } \\
\text { Tammac Homes Midland } \\
\text { Tarrock Const Ltd } \\
\text { G Percy Tretham Ltd } \\
\text { Trollope \& Colls Const } \\
\text { Wates Const Ltd } \\
\text { Whittaker Ellis Bdg } \\
\text { Willett Ltd } \\
\text { Willmott Dixan Holds } \\
\text { John E Wiltshire plc }\end{array}$ & $\begin{array}{c}7.9 \\
- \\
- \\
- \\
- \\
64.0 \\
- \\
- \\
9.6 \\
- \\
- \\
-5.9 \\
11.9 \\
- \\
4.3 \\
12.0 \\
8.47 \\
- \\
- \\
- \\
5.7 \\
- \\
- \\
4.6\end{array}$ & $\begin{array}{c}1.4 \\
9.0 \\
-3.0 \\
-25.0 \\
- \\
- \\
61.0 \\
- \\
- \\
6.9 \\
50.0 \\
15.5 \\
-7.9 \\
11.9 \\
- \\
4.2 \\
15.0 \\
11.8 \\
15.4 \\
5.5 \\
-1.04 \\
21.5 \\
-13.5 \\
-5 \\
-10.0\end{array}$ & $\begin{array}{r}-2.3 \\
2.9 \\
-10.5 \\
15.0 \\
8.0 \\
3.4 \\
74.0 \\
5.6 \\
24.0 \\
5.07 \\
19.7 \\
14.7 \\
-7.0 \\
5.7 \\
1.0 \\
11.0 \\
20.0 \\
2.05 \\
-23.0 \\
-4.0 \\
41.0 \\
-9.4 \\
-1.05 \\
8.8 \\
73.0\end{array}$ & $\begin{array}{c}8.9 \\
36.0 \\
17.6 \\
21.5 \\
4.3 \\
15.9 \\
.17 \\
- \\
- \\
- \\
12.7 \\
-6.8 \\
- \\
- \\
- \\
2.1 \\
- \\
-9.0 \\
- \\
- \\
-22.0 \\
15.1 \\
-\end{array}$ \\
\hline Average Z-score & 8.96 & 8.56 & 9.4 & 11.56 \\
\hline
\end{tabular}

TABLE 8.2: RESULTS OBTAINED FROM THE "TEST CONTINUED 70" GROUP 


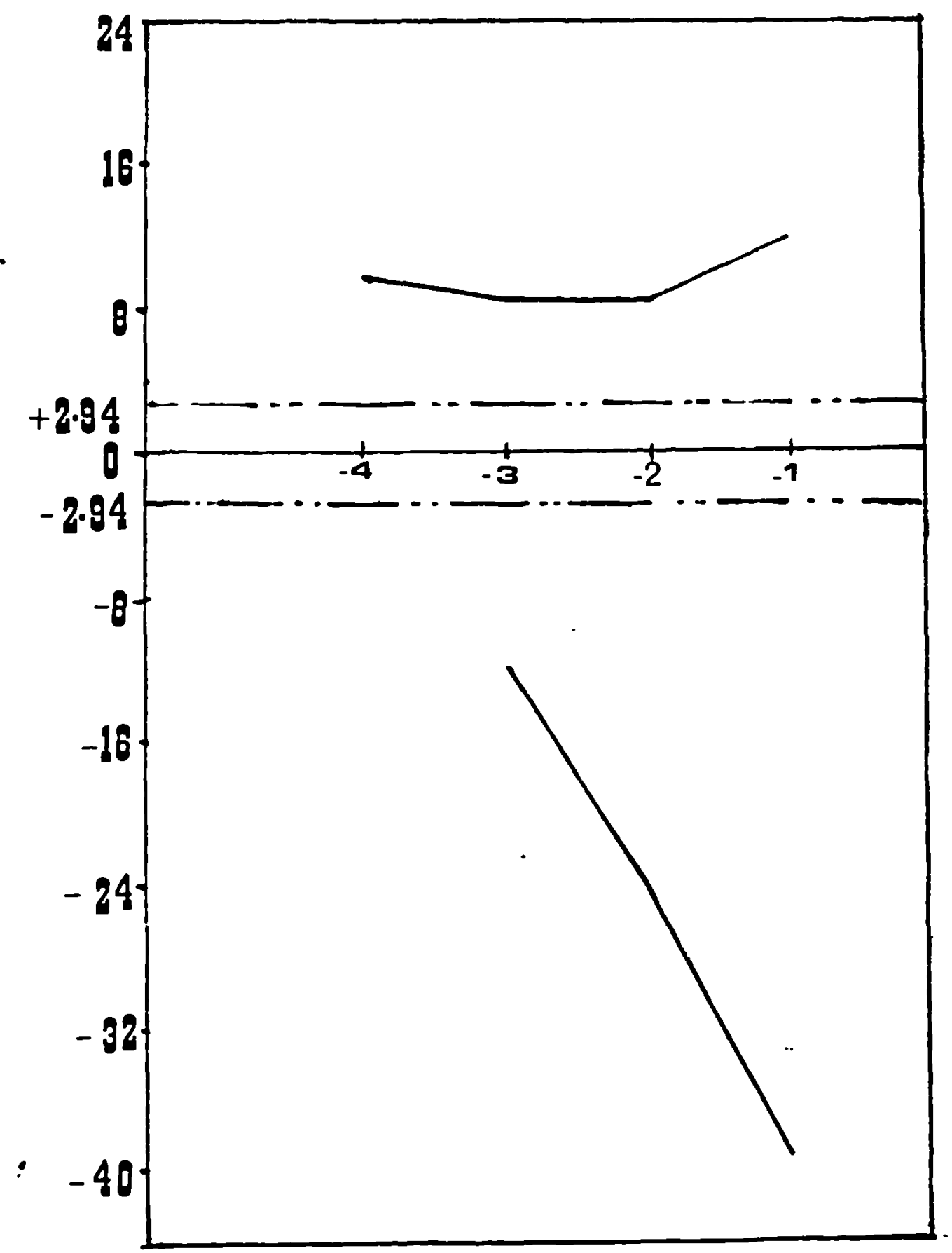

FIGURE 8.1: PRIOR YEARS $\mathrm{Z}$-SCORE MEANS TREND OF THE "TEST CONTINUED 70" AND "TEST FAILED 11" GROUPS 


\begin{tabular}{|l|c|c|c|}
\hline \multirow{2}{*}{ Groups } & \multicolumn{3}{|c|}{ Classified as } \\
\cline { 2 - 4 } & Failed & Vulnerable & "Non-failed" \\
\hline $\begin{array}{l}\text { "Test failed 11" } \\
\text { Group }\end{array}$ & $11(100)$ & - & $47(67)$ \\
$\begin{array}{l}\text { "Test Continued 70" } \\
\text { Group }\end{array}$ & $9(13)$ & $14(20)$ & \\
\hline
\end{tabular}

TABLE 8.3: CLASSIFICATION OF THE "TEST FAILED 11" AND "TEST CONIINUED 70" GROUPS

One hundred per cent are correctly classified as failed, $67 \%$ are correctly classified as non-failed and $20 \%$ classified as vulnerable. At first sight control does not appear as good as the 908 result of the "non-failed 20" group, see Table 7.3, used to form the model. Also 138 of "tested continued 70" classified as potential failures do not fall. These compantes need further investigation, because of critical financial ratios before coming to a conclusion. In addition statistical evidence is necessary that such models predict better than chance or straight classification of all cases as non-failed.

\subsubsection{Results from the "Test failed 11" and "All failed 22" Groups} The classification results for the year prior to failure for the "test failed 11" group are shown in Table 8.4:

\begin{tabular}{|c|c|c|}
\hline \multicolumn{3}{|c|}{ Classified as } \\
\hline Non-failed & Vulnerable & Failed \\
\hline- & - & $11(100)$ \\
\hline \multicolumn{3}{|c|}{ Total in Group: 11} \\
\hline
\end{tabular}

TABLE 8.4: CLASSIFICATION OF THE "TEST FAIIED 11" GROUP 
Taking into account the 'grey area', the model classified 1008 of the "test failed 11" group correctly. This result is as good as the "failed 11 " group used to form the model. This is the real measure of the model's success as a classification device.

Furthermore inspection of the classification results in Table 8.5, indicates a very good result of the total failed sample, $100 \%$ are correctly classified as "failed".

\begin{tabular}{|c|c|c|}
\hline \multicolumn{3}{|c|}{ Classified as } \\
\hline Non-failed & Vulnerable & Failed \\
\hline- & - & $22(100)$ \\
\hline & Total in Group: 22 \\
\hline
\end{tabular}

TABLE 8.5: CLASSIFICATION OF THE "ALL FAIEED 22" GROUP

\subsubsection{Prior Year Z-Score Analysis from "Test Failed 11" Group}

Having seen how well the model works on data in the year prior to failure, it would be instructive to consider how far in advance of failure a firm starts to resemble previous bankruptcies.

The results for the "Test failed 11" group are stown in Table 8.6. 


\begin{tabular}{|c|c|c|c|}
\hline \multirow{2}{*}{ Classified as } & \multicolumn{3}{|c|}{ Accounting year Prior to Company Failure } \\
\hline & -3 & -2 & Last \\
\hline $\begin{array}{l}\text { "Non-failed" } \\
\text { Vulnerable } \\
\text { Failed }\end{array}$ & $\begin{array}{l}4(40) \\
2(20) \\
4(40)\end{array}$ & $\begin{array}{l}1(10) \\
-\quad(-) \\
9(90)\end{array}$ & $11 \stackrel{-}{\overline{-}}$ \\
\hline Total: & 10 & 10 & 11 \\
\hline Average Z-Scores & -12 & -21 & -39 \\
\hline
\end{tabular}

TABLE 8.6: PRIOR YEAR CLASSIFICATION OF THE "TEST FAILED 11" GROUP (Figures in brackets are percentages of total groups)

For the "test failed 11" group the results appear good with the model classifying 908 of the group as failed up to two years prior to failure, and 1008 in the last year before failure.

8.2.5 Results from the "Test Contimed 70" and "Non-failed 20" Groups Comparison of the mean $\mathrm{z}$-scores for "test continued 70" and "non failed 20" groups for the last three years (1984, 1985 and 1986) gives $8.96,8.56,9.4$ and 9.0, 9.10, 8.59 respectively 1.e. both groups seem related to similar populations thereby indicating successful selection particularly of solvent companies.

Figure 8.1 shows the $\mathrm{z}$-scores of both "test continued 70" and "test failed 11" groups for those prior years. For "test continued 70" group they are constantly above the 'grey area', whereas the "test failed 11" group is generally below the 'grey area', 1.e. a clear indication of the discriminating power of the model. 
The change in the mean $\mathrm{z}$-scores is an indication of the changes in the construction industry from year to year, particularly in the case of the "continued" companies. It was not until 1985-86 that construction compantes experienced a real Improvement in demand while the years 1987, 1988 Improvements were mainly in private housebuilding and private sectors (IOC report) [1]. 
8.2.6 Prior Year Z-Scores Analysis from "Continued 70" and "Nonfailed 20" Groups

The classification results for the "continued 70" group are shown in Table 8.7.

\begin{tabular}{|l|c|r|c|c|}
\hline \multicolumn{1}{|c|}{ Years } & 1984 & 1985 & 1986 & 1987 \\
\hline $\begin{array}{l}\text { "Non-falled" } \\
\text { Falled }\end{array}$ & $\begin{array}{r}29(62) \\
7(15)\end{array}$ & $\begin{array}{r}38(62) \\
8(13)\end{array}$ & $\begin{array}{r}39(60) \\
14(20) \\
14(23)\end{array}$ & $\begin{array}{r}25(66) \\
7(18) \\
6(16\end{array}$ \\
\hline Total: & 47 & 61 & 67 & 38 \\
\hline Average Z-score & 8.96 & 8.56 & 9.4 & 11.56 \\
\hline
\end{tabular}

TABLE 8.7: PRIOR YEARS CLASSIFICATION OF "OONTINUED 70" GROUP (Figures in brackets are percentage of total group)

A comparison of the classification results for both the "non-failed 20" and "continued 70" groups are shown in Tables 7.4 and 8.7. It may be seen that more companies are classified as "non-failed" in the "non-failed 20" group than in the "continued 70" group i.e. sucoess was achieved in selecting particularly solvent companies in setting up the "non failed 20" group.

An attempt to detemine the proportion of companies "at risk" in the population of continued companies requires consideration of the combined population of "non failed 20" and "Test continued 70" groups called the "All 90" group. The classification results for this group are shown in Table 8.8. 


\begin{tabular}{|l|r|r|c|c|}
\hline & 1984 & 1985 & 1986 & 1987 \\
\hline $\begin{array}{l}\text { Non-failed } \\
\text { Failnerable }\end{array}$ & $\begin{array}{r}46(68) \\
10(15) \\
11(17)\end{array}$ & $\begin{array}{r}55(68) \\
9(11)\end{array}$ & $\begin{array}{r}54(62) \\
16(18) \\
17(20)\end{array}$ & $\begin{array}{r}25(66) \\
7(18) \\
6(16)\end{array}$ \\
\hline Total Co: & 67 & 81 & 87 & 38 \\
\hline Average Z-score: & 8.97 & 8.64 & 9.2 & 11.56 \\
\hline
\end{tabular}

TABLE 8.8: PRIOR YEARS CLASSIFICATION OF THE "ALL 90" GROUP (Figures in brackets are percentage of total group)

From these results it can be seen that on average approximately $18 \%$ of the continuing companies in the industry appear to have profiles similar to bankrupts and are therefore "at risk". Further to this on average another $16 \%$ of companies are in a "vulnerable" position.

The proportions of companies in danger, however, changes as the econanic condition of the country changes and in classifying a company it is important to view the company in relation to the performance of the rest of the incustry in the same year.

It can be seen in Figures 8.2 to 8.5 which show the results for the "All-90" group presented the population of construction companies for the years 1984-1987, that the histograms closely resemble the superimposed normal curves. This distribution can provide an indication of the performance of a specific company over the four year period by relating the particular $\mathrm{z}$-Score to the average of all companies in its sector of industry. 


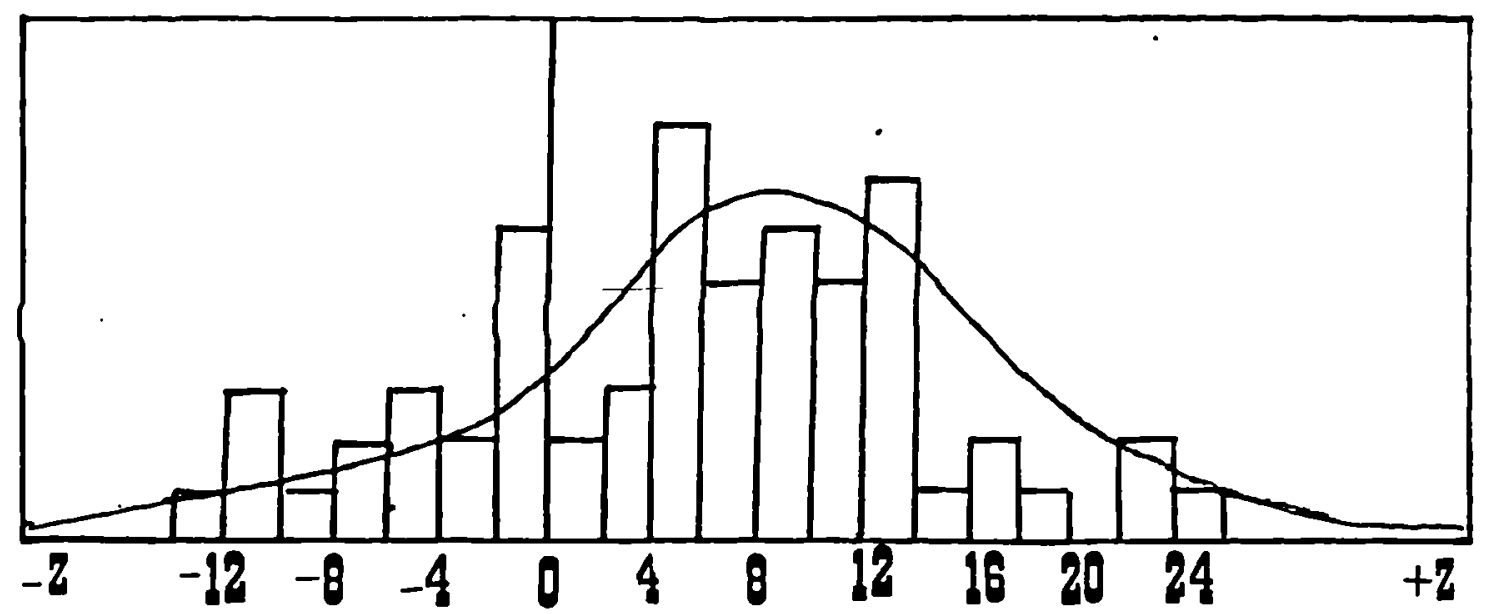

FIGURE 8.2: THE Z-SCORE DISTRIBUTION OF THE "ALL 90" GROUP FOR YEAR 1984 WITH SUPERIMPOSED NORMAL DISTRIBUTION

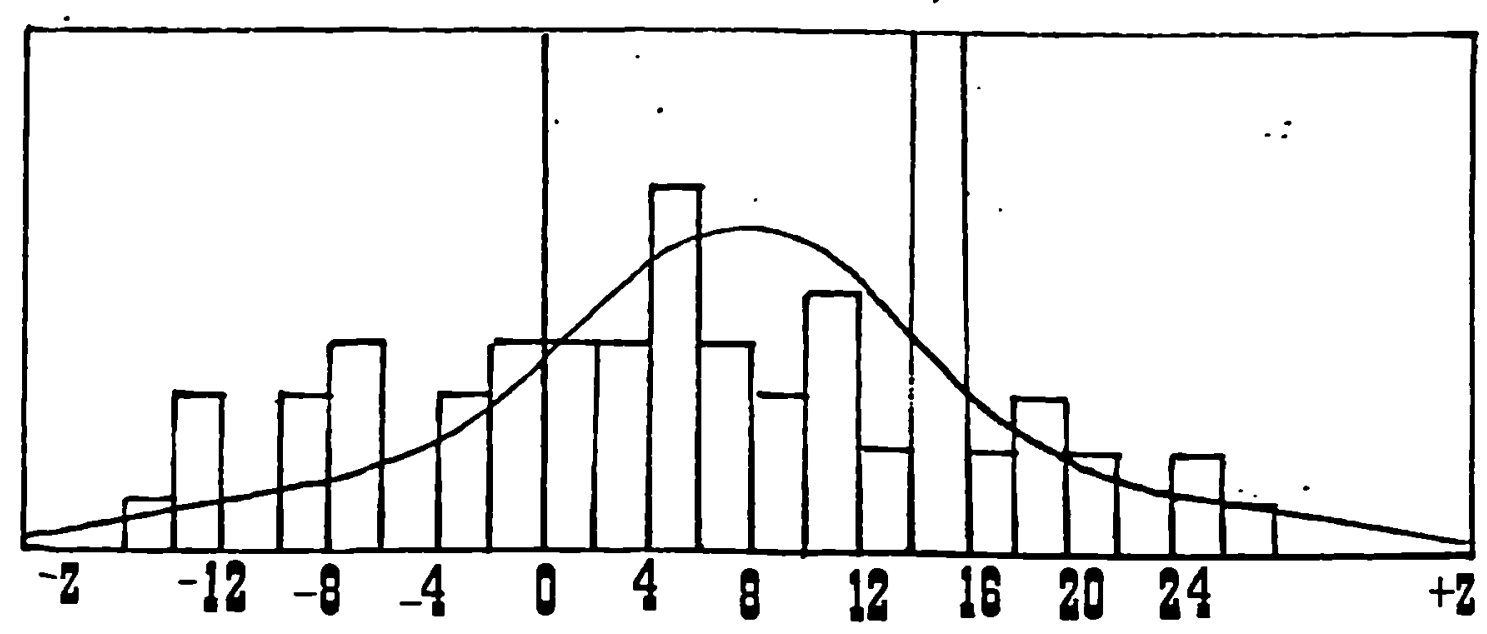

FIGURE 8.3: THE Z-SCORE ḊISTRIBUTION OF THE "ALL 90" GROUP FOR YEAR 1985 WITH SUPERIMPOSED NORMAL DISTRIBUTION 


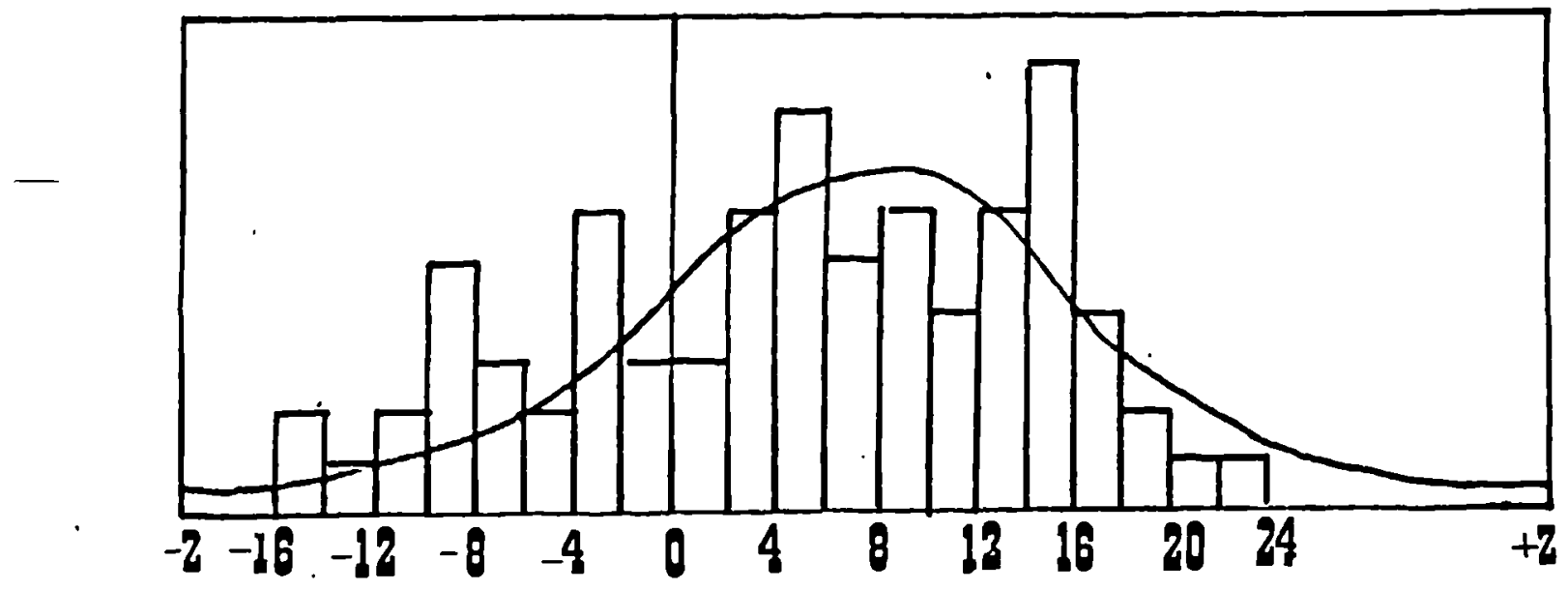

FIGURE 8.4: THE Z-SCORE DISTRIBUTION OF THE "ALL 90" GROUP FOR YEAR 1986 WITH SUPERIMPOSED NORMAL DISTRIBUTION

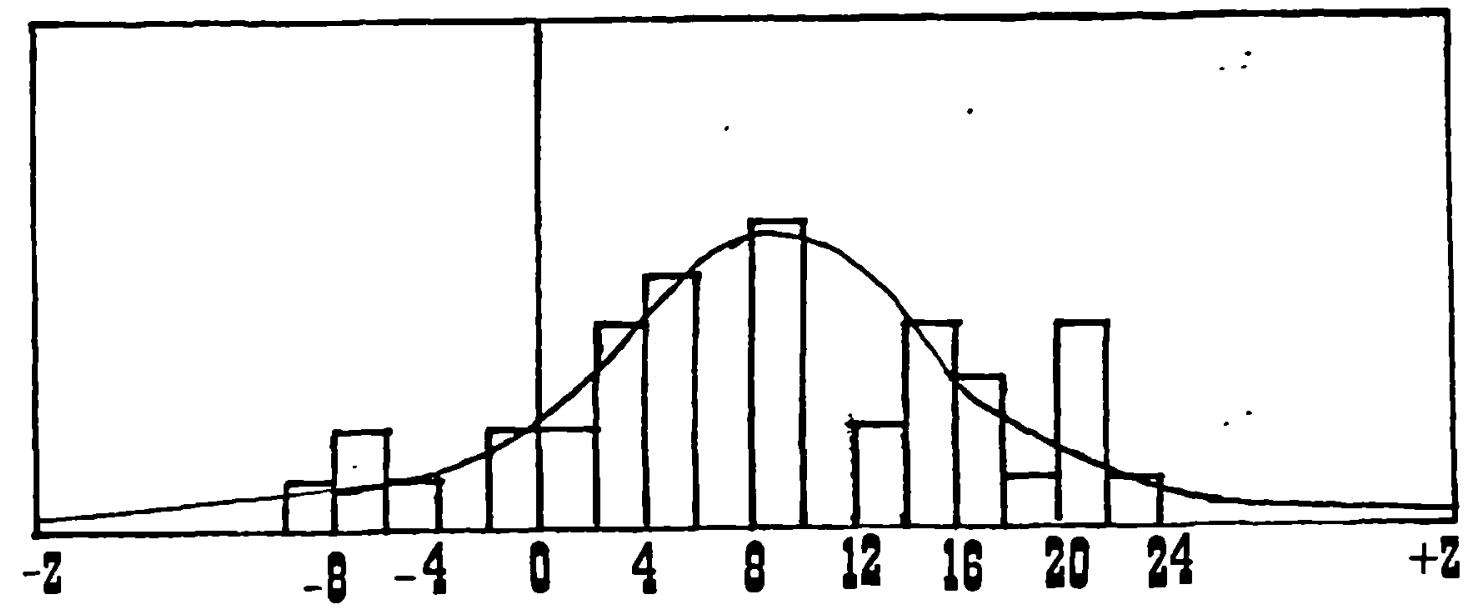

FIGURE 8.5: THE Z-SCORE DISTRIBUTION OF TEH "ALL 90" GROUP FOR YEAR 1987 WITH SUPERIMPOSED NORMAL DISTRIBUTION 
The company's z-Score movement may be judged and its position identified at any specific time, for example figure 8.4 gives a view of the results for the "All 90" group for a particular year, 1986. It can be seen that the histogram closely resembles the superimposed nomal curve. The distribution may be used to give an indication of the performance of a particular company. If the company's Z-score for 1986 is less than the mean for 1986, then its performance is obviously less than average.

\subsubsection{The Relationship Between Bankrupt and z-Score Trend}

Possession of a bankrupt profile is a necessary condition for failure but may be not sufficient if not also associated with a bankrupt trend for the whole industry, as illustrated in Figure (8.6) where the change in the mean Z-Scores provides an indication of movement from year to year.

Clearly for the period concerned it was not until 1985, that construction companies experienced a real improvement in demand as shown, the trend drop after 1985. The years 1986-1987 were it may be noticed best for the private house building and private sectors.

Overall bankrupt trend slightly rose over the years 1983, 1984 and 1985 followed by a fall in years 1986 and 1987. In contrast the mean Z-Scores of industry recuced during 1984 and 1985. Rising sharply thereafter reflecting the improvement in construction industries as shown in Figure 8.7. 


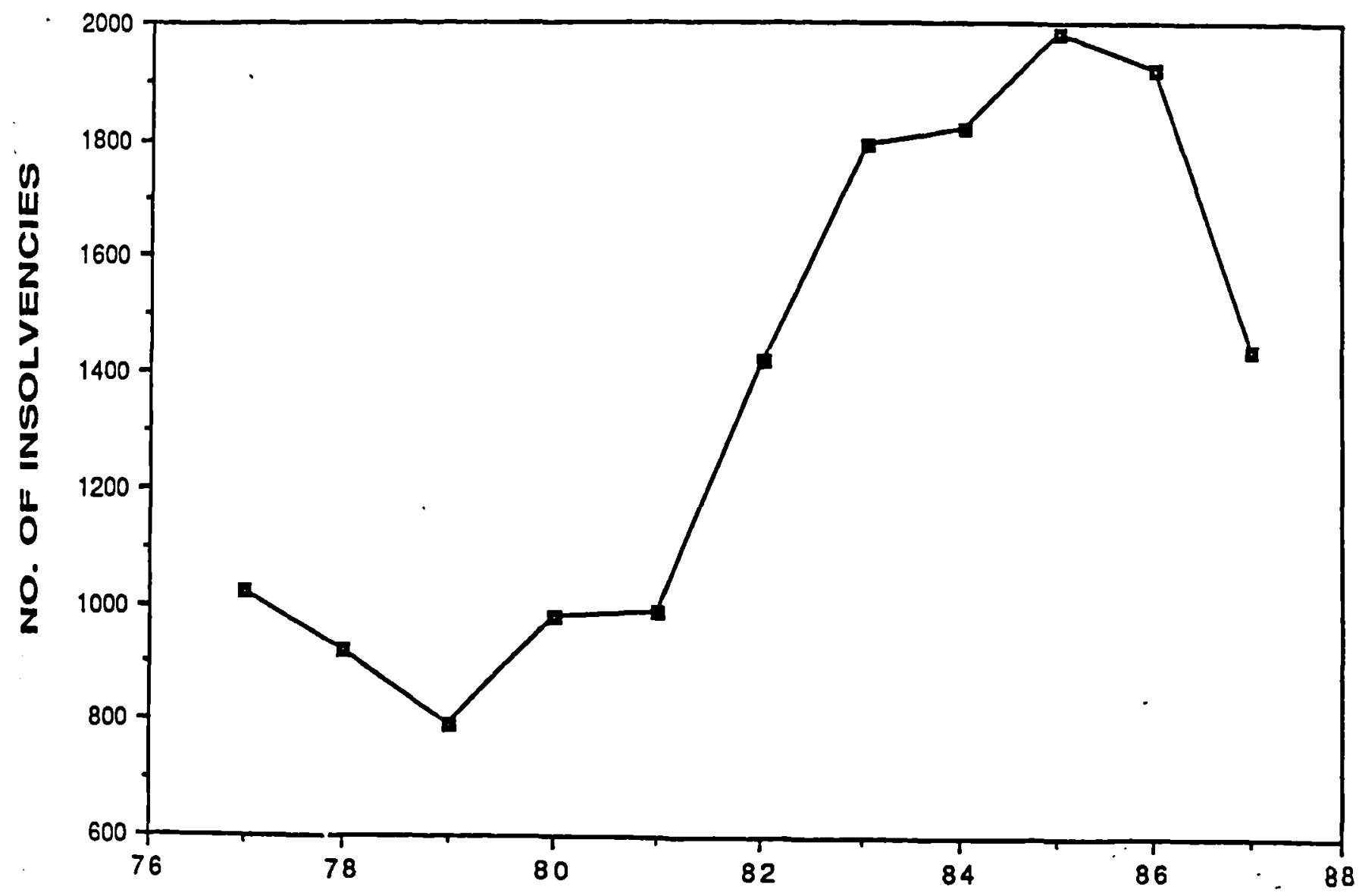

FIGURE 8.6: THE INSOLVENCY TREND IN CONSTRUCTION INDUSTRY

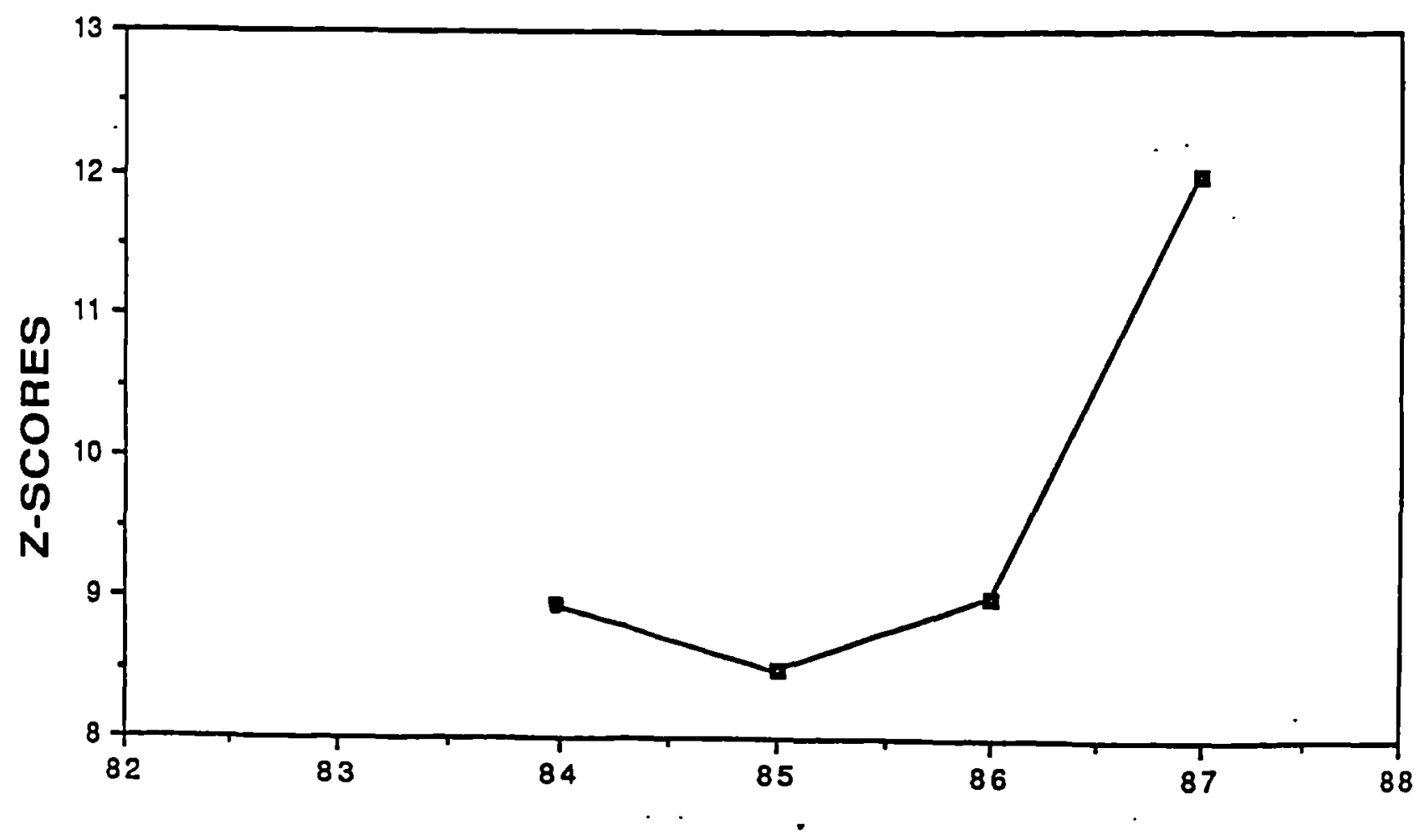

FIGURE 8.7: THE Z-SCORE MEANS TREND IN CONSTRUCTION INDUSTRY REPRESENTED. BY "ALL 90 " GROUP 


\subsubsection{Prediction of Bankruptcy Using the Discriminant Model}

A prediction of fallure is based on the z-soore gained fram the model and it is reasonable to assume that the lower the z-score for a company and the more years the company is classed as "at risk" the more likely that the company is to fail.

Although a "bankrupt" profile is a necessary condition for failure, it is not a sufficient one. Unhealthy firms may be taken over as an alternative to bankruptcy, the govermment may ball them out, or they may simply be able to recover.

Finally, when a company is classed "at risk" the fate of the company depends on the actions of its debenture holders, bankers and creditors. Therefore, z-score alone cannot predict failure but can only provide a financial indicator which gives a quantitative indication of the solvency of companies in the hands of the decision makers.

The model can anly say that a certain company has a profile very similar to a failed company and therefore has a high probability of failure. Therefore, prediction of bankruptcy using the discriminant model is possible, if the probability of a company actually failing when it is classified "at risk" is calculated.

Some indication of risk can be determined statistically by using a Bayesian approach as follows:

$$
P\left(F / C_{f}=\frac{P\left(C_{f} / F\right)}{P\left(C_{f} / F\right)+p\left(C_{f} / N F\right)}\right.
$$




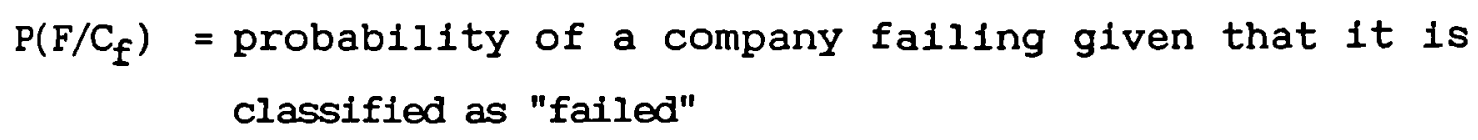

$\mathrm{P}\left(\mathrm{C}_{\mathrm{f}} / \mathrm{NF}\right)=$ probability of a company being classified as "failed" given that it will not fail.

Table 6.5 shows insolvencles in the construction industry during 1986, approximately 38 . Tables 7.5 and 8.6 show that approximately 1008 of failed companies were classified as "failed" in their last year.

Fram this information we can say that:

$$
P\left(C_{f} / F\right)=1008 \times .03=.03
$$

The denominator of equation

$$
p\left(C_{f} / F\right)+p\left(C_{f} / N F\right)
$$

can be approximated by taking the percentage of companies in the "all 90" group that are classified as "failed". From Table 8.8 we can see that it is 208 for 1986. Thus the probability of a company, classified "at risk" actually failing, can be calculated as:

$$
P\left(F / C_{f}\right)=\frac{0.03}{0.20}=158
$$


Therefore, statistically there is a a high probability that about $15 \%$ of these fims, classified as "at risk" will actually fail in 1987.

A list of companies classified as "failed" in 1986 is as follows:

1. Bellway Builders Ltd

2. Bryant Construction Ltd

3. Danbury Construction 1td

4. R J McLeod Contractors.

5. Shepherd Building Group.

6. Whittaker Builders Ltd.

7. Robert M Douglas plc.

8. Baboock Construction Ltd.

9. Balfour Beatty Ltd.

10. Boomer and Kirkland Ltd.

11. J M Jones and Sons.

12. G Percy Tretham Ltd.

13. Trollope and Colls Construction Ltd.

14. Consolidated Tern Investments.

15. Henry Boot and Sans.

16. Rush and Tomkins Group plc.

17. Charles Davies Ltd.

We expected 15\% of these companies to fail in 1987:

$17 \times 0.15=2$ companies

The probabilities tell us that two companies will fail in 1987. 
Our study successfully achieved its goal in which the following companies having been predicted as failed companies in 1986 actually falled the following year:

1. Charles Davies Ltd.

Liquidation Voluntary on 20 November 1987.

2. Whittaker Builders Ltd.

Dissolved an 1 September 1987.

Moreover, those "at risk" companies that do not fail in 1987 will not necessarily recover for example J M Jones and Sons Ltd and Rush and Tomkins plc failed in 1989 and 1990 respectively.

It has been shown that failing oompanies exhibit negative z-scores for several years prior to failure, so a single year z-score is not sufficient for prediction failure. Therefore, the individual z-scores serve to rank the companies in terms of their solvency. The lower the Z-score the more likely a company is to fail.

Thus in conclusion a Z-score alone is insufficient evidence for failure prediction and further financial analysis for companies exhibiting "at risk" $\mathrm{z}$-scores will be necessary to reinforce the prediction. 
8.3 VALIDATION OF AN ALTERNATIVE MULTIPLE RECRESSION MODET

\subsubsection{Introduction}

This section includes validation of an alternative model using the independent data described in Section 8.2 and also including the previous groupings as follows:

- "Test falled 11" group

- $\quad$ "All failed 22" group

- $\quad$ "Test continued 70" group

- $\quad$ "All continued 90" group

Part of the validation process was undertaken in cooperation with the London Borough of Camden. The final section briefly sumarises the validation of the alternative model.

\subsubsection{Results fran the "Test Failed 11" and "Contimued 70" Groups} The results obtained from the independent data for "Test failed 11" and "Continued 70" groups as shown in Tables 8.9 and 8.10 and taking into account the 'grey area' limits -1.6 , are shown in Table 8.11:

\begin{tabular}{|l|c|c|c|}
\hline Companies & -3 & -2 & $\begin{array}{c}\text { Last } \\
\text { Year }\end{array}$ \\
\hline 1 A.C. and K. Builders Ltd & -32.0 & -32.0 & -35.0 \\
2 Allied Construction Ltd & -8.5 & -5.7 & -4.7 \\
3 Bowmate Construction Ltd & +8.0 & -2.4 & -2.6 \\
4 Bright Brook Builders Ltd & -15.0 & -11.5 & -6.4 \\
5 Comber Construction Ltd & +6.7 & -0.22 & -6.38 \\
6 Pevland Construction Ltd & - & - & -3.85 \\
7 Sphinx Building Const Ltd & -14.8 & -7.36 & -7.8 \\
8 Staines Construction Ltd & -13.6 & -9.3 & -10.2 \\
9 Stevens \& Sons Build Ltd & +4.8 & 0.2 & -2.85 \\
10 Stott Mills Build Ltd & -38.0 & -62.0 & -46.0 \\
11 Stream Star Const Ltd & +4.3 & +4.64 & -32.0 \\
\hline & & & \\
\hline Averages: & -9.8 & -12.6 & -14.0 \\
\hline
\end{tabular}

TABLE 8.9: RESULTS OBTAINED FROM THE "TEST FAILED 11" GROUP BY USING MULTIPLE REGRESSION MODEL 


\begin{tabular}{|c|c|c|c|c|}
\hline Companies & 1984 & 1985 & 1986 & 1987 \\
\hline $\begin{array}{l}\text { Charles Davis Ltd } \\
\text { Bellway Builders Ltd } \\
\text { Bryant Const Ltd } \\
\text { Bovis Const Ltd } \\
\text { Charnood Const Ltd } \\
\text { Daltan Const Itd } \\
\text { Danbury Const Ltd } \\
\text { Davoo Const Ltd } \\
\text { Gargan Const Ltd } \\
\text { Tarmac Homes Midland } \\
\text { Tarrock Const Ltd } \\
\text { Tarmac Const Ltd } \\
\text { CBI Const Ltd } \\
\text { Charles Gray Blds } \\
\text { Haymills Holds Ltd } \\
\text { Ogilvie Holds Ltd } \\
\text { Eve Const plc } \\
\text { Alfred McAlpine Con } \\
\text { R J McLeod Cont } \\
\text { Shepherd Bldg Group } \\
\text { Reema Const Ltd } \\
\text { Andrew Scott (Civ) } \\
\text { Simons Const Ltd } \\
\text { Whittaker Builders Ltd } \\
\text { Amec plc } \\
\text { Amoo Indus Hold plc } \\
\text { Rush \& Tompkins plc } \\
\text { Costain Group plc } \\
\text { Robert M Douglas plc } \\
\text { Galliford plc } \\
\text { Higgs \& Hill plc } \\
\text { Johnston Group plc } \\
\text { John Laing plc } \\
\text { Walter Lawrence plc } \\
\text { F J C Lilley plc } \\
\text { Y J Lovell Hold plc } \\
\text { John Mowlem \& Co } \\
\text { Sunley Hold plc } \\
\text { John E Wiltshire plc } \\
\text { Baboock Cont Ltd } \\
\text { Balfour Beatty Ltd } \\
\text { Peter Birse Hold } \\
\text { Bowmer \& Kirkland Ltd } \\
\text { A F Budge Cont Ltd } \\
\text { Cementation Const Ltd }\end{array}$ & $\begin{array}{c}- \\
-2.29 \\
-5.8 \\
11.8 \\
-10.0 \\
-18.7 \\
-2.5 \\
- \\
- \\
-4.9 \\
- \\
0.35 \\
5.6 \\
-0.19 \\
- \\
-7.1 \\
- \\
- \\
- \\
- \\
3.2 \\
4.7 \\
2.75 \\
1.7 \\
- \\
-0.42 \\
- \\
-2.97 \\
- \\
2.4 \\
1.27 \\
2.7 \\
0.02 \\
2.8 \\
- \\
4.18 \\
3.9 \\
-11.0 \\
1.3 \\
-1.0 \\
-1.28 \\
-0.37 \\
2.06 \\
2.75 \\
-0.9\end{array}$ & $\begin{array}{c}- \\
-3.4 \\
-7.8 \\
9.65 \\
-11.9 \\
9.9 \\
3.78 \\
5.57 \\
4.64 \\
-1.76 \\
0.055 \\
1.41 \\
-1.8 \\
-3.76 \\
2.02 \\
-8.7 \\
- \\
5.92 \\
1.16 \\
0.79 \\
0.71 \\
-3.9 \\
0.7 \\
-0.76 \\
1.65 \\
3.4 \\
-2.12 \\
2.4 \\
-0.4 \\
1.85 \\
1.56 \\
2.68 \\
0.137 \\
8.4 \\
0.37 \\
-0.13 \\
9.07 \\
-16.0 \\
-4.8 \\
-1.7 \\
-2.3 \\
1.87 \\
-3.8 \\
2.45 \\
-3.5\end{array}$ & $\begin{array}{c}-4.7 \\
-6.6 \\
-2.43 \\
18.0 \\
2.8 \\
-7.0 \\
1.75 \\
1.08 \\
1.0 \\
-2.74 \\
0.47 \\
1.58 \\
-3.3 \\
2.45 \\
2.03 \\
- \\
- \\
-0.36 \\
-0.5 \\
0.43 \\
1.18 \\
12.4 \\
4.2 \\
3.4 \\
1.54 \\
-3.7 \\
-1.25 \\
2.57 \\
0.42 \\
1.36 \\
2.15 \\
3.3 \\
-0.02 \\
-0.30 \\
0.8 \\
0.9 \\
1.13 \\
0.14 \\
7.3 \\
-1.0 \\
-1.9 \\
3.13 \\
2.75 \\
3.4 \\
-0.75\end{array}$ & $\begin{array}{c}- \\
-4.66 \\
-2.35 \\
4.56 \\
5.7 \\
- \\
-2.8 \\
-1.0 \\
3.94 \\
-1.87 \\
+0.38 \\
3.02 \\
19.8 \\
- \\
2.34 \\
3.8 \\
+0.28 \\
+0.92 \\
+0.34 \\
-1.5 \\
1.17 \\
-5.5 \\
-2.3 \\
-1.67 \\
2.08 \\
- \\
0.14 \\
0 \\
1.87 \\
1.14 \\
10 \\
\end{array}$ \\
\hline
\end{tabular}

To be continued 


\begin{tabular}{|c|c|c|c|c|}
\hline Companies & 1984 & 1985 & 1986 & 1987 \\
\hline $\begin{array}{l}\text { Croudace Hold Ltd } \\
\text { Hollandsche Beton } \\
\text { J M Jones \& Sons } \\
\text { Kyle Stewart Ltd } \\
\text { James Longley \& Co } \\
\text { R Mansell Ltd } \\
\text { May Gurney Holds Ltd } \\
\text { The Miller Group Ltd } \\
\text { Norwest Holst Ltd } \\
\text { Seddon Group Ltd } \\
\text { G Percy Tretham Ltd } \\
\text { Trollope \& Colls Const } \\
\text { Wates Const Ltd } \\
\text { Willett Ltd } \\
\text { Willmott Dixon Holds } \\
\text { City of Aberdeen Ltd } \\
\text { Conder Group plc } \\
\text { Cansolidated Tern Inv Ltd } \\
\text { Denoora plc } \\
\text { Dean \& Bowes Group } \\
\text { Dunton Group plc } \\
\text { Exeter Bdg \& Const Ltd } \\
\text { London \& Clyde Hold Ltd } \\
\text { McLaughlin \& Harvey Ltd } \\
\text { Gilbert House Invest } \\
\text { John Elliott plc }\end{array}$ & $\begin{array}{c}2.5 \\
-8.5 \\
- \\
1.6 \\
-0.86 \\
- \\
-0.54 \\
- \\
4.16 \\
0.95 \\
-1.02 \\
-3.3 \\
-0.46 \\
- \\
-0.144 \\
-6.11 \\
2.34 \\
1.4 \\
- \\
4.0 \\
-2.2 \\
1.924 \\
1.15 \\
-2.27 \\
-\end{array}$ & $\begin{array}{l}1.6 \\
- \\
0.9 \\
-0.27 \\
\\
1.79 \\
1.77 \\
-0.96 \\
-2.48 \\
1.082 \\
0.538 \\
-0.104 \\
-2.05 \\
-4.4 \\
-0.6 \\
0.57 \\
-8.87 \\
-4.25 \\
-4.8 \\
8.9 \\
3.27 \\
- \\
-0.47 \\
0.60 \\
1.44 \\
-0.553\end{array}$ & $\begin{array}{l}2.23 \\
-4.7 \\
-5.9 \\
-0.467 \\
\\
2.09 \\
-0.57 \\
-0.25 \\
-1.25 \\
3.36 \\
0.096 \\
-2.32 \\
-1.53 \\
-0.34 \\
-1.67 \\
0.616 \\
-1.867 \\
-15.8 \\
-1.02 \\
7.23 \\
1.928 \\
- \\
-0.346 \\
0.28 \\
-6.5 \\
0.58\end{array}$ & $\begin{array}{c}- \\
- \\
-7.2 \\
4.2 \\
1.844 \\
3.45 \\
-0.26 \\
-0.81 \\
- \\
- \\
-1.84 \\
- \\
-1.0 \\
-0.864 \\
- \\
-2.4 \\
- \\
1.47 \\
- \\
3.4 \\
- \\
- \\
- \\
- \\
0.54\end{array}$ \\
\hline
\end{tabular}

TABLE 8.10: RESULTS OBTAINED FROM THE "CONTINUED 70" GROUP BY USING MULTIPLE REGRESSION MODEL (2) 


\begin{tabular}{|l|c|c|c|}
\hline \multirow{2}{*}{ Groups } & \multicolumn{3}{|c|}{ Classified as } \\
\cline { 2 - 4 } & Failed & Vulnerable & Non-failed \\
\hline $\begin{array}{l}\text { "Test Failed 11" } \\
\text { Group } \\
\text { "Test Continued 70" } \\
\text { Group }\end{array}$ & $11(100)$ & - & - \\
\hline
\end{tabular}

TABLE 8.11: CLASSIFICATION OF THE "TEST FAILED 11" GROUP AND "TEST CONTINUED 70" GROUPS

It can be seen that 1008 of firms are correctly classified as failed with $57 \%$ classified as non-failed and $23 \%$ classified as vulnerable. These results are clearly not as accurate as the model described previously.

Twenty per cent of the "Test continued 70" group are classified as failed compared to $13 \%$ in the previous model, reflecting the sensitivity of the model which classified 238 of "Tests cantinued 70" group as vulnerable. In other words these results reflect the inherent risk of the construction industry.

\subsubsection{Result from the "Test Failed 11" and "All failed 22" Groups} The classification results for the year prior to failure for the "Test failed 11" and "All failed 22" groups are shown in Tables 8.12 and 8.13. 


\begin{tabular}{|c|c|c|}
\hline \multicolumn{3}{|c|}{ Classified as } \\
\hline Non-failed & Vulnerable & Failed \\
\hline- & - & $11(100)$ \\
\hline & Total in Group $=11$ \\
\hline
\end{tabular}

TABLE 8.12: CLASSIFICATION OF THE "TEST FAILED 11" GROP

\begin{tabular}{|c|c|c|}
\hline \multicolumn{3}{|c|}{ Classified as } \\
\hline Non-failed & Vulnerable & Failed \\
\hline- & - & $22(100)$ \\
\hline & Total in Group $=22$ \\
\hline
\end{tabular}

TABLE 8.13: CLASSIFICATION OF THE "ALL FAILED 22" GROP

The model classified 100\% of both "Test failed 11" and "All failed 22" groups as failed for the year prior to failure, i.e. as good as previously indicating that both models classified the falled companies correctly in spite of differences of sensitivity. 
8.3.4 Prior Year z-Score Analysis from "Test Failed 11" Group The results for the "Test failed 11" group are shown in Table 8.14.

\begin{tabular}{|l|c|c|c|}
\hline \multirow{2}{*}{ Classlfied as } & \multicolumn{3}{|c|}{ Acoounting year prior to company failure } \\
\cline { 2 - 4 } & -3 & -2 & Last year \\
\hline $\begin{array}{l}\text { Non-failed" } \\
\text { Vulnerable } \\
\text { Falled }\end{array}$ & $4(36)$ & $2(18)$ & - \\
$-\overline{(64)}$ & $7(72)$ & $8(100)$ \\
\hline
\end{tabular}

TABLE 8.14: PRIOR YEAR CLASSIFICATION OF THE "TEST FAILED 11" GROPP

The model classified 648 of the group as failed up to three years prior to failure, and 728 up to two years, i.e. as good as the results of the previous model.

8.3.5 Results from the "Test Contimed 70" and "Nan-Failed 20" Groups By comparing the results of $z$-scores for companies classified as falled between the discriminant model and the regression model using the same data of "Test continued 70" and "Non-failed 20" groups, both models appear to classify similarly, i.e. 17 companies are classified as falled by the discriminant model, while the regression model classified 10 out of 17 as failed with the remaining 7 companies classified as vulnerable in 1986 as shown in Table 8.8. Clearly this test is useful in that both models are measuring the same aspect but at a different scale. 
The following companies were classified as failed in 1986 in both models:

- Bellway Builders Ltd

- Bryant Construction Ltd

- Danbury Construction Ltd

- Whittaker Bullders Ltd

- Balfour Beatty Ltd

- J M Jones and Sons Ltd

- Trollope and Colls Construction Itd

- Consolidated Tern Investments Ltd

- Henry Boot and Sons plc

- Rush and Tamkins Groups plc

8.3.6 Prior Year Z-score Analysis from "Continued 70" and "Non-failed 20" Groups by the Multiple Regression Model

The classification results for the "Continued 70" and "Non-failed 20" groups both called the "All 90" group are shown in Table 8.15:

\begin{tabular}{|l|c|c|c|c|}
\hline Classified as & 1984 & 1985 & 1986 & 1987 \\
\hline $\begin{array}{l}\text { Non-failed } \\
\text { Vulnerable } \\
\text { Failed }\end{array}$ & $\begin{array}{l}47(66) \\
10(14)\end{array}$ & $\begin{array}{l}54(63) \\
14(12)\end{array}$ & $\begin{array}{c}55(64) \\
15(17)\end{array}$ & $\begin{array}{c}26(53) \\
13(27) \\
10(20)\end{array}$ \\
\hline Total Co: & 71 & 86 & 86 & 49 \\
\hline
\end{tabular}

TABLE 8.15: PRIOR YEARS CLASSIFICATION OF THE "ALL 90" GROUP BY USING MULTIPLE REGRESSION MODEL 
From these results we can conclude that the average of the continued companies in the industry which have profiles similar to bankrupts in both models, are approximately the same as $18 \%$ for the last four years, see Table 8.8 .

This is a real test of both models. They classify similarly the failed companies but they differ in classifying the non-failed and vulnerable companies. Also we can conclude that the regression model classifled companies as vulnerable substantially larger than the developed model, therefore it has less discriminating power than the developed model in spite of its classification of the failed company, better than the developed model.

\subsubsection{Validation of Multiple Regression Model at London Borough of} Camden

It was decided to test the multiple regression second version model the Landan Borough of Camden for three reasans:

- Firstly the true predictability of the model is in practice

- Secondly, the model is simple and contains five discriminating varlables measuring five different aspects of company structure.

- Thirdly the model classified the failed companies (privately owned companies) better than the developed model. The model classified 648 of the failed companies as failed up to three years before failure, while the developed model classified $40 \%$ for the same period.

The discriminant model was originally developed for medium size to large campanies, while the multiple regression second version was presumed better for private companies because of its emphasis on the income gearing ratio, which is indeed an indicator of financial weakness in small companies. 
Practically, the practitioner needs to know who is at risk. The model has been applied on 200 construction companies dealing with the London Borough of Camden. By taking the classification boundary -1.6 as threshold, the results showed that the discriminating power of the model was better than Altman's model which was mainly developed for manufacturing companies.

Although the model is the second model developed in Britain after Mason's model for the construction industry during the past decade, it proves its operational use as a tool in vetting construction compantes on tender lists. Whatever the success the model has achieved, the model should however nover be used as the sole decision tool. The experts are aware of the potential dangers of relying exclusively upan the results of a single test (see letter from Landon Borough of Camden in Appendix D). The aims of this report have been matched to the experts approach of company fallure by using different tools to approaching fallure.

\subsection{VALIDATION OF FINANCIAL RATIOS AS A TOOL FOR PREDICTING FAIIURE}

\subsubsection{Introduction}

This section includes validation of the following financial ratios as a tool to predict company failure which are researched in Section 7.6:

- Qurrent assets/current liabilities ratio

- Net assets/current liabilities ratio

- Pre-tax profit/interest ratio.

Also this section includes a validation link between the z-soore and these financial ratios as a tool for predicting failure, by dividing the "All quoted 90" group into two groups: 
Group 1 includes 73 companies which are classified as none failed in 1986 by both z-score models.

Group 2 includes 17 companies which are classifled as failed and vulnerable in 1986 by the same Z-score models. A comparisan of the financial ratios in both groups provides us with a link between zscore and these ratios, to enhance the predictability for both Z-modes and these ratios.

\subsubsection{Results from the "Test Failed 11" Group}

The results obtained from the "Test failed 11" group for the last three years before fallure are shown in Table 8.16.

\begin{tabular}{|l|l|l|l|l|l|c|}
\hline \multirow{2}{*}{ Test Failed Companies } & \multicolumn{2}{|c|}{ CA/CL } & \multicolumn{2}{c|}{ NA/CI } & \multicolumn{2}{c|}{ EBIT/INT } \\
\cline { 2 - 7 } & -2 & -1 & -2 & -1 & -2 & -1 \\
\hline & & & & & & \\
1 A.C. \& K. Builders Ltd & .51 & 0.01 & -.15 & 1.0 & 2.2 & 1.06 \\
2 Allied Construction Ltd & 1.38 & 3.05 & 0.41 & 2.03 & 1.7 & 0 \\
3 Bowmate Constructio Ltd & 1.08 & 1.015 & 0.33 & 0.17 & 0 & 0 \\
4 Bright Brook Build. Ltd & 1.0 & 0.93 & 1.0 & 1.0 & 0.28 & 0.37 \\
5 Comber Construction Ltd & 0.63 & 0.81 & 0.207 & 0.23 & 0.5 & 1.06 \\
6 Pevland Construction Ltd & - & 0.84 & - & 0.028 & - & 1.36 \\
7 Sphinx Builders Ltd & 0.66 & 0.11 & 0.15 & 0.77 & 0 & 0 \\
8 Staines Construction Ltd & 0.66 & 0.73 & 0.33 & 0.65 & 0 & 0 \\
9 Steven \& Sons Build Ltd & 3.1 & 3.5 & 2.2 & 2.59 & 0 & 0 \\
10 Stott Mills Build Ltd & 0.6 & 0.45 & 0.02 & 0.29 & 0 & 0 \\
11 Stream Star Constr Ltd & 1.48 & 0.68 & 1.04 & 0.04 & 0 & 0 \\
& & & & & & \\
\hline
\end{tabular}

TABLE 8.16: THE RESULTS OF DISCRIMINATING RATIOS OBTAINED FROM THE "TEST FAILED 11" GROUP IN UNIVARIATE ANALYSIS

Note: The year indicates years before failure: $\mathrm{CA} / \mathrm{CT}$ - current assets/current liabilities NA/CL - net assets/current liabilities EBIT/INI - eamings before interest and tax/interest 
The results show that the current ratio i.e. the ratio of current assets to current llabilities for the "Test failed 11" companies are worse than those in the "Failed 11" companies in Section 7.7, where 8 out of 11 group has a current ratio < 1.0, while the "failed 11" group, 4 out of 11 group has a ratio less than 1.0. Relatively the ratio is less than 1.5 which is worrying on the grounds of liquidity, and therefore it was decided to reduce the value of this ratio to 1.0 as an ultimate test of company solvency.

Also the results show that the ratios of net assets to current liabilities for the "Test falled 11" group are worse than those in the "Failed 11" group in Section 7.7. Eight out of 11 have a ratio of <1.0 for the last three years before failure, while 7 out of 11 of the "Failed 11" group have a ratio less than unity.

Also closer scrutiny of the results of the "Test failed 11" group with the "Failed 11" group in Section 7.7 reveals that the "Test failed 11" group had a gearing ratio worse than those in the "Fafled 11" group, whereas all the "Test failed 11" companies the ratio was less than 2.0. In the "Failed 11" group 9 out of 11 had a ratio of less than 2.0. Thus suggesting that any company resembling failure probably has at least two ratios below a specific limit, for example, Bright Brock Builders Itd has a ratio net asset/current liabilities > 1, but its current assets/current liabilities $<1$ and pre-tax profit/interest $<2$.

Similarly Bowmate Construction Ltd has current assets/current liabilities > 1.0, but its net assets/current liabilities <1 and pretax profits/interest $<2$. 
The remaining companies in the "Test failed 11" group had the three critical ratios below the specific limit in this study. The "Test falled 11" group with "Failed 11" group are now combined to form a new group called the "All falled 22" group, with results as follows:

The current ratio for the "All failed 22" group shows that 17 out of 22 of the group is less than unity. Also the net assets to current liability ratio for the "All failed 22" group in 15 out of 22 of the group is less than unity, 1.e. percentages of misclassification are $23 \%$ and 328 respectively in this group.

Furthermore the pre-tax to interest ratio for the "All failed 22" group in 20 out of 22 of the group is less than 2.0, i.e. percentage of misclassification is 98 . Indeed 2 out of 22 of the group had two ratios above the specific limits while the remaining group had all the three ratios below the specific limit.

By comparing the above results with results obtained from the "nonfailed 20" group (see section 7.4), they show that ane out of 20 of the group is less than unity. Also the net assets to current liability ratios for the "non-failed 20" group, 5 out of 20 of the group, is less than unity, 1.e. percentages of misclassification are 58 and $25 \%$ respectively. Furthermore, the pretax profit to interest ratio for the "non-failed 20" group, 4 out of 20 of the group is less than 2.0, 1.e. percentage of misclassification is 20\%. Nevertheless 3 out of 20 of the group had two ratios below the specific limits. The ratio with the smallest error of misclassification and therefore the best single predictor was current assets/current liabilities followed by inoame gearing ratio and net assets/current liabilities ratio. This was done mainly on the basis of the dichotamous classification technique [see Beaver (3)]. 
The dichotomous classification technique predicts the likelihood of bankruptcy through the use of a given financial ratio only.

The firms are arbitrarily divided into two groups and arranged (for each ratio) in. ascending order. An optimal artoff point is chosen through trial and error as the demarcation line for falling 1.e. any firm below it being categorised as a failed firm. The results are then compared with actual data to find the percentage of incorrect predictions. Often many trial times are repeated before the optimal cut-off point is reached.

8.4.3 Validation of the $\mathrm{z}$-Score Iinked with Discriminating Financial Ratios as Predictors

It was decided to validate the discriminating financial ratios linked with the Z-score for two reasons. Firstly, there may be a company that does not respond to z-score models and gives freak results. Secondly, the experts warn of relying exclusively upan the results of a single test.

The results of critical financlal ratios for companies classified as non-failed by both Z-models group (1), and companies classified as failed or vulnerable by both $\mathrm{z}$-models group (2) are shown in Tables 8.17 and 8.18. 


\begin{tabular}{|c|c|c|c|c|c|c|}
\hline \multirow{2}{*}{ Companies } & \multicolumn{2}{|c|}{$C A / C L$} & \multicolumn{2}{|c|}{$\mathrm{NA} / \mathrm{CL}$} & \multicolumn{2}{|c|}{ EBIT/INT } \\
\hline & -2 & -1 & -2 & -1 & -2 & -1 \\
\hline $\begin{array}{l}1 \text { Baboock Const Ltd } \\
2 \text { Balfour Beatty Ltd } \\
3 \text { Benbailly Const Ltd } \\
4 \text { Bowmer \& Kirkland Ltd } \\
5 \text { Bryant Const Ltd } \\
6 \text { Consolidated Tern Inv } \\
7 \text { Danbury Constr Ltd } \\
8 \text { J.M. Janes \& Sons Ltd } \\
9 \text { Henry Boot \& Sans Ltd } \\
10 \text { G. Percy Tretham Ltd } \\
11 \text { R.G. MaLeod Cont Ltd } \\
12 \text { Rush \& Tomkins plc } \\
13 \text { Robert M. Douglas plc } \\
14 \text { Shepherd Build Group } \\
15 \text { Trollope \& Colls Con } \\
16 \text { Whittaker Build Ltd } \\
17 \text { Bellway Const Ltd }\end{array}$ & $\begin{array}{l}0.83 \\
1.8 \\
1.6 \\
1.2 \\
0.72 \\
0.97 \\
0.96 \\
0.7 \\
0.9 \\
1.14 \\
1.4 \\
1.16 \\
1.04 \\
1.8 \\
1.9 \\
1.33 \\
0.52\end{array}$ & $\begin{array}{l}0.83 \\
1.1 \\
1.6 \\
1.1 \\
0.63 \\
0.78 \\
0.81 \\
0.96 \\
0.95 \\
1.1 \\
1.33 \\
1.01 \\
0.99 \\
1.8 \\
1.7 \\
1.35 \\
0.5\end{array}$ & $\begin{array}{l}0.27 \\
0.3 \\
0.97 \\
0.7 \\
0.43 \\
0.38 \\
0.83 \\
0.28 \\
0.46 \\
0.89 \\
1.0 \\
1.48 \\
0.66 \\
1.7 \\
0.91 \\
0.6 \\
0.54\end{array}$ & $\begin{array}{l}0.3 \\
0.3 \\
0.99 \\
0.45 \\
0.67 \\
0.08 \\
0.82 \\
0.22 \\
0.42 \\
0.69 \\
0.98 \\
0.81 \\
0.73 \\
1.8 \\
0.73 \\
0.52 \\
0.71\end{array}$ & \begin{tabular}{|c}
3.6 \\
10.0 \\
0.71 \\
27.0 \\
3.17 \\
0.3 \\
2.0 \\
5.6 \\
5.0 \\
2.3 \\
11.0 \\
1.17 \\
3.0 \\
8.4 \\
2.0 \\
15.0 \\
1.8
\end{tabular} & $\begin{array}{c}10.0 \\
8.0 \\
0.58 \\
6.0 \\
2.7 \\
0.4 \\
2.0 \\
3.7 \\
1.12 \\
2.8 \\
10.0 \\
0.88 \\
6.4 \\
13.0 \\
2.0 \\
16.0 \\
1.16\end{array}$ \\
\hline
\end{tabular}

TABLE 8.17: THE RESULTS OF DISCRIMINATING RATIOS OBTAINED FROM THE "CLASSIFIED FAILED 17" GROUP 


\begin{tabular}{|c|c|c|c|c|c|c|}
\hline \multirow[b]{2}{*}{ Compantes } & \multicolumn{2}{|c|}{ QA/CL } & \multicolumn{2}{|c|}{$\mathrm{NA} / \mathrm{CL}$} & \multicolumn{2}{|c|}{ EBIT/INT } \\
\hline & -2 & -1 & -2 & -1 & -2 & -1 \\
\hline $\begin{array}{l}\text { Bovis Const Ltd } \\
\text { Charmwood Const Ltd } \\
\text { Dalton Const Ltd } \\
\text { Davoo Const Ltd } \\
\text { Gargan Const Ltd } \\
\text { Tammac Homes Midland } \\
\text { Tarrock Const Ltd } \\
\text { Tamac Const Ltd } \\
\text { CBI Const Ltd } \\
\text { Charles Gray Blds } \\
\text { Haymills Holds Ltd } \\
\text { Ogilvie Holds Ltd } \\
\text { Eve Const plc } \\
\text { Alfred McAlpine Con } \\
\text { Reema Const Ltd } \\
\text { Andrew Soott (Civ) } \\
\text { Simons Const Ltd } \\
\text { Amec plc } \\
\text { Amec Indus Hold plc } \\
\text { Costain Group plc } \\
\text { Galliford plC } \\
\text { Higgs \& Hill plc } \\
\text { Johnston Group plc } \\
\text { John Laing plc } \\
\text { Walter Lawrence plc } \\
\text { F J C Lilley plc } \\
\text { y J Lovell Hold plc } \\
\text { John Mowlem \& Co } \\
\text { Sunley Hold plc } \\
\text { John E Wiltshire plc } \\
\text { Peter Birse Hold } \\
\text { A F Budge Cont Ltd } \\
\text { Cementation Const Ltd } \\
\text { Croudace Hold Ltd } \\
\text { Hollandsche Betan } \\
\text { Kyle Stewart Ltd } \\
\text { James Longley \& Co } \\
\text { R Mansell Ltd } \\
\text { May Gurney Holds Ltd } \\
\text { The Miller Group Ltd } \\
\text { Norwest Holst Ltd } \\
\text { Seddon Group Ltd } \\
\text { Wates Const Ltd } \\
\text { Willett Ltd } \\
\text { Wid }\end{array}$ & 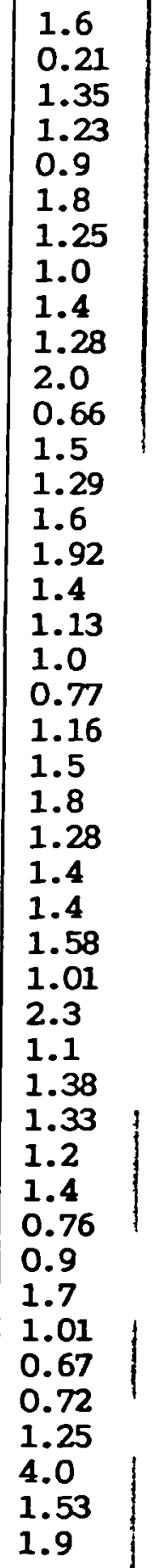 & $\begin{array}{l}1.6 \\
0.37 \\
1.25 \\
1.58 \\
1.0 \\
1.47 \\
1.33 \\
0.96 \\
1.35 \\
1.1 \\
2.0 \\
1.1 \\
1.5 \\
1.28 \\
1.66 \\
2.2 \\
1.4 \\
1.08 \\
1.0 \\
0.66 \\
1.1 \\
1.66 \\
1.66 \\
1.28 \\
1.56 \\
0.9 \\
1.56 \\
1.2 \\
2.0 \\
1.1 \\
2.6 \\
1.1 \\
1.4 \\
1.66 \\
0.9 \\
0.96 \\
0.96 \\
1.03 \\
0.67 \\
0.66 \\
1.4 \\
4.0 \\
2.1 \\
1.9\end{array}$ & $\begin{array}{l}0.55 \\
1.53 \\
0.5 \\
0.81 \\
2.9 \\
0.9 \\
0.5 \\
0.17 \\
0.58 \\
0.5 \\
1.8 \\
0.1 \\
1.05 \\
0.5 \\
0.94 \\
1.35 \\
1.8 \\
0.58 \\
0.6 \\
1.72 \\
0.62 \\
1.13 \\
1.7 \\
0.52 \\
0.61 \\
1.07 \\
1.01 \\
0.68 \\
1.9 \\
0.25 \\
0.87 \\
1.88 \\
0.33 \\
1.7 \\
0.04 \\
0.5 \\
0.5 \\
0.44 \\
1.09 \\
0.7 \\
0.5 \\
4.6 \\
0.53 \\
0.92\end{array}$ & $\begin{array}{l}0.53 \\
6.2 \\
0.33 \\
1.3 \\
1.5 \\
0.72 \\
0.55 \\
0.17 \\
0.43 \\
0.4 \\
2.1 \\
0.8 \\
1.0 \\
0.5 \\
1.05 \\
1.63 \\
1.5 \\
0.52 \\
0.6 \\
1.85 \\
0.55 \\
1.25 \\
1.85 \\
0.5 \\
0.73 \\
0.25 \\
0.85 \\
0.9 \\
2.5 \\
0.25 \\
0.68 \\
2.3 \\
0.57 \\
1.73 \\
0.2 \\
0.5 \\
0.5 \\
0.45 \\
1.17 \\
0.83 \\
0.73 \\
5.0 \\
1.18 \\
0.94\end{array}$ & $\begin{array}{c}62.0 \\
1.6 \\
25.0 \\
2.0 \\
0.9 \\
13.0 \\
2.0 \\
2.0 \\
0.77 \\
1.1 \\
2.0 \\
7.0 \\
22.0 \\
10.0 \\
10.0 \\
5.0 \\
1.47 \\
14.0 \\
3.0 \\
6.0 \\
12.0 \\
8.0 \\
14.0 \\
10.0 \\
2.1 \\
3.0 \\
5.5 \\
5.5 \\
2.6 \\
2.17 \\
8.0 \\
3.8 \\
10.0 \\
1.6 \\
4.0 \\
2.6 \\
2.6 \\
10.0 \\
5.0 \\
1.92 \\
6.5 \\
10.0 \\
2.0 \\
1.2 \\
\end{array}$ & $\begin{array}{c}62.0 \\
0.58 \\
2.0 \\
2.0 \\
2.5 \\
1.0 \\
0.55 \\
2.0 \\
1.7 \\
2.2 \\
2.0 \\
2.6 \\
22.0 \\
10.0 \\
10.0 \\
10.0 \\
0.63 \\
18.0 \\
0.8 \\
5.0 \\
12.0 \\
17.0 \\
14.0 \\
11.0 \\
3.7 \\
11.0 \\
7.0 \\
7.8 \\
1.6 \\
1.08 \\
13.0 \\
5.5 \\
10.0 \\
2.3 \\
1.4 \\
2.5 \\
2.5 \\
10.0 \\
1.1 \\
2.4 \\
2.6 \\
10.0 \\
2.0 \\
6.4\end{array}$ \\
\hline
\end{tabular}

To be continued 


\begin{tabular}{|c|c|c|c|c|c|c|}
\hline \multirow[b]{2}{*}{ Companies } & \multicolumn{2}{|c|}{$\mathrm{CA} / \mathrm{CL}$} & \multicolumn{2}{|c|}{$\mathrm{NA} / \mathrm{CI}$} & \multicolumn{2}{|c|}{ EBIT/INT } \\
\hline & -2 & -1 & -2 & -1 & -2 & -1 \\
\hline $\begin{array}{l}\text { Willmott Dixan Holds } \\
\text { City of Aberdben Ltd } \\
\text { Conder Group plc } \\
\text { Denoora plc } \\
\text { Dean \& Bowes Group } \\
\text { Dinton Group plc } \\
\text { Exeter Bdg \& Const Ltd } \\
\text { London \& Clyde Hold Ltd } \\
\text { MaLaughlin \& Harvey Ltd } \\
\text { Gilbert House Invest } \\
\text { John Elliott plc } \\
\text { Aberdeen Construction plc } \\
\text { Barratt Development } \\
\text { Benlox Holdings plc } \\
\text { C H Beazer Holdings } \\
\text { BIœC plc } \\
\text { Brown and Jackson } \\
\text { Bryant Holdings } \\
\text { Boulton and Paul plc } \\
\text { M J Geeson Group } \\
\text { George Winpey plc } \\
\text { A Monk Company plc } \\
\text { Newarthill plc } \\
\text { Taylor Woodrow } \\
\text { Tamac plc } \\
\text { Tilbury Group plc } \\
\text { Turriff Corporation plc } \\
\text { Wilson Connolly Holdings }\end{array}$ & $\begin{array}{l}1.1 \\
2.1 \\
1.0 \\
1.29 \\
1.24 \\
1.4 \\
1.32 \\
1.7 \\
1.4 \\
0.84 \\
1.1 \\
1.1 \\
2.5 \\
1.2 \\
2.8 \\
1.38 \\
2.3 \\
1.56 \\
2.5 \\
1.14 \\
1.8 \\
1.6 \\
1.33 \\
1.4 \\
1.4 \\
1.44 \\
1.15 \\
3.5\end{array}$ & $\begin{array}{l}1.1 \\
2.9 \\
1.1 \\
1.12 \\
1.52 \\
1.85 \\
1.18 \\
1.76 \\
1.35 \\
0.43 \\
0.97 \\
1.05 \\
2.7 \\
1.8 \\
2.88 \\
1.30 \\
3.1 \\
1.88 \\
2.5 \\
1.12 \\
1.66 \\
1.6 \\
1.5 \\
1.22 \\
1.5 \\
1.58 \\
1.12 \\
3.5\end{array}$ & $\begin{array}{l}0.5 \\
1.14 \\
0.35 \\
4.0 \\
0.95 \\
1.62 \\
0.91 \\
1.03 \\
1.04 \\
5.9 \\
0.31 \\
2.1 \\
2.0 \\
1.33 \\
2.2 \\
0.96 \\
1.8 \\
1.18 \\
2.2 \\
1.08 \\
1.5 \\
0.9 \\
1.7 \\
2.2 \\
1.56 \\
1.23 \\
0.56 \\
3.9\end{array}$ & $\begin{array}{l}0.58 \\
2.09 \\
0.31 \\
2.8 \\
1.31 \\
3.5 \\
0.65 \\
1.12 \\
1.1 \\
3.3 \\
0.176 \\
1.8 \\
2.59 \\
1.10 \\
1.55 \\
0.90 \\
2.8 \\
1.4 \\
2.25 \\
1.11 \\
1.5 \\
1.0 \\
1.58 \\
2.1 \\
1.56 \\
1.03 \\
0.7 \\
3.3\end{array}$ & $\begin{array}{r}1.0 \\
4.6 \\
0.4 \\
0.3 \\
20.0 \\
2.8 \\
2.0 \\
3.0 \\
5.2 \\
0.72 \\
3.4 \\
2.1 \\
3.8 \\
6.8 \\
5.6 \\
5.0 \\
5.1 \\
10.0 \\
25.0 \\
4.0 \\
2.3 \\
1.8 \\
5.0 \\
10.0 \\
5.7 \\
33.0 \\
3.8 \\
52.0\end{array}$ & $\begin{array}{c}0.9 \\
4.3 \\
1.4 \\
0.54 \\
20.0 \\
3.0 \\
0.79 \\
2.6 \\
4.47 \\
0.22 \\
32.0 \\
1.58 \\
3.3 \\
5.33 \\
3.3 \\
8.3 \\
3.7 \\
5.8 \\
25.0 \\
5.0 \\
3.2 \\
2.1 \\
3.4 \\
11.9 \\
7.5 \\
33.0 \\
11.0 \\
52.0\end{array}$ \\
\hline
\end{tabular}

TABLE 8.18: THE RESULTS OF DISCRIMINATING RATIOS OBTAINED FROM THE CLASSIFIED AS "NON-FAILED 73" GROUP 
The results obtained from groups 1 and 2 for $1986 \mathrm{z}$-scores indicate that 6 out of 73 of group (1) have current asset ratios less than unity, while for 8 out of 17 of group (2), the ratio is less than unity. Also, 30 out of 73 of group (1) have net assets/current liabilities ratio less than unity compared to 15 out of 17 of group (2). In addition 14 out of 73 of group (1) have pre-tax to current liabilities ratio less than 2.0, compared to 4 out of 17 of group (2).

Furthermore 12 out of 73 of group (1) have two critical ratios less than the specified limits in contrast to group (2). Seven out of 17 have two critical ratios less than the specified limits.

These tests indicate that companies in group (2) classified as failed using z-models, have critical ratios less than those classifled as non-failed.

Clearly the z-scores linked with the critical ratios are good predictors of failure. Indeed, there were a few companies classified as non-failed using only z-models but had two critical ratios below the specified limits indicating that some companies do not fully respond to the $\mathrm{z}$-model and need further analysis like financial ratios. 


\subsection{SUMMARY AND CONCLUSIONS}

Although the results of validation of both $\mathrm{Z}$-models were convincing and performed well on the data used in this study for quoted and unquoted companies, application of the model at the London Borough of Camden proved a very rewarding real experience in vetting compantes for tender lists in particular, and generally the smaller unquoted companies.

However, in conclusion unfortunately not all companies responded to the $\mathrm{z}$-model and other extra indicators such as traditional ratios tried and tested by time, are invaluable support evidence, particularly the critical ratios which have shown deterioration over several years.

This study was espectally successful in using the z-model with critical ratios in identifying a short list of companies at risk with confidence. However too much reliance on this aspect should be avoided in that a certain company may only have a profile very similar to a failed company Indicating a high probability of failure, but the fate of the company always depends an perscanal judgement of debenture holders, bankers and creditors etc.

Nevertheless it is reasonable to expect that the lower the Z-score, and deteriorating ratios for a company, and the more years the company is classified at risk, the more likely that company is to fail. However, unhealthy firms may be taken over as an alternative to bankruptcy, govermment assistance may be at hand, or they may simply be able to recover. 


\section{CHAPTER 9}

\section{MANAGERIAL FACTORS RET_ATING TO COMPANY FAIIUURE}

\subsection{Introduction}

9.2 Particular Factors of Failure by a Case Study Approach

9.3 Management Defects and Management Mistakes

9.4 Survey Related to Managerial Defects and Mistakes

9.5 Summary and Conclusions 


\section{CFAPTER 9}

\section{MANAGERIAL FACTORS RET.ATED TO COMPANY FAIUURE}

\subsection{INIRODUCTION}

The previous sections continued to treat z-scores and financial ratios with considerable respect as both these finance-based tools suffer from two potential defects; firstly, creative accounting, and secondly management mistakes which cannot be predicted statistically.

Companies generally fall because of inadequate management, the simple expedient of applying accounting ratios to all companies will not necessarily give a true reason for the reasons of failure. Furthermore some companies identified as certain failures by any accounting method, can survive because experienced managers adequately deal with the adverse situation.

Generally two indicators may be observed as a company moves towands collapse, namely financial, as has already been seen in Z-scores and traditional financial ratios. Unfortunately an indication appears only towards the end of the lang process of failure, probably anly in the last two years and sametimes even later.

Secondly, lang before financial distress becomes visible, many nonfinancial signs are often apparent such as management mistakes. Indeed many financial experts stress that balance sheet information alone is not enough to predict catastrophic factors such as bad management, economic down turn, overtrading, aoquisition of a failed company, excessive inventories, too much paper work and so an should 
not be overlooked. Thus some form of non-finance based analysis is also needed to classify a company at risk of failure.

Section 9.2 identifies particular factors in failure by a case study approach.

Section 9.3 briefly explains the management defects and management mistakes as evidenced in other investigations and a case study.

Section 9.4 describes a survey conducted into management defects and management mistakes.

The final section briefly discusses the managerial factors related to company fallure and provides a summary of the survey results.

\subsection{PARTICUIAR FACTORS OF FAIUURE BY A CASE STUDY APPROACH}

\subsubsection{Introduction}

It is essentlal to identify the factors behind fallure before coming to a conclusion relating to a suspect company. A case study is a very sensible approach to 1dentify particular factors in failure. Indeed a substantial amount of work has already been carried out into the reasans for particular failures via case studies, particularly cork Gully, see Appendix D for example. The following companies were declared bankrupt with Cork Gully appointed as liquidator:

1. Southern Construction Ltd

2. Crouch Construction Ltd and Crouch Group plc.

3. Mears Bros Holdings Ltd. 


\subsubsection{Case Study (1)}

Southem Construction Ltd entered into receivership as a result of a fall in turnover over several years, with the major reason for this deterioration being related to acquiring the Caffin Division of Ernest Ireland Group, including its offices at Rickmansworth and various employees, plus an assigment of several contracts. Ultimately the acquisition decision proved disastrous due to the fact that the new firm's activities did not fit in well with the existing business [see Appendix D].

\subsubsection{Case Study (2)}

Crouch Construction Ltd became a wholly owned subsidiary of Crouch Group plc in April 1978 and embarked upon a rapid expansion in contract work, particularly local authority housing.

The company then suffered severe losses beginning around April 1983 culminating in the holding company changing the board of directors of this company. The report stated that the trading position of crouch Construction Ltd curing 1983/84 suffered as a result of poor trading on contracts taken on at tight margins during a perlod of recession. Further problems had also arisen from the numerous changes in directors and senior staff.

Furthermore the company suffered from a continuing shortage of working capital caused by tied up funds in the stock of land for private house building purposes. With continued losses on contracts, Crouch Canstruction Ltd went into liquidation. The Group Board then found it impossible to continue trading without additional bank support. The Bank was unable to agree to provide an increased facility in excess of the existing borrowing. Legal advice was taken, and the Directors considered they had no altemative other than to request the Bank to appoint Receivers [see Appendix D]. 


\subsubsection{Case Study (3)}

Mears Bros Holdings Ltd was the parent company of a group of building, civil engineering and contracting companies.

In the mid 1970's the Group decided to expand its activities overseas. As part of this effort Mears Construction formed Mears Intemational to act as civil engineering contractors in the Middle East. During this period Mears Construction also expanded its UK operations, the bulk of which consisted of civil engineering work such as roads, reservoirs, sea defences, public building work and public housing.

After 1978 the trading position had deteriorated considerably. It was reported that the failure of the Group was attrlbuted by the Directors of Mears Holdings to the following factors:

1. Certain major contract loss-making due to adverse weather conditions and the tight price of contracts.

2. The delay by clients in the settlement of certain substantial claims an contracts.

3. The demands made upon the Group banking facility due to losses incurred by other companies within the Group.

4. The financial drain caused by attempts to establish a contracting trading base overseas.

5. The short term cash effects of the move to Swindon. 


\subsubsection{Canclusions}

In reviewing the reasons for fallure for these examples of failed companies, failure might be displayed in non-financial signs of deterioration as well as financial ones.

The failure of Southern Construction was caused by a deteriorating turnover observed in balance sheet information as well as managerial acts such as acquiring a disastrous company such as Caffin Division of Ernest Ireland.

The fallure of Crouch Construction Ltd and Crouch Group plc were due to deteriorating profits, also as shown in balance sheet information, as well as managerial acts like too many changes of directors and senior staff.

Also, the failure of Mears Bros Holdings Ltd was due to deteriorating Ilquidity also to be seen in balance sheet information as well as managerial acts such as the delay in claim settlements and losses on overseas contracts.

The following managerial acts could be included as leading to company failure:

1. Aoquisition of a failing firm.

2. Overtrading.

3. Losses in contract claims.

4. Losses in overseas contacts.

5. Inexperienced staff

6. Passive board of directors.

7. High leverage trading.

8. Weak response to market change. 


\subsection{MANAGEMENT DEFDCTS AND MANAGEMENT MISTAKES}

\subsubsection{Introduction}

The purpose of this section is to describe a number of specific defects observed to be existing in company management. For decades managers, receivers, academics have made lists of these defects, as published in financial joumals and previous studies. In particular John Argenti [7] describes same in his latest research work in the UK. Such deficiencles lead management into mistakes.

\subsubsection{Management Defects}

The following are considered the major deficiencies in a company's management:

1. Autocratic Chief Executive:

The autocrat may be distinguished from the team leader by the way he dominates the company, especially indicated by preservation of a position of sole authority.

2. The same person as both chief executive and chaiman:

A most important task of the company chaiman is to be able to dismiss an inadequate chlef executive; someone who is both is unlikely to do this.

3. The company board comprises too many nan-contributing directors or persons not working in the company.

4. Lack of engineering skills. 
5. Lack of a strong finance director:

It is not enough for finance directors to exercise financlal skills, they must also be able to make financial decisions. An indication of a weak finance director is shared responsibility for financial decision making.

6. Defective managerial skills:

Companies may fail from defective finance or poor human relations, or inadequate marketing or legal skills as much as from poor engineering experience.

7. Incomplete acoountancy system:

a) Inadequate cash flow plan. The financial department either has no cash flow plan, or one that is not updated or revilewed periodically.

b) Poor budgetary control system. The company either has no budgets prepared at all, or the budgets are prepared but are not reviewed periodically.

8. Defective bidding system:

When senior management are insufficiently experienced in bidding or bidding decisions are taken without cross-referring with other senior management.

9. Poor marketing skills:

A main task of the board is to review the perspective of the market. Indeed there is almost complete agreement among specialists in this field that companies that fail are those which have either not noticed a change in their business market, or have not responded to it. 
Typically many construction companies have invested heavily in land and property during boom periods, subsequently when prices slowed down and interest rates increased, substantial or occasionally critical losses have been incurred.

\subsubsection{Management Mistakes}

Management sametimes make a mistake which leads to failure many years after the first critical decision was taken. Typical examples include:

1. Too much reliance on short term loans. Companies sometimes issue debentures with a fixed interest rate in order to raise investment funds. Failing companies often appeared to allow leverage of these loans to rise to a level at which its future was placed in jeopardy. In a previous study Argenti has illustrated that companies run by ambitious autocrats, not constrained by strong finance directors, are particularly liable to make such errors.

2. Qvertrading. Companies often try to expand business to a point which will not cause overtrading typically a company expanding faster than its funding. For example, Mears Bros Holdings Ltd [see Appendix D] expanded its UK and overseas operations quickly leading to shortages in cash flow before failure. In preference an expanding company should try to increase its equity base instead of relying on loans.

3. Losses in projects. Companies that fail are often those that have undertaken large projects, involving an excessive inventory building or high technical industrial construction. 
Similar effects can result from guaranteeing the loan of a subsidiary company. The obligation may not be able to be met if matters deteriorate particularly:

a) Contract claims:

Administration should ensure that these are given the proper attention, carefully analysed and documented, to be equitably resolved as soon as possible. ance a clatm has been resolved, a change order should be issued to cover the resolution. Unresolved clafms cause shortage in liquidity and therefore could lead to failure.

ane of the main reasons behind the failure of Mears Bros Holdings Ltd seemed to be improper handling of substantial claims on contracts.

b) Overseas Contracting:

work abroad seemed to be a good option for large firms suffering declines in their home market. However, same companies suffered huge losses due to lack of managerial control in an unfamiliar enviroment. Indeed, Mears Bros Holdings Ltd suffered a critical financlal drain attempting to establish a contracting trading base overseas.

4. Acquisition of a Potentially Failing Firm. A company may unfortunately take over a firm and later find a hidden difficult financial situation resulting in disaster if the acquired firm fails. Indeed Southem canstruction Ltd failed primarily due to acquiring the Caffin Division of the Emest Ireland Group. 
Sometimes unhealthy firms are taken over as an alternative to bankruptcy, eventually causing the take over company also to fail. Indeed results obtained from the "Taken over 9" group show that 2 out of 9 were classified as failed two years before take over, with a further 2 out of 9 classified as vulnerable in the last year before take over. The remaining 5 companies were classified as non-failed but their z-soores deteriorated from year to year.

\subsubsection{Summary and Conclusions}

From case studies and previous studies [see Appendix D] the main defects in a company's management appear to be:

1. Autocratic chief executive.

2. The same person acting as both chief executive and chaiman.

3. The board of directors comprises non-contributing and executive directors.

4. Lack of engineering experience.

5. Lack of a strong finance director.

6. Inadequate managerlal skills.

7. Defective accountancy system.

8. Defective bidding system.

9. Inadequate marketing skills.

Other important factors leading to failure are:

1. Too much reliance on a short term loan.

2. Overtrading

3. Losses in projects.

4. Taking over failed firms. 


\subsection{SURVEY RETATED TO MANAGERIAL DEFECTS AND MISTAKES}

\subsubsection{Introduction}

Previous sections diagnosed the major managerial defects and mistakes leading to failure. A questionnaire was thus designed to identify these defects and mistakes and to try and disoover which corrective actions companies had taken to help survive. The survey included two groups as follows:

Group 1: Companies classified as potential failures but not failing 1.e. those scoring negatively by both $\mathrm{z}$-models, 1.e. "falled" or "vulnerable".

Group 2: Comprised compantes scoring positively by both Z-models, 1.e. those classified as "non-failed" by both models.

By comparing the two groups, some of the reasons for revival were ascertained as well as deteminting the reasans for financlal distress. Both groups were selected non-randamly in which criteria of selection was based on those medium size companies operating in construction and civil engineering which have limited liabilities and are classified in two groups according to their z-scores for the last three years. Since there are significant differences in $\mathrm{Z}$-scores in both groups there could be a difference in managerial system.

\subsubsection{The Survey}

Ninety companies were contacted and 28 responded. Unfortunately ultimately only seven provided enough information for each group as shown in Tables 9.1 and 9.2: 


\begin{tabular}{|l|r|r|r|r|r|c|}
\hline \multirow{2}{*}{ Company } & \multicolumn{3}{|c|}{ Model 1 (Origin) } & \multicolumn{3}{c|}{ Model 2 (Regression) } \\
\cline { 2 - 7 } & 84 & 85 & 86 & 85 & 86 & 87 \\
\hline & & & & & & \\
\hline & -14.0 & -6.2 & -8.0 & -1.0 & -1.7 & 1.0 \\
3 Cabcock Ltd & 2.0 & -6.4 & -6.6 & 2.3 & -4.25 & -15.8 \\
4 Cementation Ltd & 2.1 & -12.4 & 5.5 & -0.9 & -3.5 & -0.75 \\
5 J M Jonry Boot \& Sons Ltd & 4.6 & -11.2 & -5.3 & 2.9 & 3.3 & -1.2 \\
6 Trollope \& Colls Ltd & 11.0 & -43.0 & -7.6 & 0.9 & -5.9 & -7.2 \\
7 Willet Ltd & 5.0 & -4.0 & -9.0 & -1.02 & -1.04 & -2.3 \\
& -13.5 & -1.05 & -22.5 & -0.46 & -4.9 & -0.34 \\
\hline
\end{tabular}

TABLE 9.1: SHOWS Z-SCORE FOR GROUP (1) BY USING BOTH Z-MODELS

\begin{tabular}{|l|r|r|r|r|r|l|}
\hline & \multicolumn{3}{|c|}{ Model 1 } & \multicolumn{3}{c|}{ Model 2 } \\
\cline { 2 - 7 } Company & 84 & 85 & 86 & 85 & 86 & 87 \\
\hline & & & & & & \\
\hline 1 A F Budge Cont Ltd & 14.2 & 14.6 & 15.7 & 2.75 & 2.45 & 3.5 \\
2 Petbirs Hold Ltd & 14.0 & 17.9 & 9.9 & 1.87 & 3.13 & 2.1 \\
3 Tarmac Cont Ltd & 4.3 & 4.2 & 11.0 & 1.48 & 1.58 & 3.02 \\
4 Haymills Hold Ltd & 12.3 & 5.9 & 15.2 & 2.03 & 2.34 & 2.48 \\
5 Kyle Stewart Ltd & 0 & 12.4 & 34.0 & -0.27 & -0.467 & 4.2 \\
6 Croudace Hold Ltd & 13.6 & 8.96 & 10.9 & 2.5 & 1.6 & 2.23 \\
7 R Mansell Ltd & -25.0 & 15.0 & 17.6 & 1.79 & 2.09 & 1.84 \\
& & & & & & \\
\hline
\end{tabular}

TABLE 9.2: SHOWS Z-SCORE FOR GROUP (2) BY USING BOTH Z-MODELS 


\subsubsection{Results from the Survey}

The existence of managerial factors related to failure was investigated in the questionnaire using the multiple choice method, (see Appendix D). The questionnaires included 17 questions related to failure for both groups and produced the following observations:

i) The chief executive of the company has sole authority in 6 out of 7 companies in group (1), while in group (2), only 3 out of 7 has this condition, 1.e. the chief execurtive in group (1) had sole authority more than group (2) i.e. 868 in group (1) and 438 in group (2). The results reinforce the opinton that companies in group (1) experienced more difficulties than those companies with an assistant or deputy with authority.

ii) The chief executive and chairman are the same person. One out of 7 in group (1) had a combined chief executive and chaiman post, while in group (2) 5 out of 7 demonstrated this characteristic. Thus as long as a company is run by a team of managers with authority, a better chance of survival seems most likely.

iil) The board of the company comprises persons not working in the company. Two out of 7 of group (1) and 3 out of 7 of group (2) company board comprised persons not working in the company. While strong conclusions are not possible, companies may be more successful if outside persons are involved at least in authoritative decision making at the highest level as indicated by companies in group (1) classified as vulnerable. 
iv) Engineering experience. Over 708 of both groups employed engineers with less than ten years experience and little can be deduced.

v) Lack of a strong finance director. Information supplied by companies particularly identified this problem. Indeed finance directors should be clearly responsible for their company's financial deciston making. In all the companies of group (1) the financlal director had shared authorlty, while 4 out of 7 of group (2) had similar responsibility. Since group (1) had more financial difficulties than group (2), the presence of a weak financial director may be a main factor behind the financial difficulties.

vi) Lack of overall management skills observed. anly 1 out of 7 of group (1) had managers with average experience less than ten years, while none of group (2) had this deficiency. This defect in both groups seems minor, therefore any observer should not place too much emphasis on this point as in both groups managers were generally well experienced.

vii) Defects in acoountancy system. In the failing companies the finance department either had no cash flow plan or one that was not regularly updated. Borrowing requirements for the next month, quarter, or a year ahead were generally poorly evaluated. All companies in group (1) produced cash flow plans reviewed periodically, while 1 out of 7 in group (2) had not produced a cash flow plan. The survey however revealed that all companies in both groups (1) and (2) had budgetary control systems. Also, generally all construction companies had a good accountancy system, but same companies had a weak finance director. 
viii) Bidding methods. In 2 out of 7 of group (1), middle managers and specialists in bidding did not in all cases contribute, in contrast group (2) middle managers always were involved in the bidding process.

ix) Lack of response to market change. Four out of 7 in group (1) had insufficiently responded to market changes, while 2 out of 7 of group (2) indicated a slow response to market change. Against the competition and with rapid change in the construction market, companies need to be strangly placed in the market. Gork Gully [Chartered Accountants] believes that most companies suffer financial distress when attitudes to market changes are weak. Furthermore, almost complete agreement exists among specialists in that failing companies are those which have either not noticed a change in their business enviroment or have not responded to it (John Argenti [7]).

Typically construction companies that have invested heavily in land and property curing a boan period, in a subsequent slow down acocmpanied by increasing interest rates, often incurred losses that may lead to fallure.

Same particular factors in failure raised in the survey include:

i) Debentures: Normally companies issue debentures with a fixed interest rate in order to raise investment funds. Failing companies often then allow leverage to rise to a level where its future is placed in jeopardy. 
No company in group (1) had issued debentures, but 1 out of 7 in group (2) had done so. Thus debentures could be viewed as a helpful means of sterming financlal difficulties compared to other loan forms.

ii) Overtrading: Companies often try to expand to a limit which will not lead to overtrading. In group (1) 2 out of 7 firms appeared to do this, while no company in group (2) had done so. Clearly group (1) companies had taken such risks e.g. J.M. Jones Ltd but small compared to the size of the company. Overtrading generally results when a company expands faster than 1ts capital. This gives an indication of overtrading when the ratio of turnover to capital employed becomes very high. In our case $\times 7.27$ and 4.4 , respectively, 1.e. excessive for the size of business.

iii) Losses in projects: A company may undertake loss making projects, perhaps resulting in disaster in the largest cases. Six out of 7 of group (1) and 2 out of 7 of group (2) had made such commitments. Although group (1) firms incurred losses more than group (2), some companies in the survey considered the resulting losses small compared to size of business, e.g. Tarmac Construction Ltd. Misjudgements of this kind were not significant in big firms, while for small firms the results could mean bankruptcy.

iv) Taking over a failing firm: A company may take over another firm and later find a hidden difficulty. The financlal situation may then deteriorate if the acquired firm fails. Indeed Southern Construction Ltd failed due to acquiring the Caffin Division of 
the Ernest Ireland Group. In our case, 1 aut of 7 of each group Incurred such losses. However the size of losses depends upan the size of company. For example, Taylor Woodrow plc who are not included in both groups, describes such losses as minimal in the context of company size. Furthermore, in boom periods mergers often intensify to facilitate expansion of resources and so allow more ambitious undertakings, while in a recession mergers are more likely for diversification reasons to temper fluctuations or because of an opportunity to acquire cheaply.

v) Diversification: An attempt to take corrective action by diversifying business in order to secure a reasonable existence in another sector or even in the same line of business to smooth out the fluctuations in demand can be achieved by diversification. The survey indicates no company had diversified business into other sectors.

vi) Contract claims: In the survey 4 art of 7 of group (1) and 2 out of 7 of group (2) had undertaken projects involving contract claims resulting in significant losses. Clearly, unresolved claims are potential causes of failure, however large companies like Henry Boot Itd and Tamac Construction Ltd were able to sustain significant losses fram contract claims, but the effects could be more severe with small firms. As seen from the previous section, Mears Bros Holdings Ltd in particular appeared to have failed because of the delay by clients in the settlement of certain substantial claims on contracts. R D Gilbreath [38] recommends the elimination or reduction of the incidence of claim provoking conditions and claims themselves. When claims have to be presented the contract adninistrator should ensure 
that they are given the proper management visibility within the owner's organisation, carefully analysed and documented and equitably resolved a soon as possible.

vii) Overseas projects: In the survey, work abroad seemed to be a favoured option for large finms, suffering decline in their hame market. Two out of 7 of group (1) and 1 out of 7 of group (2) involved in overseas projects reported significant losses. As seen in the previous section, Mears Bros Holdings Ltd which failed had suffered a critical financial drain when attempting to establish a contracting trading base overseas. Generally losses on overseas projects could be due to lack of managerial control or restrictive regulations in these countries.

\subsubsection{Conclusians}

Comparison of the effects of managerial factors related to failure in both groups produced the following survey findings:

- The existence of managerial factors in group (1) is obviously more than in group (2).

- The effects of these factors depends upon the size of company 1.e. managerlal factors related to failure were not significant in large firms, while for the smaller type the deficiencies could cause bankruptcy.

- The majority of companies negatively Z-scoring in group (1) were dominated by an ambitious chief executive with sole authority as seen in 6 out of 7 of group (1) and not constrained by strong finance directors as demonstrated in all companies in group (1) where the financial director had shared authority. 
- The majority of companies which are negatively z-scoring in group (1), were incurring losses in projects, whereas 6 out of 7 of group ( 1 ) had been Incurring big losses additional to losses in contract claims.

- The majority of companies negatively $\mathrm{z}$-scored had high leverage i.e. total liability to equity $>3$ also the mean ratio of group of total liability/net assets > 2 .

\subsection{SUMMARY AND CONCLUSIONS}

Managerial factors related to fallure in order of importance appear to be as follows:

- Weak finance director

- Chief executive sole authority without assistant.

- Average experience of engineers less than 10 years.

- No quick response to market changes.

- Nan contributory persons on company's board.

- Sentor management staff not involved in bidding process.

- Average experience for management staff less than ten years.

- Conlef executive and chatrman same person.

Particular defects in order of importance were as follows:

- Losses in projects.

- Losses in contract claims.

- Losses fram overseas projects.

- Overtrading.

- Taking over a failing firm. 
CHAPTER 10

THE A-SCORE

10.1 Introduction

10.2 Formation of Data Group

10.3 The Developed A-Score Model

10.4 Validation of Results from the "Test 14" Group

10.5 Relationship Between A-Score and Z-Score

10.6 Sumary and Conclusions 
GPAPTER 10

\section{A-SCORES}

\subsection{INTRODUCTION}

The concept behind the A-score is based on the belief that if a company is in financial difflculty the reasons generally relate to inadequate management ability and errors perpetrated earlier.

This section is an attempt to rank the factors related to failure in order of importance and to produce a weighted result. The factors were previously described in Chapter 9.

The A-score is designed to introduce a measure of quantification of failure prediction. However, an A-score is dependent upon personal judgement normally insufficient to draw firm conclusions, in contrast company ratios analysis and $\mathrm{z}$-score evaluates are generally much more objective.

Practically, the A-soore should be used only for a suspect company when:

- accounts are not available or are late

- accounts suffer from "creative acoounting"

- z-scores or ratios give freak results. 
Section 10.2 reviews previous studies.

Section 10.3 includes formation of data groups.

Section 10.4 describes briefly the developed A-soore model.

Section 10.5 includes results obtained from the "solvent 7" and "at risk 7" groups.

Section 10.6 includes validation of the $\mathrm{Z}$-soore model.

Section 10.7 describes the relationship between-score ad Z-score models.

The final section briefly discusses the results and sumarises the results with conclusions.

\subsection{FORMATION OF DATA GROUP}

There was a general problem in obtaining the required information for a large number of companies, mainly due to the policy restrictions. Furthermore the data should include failed firms but difficulties were encountered in persuading such firms to answer the questions.

An alternative approach was to investigate continuing firms with similar financial profiles to failing firms. In response 28 out of 90 continuing firms were prepared to provide information from which 7 out of 28 were classified as vulnerable and placed in an "at risk 7" group i.e. those scoring negatively by the z-score model. Of the 21 remaining firms 7 were placed in the "solvent 7" group, i.e. those scoring positively by the z-score model. The rematning 14 finms were placed in a "test 14" group. A list of companies in the "at risk 7" and "solvent 7" groups are as follows: 
A list of companies "at risk 7":

1. Baboock Contractors Ltd

2. Cementation Construction Ltd

3. Consolidation Tern Investments Ltd

4. Henry Boot and Sons

5. J.M. Janes Ltd

6. Trollope and Colls Ltd

7. Willet Construction Ltd

A list of compantes classified as "solvent 7" grap:

1. A.F. Budge Ltd

2. Peter Birse Holdings Ltd

3. Tarmac Construction Ltd

4. Haymill Contractors Ltd

5. Kyle and stewart Cosntruction Ltd

6. Croudace Construction Itd

7. R. Mansel Contractors Ltd

The two groups were analysed statistically and significant differences between groups were found to exist, (see Appendix E).

\subsection{THE DEVELOPED A-SCORE MODEI}

As was seen in the previous section the "solvent 7" and "at risk 7" groups were used successfully for comparison of the effects of managerial factors related to failure and therefore were selected in developing the A-model.

Managerial factors related to fallure described in the previous Chapter in order of importance were as follows: 
1. Weak finance director

2. Chlef executive sole authority without authorised assistants.

3. Average experience in years for engineers, less than ten years.

4. Slow response to market changes.

5. Non-executive persons on the company board.

6. Senior management staff do not participate in bidding.

7. Average years of experience of management staff less than ten years.

8. Chief executive and chaiman, same person.

Also, the Identified managerial errors related to failure in order of importance were as follows:

1. Making losses on projects.

2. Making losses in contract claims.

3. Making losses in overseas contracts.

4. High leverage.

5. Taking over failing firms.

Having 1dentified the relevant factors they are now weighted for the survey sample of "solvent 7" and "at risk 7" groups.

The A-score for a company is then obtained by adding the weight of all factors together. Tables 10.1 and 10.2 show the A-score results obtained from the "at risk 7 " and "solvent 7" groups.

- The least A-score in group (1) considered to indicate vulnerability is 50. All companies in group (1) scored above 50, a reasonable cut off value between vulnerable and solvent companies. 
- In sample group (1) virtually all the companies were clearly in danger in contrast to the strong group (2).

- All companies of group (2) scored less than 50 with a mean value group score of 37.7. The mean value of group (1) was 65.85 .

\begin{tabular}{|l|c|}
\hline "At risk 7" Group Companies & A-Score \\
\hline 1 Baboock Contractors Ltd & 62 \\
2 Cementation Construction Ltd & 72 \\
3 Consolidation Tern Investments Ltd & 62 \\
4 Henry Boot Ltd & 96 \\
5 J M Jones Ltd & 50 \\
Trollop and Colls Ltd & 69 \\
7 Willet Construction Ltd & 50 \\
\hline
\end{tabular}

TABLE 10.1: SHOWS RESULTS OBTAINED FROM "AT RISK 7" GROUP (1)

\begin{tabular}{|l|c|}
\hline "Solvent 7" Group Companies & A-Score \\
\hline & \\
1 A F Budge Ltd & 31 \\
2 Peter Birse Holdings Ltd & 45 \\
3 Croudace Construction Ltd & 41 \\
4 Hymill Contractors Ltd & 29 \\
5Yle and Stewart Construction Ltd & 47 \\
6. Mansell Ltd & 28 \\
7 Tamac Construction Ltd & 43 \\
\hline
\end{tabular}

TABLE 10.2: SHOWS RESULTS OBTAINED FROM "SOLVENT 7" GROUP (2) 


\subsubsection{Weighted Results}

The items related to fallure weighted in accordance with their importance produced the following list:

Managerial Factors Related to Failure

1. Weak finance director

2. Autocratic chief executive

3. Lack of engineering skilis

4. Poor response to market change

5. Senior management staff not experienced in bidding

6. Company board comprised persans not working in the company

7. Crief executive and chairman, same persan

8. Lack of managerial skills Total:

\begin{tabular}{c} 
Weighting \\
\hline 17 \\
14 \\
12 \\
10 \\
5 \\
5 \\
2 \\
2 \\
67
\end{tabular}

Weighting

14

1. Making losses in projects

2. Making losses caused by contract claims 7

3. High leverage 5

4. Making losses caused by overseas contracts 5

5. Making losses caused by taking over failing firms 2 Total:

\subsubsection{Method of Scoring}

1. The scores are given only if the observer is confident that the factors and errors are clearly evident in the suspect company, otherwise nils are recorded. 
2. The score should be full values or zero. Intermediate scores are not permitted.

3. The overall critical mark is 50. A company scoring above that level is considered vulnerable, clearly a soore of this level when accompanied by a negative $\mathrm{z}$-score should signify a crisis.

\subsubsection{Statistical Analysis}

The two groups were analysed statistically and significant differences between groups were found to exist (see Appendix E).

\subsection{VALIDATION OF RESULTS FroM THE "TEST 14" Group}

Although the results in the previous section indicate that the A-score model is discriminating between "solvent" and "at risk" companies well the true test of the model's accuracy requires validation of independent data. The results obtained from data for 14 compantes are shown in Table 10.3.

\begin{tabular}{lc}
\multicolumn{1}{c}{ Companies } & A-Scores \\
\hline & \\
1. Alfred McAlpine Construction Ltd & 74 \\
2. Balfour Beatty Construction Ltd & 39 \\
3. Ben Baily plc & 48 \\
4. C H Beazer plc & 24 \\
5. Costain Construction Ltd & 76 \\
6. Dunton plc & 24 \\
7. Higgs plc & 48 \\
8. F J Lilly plc & 81 \\
9. John Laing Construction & 50 \\
10. Miller Group plc & 46 \\
11. Mowlem Group plc & 50 \\
12. Taylor Woodrow plc & 50 \\
13. Walter Lawrence plc & 41 \\
14. Willmot Dixon Construction Ltd & 50 \\
\hline
\end{tabular}

TABLE 10.3: THE A-SCORE FOR "TEST 14" GROUP 
Three out of 14 of the "test 14" group are classifled at risk, even when scoring above 50. These were very large companies, namely:

1. Alfred McAlpine Ltd

2. Costain Construction Ltd

3. F J Lilly plc.

Thus some caution should be exercised when dealing with large companies and A-scores need to be viewed with more tolerance than small companies. Furthermore, by examining the z-scores of these companies, all scored positively. Of the total "test 14" group 788 are correctly classified as solvent, when scoring less than 50 with their z-score also positive.

Thus at first sight the results do not appear as good as the $100 \%$ correctly classified in both the "solvent 7" and "at risk 7" groups. Thus it must be concluded that an A-soore alone is an insufficient tool for prediction fallure. However the results are quite valuable when placed alongside the $\mathrm{z}$-score and financial ratios methods.

\subsection{RETATIONSFIP BETWERN A-SCORE AND Z-SCORE}

The results obtained from "at risk 7" and "solvent 7" groups Indicate that there may be a relationship between A-score and Z-score, which would be useful if proven statistically, (see Appendix E).

Unfortunately the results obtained from statistical analysis show that the inter-correlations between A-score and $\mathrm{z}$-score are only $67.7 \%$ 1.e. not very strang. However, the $\mathrm{z}$-score value of zero also corresponds to an A-score of about 50 1.e. the values considered critical in both models. Nevertheless, these results may still be misleading because of the small number of companies in the survey. 
The results also indicate that when the $\mathrm{z}$-score falls below zero, the corresponding A-score increases above 50 1.e. the value considered to be a cut-off between "at risk" and "solvent" companies.

\subsection{SUMMARY AND CONCIUSIONS}

The A-score was developed to systematise fallure prediction by quantification measures based on non-financial features and then linked with z-scores.

It could be concluded that there is a link between $\mathrm{Z}$-score and Asoore. As was seen from the results of "at risk 7" and "solvent 7" groups, those companies scoring negatively in the Z-model also have Ascores above 50 in 1008 of the "at risk" group.

Furthermore the results of the "test 14" growp show that 3 out of 14 companies scoring positively in the $\mathrm{Z}$-model had A-scores above 50 , these being large firms whose strength and reputation can stave off insolvency for some considerable time.

Another point of interest is the possibility the A-score concept might be a suitable measure for those firms engaged in rescues. Put simply when a company moves down the path to failure its A-score rises above 50 and to return to a healthy situation the items that contribute to A-scores have to be corrected, for example, replacing a weak finance director or reducing leverage etc. other alternatives might be:

- a merger

- diversification

- issuing debentures. 
Finally, the above described analysis does not by itself deal with the actions required to return a failing company to health, but only to improve predictive ablifty by highlighting the factors and errors which may lead to fallure. 


\section{CHAPTER 11}

\section{DISOUSSION AND CONCLUSIONS}

11.1 Introduction

11.2 The Z-Score

11.3 The Traditional Ratios

11.4 The A-Scores

11.5 Research Findings

11.6 Recommendations for Implementing the Research Findings for Vetting Construction Companies on Tender lists

11.7 Contribution of Thesis to Construction Industry

11.8 Further Research Work 


\section{CHAPTER 11}

\section{DISCUSSION AND CONCLUSIONS}

\subsection{INTRODUCTION}

Construction is a high risk business, clearly therefore advantages accrue if potential failures can be recognised at the earliest possible stage and thereby minimise costs of liquidation to all concerned. Some method is apparently needed which will give a quantitative indication of the solvency.

This chapter discusses some of the other methods available to predict company fallure, also considers linkages between them. The three methods developed in this research were namely the Z-scores (see Section 11.2), the traditional ratios (Section 11.3), and the A-score technique (Section 11.4). This latter method of failure identification however operates on different principles to either the Z-scores or the traditional ratios.

Section 11.5 brings all the research findings together and attempts to conclude how well the methods developed meet the research objectives.

Section 11.6 makes recommendations for implenenting the research findings in practice.

Finally the chapter presents the conclusions of the thesis and recommendations for future studies. 


\subsection{THE Z-SCORES}

This research is first detailed attempt to develop a Z-scores model for construction companies in the UK following Mason's earlier work in the late 1970s and covers development of three new z-models and reexamination of Mason's model.

Two of the models failed to meet completely all the underlying statistical criteria required in the discriminant approach because of the small number of company accounts in the survey, restrictive policies of construction firms in providing sensitive information, and also "creative accounting" of some suspect companies.

Nevertheless, both these models were able to distingulsh between "failed" and "solvent" companies well and could identify a short list of "at risk" i.e. the profiles are very similar to failed companies and that they are likely to experience financial distress which may cause failure.

Indeed the results obtained from the "all-90" group continuing companies in the industry indicate that over the last four years 17\% and $20 \%$ respectively have profiles similar to those bankruptcies in both models. See Tables 8.8 and 8.15. This is a real test of both models.

Furthermore the regression model classified companies as vulnerable substantially better than the original model particularly with respect to sensitivity to failed company data, although the model had less discriminating power than the original model. It also classified the geared up company better than the original model 1.e. those companies 
relying on borrowed funds over a lang period. In practice industry prioritise those firms typified to be at risk and for this reason a decision was made to evaluate the regression model further with the Iondon Borough of Camden with over 200 firms involved with this local authority. By taking the classification boundary at the -1.6 threshold, the discriminating power of the model was shown to be good.

Further verification of the quality of both models can be seen in their composition with similar discriminating variables. The main difference being that the regression model includes five varlables, indeed 3 out of 7 of the discriminating variables in the original model were removed and replaced by better representatives, namely income gearing ratio, i.e. the ratio of interest to profit before tax and interest.

Figure 7.15 shows the trend in inocme gearing for the failed group rising sharply to crisis level at the year of failure while for the solvent group its value is stable indicating the discriminating power of this variable.

The updated results of Mason's model are shown in Section 7.5 which Indicates the model has less discriminating power than those developed in this research and thus needs further testing to provide its validity.

Finally when applying $\mathrm{Z}$-scores in vetting construction cormpanies on tender lists, the user should consider the following: 
- not to rely an single z-score values for a single period. At least three years or maybe a longer period may be needed because same companies continue in the business depending on their capabilities.

- individual z-scores serve to rank companies in terms of their solvency, the lower the z-score or the more companies exhibit negative Z-scores for several years indicate more likelthood of failure.

- the study introduced a distribution to give the user an indication of the performance of a particular company, 1.e. If the company zscore for 1986 is less than the mean for the industry in 1986 then its performance is obviously less than average (see Figure 8.4).

- Z-scores alone cannot predict failure but only provide a financial indicator to give a quantitative indication of the solvency of a company, or a simple rule for gauging financial health.

\subsection{THE TRADITIONAL RATIOS}

Among 31 financial ratios analysed in this study, only three ratios were considered to be reliable failure prediction tools i.e. those critical ratios reflecting financial difficulties in a company (see Sections $7.7,8.4$ ).

The results obtained from the "All failed 22" group produced the following values:

- the current ratio in 17 out of 22 of the group is less than unity

- the net assets to current liabilities ratio in 15 out of 22 of the group is less than unity 
- the pretax profit to interest ratio in 20 out of 22 of the group is less than 2.0

Furthemore, the study suggests that the above ratios can help to identify failing companies when deterioration has continued over several years. Also the study showed that a company with a low Zscore and deteriorating ratios is likely to fail.

Finally, the study managed to combine Z-scores with critical ratios i.e. companies classified as failed by $\mathrm{Z}$-scores analysis when the critical ratios were also less than the specified limit for these ratios.

\subsection{THE A-SOORES}

The A-score was developed to systematically predict failure with a quantification measure based on nan-financial features linked to zscores.

The A-score alone was by itself an insufficient tool for predicting failure, but provides a valuable indicator when placed alongside Zscores and financial ratios.

It was apparent from the results that $\mathrm{z}$-scores below zero and A-scores above 50, are values considered to be cut-offs between at risk and solvent companies, the exception being large firms which need to be viewed more tolerantly because of strength and reputation. Usually, small companies suffer first in a recession period and therefore become more vulnerable than large firms [interview with Addy of cork Gulley]. 
Finally the A-score concept might be very suitable for those engaged in rescues, put simply when a company moves down the path to failure its A-score rises above 50. To return to a healthy situation the items that contribute to A-scores have to be corrected, for example replace a weak finance director or reduce leverage etc.

\subsection{RESEARCH FINDINGS}

The ultimate findings of this work are:

1. There are likely to be two features of company failure; firstly financial as has been seen $z$-scores and traditional ratios are indicators of approaching failure, which generally appear in the last three years before collapse. Secondly, non-financial features as observed through A-scores.

2. Z-scores alone cannot predict failure; similarly a combination of traditional ratios and $\mathrm{z}$-soores.

3. There will be companies that do not respond to $z$-scores analysis and give freak results. Similarly traditional ratios cannot always provide a reliable overall picture of performance but can pinpoint particular areas of concern. Some large fims do not always respond to A-scores and need to be examined by other tools.

4. z-scores and traditional ratios are liable to be influenced by changes in the econamy i.e. a rise in interest rates which may cause a deterioration in all gearing for all companies. 
5. Traditional ratios and $z$-scores should be ranked with those for its own sector of industry.

6. Z-score models need redevelopment when they become "old and tired" as "bankruptcy prediction models are fundamentally nonstationary" (see Mensah, 1984 [18], 391) also the test of Masan's model after 10 years in Section 2.3.6 .

7. Prediction of bankruptcy using z-scores is likely when the probability using a Bayestan approach (see section 8.2.8) of a company actually falling is classified as at risk can be calculated approximately.

8. The results obtained fram the "All 90" group, suggest that $18 \%$ of continuing companies in the industry might have profiles similar to the bankruptcy profile in both z-models i.e. approximately $18 \%$ to be over the last four years (see Tables 8.8 and 8.15).

9. Failure signs can be seen in financial ratios and indicate an increasing rellance on borrowed funds over at least a three year period. In particular net assets to arrent liabilities ratios of failed companies deccease, while the ratio remains stable in the continuing firms.

10. The current ratio in failed companies deteriorates at least two years prior to failure, while in contimuing firms it remains stable. Pretax profit to interest ratio of failed companies is lower than 2.0 . 
11. The following ratios are considered to be an ultimate test of company solvency, if their values decrease to specific limits as calculated from the means of "All failed 22" and "Non-failed 20" groups (see Section 8.4.2):

- current assets/current liabilities $<1.0$

- net assets/current liabilities < 1.0

- pretax profit/interest $<2.0$

12. The results obtained from 73 continuing companies with positive Z-soores had the above three ratios as follows:

1) 6 out of 73 of the group had a current ratio less than unity (see section 8.4.3)

11) 30 out of 73 of the group had a net assets to current liabilities ratio less than unity thus reflecting that over 408 of construction companies rely on having borrowed funds, considered to be unusual in other industries.

iii) 14 out of 73 of the group had a pretax profits to payable interest ratio less than 2.0 .

13. Twelve companies out of 73 of the group had two ratios mentioned above less than the specified limits of the "failed 22" group 1.e. about 168 of ontinuing companies have profiles similar to failed companies.

14. The lower the $\mathrm{Z}$-score and deteriorating ratios for a company and the more years the company is classified at risk the more likely that company is to fail. 
15. The evaluation of the managerial factors related to failure in order of importance were as follows:

- weak finance director

- chief executive sole authority without authorised assistants

- lack of engineering skills

- poor response to market change

- non-contributing persons on company board

- senior management staff not involved in bidding process

- lack of managerlal skills

- chief executive and chaiman, same person.

16. The evaluation of management errors in order of importance were:

- making losses in projects

- making losses in contract claims

- making losses in overseas contracts

- high leverage

- taking over failing firms

17. The results obtained from case studies showed that the following factors and errors can lead to failure:

- poor trading on contracts taken on at tight margins

- delays in settlement of substantial claims

- losses incurred by other companies within the group such as guaranteelng loans of a subsidiary company

- acquiring failing firms with activities not fitting in well with the parent business

- financial drain caused by expansion of home or overseas work. 
18. The analysis of trends of failed and non-failed companies was as follows:

- profitability ratios for solvent companies is always positive, while for failed firms declines sharply and beocmes negative (see Figures 7.5, 7.10, 7.12)

- current assets to net assets ratio for failed firms rises due to increased reliance on borrowed funds, net assets decrease sharply, current assets remains stable in continuing firms (see Figure 7.6)

- turnover to net assets ratios for failed companies rises due to overtrading, while for continuing companies remains stable (see Figure 7.7)

- current liabilities to net asset ratios for failed companies rises due to increased reliance on borrowed funds with sharp decreases in net assets, but for continuing companies remains stable (see Figure 7.14).

\subsection{RECOMMENDATIONS FOR IMPLEMENTING THE RESEARCH FINDINGS IN VEITING CONSTIRUCTION COMPANIES ON TENDER IISTS}

To obtain rellable results in vetting construction companies on tender lists, application of the developed models of this study as classification devices required the following to be implemented:

- Financial ratios and z-scores should be ranked with those in its own sector of industry. It is important to view the company in relation to the performance of the rest of the industry. 
- Produce a distribution of Z-scores for the industry each year, and compare the performance of a particular company with the mean of Zscores for that year.

- There is potential danger in relying upon the results of single tests, at least two methods should be adopted in vetting construction companies on tender lists.

- At least two financial ratios out of the three critical ratios are needed to give results less than the specified limits and to exhibit negative $\mathrm{Z}$-scores for at least three years before coming to the conclusion that a company is "at risk".

- A-scores should only be used for companies exhibiting failure Zscores and/or critical ratios methods.

- A-scores should be viewed more tolerantly for large compared to small firms because of their strength and reputation in the market.

For a systematic appraisal of contractors, the procedure is as shown in Figure 11.1 and is designed to facilitate the vetting of construction companies on a tender list. However, the developed models should only be used as part of an overall assessment of company stability. Any predictions should be interpreted with caution as the models require further testing on a broader range of companies. It is also important to appreciate that the use of such models to exclude companies from tender lists could accelerate or even cause failure. 


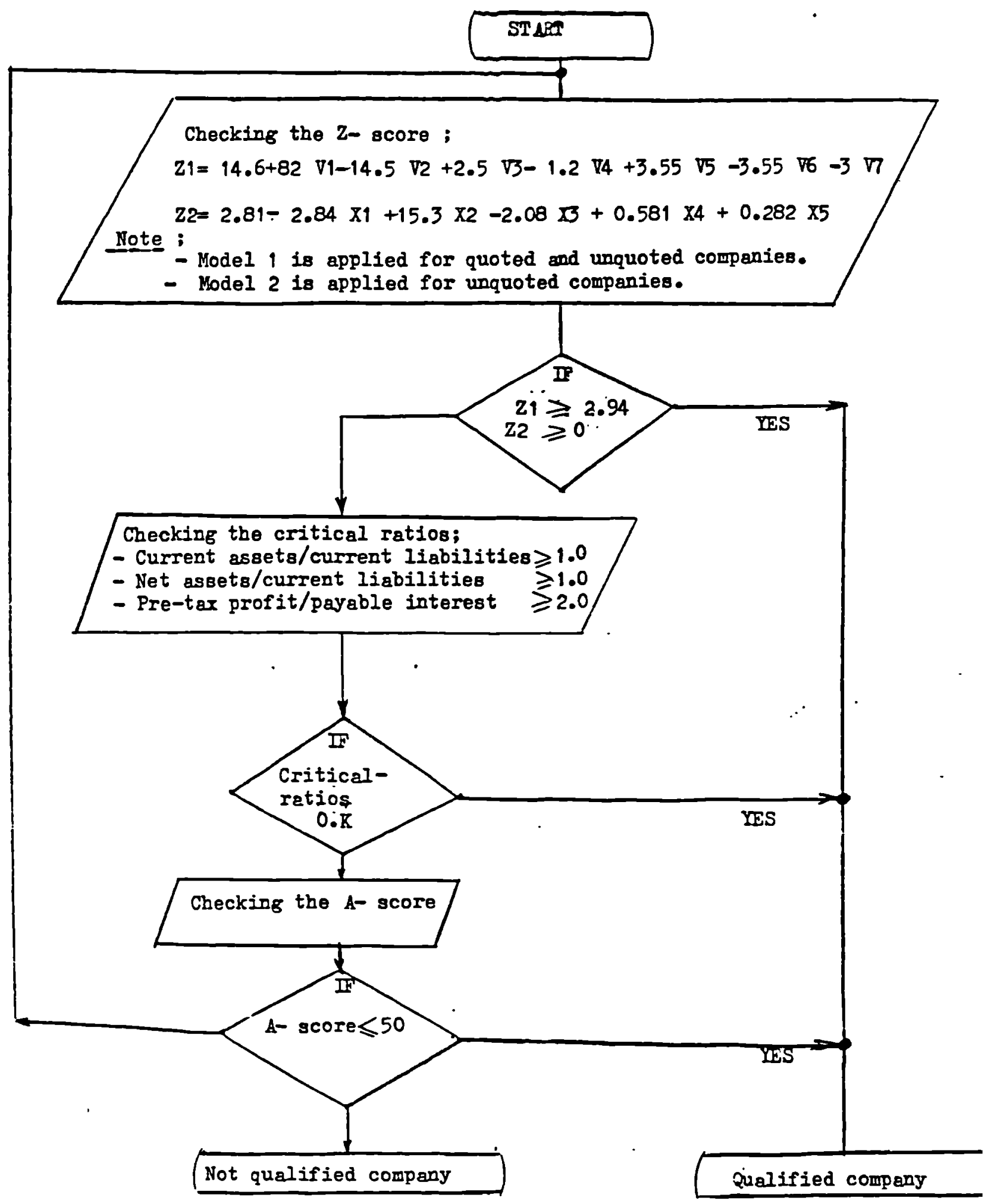

FIGURE 11.1: SHOWS A SYSTEMATIC APPRAISAL OF CONTRACTORS IN THE CONSTRUCTION INDUSTRY 
Model (1)

$z_{i}=14.6+82 \nabla 1-14.5 \mathrm{~V} 2+2.5 \mathrm{~V}-1.2 \mathrm{~V} 4+3.55 \mathrm{~V}-3.55 \mathrm{~V} 6-3 \mathrm{~V}$

$\nabla 1$ : As a ratio of earnings after tax and interest to not capital employed -

V2 : 1 a ratio of current assets to net asset .

$\sqrt{3}: 1$ a ratio of tarnover to net asset

V4 : 4 a ratio of ahort term loan to earnings before tax and interest

V5: As a tax trond

V6 : Earnings after tax trend : $\frac{E_{n}+E(n-1)}{\frac{2}{E(n-2)}-E(n-2)}$

$\nabla 7$ : Short term loan trend

$$
\frac{\frac{I n+I(n-1)}{2}-I(n-2)}{I(n-2)}
$$

Model (2)

$z=2.81-2.84 \times 1+15.3 \times 2-2.08 \times 3+0.581 \times 4+0.282 \times 5$

$X 1$ : As a ratio of current assets to net asset

$X_{2}:$ ss a ratio of earning after tar and interest to net capital employed

$x 3$ : As a ratio of interest to earaing before tax and interest.

$X 4:$ Tax trend $\frac{T n+T(n-1)}{2}-T(n-2)$

$$
T(n-2)
$$

$X 5$ : As a ratio of turnover to net asset

Note ;

- The denominator is taken as the absolnte value

- The trend retios are calculated for jear $n$.

FIGURE 11.2: KEY TO FIGURE 11.1 


\subsection{CONIRIBUTION OF THESIS TO THE CONSTRUCTION INDUSTRY}

This research provldes an Insight into the methodology of predicting company failure in the construction industry and offers an opportunity to link several methods together in order to systematically appraise contractors on tender lists. Until now other construction based systems in the UK have been unavailable.

The research provides several models which provide quantitative indications of the solvency of companies.

Finally, the research highlighted managerial factors contributing to failure and provides the A-score test suitable for those engaged in rescues.

\subsection{FURTHER RESEARCH WORK}

1. Development of an expert system package to help in vetting construction companies on tender lists, perhaps using the models indicated in this research.

2. Produce an alternative remedy to bankruptcy for companies classified at risk in the construction industry.

3. Development of quantitative measures to return a failing company to health in the construction industry, perhaps using the models indicated in this research.

4. Multivariate Discriminant Analysis approach for analysing menger activity in the construction industry. 


\section{REFERENCES}

1. Construction Statistics, 1988. Market Review UK Construction Industry $\cdot($ Key note $-1 \mathrm{C} C)$

2. Merwin, C.L., 1942. Financing Small Corporations in Five Manufacturing Incustries 1926-1936, New York.

3. Beaver, W.H., 1966. Financlal ratios as predictors of fallure. Empirical Research in Acoomting Selected Studies. Supplement to the Journal of Acoounting Research, Vol. 5 (1967), pp 71-111.

4. Beaver, W.H. Market Prices, Financlal Ratios and the Prediction of Fallures. Journal of Acoounting Research. Autumn 1968, pp 179192.

5. Beaver, W.H. Alternative Accounting Measures as Predictors of Failure. Accounting Review, Vol. 43, No. 1, January 1968, pp 113122.

6. Pinches, G.E., 1980. Factors Influencing classification results from multiple discriminant analysis. Journal of Business Research 8, No. 4, pp 429-456.

7. Argent1, J., 1983. Predicting corporate failure. Institute of Chartered Acoountants in England and Wales, Accountant Digest, No. 138.

8. Altman, E.I., 1968. Financial ratios, discriminant analysis and the prediction of corporate bankruptcy. Journal of Finance 23, No 4, pp 589-609.

9. Altman, E.I., 1974. Evaluation of a company as a going concern. Journal of Accounting, Vol. 138, No. 6, December 1974, pp 50-57. 
10. Altman, E.I. and Bettina, Loris, 1976. A financial early warning system for over-the-counter broker-dealers. Journal of Finance, Vol. 31, No. 4, September 1976, pp 1201-1217.

11. Taffler, R.J., 1976. Finding those firms in danger. City University Business School, working Paper No. 3, September 1977.

12. Taffler, R.J., 1982. Forecasting company failure in the UK using discriminant analysis and financial ratio data. Joumal of the Royal Statistical Society, Series A, Vol. 145, Part 3, pp 342-58.

13. Taffler, R.J., 1983. The assessment of company solvency and performance using a statistical model. A comparative UK-based study. Accounting and Business Research, Vol. 15, No. 52 (Autumn), pp 295-308.

14. Taffler, R.J., 1984. Empirical models for the monitoring of UK corporations. Joumal of Banking and Finance, Vol. 8, No. 2, pp 199-227.

15. Taffler, R.J., 1985. Insolvency predictors. Certified Acoountant, February 1985, pp 20-24.

16. Taffler, R.J. and Gomar, M.J. 1985. An analysis of the comparative performance of UK companies involved in successfully fought off take-over bids. Unpublished paper read at the 1985 British Acoounting Association Anmual Conference, University of Full.

17. Mason, R.J. and Harris, F.C., 1978. Bankruptcy prediction by discriminant analysis. MSc Thesis, LUT, UK.

18. Mensah, Y.M., 1984. An examination of the stationarity of multivariate bankruptcy prediction model. A methodological study. Joumal of Acoounting Research, Vol. 22, No. 1, pp 392-3. 
19. Deakin, E.B., 1972. A discriminant analysis of predictors of business failure. Journal of Accounting Research, Vol. 10, No. 1, (Spring 1972), pp 167-179.

20. Johnsan, C.C., 1970. Ratio analysis and the prediction of firm, failure. Journal of Finance, Vol. 25, No. 5 (December 1970), pp 1166-1168.

21. Blum, M., 1974. Failing coṇany discriminant analysis. Joumal of Accounting Research, Vol. 12, No. 1 (Spring 1974), pp 1-25.

22. Laurence, Prust and Company, 1976. "The LP Solvency Model". Investment Research Circular, 29 March 1976.

23. Morrison, D.G., 1969. On the interpretation of discriminant analysis. Journal of Marketing Research 6, No. 2, pp 156-163.

24. Joy, O.M. and Tollefsan, J.O., 1969. On the financial application of discriminant analysis. Journal of Marketing Research, Vol. 6, No. 2, May 1969, pp 156-163.

25. Deakin, E.B., 1977. Distribution of financial accounting ratios, some empirlcal evidence. The Accounting Review, Vol. 51, No. 1, January 1976, pp 90-96.

26. Zavgren, C.V., 1985. Assessing the vulnerability to failure of American Industrial Firms. A Logistic Analysis, Journal of Business Finance and Accounting,. Vol. 12, No. 1 (Spring), pp 1945.

27. Zmijewski, M.E., (1984). Methodological issues related to the estimation of financial distress prediction model. Joumal of Accounting Research, Vol. 22, Supplement pp 59-82. 
28. Cooley, W.W. and Lohnes, Paul R. Multivariate data analysis. John Wiley and Sons, 1971.

29. Dunteman, G.H. An introduction to multivariate analysis, SAGE Publications Ltd, London 1984.

30. Ohlson, J.A., 1980. Financial ratios and the probabilistic prediction of bankruptcy. Journal of Accounting Research, Vol. 18, No. 1 (Spring), pp 104-31.

31. Elsenbels, R.A., 1977. Pitfalls in the application of discriminant analysis in business, finance and economics. Joumal of Finance, Vol. 32, No. 30, (Jine), pp 875-98.

32. Eisenbeis, R.A. and Avery, R.B. 1972. Discriminant analysis and classification procedure. D.C. Heath and Company, Lexington, Mass.

33. Eisenbeis, R.A. and Altman, E.I. 1976. Financial applications of discriminant analysis, a clarification. New York University, Salomon Brothers Centre for the Study of Financial Institutions, working Paper 79 (Autum 1976).

34. Troy, D. PhD Thesis, Alabama University, USA, 1968. The computations are taken fram Hoel (pp 181-182) and lecture notes from Dr Paul M. Hummel's Course on Mathematical statistics at the University of Alabama.

35. Mosteller, F. and Wallace, D.L. 1963. Inference in the authorship problem. Journal of the American Statistical Association 58, No. 302, pp 275-309.

36. SPSSX Manual, Statistical package for the Social Sciences, MoGraw Hill Book $\infty$. 
37. Tisshaw, 1976. Model for the analysis of privately owned manufacturing companies.

38. Gilbreath, R.D. Managing construction contracts. A WileyInterscience Publication, 1983.

39. Prais, S.J. Varlation between industries. Tew, B. and Henderson, R.S. Studies in Company Finance, London, NIESR, 1958.

40. Chudson, W.A. The pattern of corporate financial structures: a cross-section of manufacturing, mining, trade and construction 1937 (New York, NBER, 1945). 


\section{APPENDICES}

A. Manual for Use with the Fortran Program "ADNAN-FOR" for the Computation of Financial Ratios

B. A Manual for Use with the "SPSS-X" Statistical Package for the Social Sciences Sub-program "Discriminant" an output

C. A Manual for Use with the Minitab Statistical Package and its output

D. Correspondence, diagrams, case studies and questionnaire

E. Statistical Tests 


\section{APPENDIX A}

\section{MANUAL FOR USE WITH THE FORTRAN PROGRAM "ADNAN-FOR" FOR THE}

\section{COMPUTATION OF FINANCIAL RATIOS}

\subsection{INIRODUCTION}

The Fortran program, ADNAN.FOR developed to perform the financial ratio calculations and data manipulation including:

- the User Manual

- the Program Documentation

\subsection{USER MANUAL}

\subsubsection{Introduction}

The computer program ADNAN.FOR has been written and developed for specific use in the calculations required in this project and could be used in financial institutions. The User Manual sets out how the program may be used to perform the calculations and the program documentation section allows the program to be understood.

The program calculates, from 18 pieces of financial information obtained from company financial reports, a series of financial ratios and measures 46 in all relevant to this study.

The program is in two parts:

- the 18 pieces of financial information are read by the computer and printed out for checking 
- the program calculates the 46 financial ratios and measure of performance for the six years as maximum period, and the program asks the user the required number of years, and name of file for output.

The program also calculates the means of financial ratios for the required period, and the program prints the trend and growth ratios for the 18 pieces of financial data and also the means of the results.

\subsubsection{Input Data}

This section describes the financial information extracted by the user from the company financial reports to the computer. The following information is required for input for six years as maximum period.

\begin{tabular}{rll}
\hline $\begin{array}{c}\text { Financial } \\
\text { Data No }\end{array}$ & \multicolumn{1}{c}{ Description } & Units \\
& & \\
1 & Annual turnover & x $10^{6}$ \\
2 & Profit after tax & \\
3 & Profit before tax & \\
4 & Cash assets & \\
5 & Current assets \\
6 & Current liabilities \\
7 & Fixed assets \\
8 & Stock and work in progress \\
9 & Debtors \\
10 & Debit over one year \\
11 & Total interest charged \\
13 & Short term loan and overdraft \\
14 & Depreciation \\
15 & Retained profit \\
16 & Equity \\
18 & Employees remmeration \\
\hline
\end{tabular}

Note: The maximum number which could be used in this program is 6 characters without decimals, three places if decimals are avallable for all data. Each number must have a decimal point, and may be written anywhere in the 10 allocated columns. 
Figure Al shows the method of Inputting data, and Figure A2 shows a sample printout.

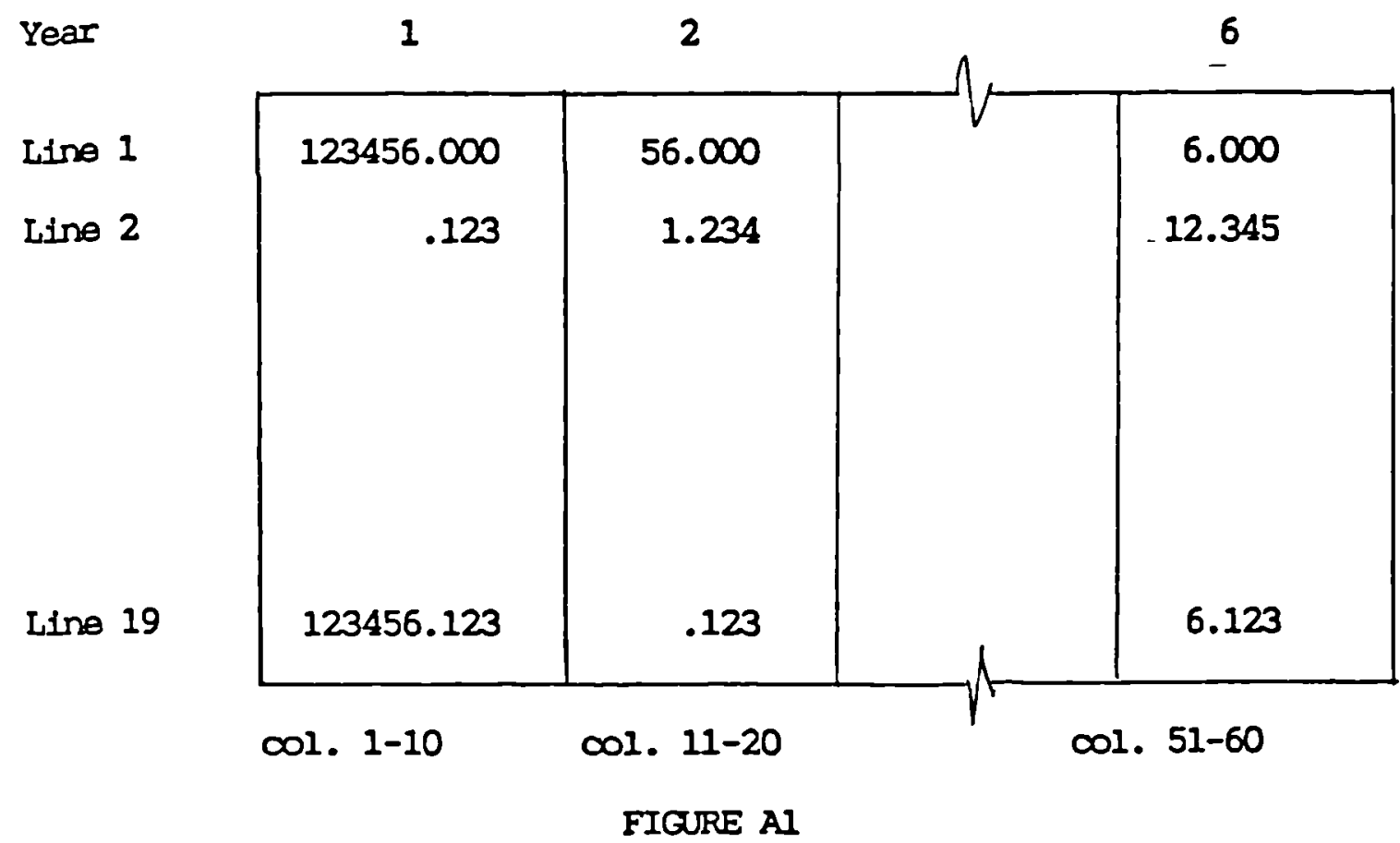

\subsubsection{Output}

The output is tabular in form, the printart includes:

1. the financial data for each ompany.

2. the financlal measurements of performance for each company including financial ratios for six years with mean, trends and growth ratios.

To indicate what the user should expect fran the program, Figures A3 and A4 show some output resulting from numing the program. 
A conclise flowchart of the four parts is as follows:

For all companies in the study
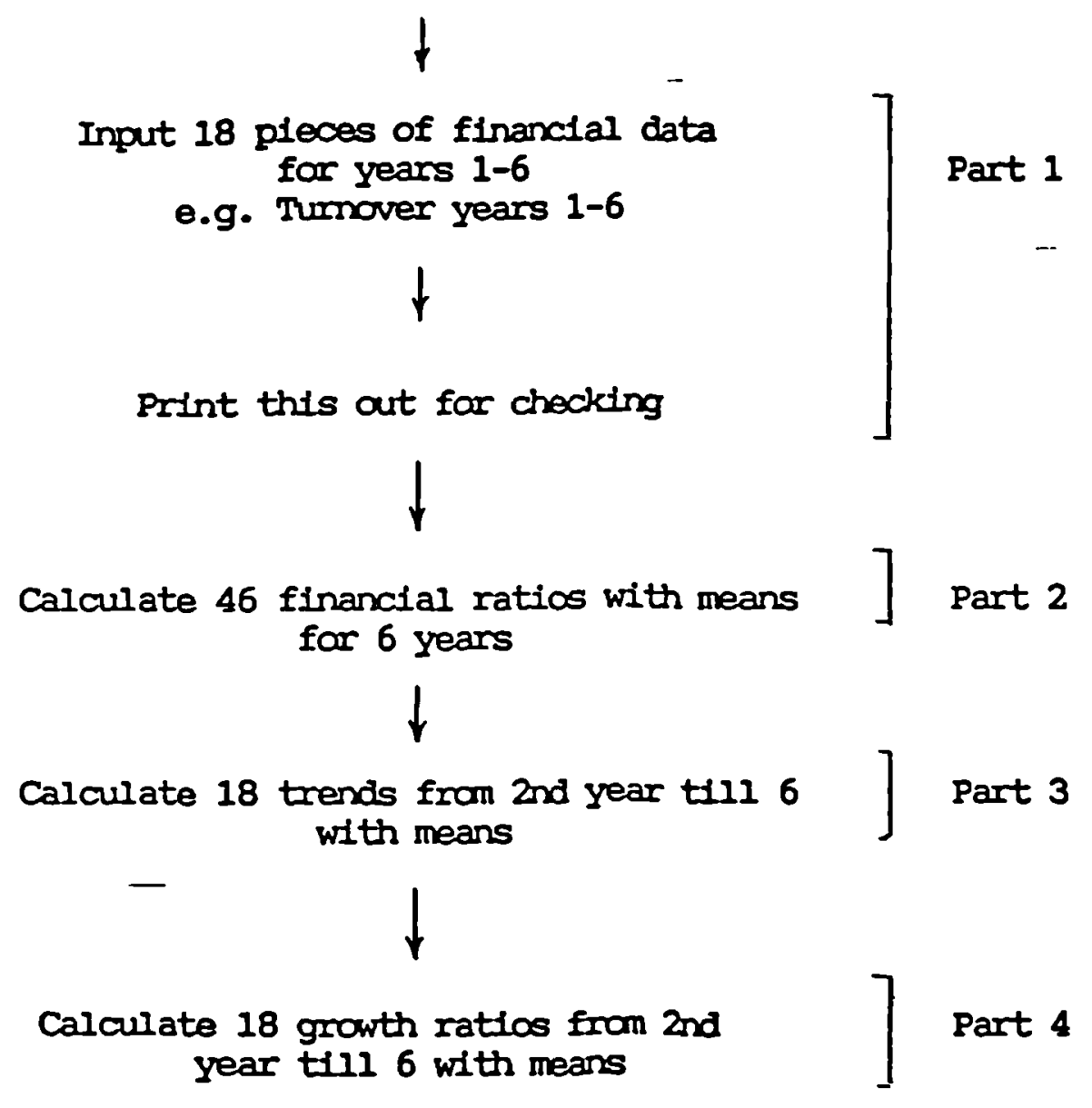

The data should be inputted as follows:

1. For each of the 30 companies, 19 lines of recording must be completed.

2. On line 1 the company number is written 1.e. 1-30 which should for clarity not contain a decimal point and should be in the first 10 columns. This enables the company data to be easily identified.

3. Iines 2-19 the financial data, 1-18 above is entered. 


\subsection{PROGRAM DOCUMENTATION}

\subsubsection{Introduction}

ADNAN.FOR is a computer program written in the programing language FORTRAN 77 for use on the PC-IBM.

Core space required 141186 bytes.

Input data is stored in a three-dimensional array, and all calculations are performed using three-dimensional arrays.

\subsubsection{Variables}

The following variables are used:

$1 \mathrm{~V}:$ a three-dimensional array $30,18,6$ containing the 18 pieces of input financial data for 6 years and for 30 companies.

2 R: a three-dimensional array $30,46,10$

containing the 46 calculated financial ratios for 6 years, and for 30 companies. Further the means of the data are held in R.

3 A file name for output

$4 \mathrm{~N}$ the number of the company

5 ny the number of years

$6 \mathrm{Ii}, i=1,, 18$ the subscripted variables used as a counter in the DO loops. 
=omminn $\because(30,18,6)$

real $1 \times 8 R(30,46,10)$

chäacter $* 32$ fname

write(*," (" Enter data fjlename" :)")

read (*, ( $(a)$ ) fname

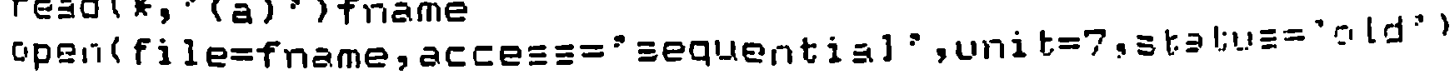

writel*,", Enter number af years $: 1:)$

$r \in a d(*, *)$ ny

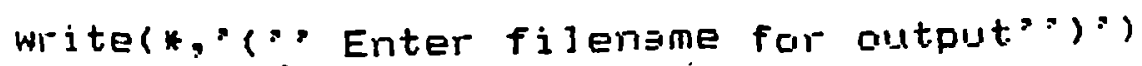

read (*)" (a)") f name

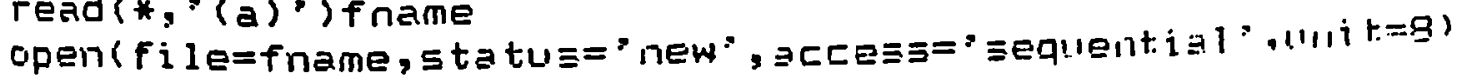

URITE (8,999)

999 FORMAT $(1 \mathrm{H}, 1 / 1 / 1 / 1 / 1 / 1 / 1 / 1 /)$

$i 1=1$

1 continue

C

C

C

READ COIMFAINY INIJIAEER

REFIO 7,10, end $=300$, err $=300) \mathrm{it}$

10 FORNIAT ( 3 ).

DO $50 \quad I Z=1,18$

C

c

C

READ I:TH COHFANY DATA

READ $(7, x$, end $=300$, err $=300)(V(11,12,13), I 3=1, n ;)$

C

c

C

WF:I JE ( 8,55$)$

55 FOFIMT ( $1 \mathrm{HI})$

WRITE $(8,160)$

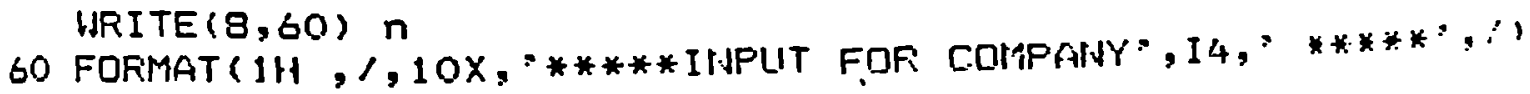
URITE $(8,160)$

WRITE $(8,70)$

70 FORIMAT (1H, 'DATA:, $7 X$,

WRI TE ( $8: 150)$

DD $90 \quad I 4=1,18$

WRITE $(8,80) I 4,(V(I 1, I 4, I 5), I 5=1, n Y)$

80 FORMAT (I3, $\left.6 F_{14} 4.3\right)$

9O COHJTIHUE 


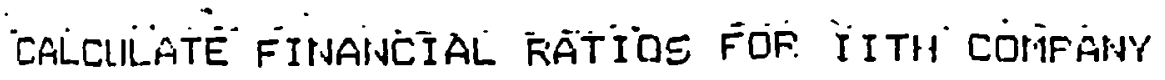

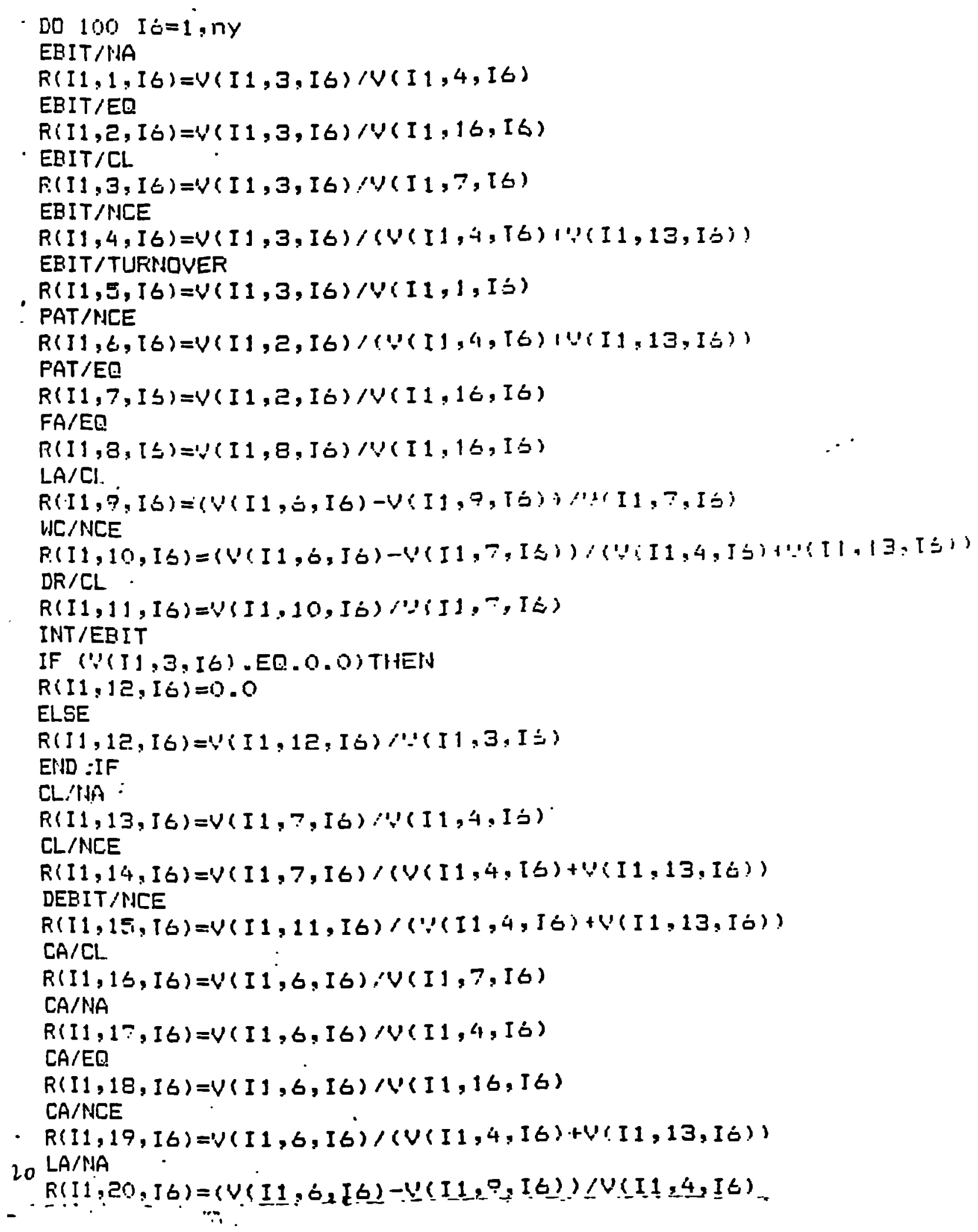




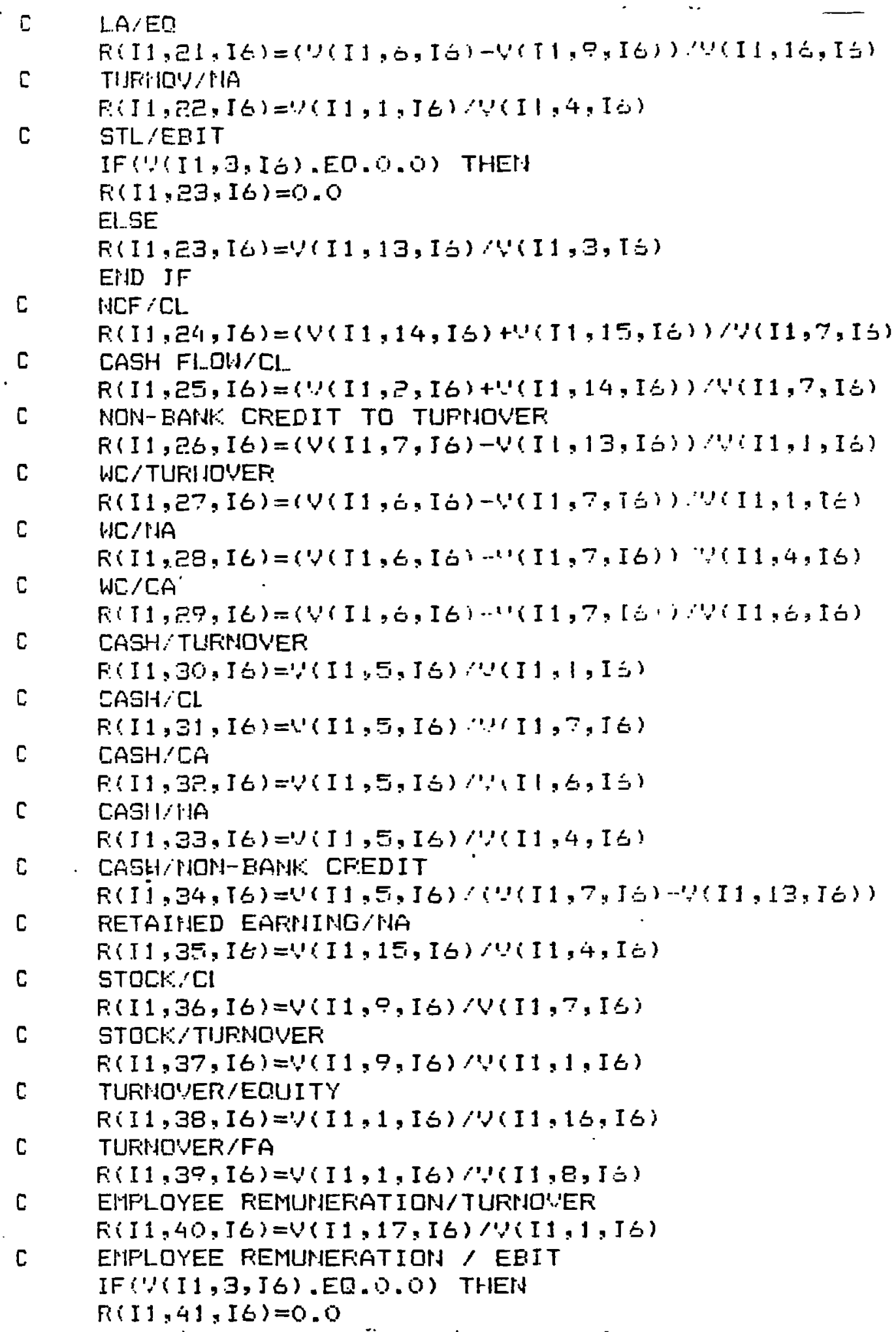




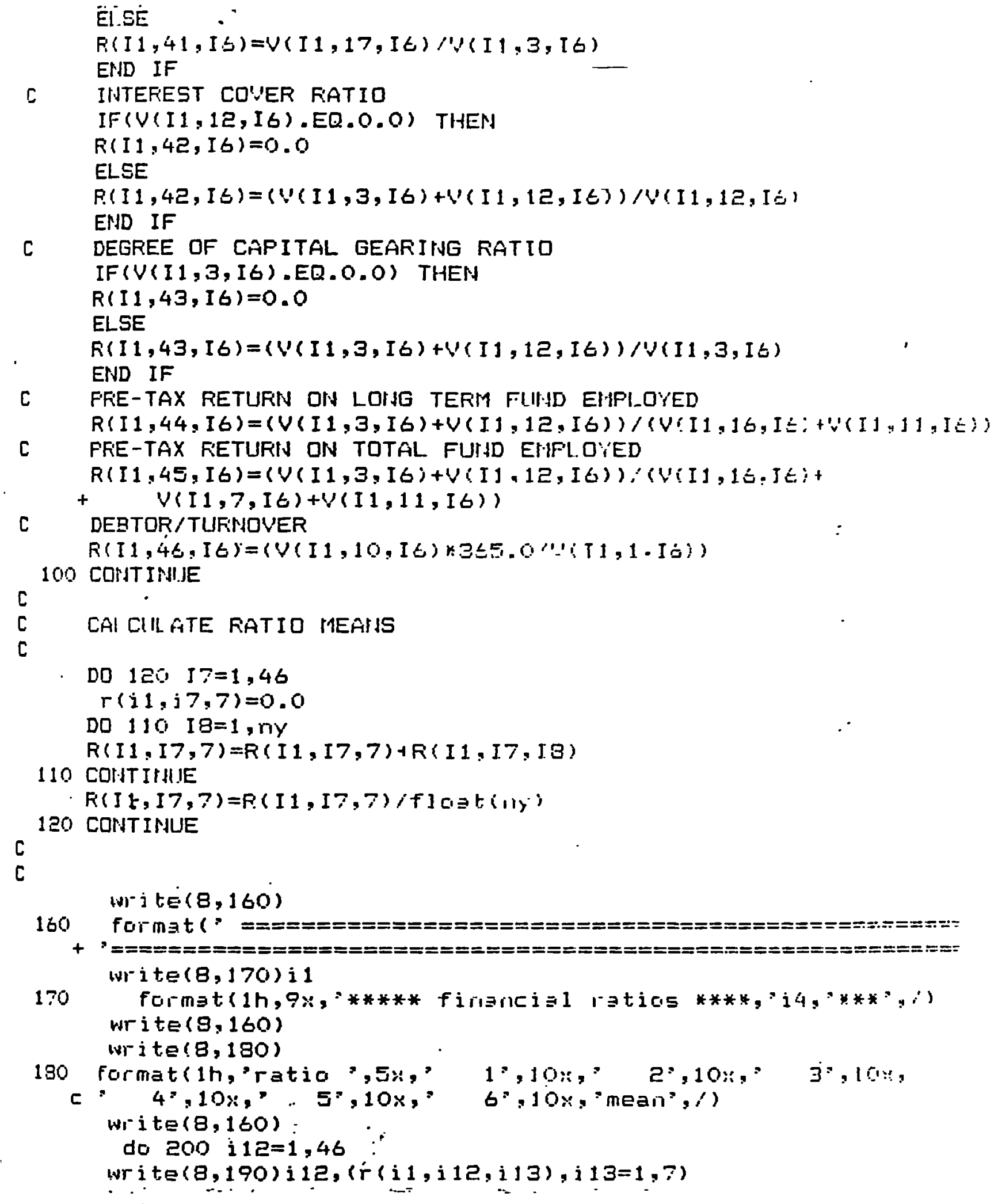


190 format $\ddot{(i 3}, 3 f i 4.3)$

200 continue

wrj.te $(8,160)$

write $(8,160)$

write $(8, "("$ TRENDS": $)$ )

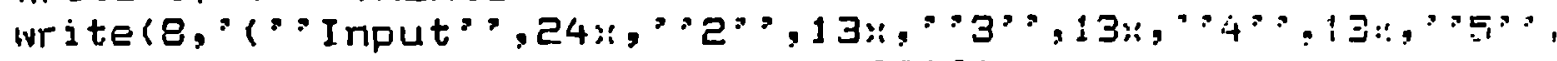
$13 x, " 6 "=13 x, "=$ mean": ")

(w) ite $\left.(8, *(/))^{\prime}\right)$

DO $777, I=1,18$

Ca] I tirend (I, ny, i I)

777 CONTIRUE

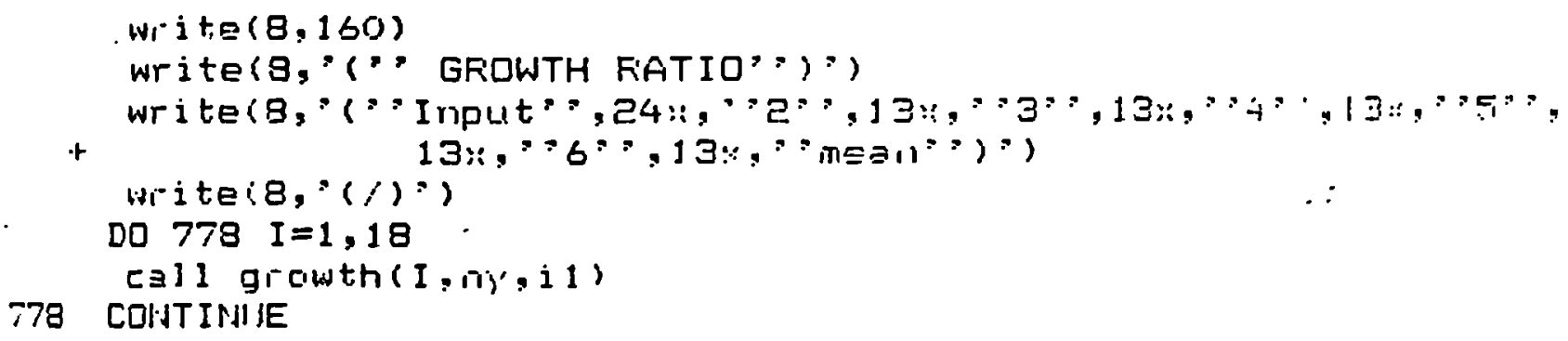

778 COIJTINIE

Write $(\theta, 160)$

write $(8,160)$

$i 1=i 1+1$

goto 1

300

continue

step

eind

$$
\therefore
$$

Elbroutine trend (n,ny,ic)

cemmon $\vee(30,18,6)$

dimension $*(6)$

$x(6)=0.0$

do $10 i=1,(n y-1)$.

if $(v($ ic, n,i).eq.0.0) then

$\because(i)=0.0: ;$.

el $\equiv$ e

$x(i)=(v(i c, n,(j+1))-v(i c, n, i)) / v(i c, n, i)$

endj $f$

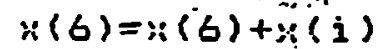

10

continue.

$x(6)=x(6) \times(n y-1)$ 
write $\left(\theta^{\prime}, '(i 3,14 x, 7 f 14.3) \cdot\right) n,(x(j), i=1,6)$

return

end

subrcutirie groutti(n,ny, ic)

camman $v(30,18,6)$

dinensjon $\because(6)$

$\because(6)=0.0$

do $10 \mathrm{j}=1,(n y-1)$

if $(v(i c, n, i)$.eq.0.0) then

$\because(i)=0.0$

el. $\mathrm{Ee}$

$x(i)=v(i c, n,(i+1)) / v(j c, n, i)$

endif

$u(6)=x(6)+x(i)$

10 cantinie

$\because(s)=x(a) \cdot(n y-1)$

write $(8, *(i 3,14 x, 7 f 14.3)=) n,(x(i), i=1, \dot{1})$

return

end 
. $\frac{1}{17268} 2571121489$

$\begin{array}{llll}535 & 1834 \quad 1184\end{array}$

" 55120091280

80151750812761

515458115982 -

188193076924794

12665249581881

1961.116976779

L: 168972397320435

78024201600

45051192784

139017391564

" $840917007 \quad 12704$

177203190

ir 2581603930

$7565 \quad 123899977$

in $799 \quad 1047923$

461616

" 2

238435262955

$\begin{array}{lll}-145 & -738 & -441\end{array}$

$-734-145-439$

984050917

880994937

9321034993

181220281920

186418441854

$\begin{array}{lll}234 & 176 \quad 205\end{array}$

$693 \quad 055774$

33.4338

. $9117 \quad 128 \quad 122$

1120865992

$425 \quad 471448$

mal $-746-145-445$

$951807 \quad 979$

126910641166

440

3

456641054586

$95-592-2$

$40112-584$

$2910 \quad 1886 \quad 1429$

$460 \quad 272 \quad 120$

218320402420

$1 / 2323122541$ ?

237820861450

$031509 \quad 344$

$1324 \quad 1529 \quad 1374$

925643496

157219209

$517 \quad 1113 \quad 1214$

$\begin{array}{lll}71 & 175 & 274\end{array}$

$56-596-6$

291018861429

., 1782

4

162402104918544.

48719051196

$\begin{array}{llll}578 & 1905 \quad 1241\end{array}$

$13546 \quad 8796 \quad 11171$

973350207376

$2033314751 \quad 17542$

1vown- 7101 - 14265

$3913 \quad 3776 \quad 3794$

. 134051090512155

$637 \quad 656 \quad 647$

665446245639

132115125

$294-1905-805$

$7745 \quad 3906 \quad 5825$

$\begin{array}{llll}2415 & 2672 & 2543\end{array}$

271910

5

FIGURE A.2: THE INPUT FINANCIAL DATA 


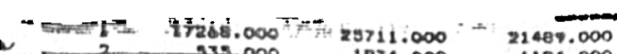

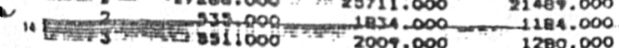

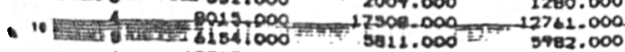

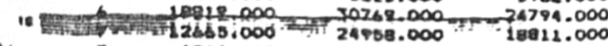

" 20 F

- $n$ F

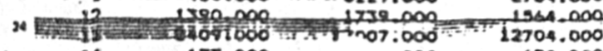

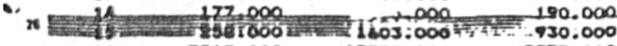

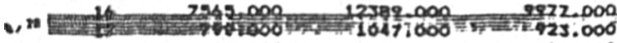

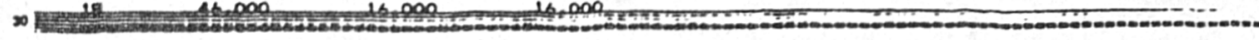

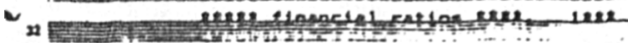

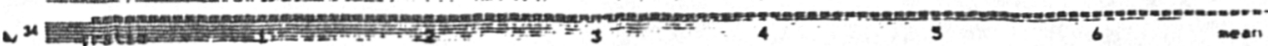

"

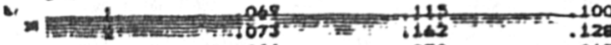

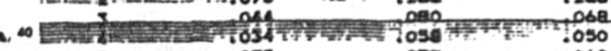

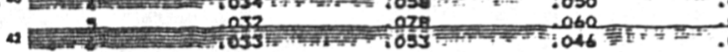

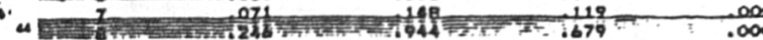

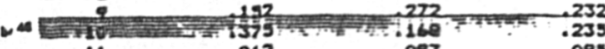

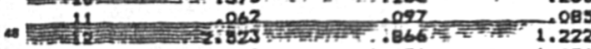

$\nu_{10} 11$.

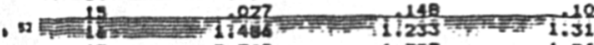

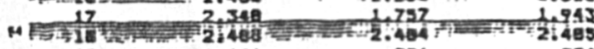

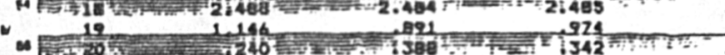

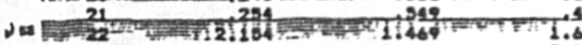

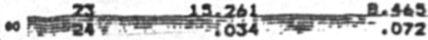

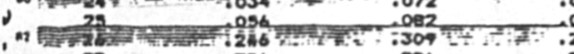

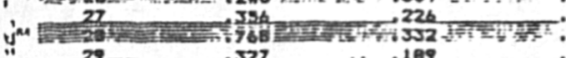

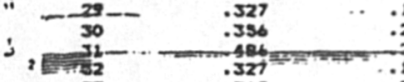

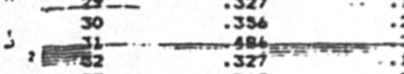

ر.

-

$\therefore$. 1.279

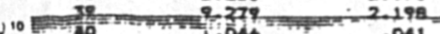

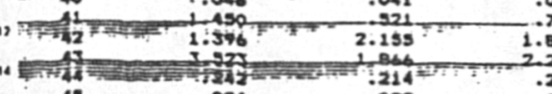

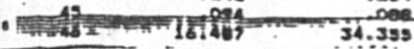

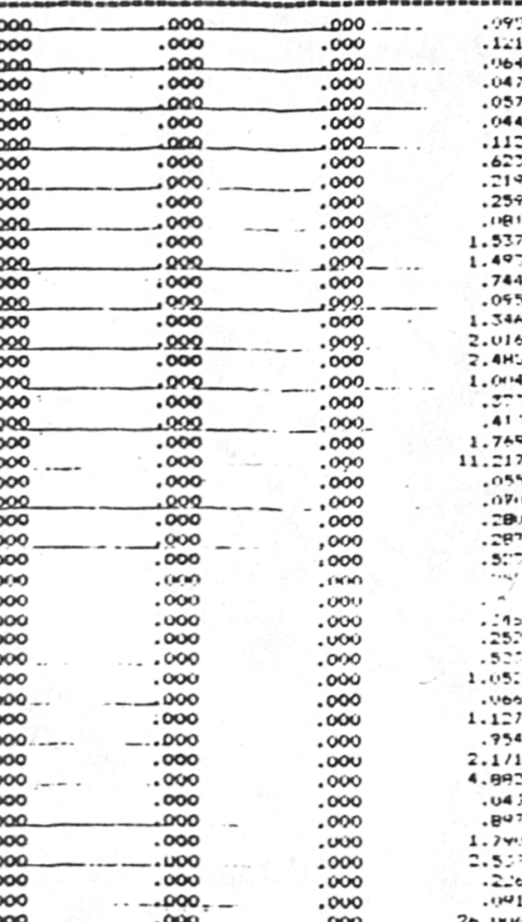

물.

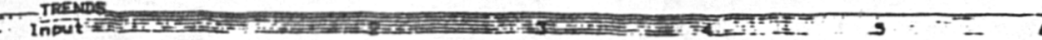

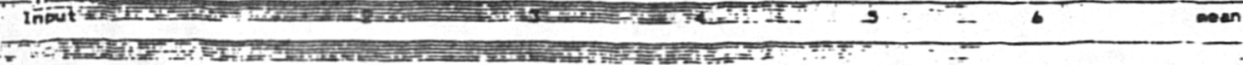

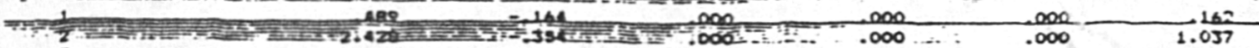
-3
-3

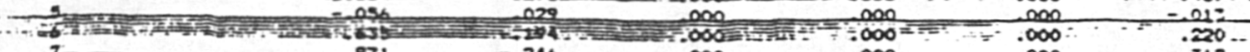

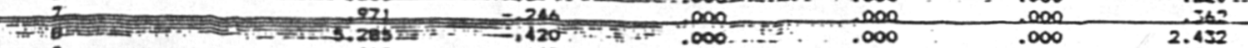

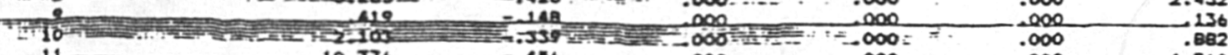

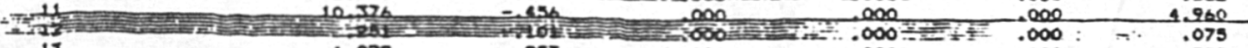

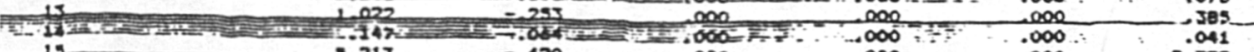

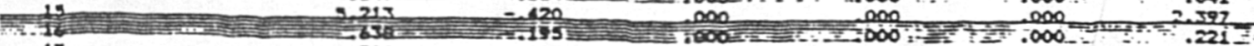

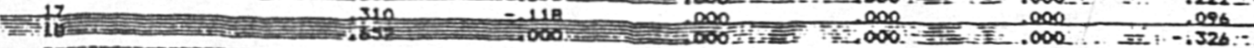

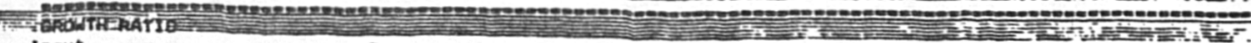

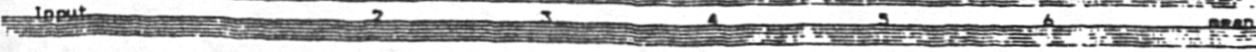

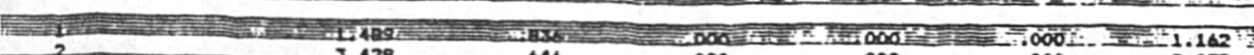

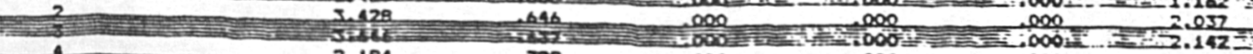

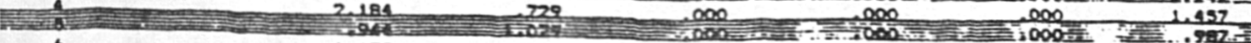

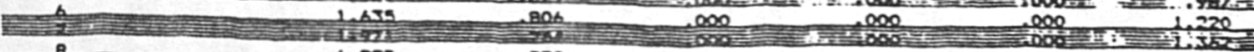

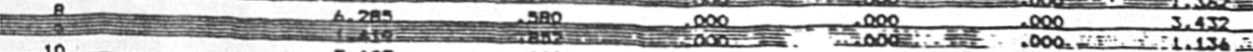

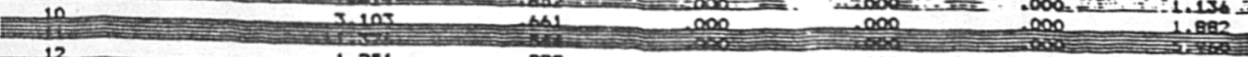

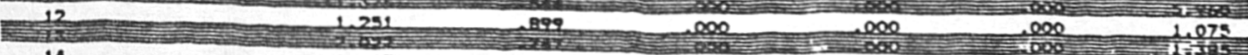

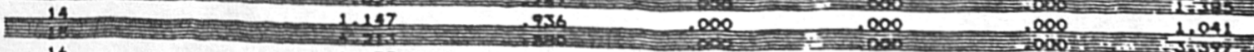

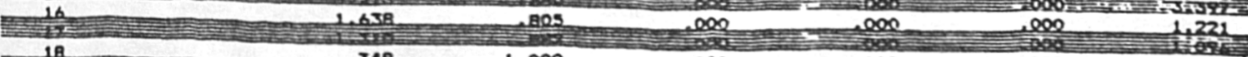

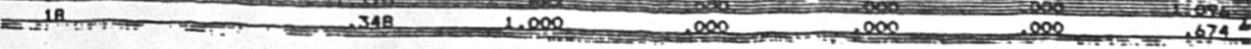

FIGURE A.3: THE CALCULATED FINANCIAL RATIOS FOR COMPANY 1 


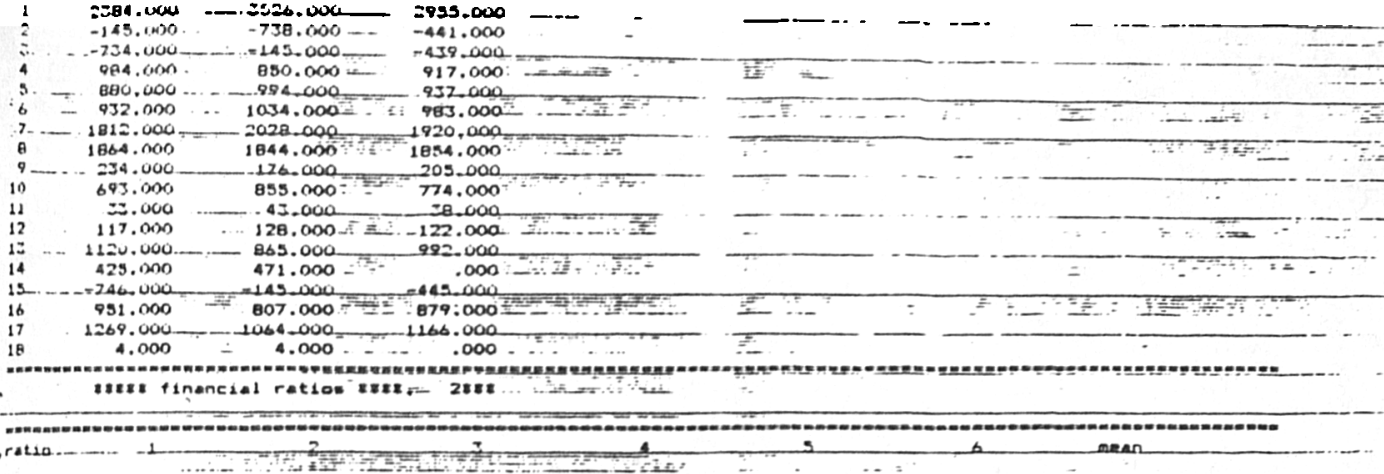

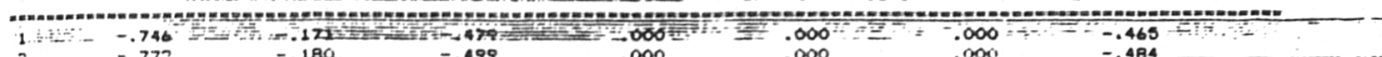

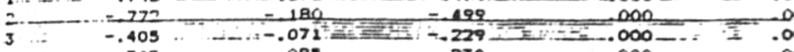

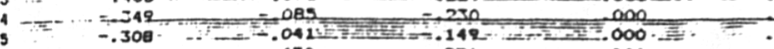

0.000

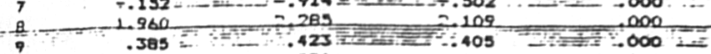

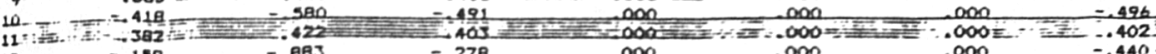

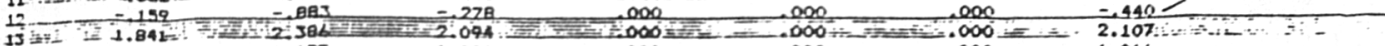

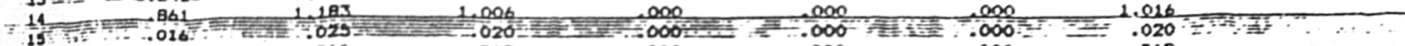

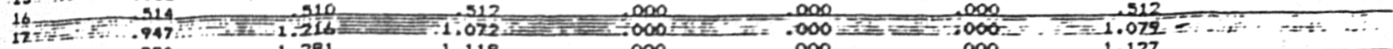

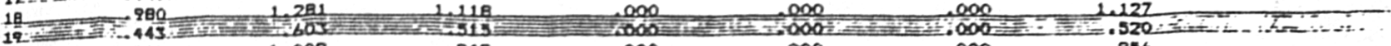

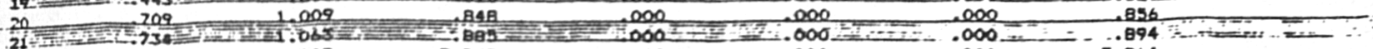

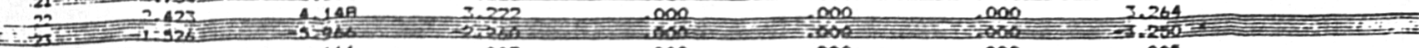

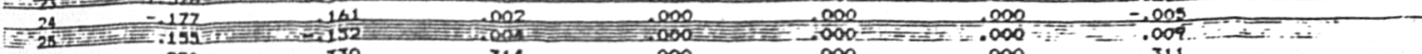

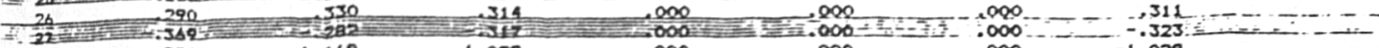

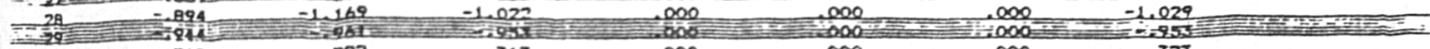

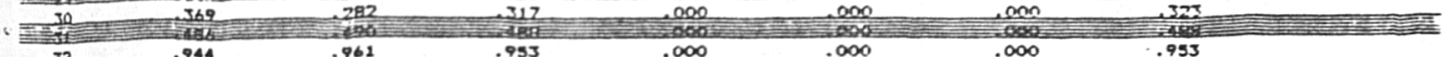

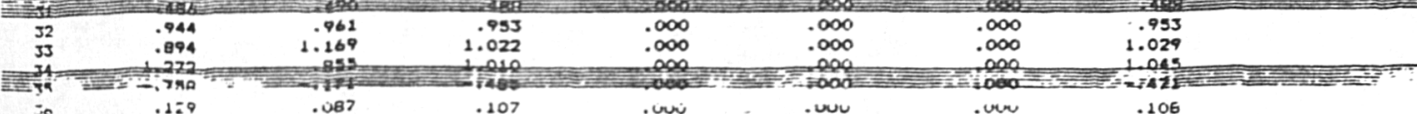

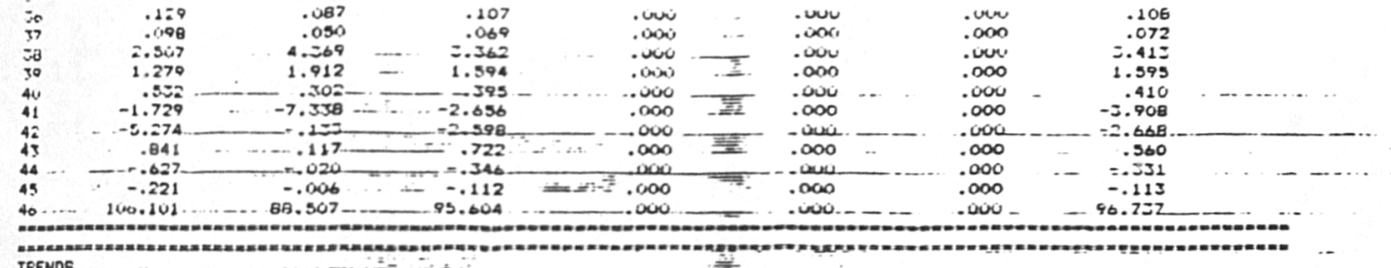

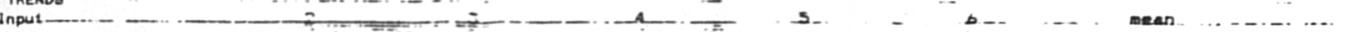

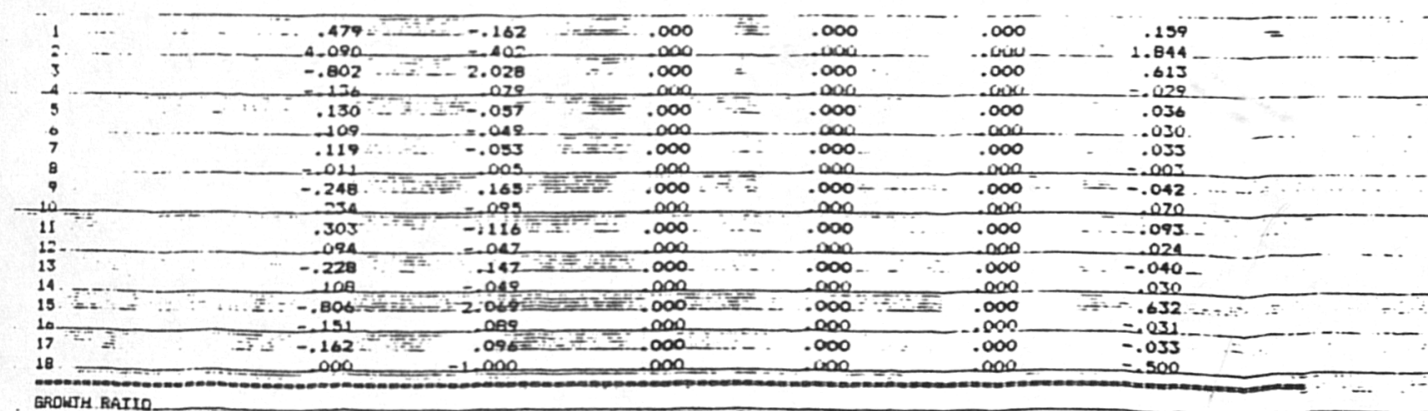
GRowT RATIO Fis 1 .

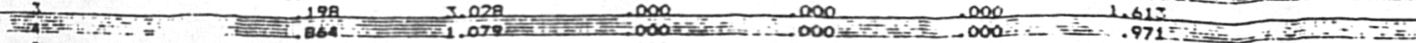

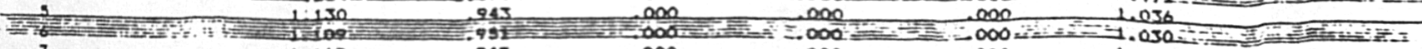

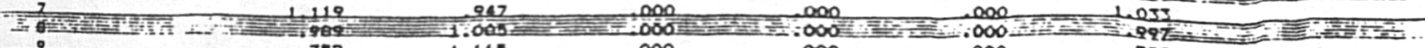

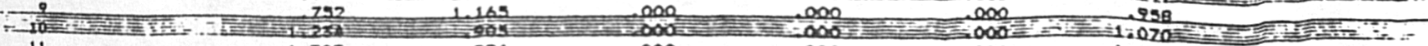

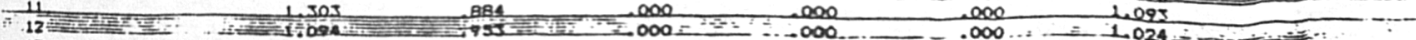

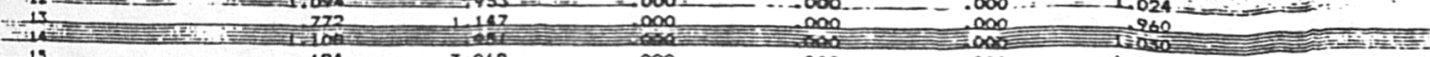

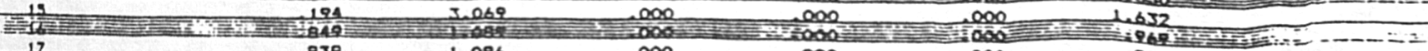

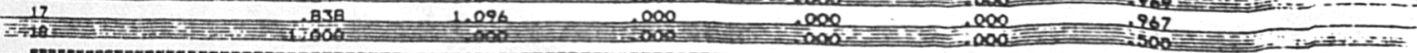
青

1 1. 


\section{APPENDIX B}

A MANUAL FOR USE OF THE "SPSS-X" STATISTICAL PACKAGE FOR THE SOCIAL SCIENCES SUBPROGRAM "DISCRMMINANT" AND ITS OUIPUT

\section{INIRODUCTION}

The statistical package described here is used through the Computer Centre of Loughborough University of Technology, see SPSS (Version X) Manual, MoGraw-Hill and SPSSX Handbook by M J Hunt.

2. THE STANDARD PROGRAM

A listing of a standard program to call up the DISCRIMINANT program, is shown on page 264 using the Multics command SPSSX followed by the name of the file, the SPSSX command (called the control file).

To run SPSS-X requires constructing a file giving two different types of information:

1. Definition command, which describes the data

2. SPSS-X procechures, which perform the analysis.

The data itself should be held on a separate file.

All lines must begin with a command name, unless the line is a continuation of a command given an a previous line. Continuation lines must begin with at least one blank character. The command name is usually followed by further information. For example, the first 
command title is followed by the actual legend of desired companies in quotation marks:

Title "Comparison of profitable and insolvent campanies"

often requires more lengthy information and is often broken up by the slash character ' $/$ ' with key words followed by the = character, for example

file handle acoount/at d=" file-adnan.data"

in which the name of the file to be handled, in our case "adnan.data" which includes 31 financlal ratios for both "solvent and insolvent companies".

The file handle command simply tells SPSS-X where to find the data i.e. the name of the data file.

The next command needed is the data list. This command tells SPSS- $\mathrm{X}$ whereabouts in the data file to find each item of data.

The variable labels command is simply used to give meaning to the blunt variable names in the data list command. The two labelling commands are:

Variable labels V32 "status"

Value labels V32 1 "Solvent" 2 "Insolvent".

Both label commands are not essential but enable us to remember what we are doing and interpret printout, and will help future researchers to use the same work. 


\section{SUBCOMMANDS}

The subcommands which are used in this program are as follows:

\subsection{The "GROUPS" Subocmmand}

The GROUP subcommand defines the groups. Each case used in the computation of discriminations is assigned to a group based on its value on grouping vartables for example:

$$
\text { DISCRTMINANT GROUPS }=V_{32}(1,2)
$$

In our case two groups are defined by the variable $v_{32}$.

\subsection{The VARIABLES Subcommand}

The VARIABLES subcommand names the variables to be used as discriminating variables during the analysis phase, for example

$$
\text { VARIABLES }=v_{1} \text { to } v_{31}
$$

specifies that variables $v_{1}$ through to $v_{31}$ are to be used during the analysis phase.

\subsection{The ANALYSIS Subcommand}

Several discriminant analyses can be done with one DISCRIMINANT command. The user should be named all the variables to be used in the various analyses on the VARIABLES suboommand and then use the ANALYSIS subcommand to specify subsets of variables for individual analysis. For exarmple:

$$
\text { ANALYSIS }=v_{4} \quad v_{9} v_{1} v_{13} \text { etc }
$$




\subsection{The METHOD Subcommand}

Different stepwise methods in the METHOD suboammand are available. These methods enter and remove variables one at a time, selecting them on the basis of specific criteria. Different criterla are used for different stepwise methods.

The METHOD suboamand follows the ANALYSIS suboommand and the method applied in this research was wilks, in which the variables that minimise the overall Wilks' Lambda are selected. The other methods are described in the Manual, MoGraw Hill.

\subsection{The STATISTIC Command}

Several optional statistics are available in this program, see (SPSSX) Manual by MoGraw-Hill.

\section{OUIFUT FROM THE DISCRIMINANT PROGRAM}

The following is some output resulting from the program listing on page 264. The liable card results in the printout as shown in Figure 1, the number of cases by group, in our case in two groups, solvent group 20 cases and insolvent group 11 cases.

Prior to each subanalysis the information shown in Figure 2 is printed out, the information includes the tolerance level "Maximum number of steps" that are allowed for the analysis, minimum "F-value" of variables for inclusion into the function, and the "F-value" for deletion from the function, statement of the method to be used in the analysis and value of the prior probabilities of group membership are included. 
In stepwise method the program automatically prints out standard step by step information, as shown in Figure 3, also the information includes at each step, a value for "Wilks Lambda", for which an approximate "F-test" of significance is given. These are followed by Information about each of the discriminating variables. The variables which have been entered into the analysis are listed, and the value of the "Entry criterion" at the time the variable was selected is given along w1th the current "F to remove".

At step 9, seven discriminant variables have resulted as shown in Figure 4. The program also results in the "statistic 11" unstandardised canonical discriminant functions. These coefficients are multiplied by the raw input data to arrive at discriminant soores. coefficients and canonical discriminant functions are evaluated at group means (group centroids) as shown in Figure 5, and the "Statistic 14" discriminant scores as shown in Figure 6.

The "actual" group for each case and also the group for which it has the highest probability of membership under $P(G / X)$ is printed as the probability of membership on which the classification was based.

The secand highest group probability $P(G / X)$, is also printed if it exceeds .0005. These are then followed by the "Discriminant Scores".

Assuming the statistics table as shown in Figure 7 includes eigenvalues, percentage of variance, cumulative percentage of variance, canonical correlation, Wilks Lambda, chi-square, degree of freedom, and significance of chi-square are reported for the functions. 


\section{OUTPUT FROM THE PROGRAM BY USING THREE GROUPS}

An attempt was made to discriminate between three groups of companies used in this analysis and these groups are namely:

1. "Continued 20" group.

2. "Falled 11" group.

3. "Taken-over 9" group.

Because of the complexity of functions which are included, 19 discriminating variables, the discriminating model has not been developed for the following reasons:

- time restriction

- has not strictly adhered to failure prediction

- requires further research beyond the soope of this thesis

The following is output resulting fram the program listing on page272.

The program resulting from the "Statistic 11" unstandardised canonical discriminant function coefficients for functions 1 and 2 are shown in Figure 8.

The "Statistic 10" territarial map as shown in Figure 9 shows the allgroup scatter plot and the "Statistic 14" discriminant scores are as shown in Figure 10.

The "Statistic 13" classification results are shown in Figure 11 and include a portion of cases classified correctly. The overall classification rate is $97.5 \%$. 
The "Statistic 16" separate-groups plots, in our case three scatter plots, are produced as shown in Figure 12 including all the groups scatter-plots.

To compare the territorial map as shown in Figure 9 with the all-group plot, we can identify the misclassified cases, those are the cases not falling within the outline boundaries on the territorial map. Assuming statistics as shown in Figure 13, eigenvalue, percentage of varlance, cumulative percentage of varlance, canonical correlation, Wilks Lambda, chi-square, degree of freedom and significance of chisquare are included. 


\section{PROGRAM LISTING FOR TWO GROUPS}

20 MAY 88 SPSS-X RELEASE 1.0 A Honeywell/multics

$$
\text { Loughborough University Honeywell } 68180 \text { Multics }
$$

SPSS INC LICENSE NUMBER: 906

\footnotetext{
10 title - Comparison of Profitable and.Insolvent Compani.

20

30

40

50

60

70

80

90

100

190

file handle accounts latda"vijle_ adnan-data"

data list fileraccounts freef vi to v32

variable labels $v 32$ 'status"

value labels $v 321^{\circ}$ "Solvent" 2 . Insolvent"

$1+$ breakdown tables $=v 1$ to $v 31$ by $v 32$

discriminant groupsav $32(1.2) /$

variables a $v 0$ v31/

ltanalysis = v4 v9 v19.v13v16 v18v20v22v26/ method $=$ wilksl

staristics 11,14

THERE ARE 997480 BYTES OF MEMORY AVAILABLE.

THE LARGEST CONTIGUOUS AREA HAS 997480 BYTES.

SINCE ANALYSIS= WAS OMITTED FOR THE FIRST ANALYSIS ALL VARIABLES

ON THE VARIABLES = LIST HILL BE ENTERED AT LEVEL 1.

THIS DISCRIMINANT ANALYSIS REQUIRES 235446 23.OKJ BYTES OF HO
} 
.20 MaY 88 Comparison of Profitable and Insolvent Companies

Loughborough University.

Honeywell. $68 / 80$ Multics-

- I.S:CRIMTNANTTA

ON GROUPS DEFINED BY V 32 STatUS

31 (UNWEIGHTED) CASES HERE PROCESSED.

O OF THESE HERE EXCLUDED. FROM THE ANALYSIS.

31 (UNWEIGHTED) CASES HILL. BE USED IN THE ANALYSIS.

NUMBER OF CASES BY GROUP

v32

NUMBER OF CASES

UNWEIGHTED WEIGHTED LABEL

$\begin{array}{lll}1 & 20 & 20.0 \\ 2 & 11 & 11.0 \text { Solvent }\end{array}$

TOTAL

31

31.0

FIGURE 1: NUMBER OF CASES BY GROUP 
I MAY 88 Comparison of Profitable and Insolvent Companies

I Loughborough University

Honeywelt 68180 Multics

\section{I S C R I M INANTA I}

I GROUPS DEFINED BY V32 STatUS

IALYSIS NUMBER 1

PEPWISE VARIABLE SELECTION

SELECTION RULE: MINIMIZE HILKS LAMBDA

MAXIMUM NUMBER OF STEPS.................. 62

MINIMUM TOLERANCE LEYEL.................. 0.00100

MINIMUM F TO ENTER_...................... 1.0000

MAXIMUM F TO REMOVE....................... 1.0000

SNONICAL DISCRIMINANT FUNCTIONS

MAXIMUM NUMBER OF FUNCTIONS............

MINIMUM CUMULATIVE PERCENT OF VARIANCE... 100.00

MAXIMUM SIGNIFICANCE OF HILKS ' LAMBDA.... 1.0000

RIOR PROBABILITY FOR EACH GROUP IS 0.5000O

FIGURE 2: STEPWISE VARIABLE SELECTION 
20 MAY 88 . Comparison of Profltable and Insolvent Companies

AT STEP 1. VIT

WAS INCLUDED IN THE ANALYSIS.

WILKS - LAMBDA
EQUIVALENT F

0.66258

14.7684 $\begin{array}{crrrr}\text { OEGREES OF FREEDOM } & \text { SIGNIF. } \\ 1 & 1 & 29.0 & & \\ & 1 & 29.0 & 0.0006 & \end{array}$

VARIABLES IN THE ANALYSIS AFTER STEP

1

hariable tolerance F to remove hilks lamboa

$\begin{array}{lll}v 17 \quad 1.0000000 & 14.768\end{array}$

VARIABLES NOT

MINIMUM

VARIABLE TOLERANCE TOLERANCE

v1

V2

V3

V4

V5

v6

v7

v8

v9

त 10

v9

V12

V13

V74

v15

V16

v18

V19

V20

V21

V22

V23

V24

V25

V26

V27

V28

V29

V30

V31
0.9990450

0.9681785

0.9983150

0.9985298

0.9993747

0.9917448

0.9653664

0.9909484

0.9992914

0.9406767

0.9751889

0.9803528

0.8935987

0.7227410

0.7893639

0.9426998

0.7477856

0.4454334

0.9758882

0.8782115

0.9897215

0.6022425

0.9926706

0.9194308

0.9960822

0.9910142

0.9126132

0.9709617

0.9519061

0.9770676
0.9990450

0.9681785

0.9983150

0.9985298

0.9993747

0.9917448

0.9653664

0.9909484

0.9992914

0.2406767

0.9751889

0.9803528

0.8935987

0.7227410

0.7893639

0.9426998

0.7477856

0.4454334

0.9758882

0.8782175

0.9897215

0.6022425

0.9926706

0.9194308

0.9960822

0.9910142

0.9126132

0.9709617

0.9519061

0.9770676

IN THE ANALYSIS AFTER STEP

I

HILKS - LAMBOA

4.6439
1.4144
5.9521
.81888
6.0529
17.193
3.1499
2.3178
.24032
.74155
.36107
9.8783
2.0991

$0.19159 E-01$

$0.74505 E-02$

5.9474

.23070

8.8747

$0.63005 E-01$

.23516

3.7502

3.4224

7.0123

3.0076

.67371

$0.44931 E-01$

.62446

.89549

.11358

.23636
0.56832

0.63072

0.54642

0.64375

0.54481

0.47336

0.59558

0.69192

0.65694

0.64548

0.65414

0.48978

0.61637

0.66213

0.66240

0.54650

0.65716

0.50311

0.66909

0.65706

0.58432

0.59041

0.52988

0.59831

0.65156

0.66152

0.64812

0.64204

0.65990

0.65703

FIGURE 3: VARIABLES IN THE ANALYSIS AT STEP 1 
:O Mar 88 Coeparison of Profitable asd Insolvent Companies Loughborough University Honeywell $68 / 80$ Multics

IT STEP 9. VI2 HAS REMOVED FROA THE ANALYSIS.

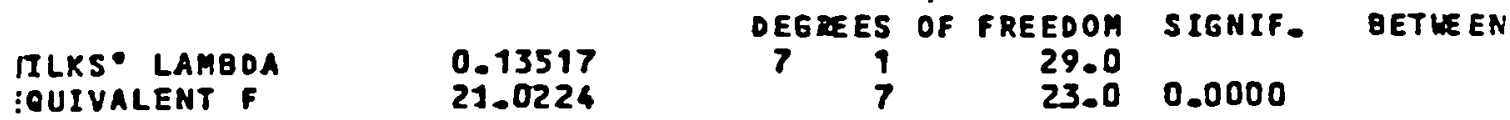

VARIABLES IN THE ANALTSIS AFTER STEP

$\begin{array}{llll}\text { IARIABLE } & \text { TOLERANCE } & \text { F TO REMOVE } & \text { HILKS" LAMBDA } \\ \text { YE } & 0.5602124 & 29.295 & 0.30734 \\ 1 E & 0.3447527 & 29.648 & 0.30947 \\ 117 & 0.2829541 & 16.182 & 0.23027 \\ 123 & 0.6434045 & 13.928 & 0.21703 \\ 124 & 0.5173777 & 19.161 & 0.24778 \\ 125 & 0.5479918 & 8.5112 & 0.18599 \\ 126 & 0.6915605 & 6.8454 & 0.17540 \\ 130 & & & \end{array}$

VARIAGLES NOT

\begin{tabular}{|c|c|c|c|c|}
\hline IARIABLE & TOLERANCE & $\begin{array}{l}\text { MINIAUA } \\
\text { TOLERANCE }\end{array}$ & F TO ETTER & HILKS LAMBOA \\
\hline $\begin{array}{l}11 \\
v 2 \\
v 3 \\
i f \\
v 7 \\
v 8 \\
v 9 \\
v 10 \\
v 91 \\
v 12 \\
v 13 \\
v 14 \\
v 15 \\
v 16 \\
v 18 \\
v 19 \\
v 20 \\
v 21 \\
v 22 \\
v 27 \\
v 28 \\
v 29 \\
v 31\end{array}$ & $\begin{array}{l}0.1546806 \\
0.2803695 \\
0.3626945 \\
0.8003164 \\
0.2270301 \\
0.1747145 \\
0.8036324 \\
0.5767617 \\
0.8359510 \\
0.8100130 \\
0.1695183 \\
0.4297389 \\
0.4924572 \\
0.5726225 \\
0.3735249 \\
0.5475379 \\
0.3171498 \\
0.7387956 \\
0.7220602 \\
0.8627361 \\
0.9404892 \\
0.7182636 \\
0.8042650 \\
0.9175061\end{array}$ & $\begin{array}{l}0.1546806 \\
0.2306829 \\
0.2643240 \\
0.2795612 \\
0.1956506 \\
0.1747145 \\
0.2810149 \\
0.2801188 \\
0.2828646 \\
0.2795873 \\
0.1491478 \\
0.2194048 \\
0.2365650 \\
0.2715193 \\
0.2652799 \\
0.2417479 \\
0.2593306 \\
0.2726227 \\
0.2716766 \\
0.2793084 \\
0.2826655 \\
0.2748877 \\
0.2795671 \\
0.2792637\end{array}$ & $\begin{array}{l}-46462 \\
0.32042 E-03 \\
.80408 \\
-45011 \\
-50261 \\
-13911 \\
0.49684 E-01 \\
-69035 \\
0.85863 E-01 \\
.28084 \\
0.23381 E-01 \\
-49203 \\
0.95672 E-02 \\
0.57554 E-04 \\
-17501 \\
-11248 \\
0.45041 E-01 \\
-12648 \\
-31060 \\
-68119 \\
0.69288 E-02 \\
0.13368 E-01 \\
044794 \\
0.67571 E-01\end{array}$ & $\begin{array}{l}0.13237 \\
0.13517 \\
0.13040 . \\
0.13246 \\
0.13215 \\
0.13432 \\
0.13486 \\
0.13106 \\
0.13464 \\
0.13347 \\
0.13503 \\
0.13221 \\
0.13517 \\
0.13517 \\
0.13410 \\
0.13448 \\
0.13489 \\
0.13440 \\
0.13449 \\
0.13111 \\
0.13513 \\
0.13509 \\
0.13247 . \\
0.13476\end{array}$ \\
\hline
\end{tabular}

FIGURE 4: VARIABLES IN ANALYSIS AT STEP-9 
20 MAY 88 Comparison of Profitable and Insolvent Companies Loughborough University. Honeywell $68 / 80$ Multics

UNSTANDAROIZED CANONICAL DISCRIMINANT FUNCTION COEFFICIENTS

$\begin{array}{lr}j & \text { FUNC } \\ \text { v6 } & -16.06449 \\ v 17 & 2.848277 \\ v 23 & -.4894365 \\ v 24 & .2345166 \\ \text { V25 } & -.6957342 \\ \text { V26 } & .6957439 \\ \text { V30 } & .5972381 \\ \text { (CONSTANT) } & -2.854138\end{array}$

CANONICAL DISCRIMINANT FUNCTIONS EYALUATED AT GROUP MEANS PGROUP CENTROID: \begin{tabular}{rrr} 
GROUP & \multicolumn{1}{c}{ FUNC } & 1 \\
1 & -1.81437 \\
2 & 3.29885
\end{tabular}

FIGURE 5: UNSTANDARDISED CANONICAL DISCRIMINANT COEFFICIENTS 
AY 88 Comparison of Profitable and Insolvent Companies Loughborough University Honeywell $68 / 80$ Multics

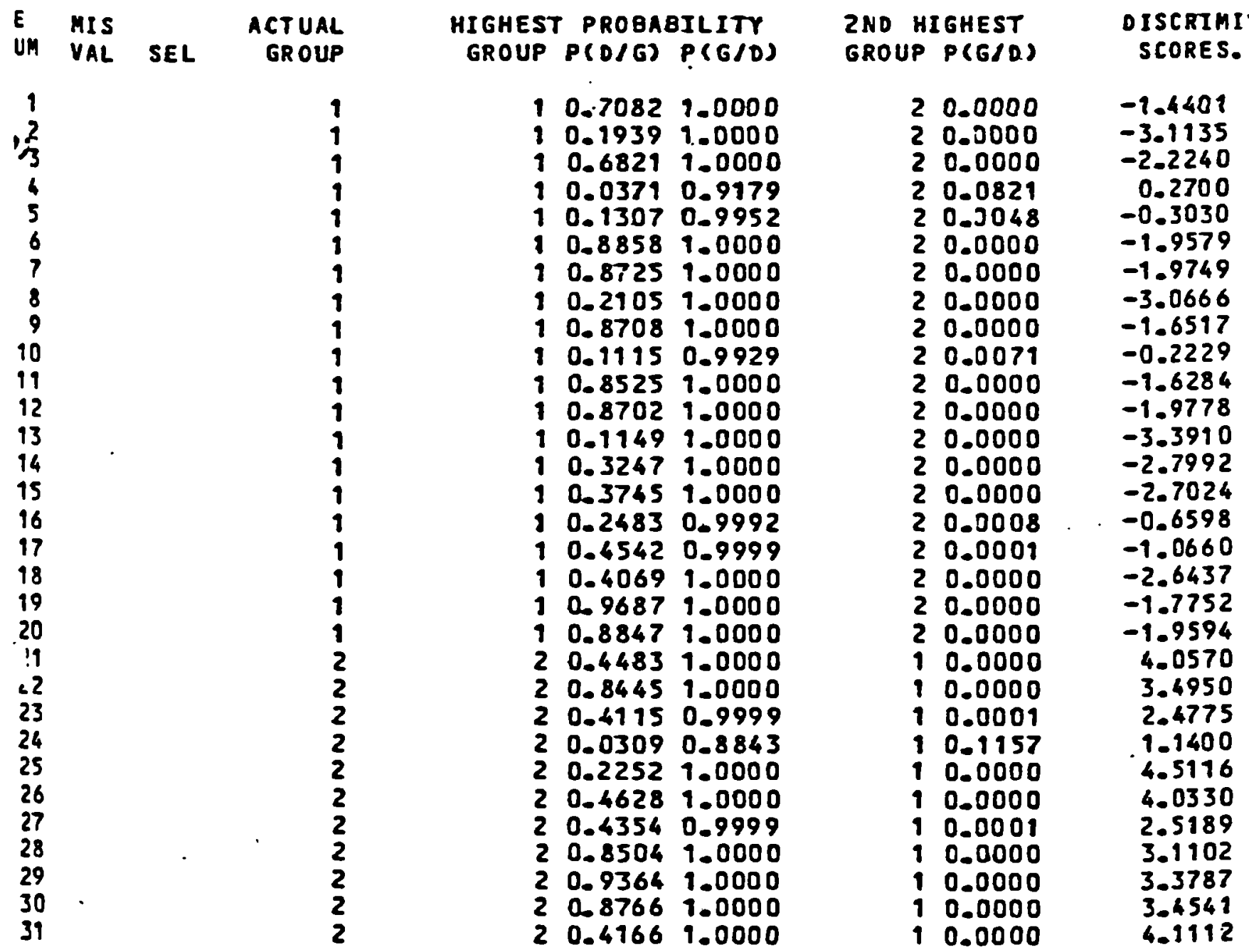

\section{ISIFICATION PROCESSING SUMMARY}

37 CASES HERE PROCESSED.

O CASES HERE EXCLUDED FOR MISSING OR OUT-OF-RANGE GROUP CODES.

O CASES HAD AT LEAST ONE MISSING OISCRIMINATING VARIABLE.

31 CASES HERE USED FOR PRINTED OUTPUT.

FIGURE 6: THE DISCRIMINANT SCORES 
20 MAY 88 Comparison of Profitable and Insolvent Companies Loughborough University Honeywell $68 / 80$ Hulti

SUMMARY TABLE

$\begin{array}{cl}\text { STEP } & \text { ENTER } \\ 1 & V 17 \\ 2 & V 6 \\ 3 & V 12 \\ 4 & V 25 \\ 5 & V 23 \\ 6 & V 26 \\ 7 & V 30 \\ 8 & V 24 \\ 9 & \end{array}$

ACTION VARS WILKS

IN LAMBOA SIG. LABEL

v12

$\begin{array}{lll}1 & -66258 & -0006 \\ 2 & -47336 & -0000 \\ 3 & -35081 & -0000 \\ 4 & -25383 & -0000 \\ 5 & -21584 & -0000 \\ 6 & -17535 & -0000 \\ 7 & -15087 & -0000 \\ 8 & -13503 & -0000 \\ 7 & -13517 & -0000\end{array}$

CANONICAL DISCRIMINANT :

\begin{tabular}{|c|c|c|c|c|c|}
\hline FUNCTION & EIGENVALUE & $\begin{array}{l}\text { PERCENT OF } \\
\text { VARIANCE }\end{array}$ & $\begin{array}{c}\text { CUMULATIVE } \\
\text { PERCENT }\end{array}$ & $\begin{array}{l}\text { CANONICAL } \\
\text { CORRELATION }\end{array}$ & $\begin{array}{l}: \text { AFT } \\
: \text { FUNCT }\end{array}$ \\
\hline $9 *$ & 6.39813 & 100.00 & 100.00 & 0.9299627 & $:$ \\
\hline
\end{tabular}

STANDARDIZED CANONICAL DISCRIMINANT FUNCTION COEFFICIENTS FUNC 1

$\begin{array}{lr}\text { V6 } & -1.07529 \\ v 17 & 1.37431 \\ v 23 & -1.29912 \\ V 24 & 0.82331 \\ V 25 & -1.01372 \\ V 26 & 0.75494 \\ v 30 & 0.61927\end{array}$

FIGURE 7: EIGENVALUE, PERCENTAGE OF VARIANCE CANONICAL CORRELATION 
PROGRAMME LISTING FOR THREE GROUPS

Loughborough University

Honeywelt- $68 / 80$ Multics

SPSS INC LICENSE NUMBER: 18950

0

title "Comparison of Profitable and Insolvent Companies"

file handle accounts /atd="vfile_ set2. data"

data list filezaccounts freel v1 to $v 32$

variable labels $v 32$ 'status"

value labels v32 1 "solvent" 2 "Insolvent" 3 "Take over"

breakdown tables $=v 1$ to $v 31$ by $v 32$

ARE 995960 BYTES OF MEMORY AVAILABLE.

JPGEST CONTIGUOUS AREA HAS 995960 BYTES.

- GIVEN WORKSPACE ALLOWS FOR 6224 CELLS HITH 1 OIMENSIONS FOR BREAKDOK 


\begin{tabular}{|c|c|c|}
\hline 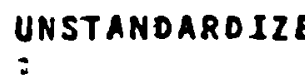 & CANONICAL & 1 \\
\hline & F UNC & FUNC \\
\hline 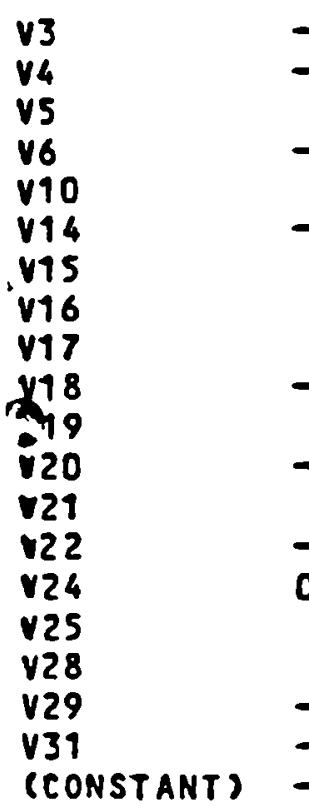 & $\begin{array}{r}-7.530362 \\
-11.09368 \\
64.82103 \\
-14.13432 \\
5.210845 \\
-4.581054 \\
12.51857 \\
7.550571 \\
5.817900 \\
-3.333902 \\
1.657647 \\
-3.879387 \\
5.320921 \\
-1.993904 \\
0.2681234 E-01 \\
-2507642 \\
4.792134 \\
-.7492963 \\
-4.632241 \\
-6.554657\end{array}$ & $\begin{array}{r}1.55542 \\
3.95178 \\
1.33834 \\
-19.7016 \\
-442167 \\
6.39520 \\
-3.63496 \\
-3.97165 \\
--4.19262 \\
1.73246 \\
-6.35769 \\
3.19073 \\
-2.58615 \\
1.96206 \\
-248120 \\
-.646673 \\
--278546 \\
-.393843 \\
1.08096 \\
-.673703\end{array}$ \\
\hline
\end{tabular}

CANONICAL DISCRIMINANT FUNCTIONS EYALUATED AT GROUP MEANS CGROUP CENTROI GROUP FUNC 1 FUNC 2

$\begin{array}{rrr}1 & 1.23286 & -1.66466 \\ 2 & 1.24474 & 3.02013 \\ 3 & -4.26105 & 0.00798\end{array}$

FIGURE 8: UNSTANDARDISED CANONICAL DISCRIMINANT FUNCTION COEFFICIENTS 
TERRITORIAL MAP * INOICATES A GROUP CENTR

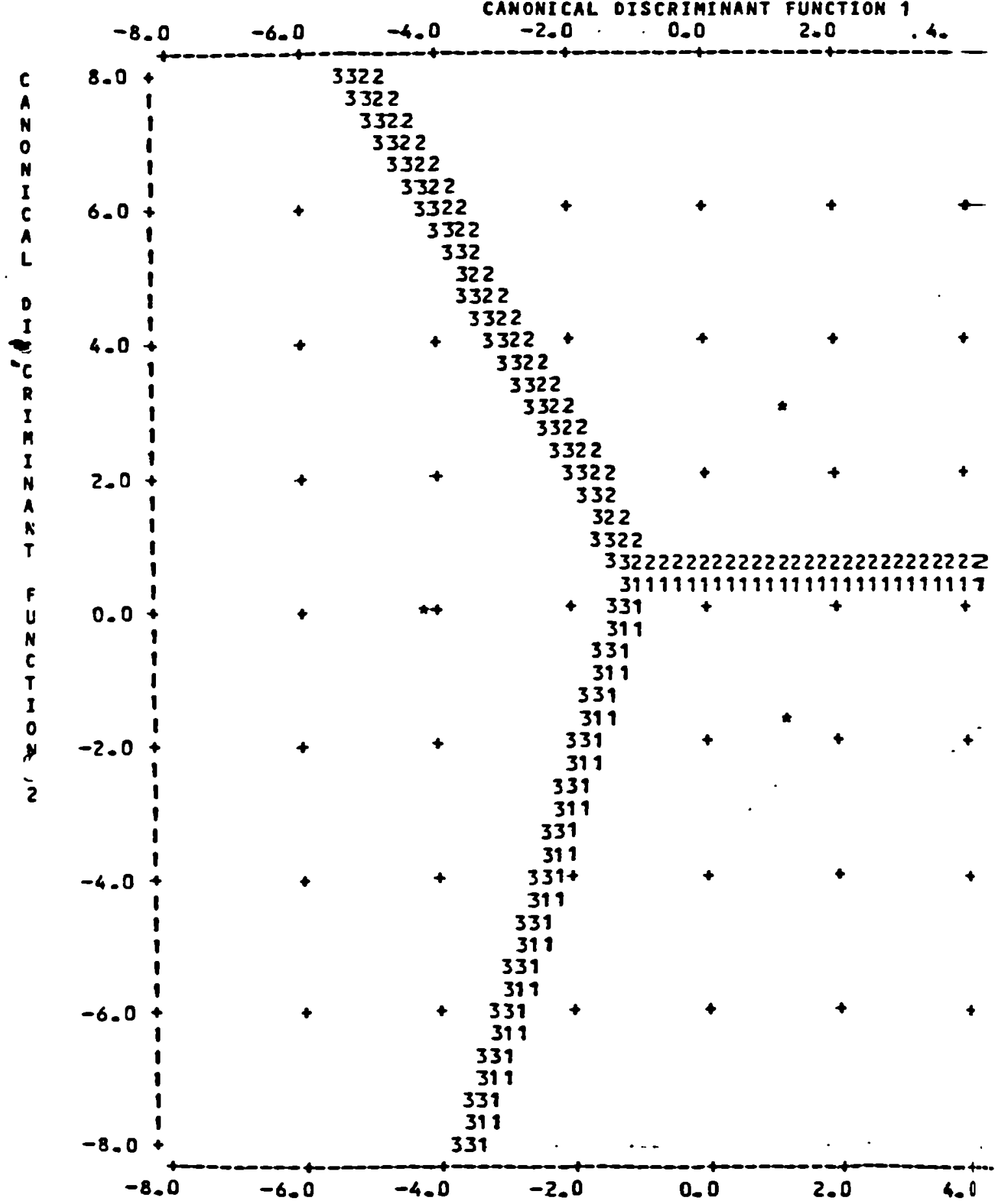

FIGURE 9: ALI GROUP SCATTER PLOT 
romparison of Profitable and Insolvent Companies oughoorough University

Honeyuell $68 / 80$ Multics

$\begin{array}{ccl}\text { ACTUAL } & \text { HIGHEST PROBABILITY } & \text { 2ND HIGHEST } \\ \text { SEL GRDUP } & \text { GROUP P(D/G) P(G/D) } & \text { GROUP P(G/D) }\end{array}$

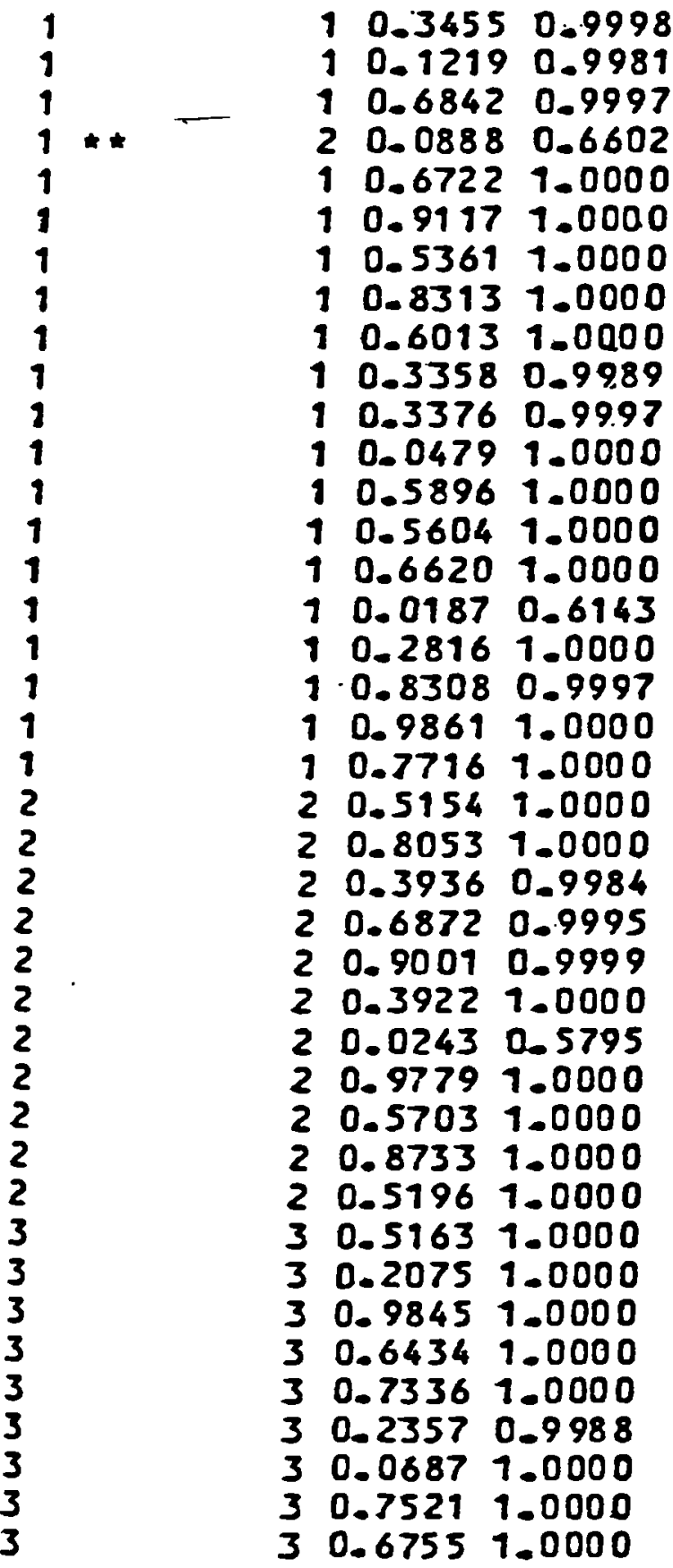

$\begin{array}{ll}3 & 0.0002 \\ 3 & 0.0019 \\ 2 & 0.0003 \\ 1 & 0.3398 \\ 2 & 0.0000 \\ 2 & 0.0000 \\ 2 & 0.0000 \\ 2 & 0.0000 \\ 2 & 0.0000 \\ 2 & 0.0009 \\ 2 & 0.0003 \\ 2 & 0.0000 \\ 2 & 0.0000 \\ 3 & 0.0000 \\ 2 & 0.0000 \\ 2 & 0.3629 \\ 2 & 0.0000 \\ 2 & 0.0003 \\ 2 & 0.0000 \\ 2 & 0.0000 \\ 1 & 0.0000 \\ 1 & 0.0000 \\ 1 & 0.0016 \\ 1 & 0.0005 \\ 1 & 0.0001 \\ 1 & 0.0000 \\ 1 & 0.4143 \\ 1 & 0.0000 \\ 1 & 0.0000 \\ 1 & 0.0000 \\ 1 & 0.0000 \\ 2 & 0.0000 \\ 1 & 0.0000 \\ 1 & 0.0000 \\ 1 & 0.0000 \\ 1 & 0.0000 \\ 1 & 0.0012 \\ 1 & 0.0000 \\ 1 & 0.0000 \\ 1 & 0.0000 \\ 1 & \end{array}$

DISCRIMINANT

SCORES...

$-0.2170 \quad-9.818$

$-0.7692-2.113$

$1.8265-1.027$

$.1 .2479 \quad 0.819$

$2.0786-1.945$

$1.6285^{\circ}-1.832^{\prime}$

$2.3392-1.815 ;$

$0.7803-2.070$

$0.8660 \quad-2.604 \%$

$0.0172-0.825:$

$2.5809-1.0691$

$2.7958 \quad-3.5716$

$1.7352-2.5615$

$0.5037-2.4561$

$0.6022-2.3183$

$\begin{array}{rr}-0.4899 & 0.5698\end{array}$

$2.8097 \quad-1.8839$

$1.3317-1.0639$

$1.2814-1.5048$

$1.7138-2.2007$

$1.4757 \quad 4.1480$

$1.3984 \quad 3.6600$

$2.2024 \quad 2.0465$

$0.7374 \quad 2.3224$

$1.2885 \quad 2.5635$

$2.3258 \quad 3.8588$

$-0.2694$

1.0663

0.2054

1. 5330

1.7348

$-3.3885$

$-6.0067$

$-4.3479$

$-4.9349$

$-4.7603$

$-2.6532$

$-5.2786$

$-3.5086$

$-3.4707$
0.7532

3.1338

3.2275

3.4536

4.0542

0.7568

0.3213

$-0.7461$

0.6621

0.6165

$-0.5443$

$-2.0709$

0.0682

0.4082 .

FIGURE 10: THE DISCRIMINANT SCORES 
JUN 88 - Comparison of Profitable and Insolvent Companies Loughborough University Honeyuell $68 / 80$ Multics

ASSIFICATION RESULJS -

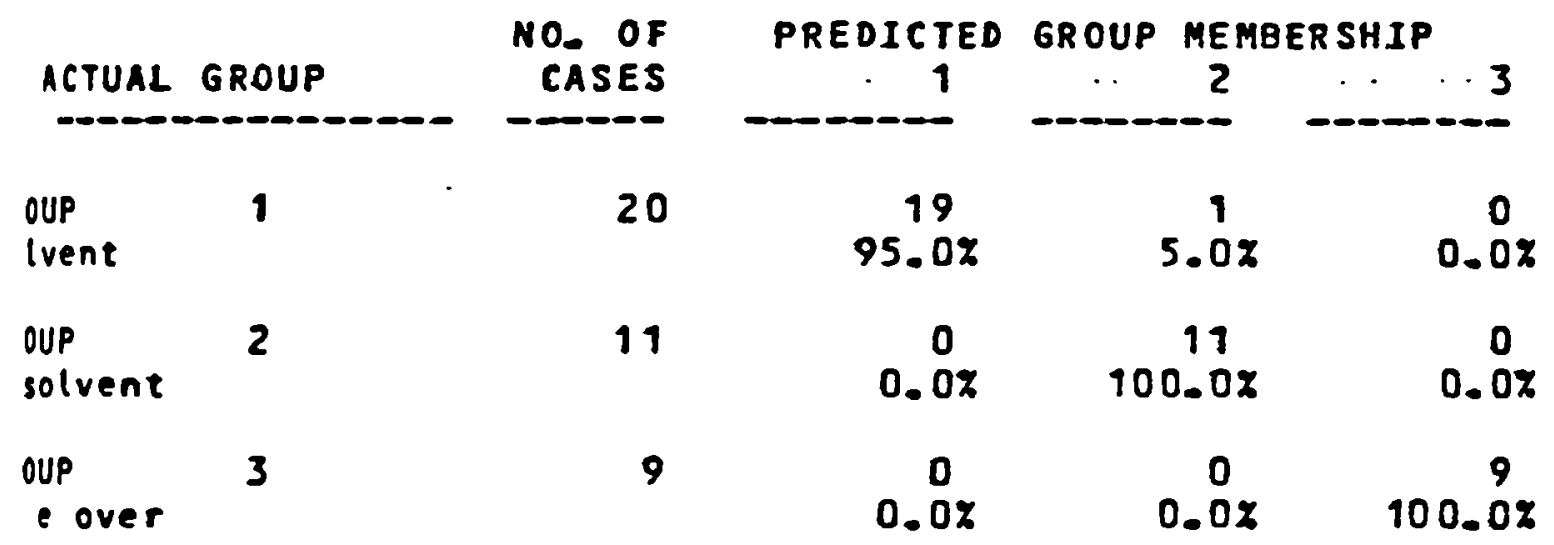

RCENT OF "GROUPEO" CASES CORRECTLY CLASSIFIED: 97.5OZ

ASSIFICATION PROCESSING SUMMARY

40 CASES HERE PROCESSEO.

D CASES WERE EXCLUDED FOR MISSING OR OUT-OF-RANGE GROUP CODES.

O CASES HAD AT LEAST ONE MISSING OISCRIMINATING VARIABLE.

40 CASES WERE USEO FOR PRINTED OUTPUT.

FIGURE 11: CLASSIFICATION RESULTS 
JUN 88 Compartson of Proftesble and Insolvent Companies
Loughborough University Haneywell $68 / 80$ Multics

ALL-GROUPS SCATTERPLOT - I INOICATES A GROUP CENTE

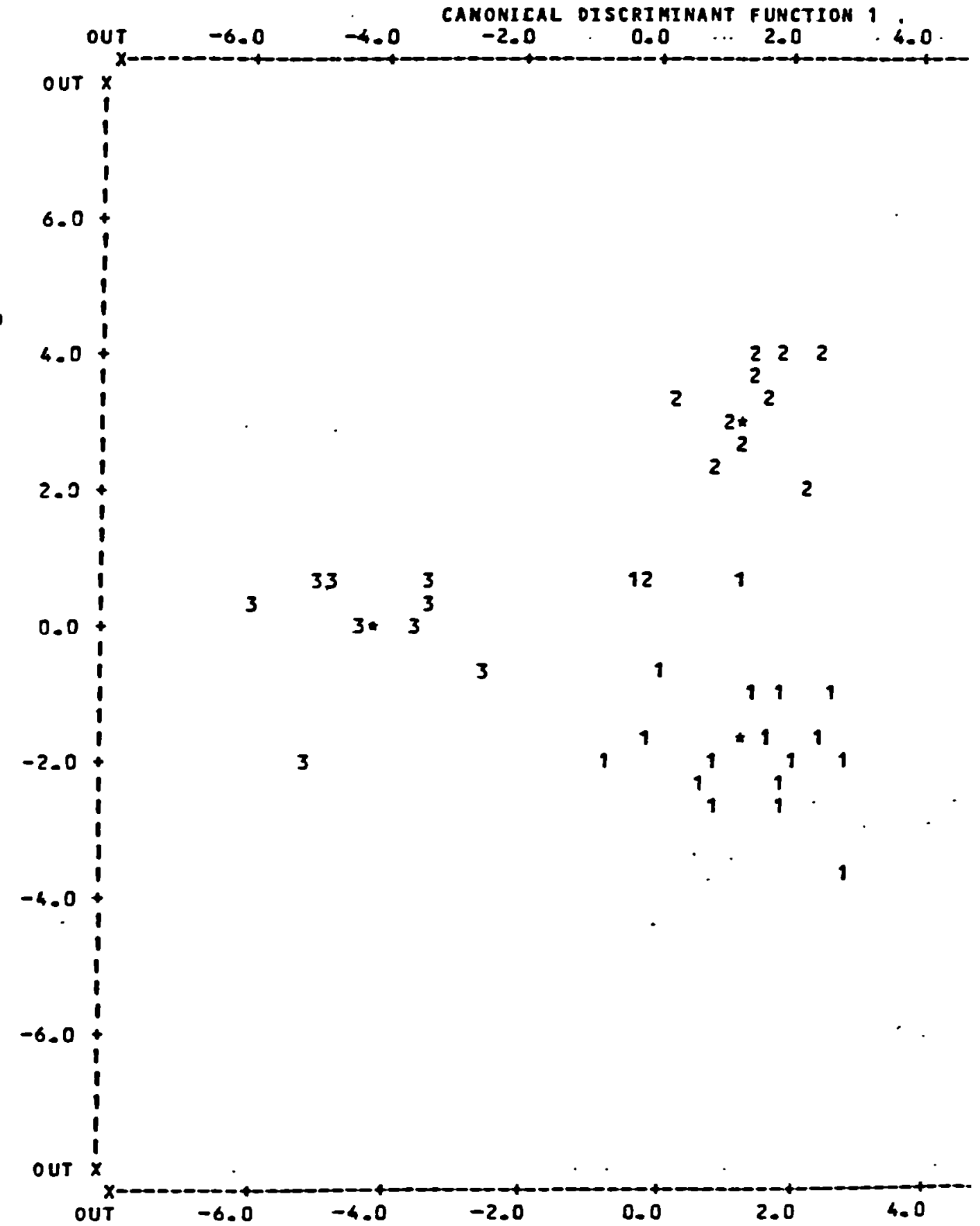

FIGURE 12: ALL GROUPS SCATTER PLOTS 
15 JUN 88 Comparison of Profitable and Insolvent Companies Loughborough University Honeywelt $68 / 80$ Muttics

CANONICAL DISCRIMINANT FUNCTIONS

\begin{tabular}{|c|c|c|c|c|c|c|c|}
\hline INCTION & E I GENVALUE & $\begin{array}{l}\text { PERCENT OF } \\
\text { VARIANCE }\end{array}$ & $\begin{array}{c}\text { CUMULATIVE } \\
\text { PERCENT }\end{array}$ & $\begin{array}{l}\text { CANONICAL. } \\
\text { CORRELATION }\end{array}$ & $:$ & $\begin{array}{c}\text { AFTER } \\
\text { FUNCTION }\end{array}$ & WILK \\
\hline & & & & 0.9223431 & 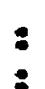 & 0 & 0 \\
\hline $\begin{array}{l}1 * \\
2 \star\end{array}$ & $\begin{array}{l}5.69868 \\
4.20961\end{array}$ & $\begin{array}{l}57.51 \\
42.49\end{array}$ & $\begin{array}{r}57.51 \\
100.00\end{array}$ & $\begin{array}{l}0.9223431 \\
0.8989143\end{array}$ & : & & \\
\hline
\end{tabular}

- MARKS THE 2 CANONICAL DISCRIMINANT FUNCTIONS REMAINING In the ANALY

gianoaroized canonical discriminant function coefficients

FUNC 1 FUNC 2

$\begin{array}{lrr}13 & -1.22079 & 0.25216 \\ 14 & -1.10525 & 0.39365 \\ 15 & 3.01058 & 0.06216 \\ 16 & -0.88397 & -0.73183 \\ 110 & 0.98088 & 0.08323 \\ 114 & -1.58097 & 2.20706 \\ 115 & 1.14318 & -0.33194 \\ 116 & 1.87153 & -0.98444 \\ 117 & 2.97854 & -0.21465 \\ 118 & -7.41498 & 3.85319 \\ 119 & 0.64408 & -2.47027 \\ 120 & -1.31478 & 1.08138 \\ 121 & 6.60072 & -3.20818 \\ 122 & -0.81020 & 0.79726 \\ 194 & 0.10640 & 0.98461 \\ .15 & 0.33065 & -0.85268 \\ 128 & 1.57714 & -0.09167 \\ 129 & -0.85922 & -0.45162 \\ 131 & -2.10811 & 0.49194\end{array}$

FIGURE 13: EIGENVALUE CANONICAL CORRELATION AND STANDARDISED CANONICAI DISCRIMINANT FUNCTION COEFFICIENTS 


\section{APPENDIX C}

\section{A MANUAL FOR USE OF THE MENITAB STATISTICAL PACKAGE}

AND ITS OUTPUT

\section{INTRODUCTION}

Minitab is an interactive statistics package written and distributed by Minitab Inc, Pennsylvania.

Minitab stores the data being analysed in a worksheet which is arranged in a structure of rows and columns. The values of each different variable are stored in a separate column of the worksheet within Minitab. These columns are designated $c_{1}, c_{2} \ldots c_{20}$.

The package offers various statistical analyses as follows:

- simple descriptive statistics

- graph and histogram plots

- correlation and significance testing

- regression analysis (including stepwise)

- probabilities

- variance analysis.

\section{MINITAB COMMANDS}

There are over 100 Minitab commands of which any one user will probably analyse a few of them. The following commands are used in this thesis. 


\subsection{The "Set" Command}

To input data from the teminal in prime systems, it needs to use the "set" cammand which inputs data one column at a time. The values of 31 financlal ratios were inputted in separate columns of the worksheet.

\subsection{The "End" Command}

The input is terminated by the "end" command. The following columns were inputted onto the worksheet.

$\mathrm{C}_{1}-\mathrm{C}_{31}$ : represents 31 financial ratios.

$\mathrm{C}_{32}$ : represents $\mathrm{Z}$-values calculated from the Mason model.

$\mathrm{C}_{34}$ : represents the value of discriminant soores obtained fram MDA, see Figure 5.5.

\subsection{The "Save" Command}

To store the data on file, the "save" command is used, followed by "filename". For example, save "Adnan".

\subsection{The "Stop" Command}

To leave the Minitab, the "stop" cammand is used which stops the program.

\subsection{The "Retrieve" Command}

To retrieve the data, it is necessary to use the "retrieve" command, followed by the filename. For example, retrieve "Adnan".

\subsection{The "Help" Command}

The Minitab program is itself able to supply information on its own command and method of use.

To use the "help" command, type "help" followed by the command, e.g. help regress or help correlation. 


\section{STATISTICAL COMMANDS}

The package offers various statistical commands and can be used for data manipulation. Several optional statistics are available in this program. The commands which are used in this program are as follows.

\subsection{The "Describe" Command}

This is used to deliver descriptive statistics about continuous type data variables. In particular, "describe" gives the mean standard deviation etc.

To use "describe" simply give the command followed by any number of columns. For example, describe $c_{1}-c_{31}$.

\subsection{The "Histogram" Command}

This is used to plot histograms. To use "histogram" simply give the command, followed by any number of columns, e.g. Hist $\mathrm{C}_{1}$.

\subsection{The "Regression" Command}

To use "regress" simply give the command "regress" followed by number of independent variables which are included in the analysis. For example, regress $c_{32}{ }^{5} c_{6} c_{12} c_{17} c_{23} c_{25}$.

\subsection{OUTPUT FROM THE MINITTAB PROGRAM}

The following is same output resulting from the program listing an pages 282 to 301 . 


\begin{tabular}{|c|c|c|c|c|c|c|c|c|}
\hline row & C1 & 62 & C3 & C4 & C5 & C6 & C7 & 6 \\
\hline 1 & 0.6755 & 0.1000 & 0.1100 & 0.967 & 0.0330 & 0.6570 & 9.9620 & 0.6960 \\
\hline 2 & 0.156 & 0.1620 & 0.1470 & 155 & 9.06 & 960 & & \\
\hline 3 & 0.68 & 0.1600 & 0.1506 & 68 & & 0.06 & & \\
\hline 4 & 0.04 & 0.07 & 0.0630 & 5 & 0.0250 & 56 & 6 & \\
\hline 5 & 0.0970 & & 760 & $\theta$ & .0680 & & & \\
\hline 6 & 9.1500 & 0.1600 & 0.1560 & 0.150 & 0.0270 & 9.1939 & 0.1150 & 0.4460 \\
\hline 7 & 0.1540 & 0.1850 & 3.1870 & 0.146 & 0.8490 & 0.0900 & 0.1290 & 0.7700 \\
\hline 8 & 0.22 & 0.2780 & 0.7500 & 0.210 & 0.1700 & 0.1260 & & 0.3690 \\
\hline 9 & 0.8830 & 0.1070 & & 0.070 & 0.0600 & 130 & & 500 \\
\hline 10 & 0.1150 & 0.1300 & 0.07 & 100 & & 60 & & 306 \\
\hline 11 & 0.158 & 0.1769 & 0.0949 & 0.118 & 0.1120 & 36 & 0.1 & \\
\hline 12 & 0.0960 & 0.1256 & 0.2 & 0.095 & 0.0 & & & \\
\hline 13 & 0.23 & 0.3300 & & 8 & 0.0877 & & & \\
\hline 14 & 0.2130 & 0.2360 & 0.5120 & 6 & 220 & & & 0. \\
\hline 15 & 0.0960 & 0.1060 & 0.1060 & 6.683 & 0.0300 & 0.0770 & 0.0990 & 1.7906 \\
\hline 16 & 0.1729 & 0.2250 & 0.1600 & 0.210 & 0.0470 & 9.0440 & 0.1300 & 0.8190 \\
\hline 17 & 0.0909 & 0.1000 & 0.1070 & 0.061 & 0.0360 & 0.6480 & 0.0770 & 0.3870 \\
\hline 18 & 0.6579 & 0.0550 & 1.0740 & 0.055 & 0.0060 & 0.0430 & 9.0500 & 0.3009 \\
\hline 19 & 0.1620 & 0.1890 & 0.2100 & 0.568 & 0.0900 & 0.0930 & 0.1230 & 1.5860 \\
\hline 20 & 0.1270 & 0.1791 & 0.2060 & 0.117 & 0.0800 & 0.0760 & 0.1260 & 1.3889 \\
\hline 21 & 0.0913 & .1170 & 0.0619 & 0.046 & 0.0549 & 9.0430 & 0.1000 & 0.5950 \\
\hline \multicolumn{9}{|l|}{ Cont: } \\
\hline 22 & -1.4576 & -1.4750 & 0.5590 & 9.216 & -1.1740 & -0.2490 & -0.5336 & \\
\hline 23 & -0.0800 & -9.6800 & -0.0200 & 6.681 & -0.0027 & -0.0459 & -0.0 & 680 \\
\hline 2 & & 0.2810 & 0.1240 & 9.085 & 0.0625 & 0.6830 & 0.2 & 315 \\
\hline 25 & 0.9406 & & 0.04 & 0.028 & 6.81 & & 9.0 & \\
\hline 26 & -6.1710 & -8.1716 & -6.8609 & 0.085 & -6.0277 & -0.0980 & 926 & \\
\hline 27 & 1160 & 0.1160 & & & 0.65 & & & \\
\hline 28 & -0.5960 & -0.5900 & -0.1270 & 9.274 & -6.0386 & -0.1310 & -6.3 & 1.2200 \\
\hline 29 & 2440 & .9698 & 0.848 & & & & & \\
\hline 3 & & & & & & & & \\
\hline 39 & & wevora & & 0.085 & 0.0428 & 0.6510 & 0.4090 & 0.9190 \\
\hline
\end{tabular}




\begin{tabular}{|c|c|c|c|c|c|c|c|c|}
\hline & C9 & C10 & C11 & $c 12$ & {$[13$} & Ci4 & $C 15$ & $C 1$ \\
\hline 1 & 0.480 & 0.4220 & 0.320 & 0.3600 & 0.676 & 0.6000 & 0.2100 & 0.5960 \\
\hline 2 & 6.420 & & 0.165 & 0.3150 & 1.100 & 1.1000 & & \\
\hline 3 & 0.320 & & 0.27 & 390 & & 4400 & 0.1400 & \\
\hline 4 & 9.3 & & 1.2 & $\emptyset$ & .760 & 0.5800 & 0.25 & 30 \\
\hline 5 & 0.560 & .6000 & 9.2 & $\theta$ & . & 6.4 & 0.1880 & 0 \\
\hline 6 & 0.980 & .5800 & 0.460 & & & 900 & 0.0830 & 0.610 \\
\hline 7 & 0.560 & 0.3100 & 9.560 & 6.6300 & 9.820 & 0.7460 & 0.3790 & 0.700 \\
\hline 8 & 1.460 & 0.6800 & 0.160 & 0.0197 & 0.306 & 0.2770 & 0.1930 & 0.298 \\
\hline 9 & 0.780 & 0.1330 & 0.135 & 0.1900 & 0.430. & 0.3770 & 0.2650 & 0.600 \\
\hline 10 & 0.820 & 1.3300 & 0.367 & 0.2360 & 1.580 & 1.4100 & 0.1300 & 0.800 \\
\hline \multicolumn{9}{|c|}{ Continue? } \\
\hline 11 & 0.455 & 0.1441 & 1.323 & 1.3540 & 1.660 & 1.2760 & 0.9826 & 1.956 \\
\hline 12 & 0.500 & 0.1780 & 0.020 & & 0.470 & 0.46 & 0.2260 & 0.727 \\
\hline 13 & 0.634 & 0.2070 & 0.037 & 0.1396 & 0.763 & 0.9320 & 0.2940 & 680 \\
\hline 14 & 0.940 & 0.6000 & 9.570 & 0.0400 & 0.420. & 0.3100 & 0.0 & \\
\hline 15 & 0.980 & 0.2700 & 0.610 & 1580 & 0.880 & & 0.0 & 0.780 \\
\hline 16 & 0.776 & 6.3378 & 9.517 & .1646 & 1.070 & 0.9506 & 0.0480 & 0.736 \\
\hline 17 & 0.430 & 0.4000 & 0.389 & 1.4200 & 0.930 & 0.5706 & 0.0430 & 0.585 \\
\hline 18 & 1.560 & 0.7109 & 0.490 & 0.1926 & 0.960 & 0.9300 & 0.9900 & 0.480 \\
\hline 19 & 0.080 & 6.4390 & 0.942 & 0.1000 & 0.600 & 0.6700 & 0.1220 & 0.616 \\
\hline 20 & 9.800 & 0.6740 & 0.270 & 0.2380 & 0.630 & 0.5700 & 0.2650 & 0.4600 \\
\hline 21 & 0.400 & 0.3580 & 0.679 & 1.6900 & 1.560 & 9.7530 & 0.6880 & 0.741 \\
\hline 22 & 9.464 & 0.4989 & 0.490 & 0.5200 & 2.110 & 1.0200 & 0.6203 & 1.9560 \\
\hline 23 & 0.710 & 0.0930 & 0.623 & -1.5100 & 1.190 & 0.7560 & 0.1950 & 0.9940 \\
\hline 24 & 0.522 & 0.4270 & 0.376 & 0.7250 & 0.944 & 0.6259 & 0.3240 & 0.5990 \\
\hline 25 & 1.228 & 0.27 & 9.326 & 0.9360 & 0.790 & 0.8160 & & 0.686 \\
\hline 26 & 0.586 & 0.2 & 0.580 & 0.2590 & 9.723 & 0.9260 & 9.0001 & 0.7998 \\
\hline 27 & 0.7 & & 9.7 & 6.6 & 1.170 & 6.9 & & 0.7228 \\
\hline 28 & 0.230 & 6.2720 & 0.218 & 0.0926 & 2.760 & 1.3 & & \\
\hline 29 & 0.278 & 0.3680 & 9.268 & 1.3756 & 1.497 & 1.1580 & 0.0981 & 0.7860 \\
\hline 30 & 0.989 & 0.7320 & 0.255 & 0.6160 & 0.890 & 0.9735 & & .5648 \\
\hline 31 & 0.525 & 0.2940 & 0.520 & 0.6000 & 1.090 & 0.7990 & 0.0830 & 0.730 \\
\hline
\end{tabular}




\begin{tabular}{|c|c|c|c|c|c|c|c|c|}
\hline $\begin{array}{l}\text { ROH } \\
\text { Cont }\end{array}$ & C17 & C18 & 019 & $\mathrm{C} 20$ & C21 & C22 & {$[23$} & $\mathrm{C} 24$ \\
\hline 1 & 1.1900 & 1.530 & 1.020 & 0.3201 & 1.436 & 1.631 & 2.240 & 1.759 \\
\hline 2 & 1.2000 & 1.240 & 1.200 & 0.4700 & 6.480 & 1.240 & 2.590 & 2.311 \\
\hline 3 & 0.5900 & 0.676 & 0.460 & 1.0800 & 1.310 & 1.450 & 1.800 & 2.870 \\
\hline 4 & 0.9000 & 1.360 & 0.690 & 0.2606 & 0.400 & 1.506 & 1.960 & 6.100 \\
\hline 5 & 1.2360 & 1.570 & 1.670 & 0.2890 & 0.360 & 1.276 & 1.480 & 3.340 \\
\hline 6 & 1.5600 & 1.700 & 1.560 & 0.9500 & 1.049 & 1.380 & 5.430 & 2.311 \\
\hline 7 & 1.1780 & 1.420 & 1.060 & 0.4600 & 6.560 & 1.580 & 3.100 & 0.688 \\
\hline 8 & 0.7500 & 1.160 & 0.965 & 0.4300 & 0.540 & 1.500 & 1.010 & 0.210 \\
\hline 9 & 0.7200 & 0.930 & 0.625 & 0.4560 & 0.590 & 0.178 & 1.350 & 1.770 \\
\hline 10 & 1.9600 & 2.300 & 1.750 & 1.3090 & 1.540 & 1.326 & 6.750 & 1.700 \\
\hline 11 & 1.7000 & 1.87 & 1.310 & 0.7440 & 0.824 & 1.500 & 6.250 & 1.780 \\
\hline 12 & 0.5270 & 0.788 & 0.645 & 9.2349 & 9.367 & 9.360 & 1.410 & 0.163 \\
\hline 13 & 0.9860 & 1.415 & 0.932 & 0.4800 & 0.696 & 9.539 & 2.115 & 0.220 \\
\hline 14 & 1.0340 & 0.880 & 1.664 & 0.3960 & 0.435 & 1.800 & 1.736 & 0.390 \\
\hline 15 & $i .1600$ & 1.290 & 1.840 & 0.8750 & 0.970 & 1.740 & 3.270 & 1.730 \\
\hline 16 & 1.4500 & 1.980 & 1.300 & 0.8160 & 1.999 & 1.620 & 3.620 & 0.740 \\
\hline 17 & 1.5606 & 1.690 & 0.970 & 0.3870 & 0.390 & 1.680 & 2.500 & 11.300 \\
\hline 18 & $\therefore .6800$ & 1.856 & 1.400 & 1.2860 & $1.32 \theta$ & 1.036 & 12.260 & 9.880 \\
\hline 19 & 1.2660 & 1.590 & 1.105 & 0.0610 & 0.070 & 0.837 & 1.800 & 0.961 \\
\hline 20 & 1.3600 & 1.986 & 1.240 & 0.4900 & 9.740 & 1.426 & 1.630 & 0.735 \\
\hline 21 & 2.0520 & 2.480 & 1.020 & 0.3130 & 0.401 & 1.356 & 1.811 & 12.866 \\
\hline 22 & 1.0815 & 1.896 & 0.523 & 0.8590 & 0.898 & 1.900 & 3.285 & 3.740 \\
\hline 23 & 1.1800 & 1.180 & 9.760 & 0.8330 & 1.060 & 2.650 & 2.156 & 8.000 \\
\hline \multicolumn{9}{|c|}{ Continue? } \\
\hline 24 & 1.5390 & 3.210 & 1.052 & 9.4746 & 1.836 & 1.829 & 1.792 & 6.960 \\
\hline 25 & 1.1426 & 1.143 & 0.860 & 0.9480 & 9.850 & 1.572 & 1.521 & 6.159 \\
\hline 26 & 2.6400 & 2.630 & 1.160 & 1.1250 & 1.124 & 1.925 & 5.476 & 0.460 \\
\hline 27 & 1.5860 & 1.580 & 1.330 & 0.8436 & 0.843 & 2.275 & 2.360 & 1.767 \\
\hline 28 & 2.5300 & 2.530 & 1.285 & 9.6436 & 0.643 & 1.238 & 10.160 & 2.566 \\
\hline 29 & 1.8990 & 1.899 & 1.466 & 0.3380 & 0.448 & 1.313 & 6.900 & 16.100 \\
\hline 30 & 2.3756 & 14.606 & 1.705 & 1.2920 & 8.236 & 1.627 & 2.726 & 4.740 \\
\hline 31 & 2.7700 & 8.960 & 1.080 & 0.0808 & 3.420 & 1.850 & 4.860 & 2.800 \\
\hline
\end{tabular}




\begin{tabular}{|c|c|c|c|c|c|c|c|}
\hline ROH & $C 25$ & $C 26$ & {$[27$} & $C 28$ & C29 & $c 30$ & C31 \\
\hline 1 & 0.700 & 9.143 & 9.670 & 0.627 & 1.760 & 0.023 & 0.0650 \\
\hline 2 & 2.936 & & & & & & 0.2100 \\
\hline 3 & 0.320 & 0.280 & 0.450 & 0.680 & 0.800 & 6.250 & .1300 \\
\hline 4 & 0.290 & 0.296 & 0.356 & 0.430 & 0.210 & 90 & 0.4700 \\
\hline 5 & 0.500 & 0.410 & 0.22 & 6 & & 6.725 & 0.2380 \\
\hline 6 & 0.87 & 0.650 & 0.310 & 0.28 & 0.14 & & .130 \\
\hline 7 & 0.280 & 0.210 & 0.510 & 0.530 & 1.000 & 0.630 & 0.4300 \\
\hline 8 & 0.490 & 0.380 & 0.081 & 0.237 & 1.879 & 0.336 & 0.2100 \\
\hline 9 & 0.225 & 0.270 & 0.700 & 0.220 & 9.350 & 0.695 & 0.8800 \\
\hline 10 & 0.440 & 9.520 & 0.220 & 0.136 & 1.060 & 2.250 & 0.3400 \\
\hline 11 & 1.370 & 1.050 & 0.400 & 0.240 & 2.860 & 1.780 & 0.3100 \\
\hline 12 & 0.205 & 0.520 & 0.480 & 0.114 & 0.105 & 1.400 & 0.1600 \\
\hline \multicolumn{8}{|c|}{ Continue? } \\
\hline 13 & 9.550 & 0.255 & 0.154 & 0.142 & 0.623 & 0.345 & 1.1210 \\
\hline 14 & 0.850 & 0.170 & 0.042 & 9.083 & 1.043 & 0.620 & 0.1470 \\
\hline 15 & 3.250 & 1.210 & 0.196 & 9.500 & 0.830 & 1.170 & 0.4566 \\
\hline 16 & 0.084 & 0.160 & 0.110 & 0.074 & 0.183 & 0.530 & 0.0660 \\
\hline 17 & 7.300 & 1.400 & 0.145 & 0.316 & 0.600 & 1.330 & 0.1530 \\
\hline 18 & 1.260 & 3.620 & 0.265 & 0.400 & 0.685 & 0.400 & 0.8289 \\
\hline 19 & 0.860 & 0.068 & 1.280 & 0.920 & 0.840 & 0.343 & 0.1825 \\
\hline 20 & 3.000 & 0.960 & 0.456 & 1.570 & 1.060 & 0.480 & 2.3209 \\
\hline 21 & 1.009 & 9.056 & 0.500 & 9.579 & a..325 & Q.5. $\mathrm{ag}$ & $1 . .2 \varepsilon \geq 0$ \\
\hline 22 & 0.700 & 0.330 & 0.116 & 0.860 & 0.265 & 0.436 & 0.1140 \\
\hline $\begin{array}{l}23 \\
24\end{array}$ & $\begin{array}{l}0.600 \\
0.357\end{array}$ & & & $\begin{array}{l}0.155 \\
0.940\end{array}$ & $\begin{array}{l}1.559 \\
0.414\end{array}$ & & $\begin{array}{l}.0825 \\
.02220\end{array}$ \\
\hline 25 & 0.011 & 4.900 & 0.290 & 9.180 & 0.198 & 0.690 & 0.2406 \\
\hline 26 & 9.625 & 0.378 & 0.185 & 0.200 & 6.177 & 9.928 & 0.1800 \\
\hline 27 & 9.569 & 21 & 0.590 & 6.785 & 1.575 & 5.485 & 0.1960 \\
\hline 28 & 2.93 & 2.930 & 0.910 & 0.910 & 1.196 & 1.687 & 0.8260 \\
\hline 29 & 0.5 & 0.600 & 0.260 & 0.007 & 0.21 & 0.500 & 0.1873 \\
\hline 30 & & & 0.025 & 0.1 & 1.4 & 0.176 & 1.1037 \\
\hline 31 & 0.398 & .576 & 486 & 9.833 & 1.070 & 2.500 & 0.4746 \\
\hline
\end{tabular}

ATB > pint 634

C34

$\begin{array}{rrrrrrrr}1.1411 & 3.1135 & 2.2240 & -0.2700 & 0.3131 & 1.9579 & 1.9749 & 3.0636 \\ 1.6517 & 0.2229 & 1.6284 & 1.9778 & 3.3910 & 2.7992 & 2.7024 & 1.6598 \\ 1.0660 & 2.6437 & 1.7752 & 1.9594 & -4.0570 & -3.4950 & -2.4775 & -1.1400 \\ -4.5116 & -4.9330 & -2.5189 & -3.1102 & -3.3787 & -3.4541 & -4.1112 & \end{array}$




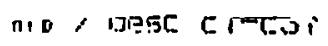

\begin{tabular}{|c|c|c|c|c|c|c|}
\hline & N & MEAN & MEDIAN & TRKEAH & STDEV & SEMEAN \\
\hline CI & 31 & 0.9721 & 9.1150 & 0.1040 & 0.1805 & 0.0324 \\
\hline 12 & 31 & 9.1306 & 0.1270 & 0.1344 & 9.2529 & 0.0454 \\
\hline 13 & 31 & 6.1217 & 0.1100 & 0.1184 & 9.2015 & $0.9362^{2}$ \\
\hline C4 & 31 & $0.127 \theta$ & 0.8859 & 0.1123 & 0.1634 & 0.0186 \\
\hline 15 & 31 & 0.0413 & 0.0470 & 0.9445 & 0.9579 & 0.6194 \\
\hline 16 & 31 & 0.0463 & 0.6600 & 0.8571 & 0.0807 & 0.0145 \\
\hline 67 & 31 & 0.6809 & 0.1000 & 0.8974 & 0.1722 & 1.0319 \\
\hline 18 & 31 & 0.8443 & 0.7300 & 0.7558 & 0.5533 & 0.6994 \\
\hline 19 & 31 & 0.6665 & 0.5690 & 0.6356 & 0.3433 & 0.8617 \\
\hline 196 & 31 & 0.3610 & 0.3300 & 0.3564 & 0.1955 & 0.0351 \\
\hline 111 & 31 & 0.3362 & 0.3230 & 0.3338 & 0.1888 & 6.6339 \\
\hline 112 & 31 & 0.4856 & 0.3150 & 0.4371 & 0.4679 & 0.8840 \\
\hline 613 & 31 & 0.9890 & 0.8990 & 0.9285 & 9.5239 & 0.6941 \\
\hline 114 & 31 & 9.7911 & 0.7600 & 0.7856 & 0.2935 & 9.6527 \\
\hline 115 & 31 & 9.1332 & 0.0950 & 0.1272 & 0.1053 & 0.0189 \\
\hline 116 & 31 & 0.7347 & 0.7270 & 0.7085 & 0.2853 & 0.6512 \\
\hline 117 & 31 & 1.446 & 1.260 & 1.419 & 0.582 & 0.115 \\
\hline 118 & 31 & 2.267 & 1.570 & 1.679 & 2.698 & 0.485 \\
\hline 199 & 31 & 1.0835 & 1.9600 & 1.6796 & 9.3178 & 0.6571 \\
\hline$[2]$ & 31 & 9.6266 & 0.4860 & 0.6182 & 0.3532 & 0.6634 \\
\hline 121 & 31 & 1.060 & 0.740 & 9.771 & 1.456 & 0.261 \\
\hline $\begin{array}{l}\text { l22 } \\
\text { Cont }\end{array}$ & 31 & 1.4361 & 1.5600 & 1.4687 & 0.4665 & 9.6838 \\
\hline$c 23$ & 31 & 3.427 & 2.360 & 3.819 & 2.627 & 1.472 \\
\hline$l_{24} 4$ & 31 & 3.478 & 1.780 & 2.909 & 3.942 & 1.768 \\
\hline 025 & 31 & 1.097 & 0.569 & 0.865 & 1.456 & 0.262 \\
\hline $12 \delta$ & 31 & 6.862 & 0.380 & 0.601 & 1.689 & 0.998 \\
\hline$[2]$ & 31 & 0.3318 & 0.2600 & 0.2974 & 0.2687 & 0.0483 \\
\hline ¿28 & 31 & 0.3355 & 0.2000 & 0.2917 & 0.3523 & 9.0633 \\
\hline 629 & 31 & 0.825 & 0.890 & 0.763 & 6.644 & 0.116 \\
\hline$[30$ & 31 & 0.911 & 0.620 & 0.746 & 1.047 & 0.188 \\
\hline C31 & 31 & 0.3737 & 0.2100 & 0.2956 & 0.4570 & 0.9821 \\
\hline
\end{tabular}

Continue?

HIN MaY ne -- 


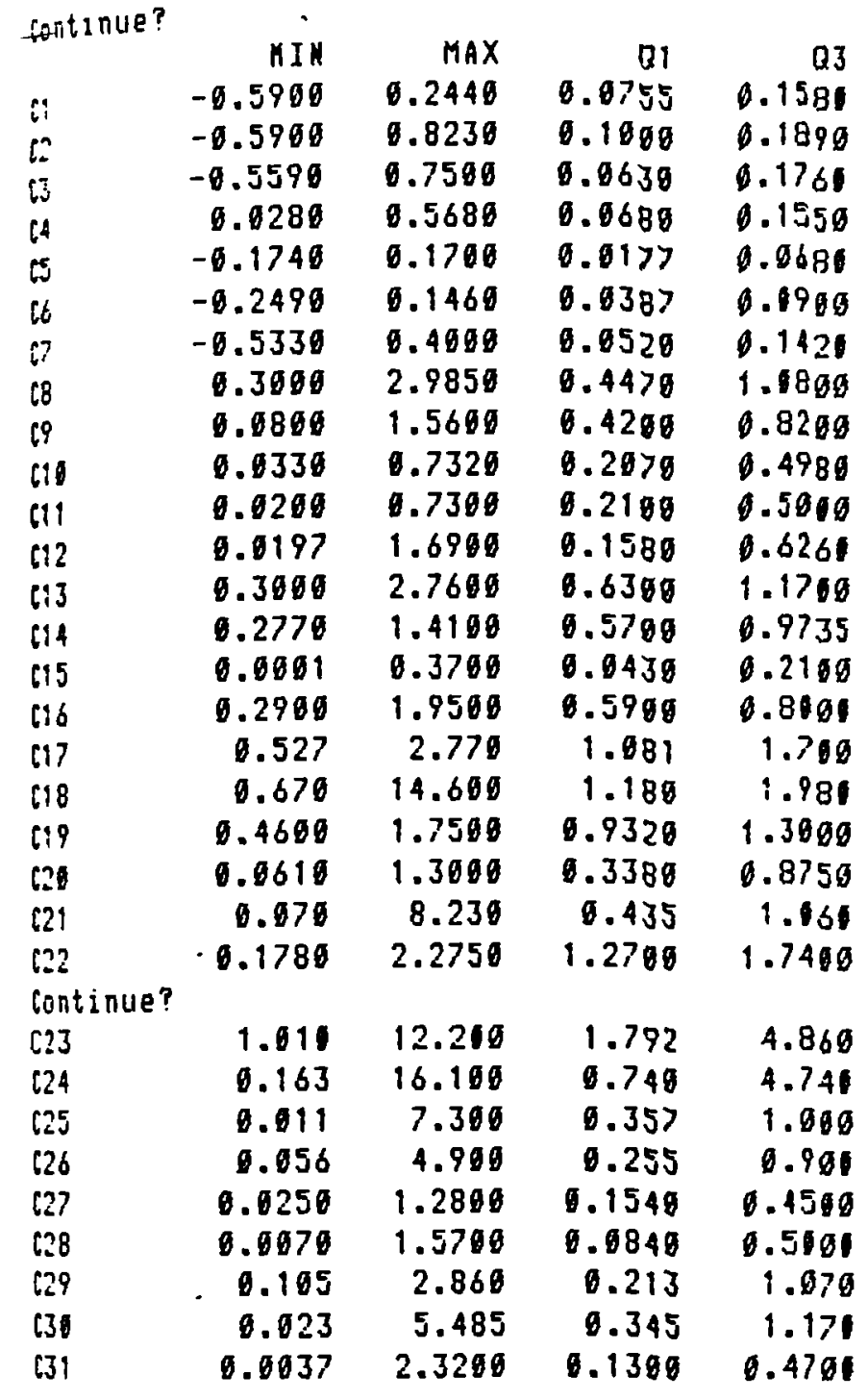


เTB > step 634 ic1-c31

STEPWISE REGRESSION OF C34 ON 31 PREDICTIORS, VITH $N=31$ Continue?

\begin{tabular}{|c|c|c|c|c|c|c|c|}
\hline $\begin{array}{r}\text { STEP } \\
\text { CONSTANT }\end{array}$ & $\begin{array}{r}1 \\
4.148\end{array}$ & $\begin{array}{r}2 \\
2.512\end{array}$ & $\begin{array}{r}3 \\
3.273\end{array}$ & $2.973^{4}$ & 2.809 & $\begin{array}{r}6 \\
3.149^{6}\end{array}$ & 3.067 \\
\hline $\begin{array}{l}117 \\
\text { I-RATIO }\end{array}$ & $\begin{array}{l}-2.87 \\
-4.31\end{array}$ & $\begin{array}{l}-2.25 \\
-3.99\end{array}$ & $\begin{array}{l}-1.95 \\
-4.23\end{array}$ & $\begin{array}{l}-2.16 \\
-6.85\end{array}$ & $\begin{array}{l}-2.84 \\
-7.86\end{array}$ & $\begin{array}{r}-3.14 \\
-11.91\end{array}$ & $\begin{array}{r}-2.87 \\
-17.39\end{array}$ \\
\hline $\begin{array}{l}\text { Co } \\
\text { T-RATIO }\end{array}$ & & $\begin{array}{r}16.14 \\
3.96\end{array}$ & $\begin{array}{r}13.99 \\
4.20\end{array}$ & $\begin{array}{r}13.65 \\
5.45\end{array}$ & $\begin{array}{r}15.34 \\
7.11\end{array}$ & $\begin{array}{r}14.77 \\
9.62\end{array}$ & $\begin{array}{l}15.66 \\
16.68\end{array}$ \\
\hline $\begin{array}{l}\text { CI2 } \\
\text { T-RATIO }\end{array}$ & & & $\begin{array}{l}-2.26 \\
-3.99\end{array}$ & $\begin{array}{l}-2.58 \\
-6.00\end{array}$ & $\begin{array}{l}-2.08 \\
-5.37\end{array}$ & $\begin{array}{l}-1.82 \\
-6.51\end{array}$ & $\begin{array}{r}-1.85 \\
-10.90\end{array}$ \\
\hline $\begin{array}{l}\text { C25 } \\
\text { I-RATIO }\end{array}$ & & & & $\begin{array}{r}0.628 \\
4.69\end{array}$ & $\begin{array}{r}0.581 \\
5.12\end{array}$ & $\begin{array}{r}0.642 \\
7.88\end{array}$ & $\begin{array}{l}0.660 \\
13.37\end{array}$ \\
\hline $\begin{array}{l}\text { Z23 } \\
\text { I-RATIO }\end{array}$ & & & & & $\begin{array}{r}0.282 \\
3.45\end{array}$ & $\begin{array}{r}9.439 \\
6.67\end{array}$ & $\begin{array}{l}0.446 \\
11.19\end{array}$ \\
\hline $\begin{array}{l}\text { I26 } \\
\text { T-RATIO }\end{array}$ & & & & & & $\begin{array}{r}-0.630 \\
-5.65\end{array}$ & $\begin{array}{r}-1.647 \\
-8.57\end{array}$ \\
\hline $\begin{array}{l}\text { WO } \\
\text { T-RATIO } \\
\text { Continue? } \\
\mathrm{S}\end{array}$ & $\begin{array}{r}e .34 \\
2.12\end{array}$ & $\begin{array}{r}017 \mathrm{c} \\
1.73\end{array}$ & $\begin{array}{r}12 c 25 \mathrm{c} \\
1.41\end{array}$ & -2.3 & 0.880 & 6.625 & $\begin{array}{r}-6.159 \\
-6.52 \\
-0.378\end{array}$ \\
\hline \multicolumn{8}{|c|}{$\begin{array}{l}\text { To print nore output, type } Y \text { or YES or push return. } \\
\text { To terminate printing, type N or NO. } \\
\text { for more information, see HELP OUTPUT. } \\
\text { (Mote that before typing HELP OUTPUT, you nust either piaish } \\
\text { printing or terninate this OUTPUT.) }\end{array}$} \\
\hline $\begin{array}{l}\text { R-SP } \\
\text { NORE? (Y } \\
\text { SUBC) abo } \\
\text { MTI ? } \\
\text { NTI > reg }\end{array}$ & $\begin{array}{l}39.12 \\
\mathrm{NO}, \mathrm{s}\end{array}$ & $\begin{array}{r}60.92 \\
\text { COMKAN }\end{array}$ & $\begin{array}{c}75.43 \\
\text { OR HELP) }\end{array}$ & 86.68 & 98.98 & 95.63 & 98.47 \\
\hline
\end{tabular}


The regression equation is

$[34=2.81-2.84$ C17+15.3 C6 $-2.68 c 12+1.581[25+1.282$ C23

$\begin{array}{lrrr}\text { Predictor } & \text { Coef } & \text { Stdev } & t \text {-ratio } \\ \text { ionstant } & 2.8093 & 0.4977 & 5.65 \\ \text { i17 } & -2.8426 & 0.3618 & -7.86 \\ \text { C6 } & 15.336 & 2.156 & 7.11 \\ i 12 & -2.9820 & 0.3876 & -5.37 \\ i=5 & 0.5867 & 9.1134 & 5.12 \\ i 23 & 0.28192 & 0.88161 & 3.45\end{array}$

$i=0.8798 \quad R-5 q=91.8 \% \quad R-5 q(\bar{\sigma} \mathrm{JJ})=89.2 \%$

Airalysis of Variance

$\begin{array}{lrrr}\text { SOURCE } & \text { DF } & \text { SS } & \text { MS } \\ \text { Regression } & 5 & 195.194 & 39.039 \\ \text { Error } & 25 & 19.359 & 0.774 \\ \text { lotal } & 30 & 214.544 & \end{array}$

$\begin{array}{lrr}\begin{array}{lrl}\text { COntinue? } \\ \text { SOURCE }\end{array} & \text { DF } & \text { SER SS } \\ 617 & 1 & 83.797 \\ 66 & 1 & 47.991 \\ 612 & 1 & 31.114 \\ 625 & 1 & 24.138 \\ 623 & 1 & 9.236\end{array}$




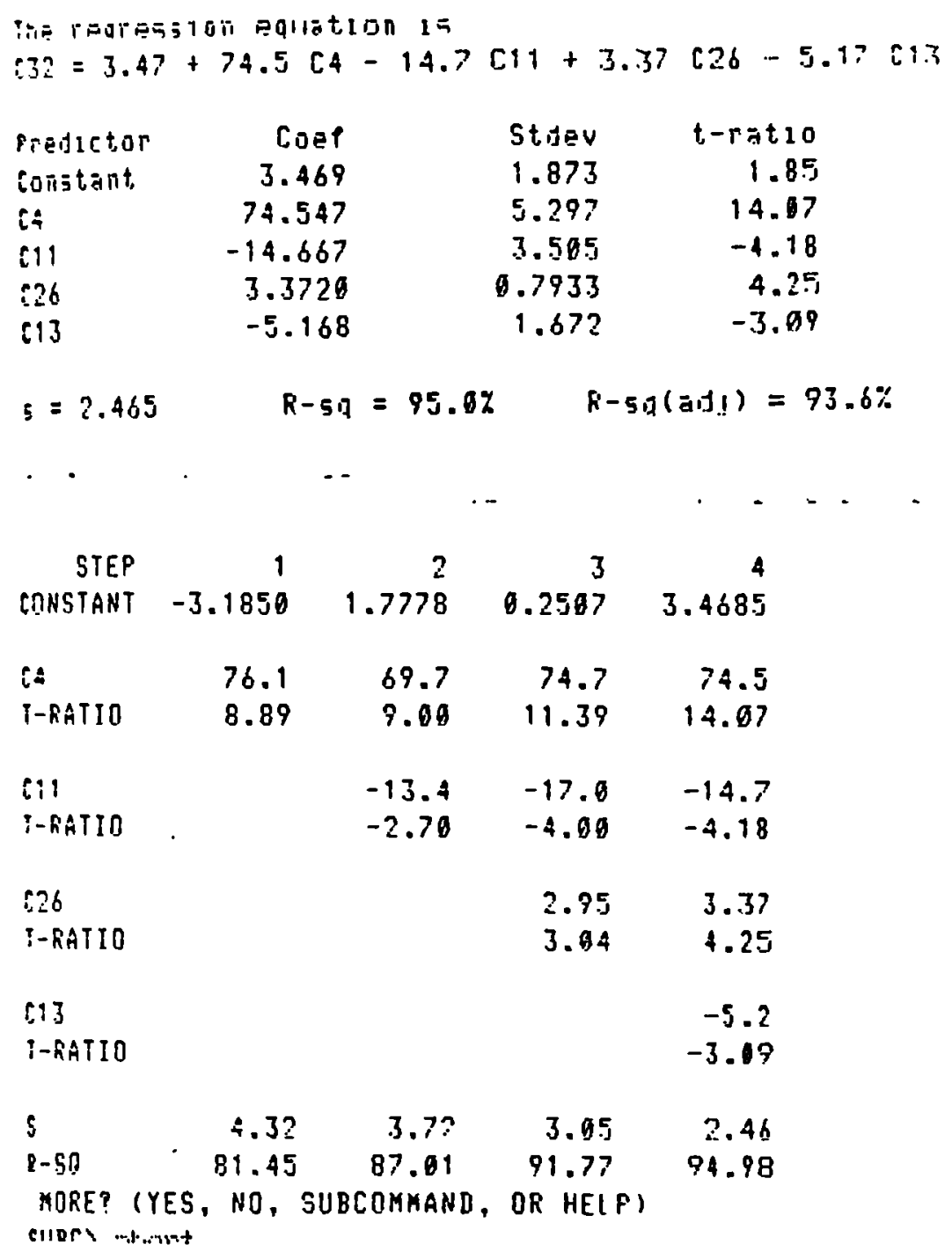


HTB > Hotst ey-c.31

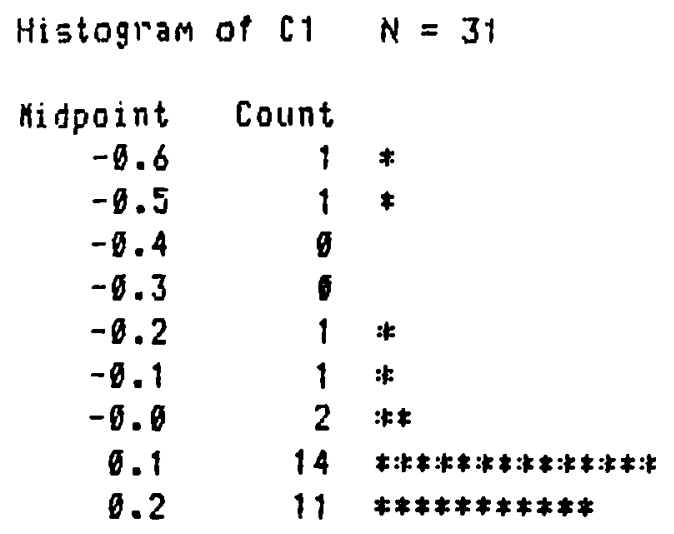

Continue?

Histogram of $C 2 \quad N=31$

Hidpoint Count

$-0.6 \quad 1 \neq$

$-0.4 \cdot 1=$

$-0.2 \quad 1 ;$

$-0.0 \quad 4$ :*:***

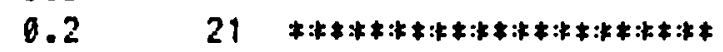

$0.4 \quad 1 \neq$

$0.6 \quad 1 \neq$

$0.8 \quad 1 *$

Continue?

\begin{tabular}{|c|c|c|}
\hline$H_{1}$ 56ogram & of $c 3$ & $H=31$ \\
\hline Kidpoint & Count & \\
\hline-0.6 & 1 & \# \\
\hline-6.4 & 0 & \\
\hline-0.2 & 1 & ; \\
\hline-9.0 & 9 & 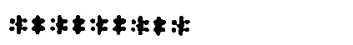 \\
\hline 0.2 & 17 & 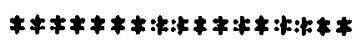 \\
\hline 0.4 & 1 & F \\
\hline 0.6 & 1 & * \\
\hline 0.8 & 1 & $\neq$ \\
\hline
\end{tabular}

Continue? 


\begin{tabular}{|c|c|c|}
\hline Hl 5togiam & or $[4$ & $N=S i$ \\
\hline Nidpolnt & Count & \\
\hline 0.05 & 10 & $\notin: k \neq: k \notin: k \notin: k \neq: k$ \\
\hline 0.10 & 11 & 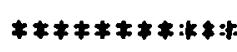 \\
\hline 0.15 & 3 & $\neq * \neq$ \\
\hline 0.20 & 5 & $\neq \neq * \star \neq$ \\
\hline 0.25 & 1 & $*$ \\
\hline 0.30 & $\theta$ & \\
\hline 0.35 & 0 & \\
\hline 0.49 & $\theta$ & \\
\hline 0.45 & 6 & \\
\hline 0.50 & $\boldsymbol{g}$ & \\
\hline 0.55 & 1 & $\bullet$ \\
\hline
\end{tabular}

Continue?

\begin{tabular}{|c|c|c|}
\hline Histogiam & of 65 & $N=31$ \\
\hline$n i d p 02 n t$ & Count & \\
\hline-0.15 & 1 & $\neq$ \\
\hline-0.10 & $\theta$ & \\
\hline-8.65 & 2 & $\$: *$ \\
\hline-6.60 & 5 & $: \neq * * *: *$ \\
\hline 0.65 & 17 & 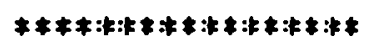 \\
\hline 0.16 & 5 & $\star \star \star \star \star$ \\
\hline 0.15 & 1 & $*$ \\
\hline
\end{tabular}

Continue?

Histogram of $66 \quad N=31$

Midpoint Count

$-0.25 \quad 1$ *

$-6.26$

$-0.15$

$-0.10$

$-0.05$

$-0.00$

0.65

0.10

0.15

6

$1 *$

$1 *$

$1 *$

$2 * *$

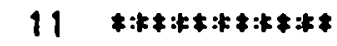

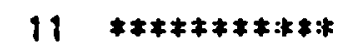

$3 \neq *$

Continue? 


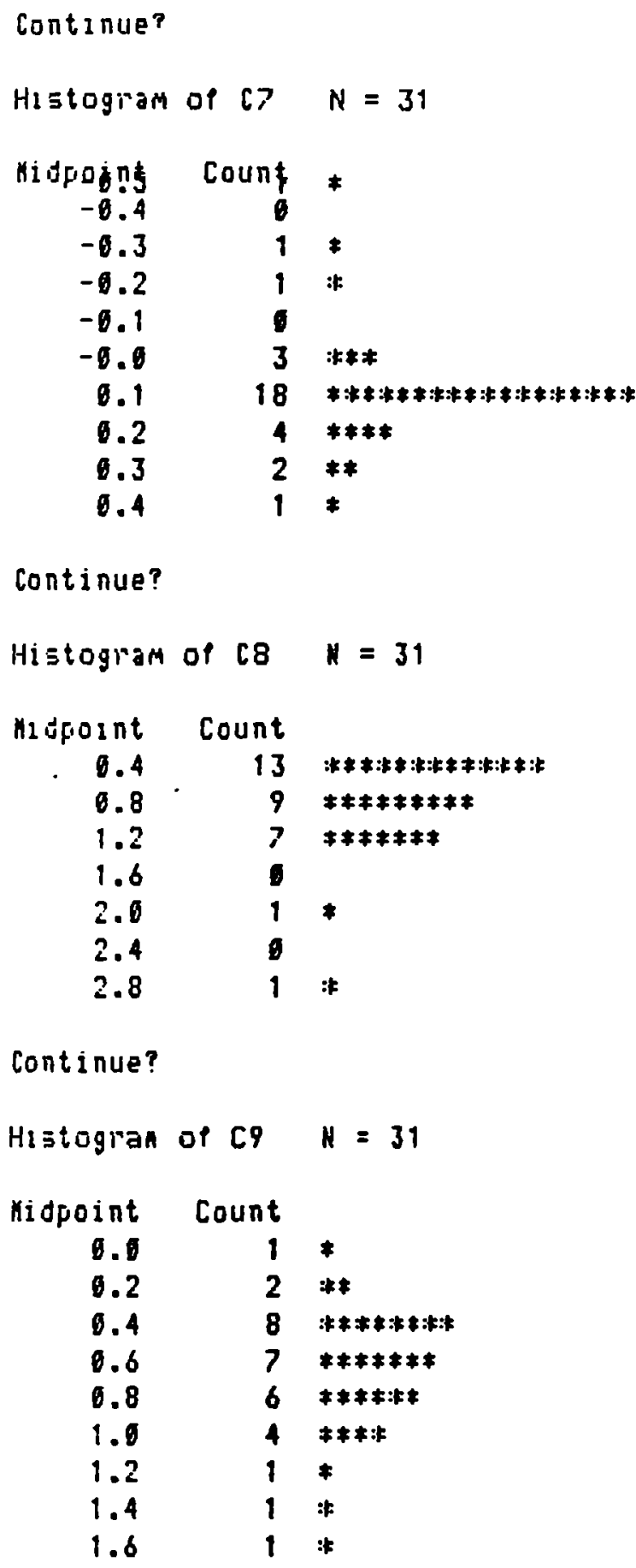


continue?

\begin{tabular}{|c|c|c|}
\hline Histogram & of $c 10$ & $N=31$ \\
\hline Hidpoint & Count & \\
\hline 0.0 & 1 & $\star$ \\
\hline 0.1 & 5 & 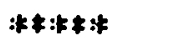 \\
\hline 0.2 & 2 & $* *$ \\
\hline 6.3 & 9 & 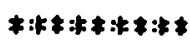 \\
\hline 0.4 & 6 & 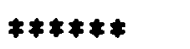 \\
\hline 6.5 & 1 & $\star$ \\
\hline 0.6 & 3 & $* * *$ \\
\hline 0.7 & 4 & 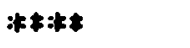 \\
\hline
\end{tabular}

Continue?

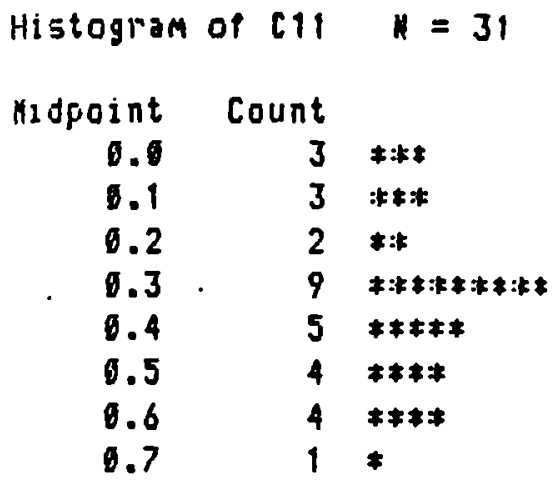

Continue?

Histogram of $\quad 12 \quad H=31$

Vidpoint Count

0.04 $4 * * *$

$0.2 \quad 11 \quad * * \neq * * * * * * * *$

$6.45 \neq * \neq * *$

$0.6 \quad 4 * * * \neq$

$0.8 \quad 1$

$1.02 *$

1.2

$1.42 * *$

$1.62 * *$

Continue? 


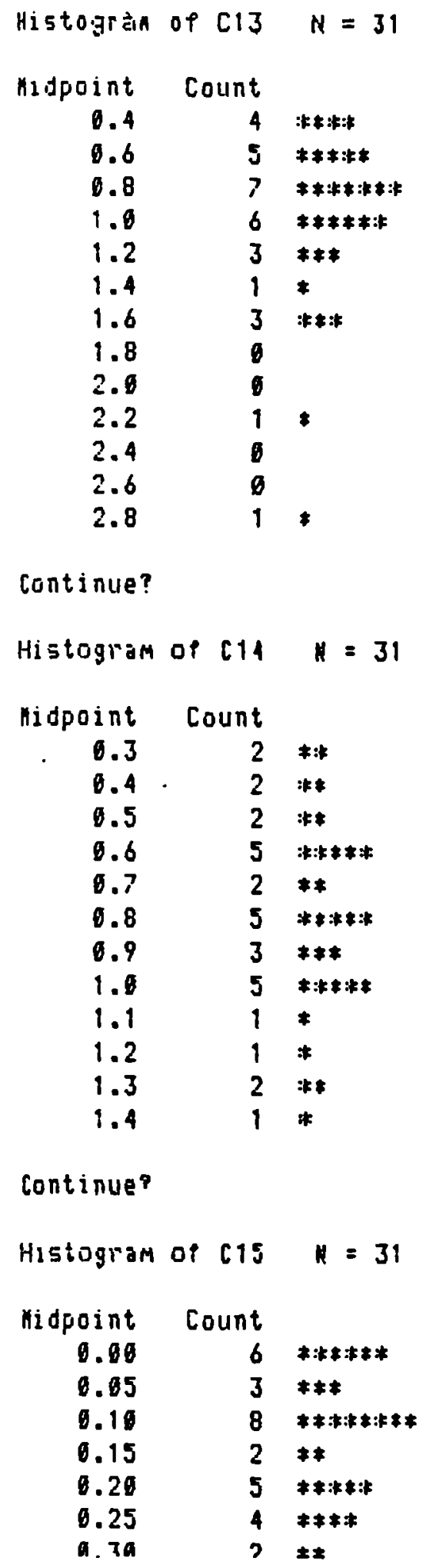




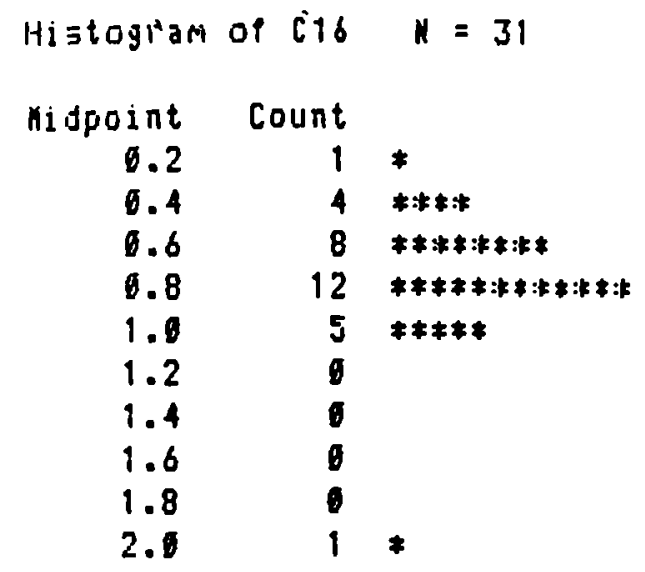

Continne? 


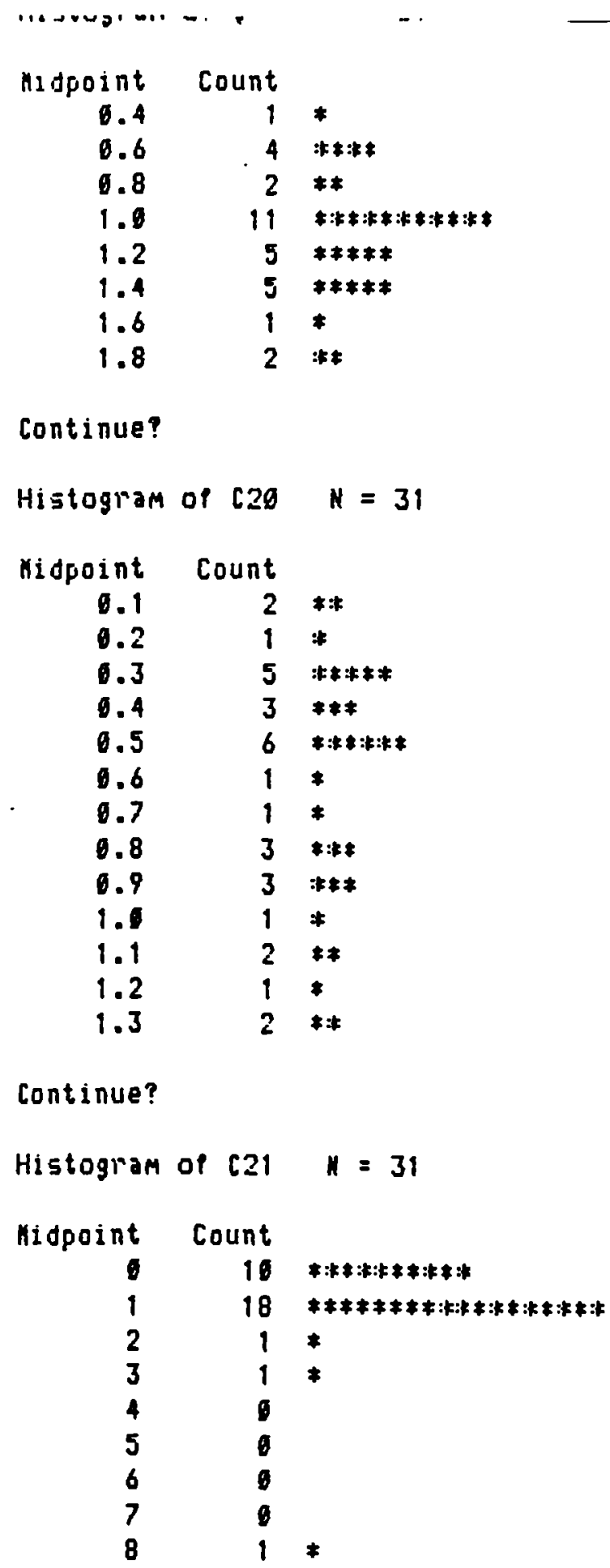

Continue? 


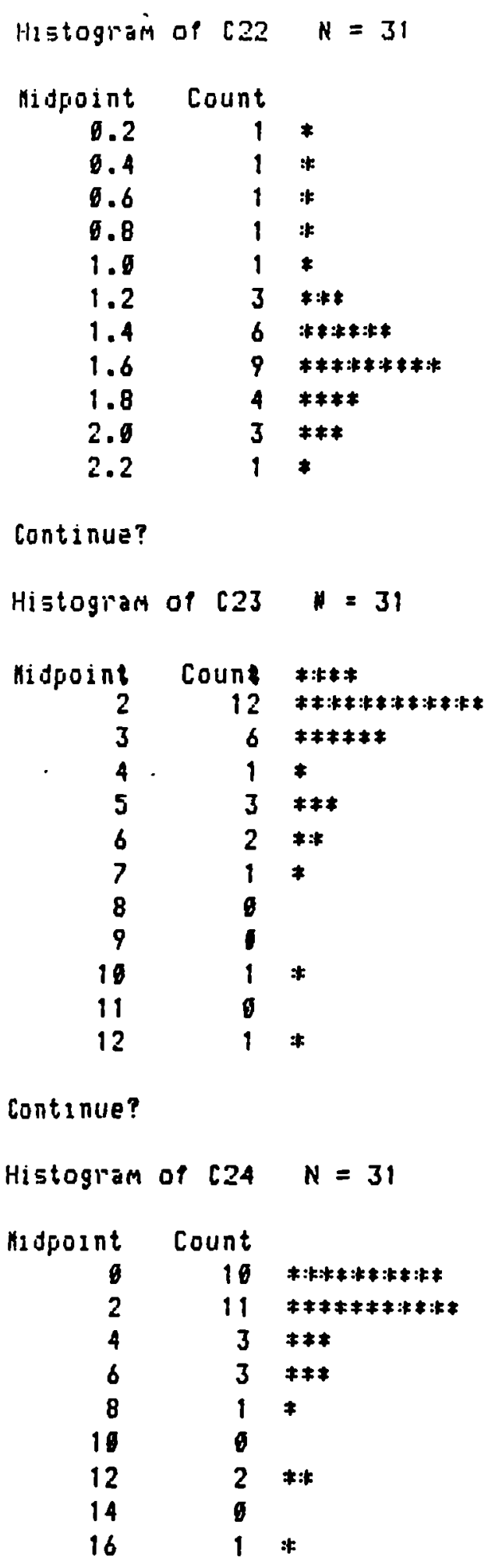




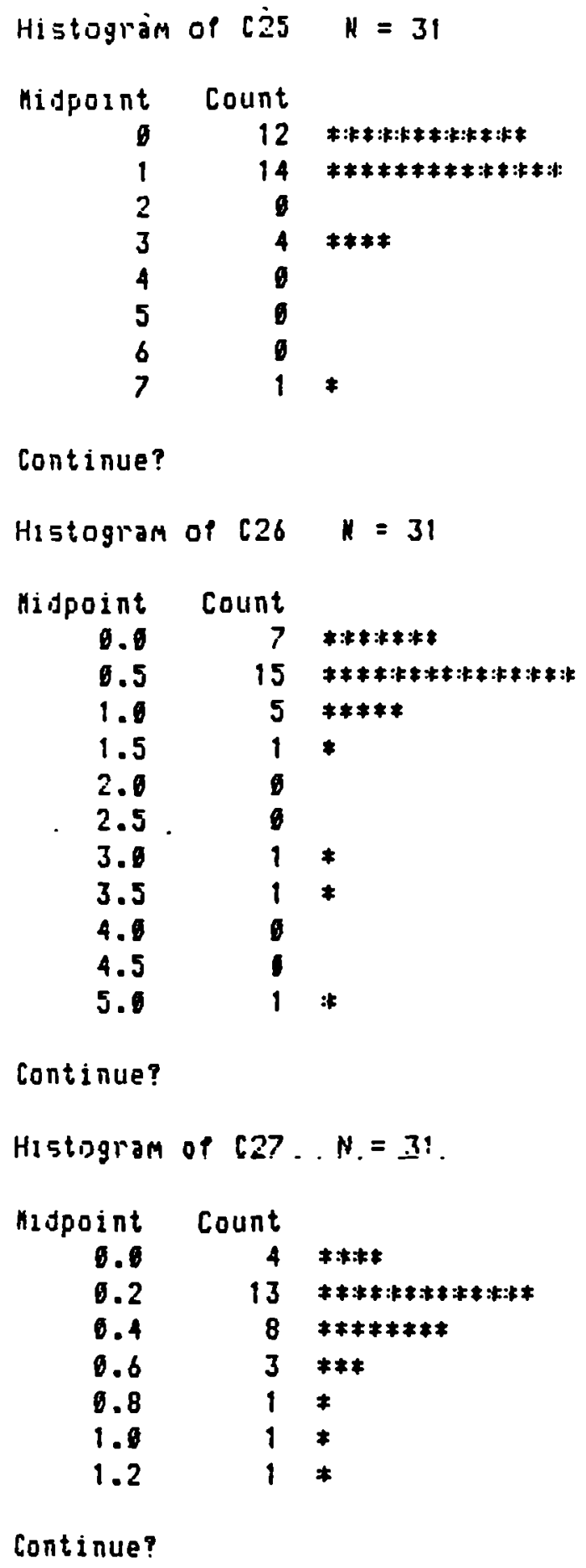

Continue? 


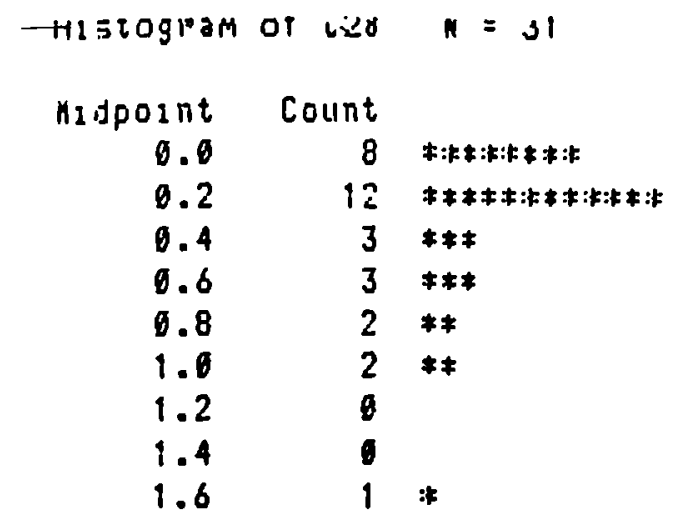

Continue?

\begin{tabular}{|c|c|c|}
\hline Histogram & of 629 & $N=31$ \\
\hline Hidpoint & Count & \\
\hline 0.0 & 6 & $\neq: k:: k: * z$ \\
\hline 0.4 & 6 & $\neq \neq \neq \neq: \neq: *$ \\
\hline 0.8 & 7 & $\neq * * \neq * ; * *$ \\
\hline 1.2 & 6 & $\neq \neq \# \#: k *$ \\
\hline 1.6 & 4 & $\neq * \neq *$ \\
\hline 2.6 & 1 & * \\
\hline 2.4 & $g$ & \\
\hline 2.8 & 1 & * \\
\hline
\end{tabular}

Continue?

Histogram of $131 \quad N=31$

Nidpoint Count

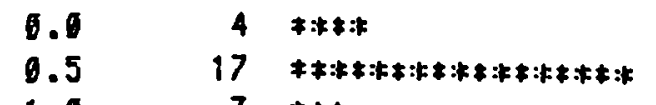

$1.03 \quad 3 \neq *$

$1.5 \quad 3 \neq * *$

2.11 *

$2.5 \quad 2 * *$

3.0

$\begin{array}{ll}3.5 & 0 \\ 4.0 & 0\end{array}$

4.5

5.0

5.5 - I - 


\begin{tabular}{|c|c|c|}
\hline Histogram & of $c 31$ & $N=31$ \\
\hline Nidpoint & Count & \\
\hline 0.0 & $\mathbf{5}$ & $* * * * * * *$ \\
\hline 0.2 & 14 & 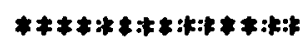 \\
\hline 0.4 & 7 & $\neq * * * * \neq *$ \\
\hline 0.6 & 1 & $*$ \\
\hline 0.8 & 2 & $* *$ \\
\hline 1.0 & 0 & \\
\hline 1.2 & 1 & * \\
\hline 1.4 & 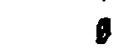 & \\
\hline 1.6 & 6 & \\
\hline 1.8 & 6 & \\
\hline 2.0 & 1 & \\
\hline 2.2 & 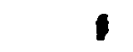 & \\
\hline 2.4 & 1 & * \\
\hline
\end{tabular}

КTB > 
APPENDIX D

CORRESPONDENCE, DIAGRAMS, CASE STUDIES AND QUESTIONNAIRE

\section{INTRODUCTION}

This appendix consists of five sections as follows:

$\underline{D-1}$ Includes results of survey of 25 Landan authorities obtained fram London Borough of Richmond-upon-Thames (research section), about financial appraisal procedure - approved list of contractors and competitive tendering. An analysis of the results of the survey is attached.

D-2 Includes certificate obtained from London Borough of Camden concerned with the validation of multiple regression model on those private companies dealing with LBC.

D-3 Contains the z-score trends during the period 1982-1986 for the "non-failed 20" companies and the last three years before failure for the "failed 11" companies

D-4 Includes three case studies obtained from Cork Gully Chartered Accountants, and these include the following oompanies declared bankrupt with Cork Gully appointed as liquidators:

1. Southern Construction Ltd

2. Crouch Construction Ltd and Crouch Group plc

3. Mears Bros Holdings Ltd.

D-5 Includes a questionnaire designed to identify the managerial defects and mistakes related to failure, and includes 27 questions investigated by using the multiple choice method. 
APPENDIX D-1

RESULTS OF SURVEY ABOUT FINANCIAL APPRAISAL PROCEDURE

by

LONDON BOROUGH OF RICHMOND-UPON-THAMES RESPARCH SECTION 


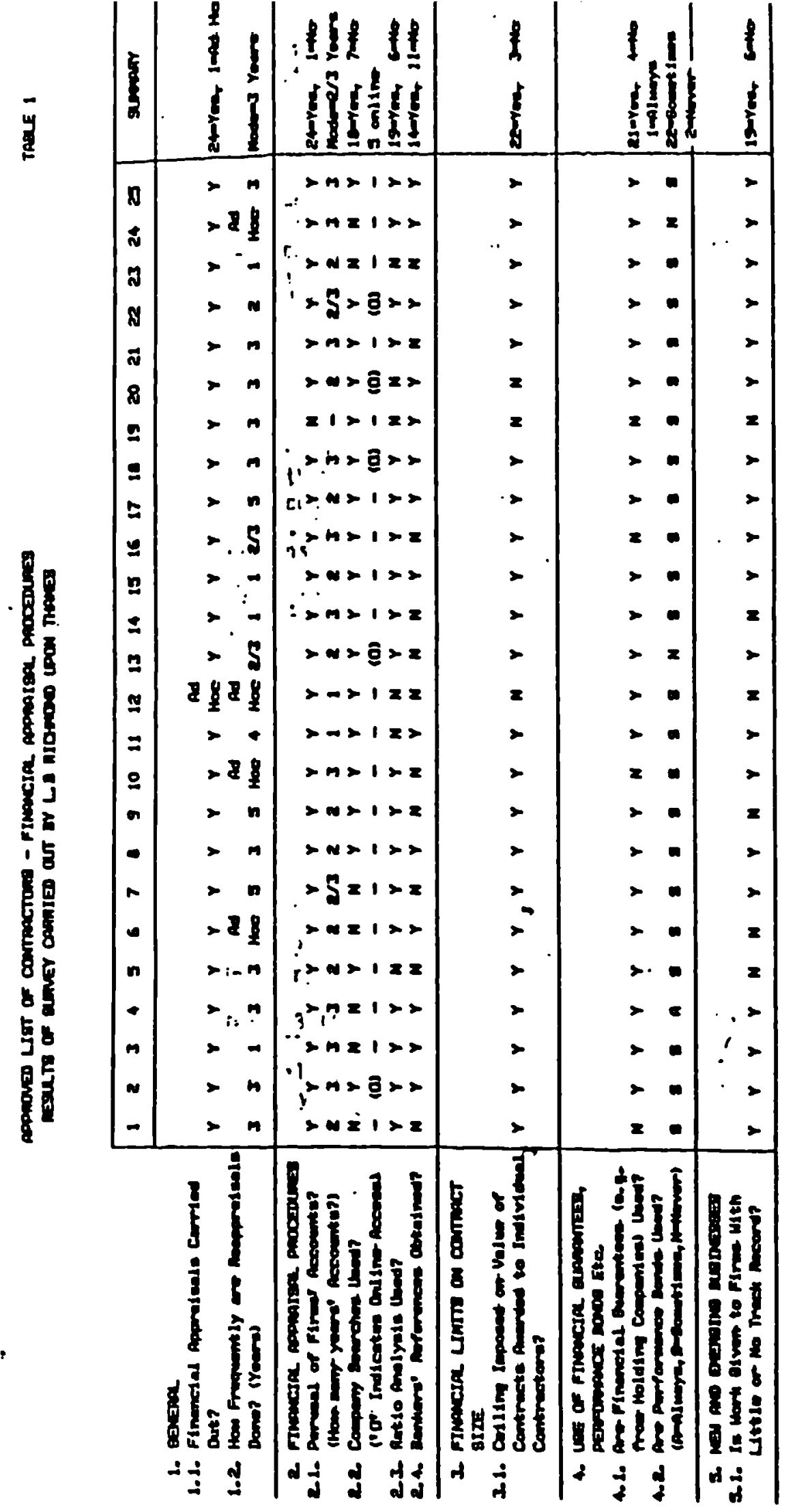


Introduction

Tab le 1 summar ises the responses to questlons requiring Yes/No type answers. As a number of authoritles preferred not to be Identified the results are presented anonymously. Responses were recelved from 25 of the 33 London authoritles surveyed, a response rate of $76 \%$. These notes sumartse and comment upon the results shown in Table 1 and discuss the results of the more detalled questions. The results have not been converted into percentage terms as $11 t t l e$ would be ga ined from do ing so.

1. General

All 25 authorities carry out financlal appraisals of firms applying to do work for then, whe ther for a select 1 ist of contractors, annual ma intenance contracts or other ad hoc contracts. Tab le 2 summarises the answers to 0.1 .2 concerning the frequency of reappraisal, the most common response being 'every 3 jears' (10 authorities).

Table $2(0.1 .2)$

Frequency of

No. Responses

Annual.

2. Financial Apprajsal Procedures

2.1 Table 3 sumarises the sources of information and techniques used in carrying out financtal appra isals.

\section{Tab le $3(0.2 .1)$}

a) Perusal of Firm's Accounts

b) Company Searches

c) Ratio Analys is

d) Bankers', References
Yes, № $\quad$ Total

$24 \quad 25$

$18 \quad 25$

$20 \quad 5 \quad 25$

$14 \quad 11 \quad 25$

a) Compantes' Accounts

- The majority of author ities (24 out of 25) examine firms' financlal accounts, with only 1 authority relying solely on company status reports produced by outs ide agencies. Eleven respondents prefer to see accounts for_the last 3 years, a fur the 11 expect to see the last 2 years' accounts, and the remitning 2 base their appra isaís an the mosit recent vear's results a lone. 
b) Company Searches

Elghteen authorftles use company searches prodsced by outside agencies lof which the most popular are infocheck (8) and Dunn and $\mathrm{Brads}$ treet $(6)$. On Iy 5 authorities have. acjess to company searches on line. Seventeen. au thor t ties obta in informatinn. both directly from i irms acsounts and trom company searches with only one using company searsies aidoie.

c) - Ratto Analysts

Twenty authoritles use ratio analys is (to a greater or lesser extent) to assess the financial standing of prospective contractors. Four authorities rely on company status reports produced by outside agencles, some of which quote ratios as part of their analys ts of sourse.

Use of Z-Score Analysis

Of the 20 author itfes us inq ratios 6 use Z-score analvsis. (Wo in iv Altmans 2-score) to assess the solvency of potential con wactors.

A 2-score for a particular firm is calculated by adding together a number of ratios, each having been weighted according to its usefulness. The formula results in a single score which is compared with standard bench marks e.g. a score greater than 3 al todfeates that the company should be safe

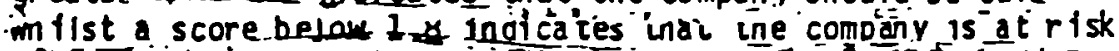
of faTure. The ratios incorporaced in to $\tau$-s core analys is

- inciüoe : working capital/total assets; retained

earnings/total assets; profits before interest and tax/total assets; market capital isation/book value of debts; and, sales/total assets.

Given its comparative complexity, Z-score analysis requires the use of spreadsheet software if it is to be carried out on a regular bas 15 .

Further Information on the Z-score technique can be found in an article by David Citron and Richard Taffler: "The Financial Vetting of contractors" in PFA (Sept 9 th 1988). This also discusses the use of $r$ isk indices and PAS-scores or

performan ce meas ures.

\section{Traditional Ratio Malys is}

- Fourteen authorittes use traditional ratio analys is i.e. selected ratlos are calculated and the results used to make professtonal judgements as to the continuing financial viabllity of potential and existing contractors. Table 4 loverleaf) outl ines the different ratios used and the number of authorities using each one. 
Rat1o

Current Rat fo (Curr.Assets/Curr.Llabs)

Acid Ratto (Curr. Assets-Stock and WIP/ Curr. Llabs)

Profitability Ratfos (various)

Gearing

Net Morth/Turnover

Horking Capltal/Turnover 1

Return on Capital Employed 2

Debtors/Turnover 1

Creditors/Cost of Sales 1

Earnings Per Share 1

All of the authorities using traditional ratio analys is calculate the current ratio and wost use the actd or quid ratto in addition. The vajorfty of authoritfes expect to see min imum values of be tween 0.7 and 1,0 for the current ratio, and between 0.5 ando 1.0 for the actid ratio.

Nine authorities use profitability ratfos, most commonly net proftt before interest and tax/turnover, al though gross profit margins are also used. Two authorities expect to see net profit margins of at least $3 x$, and one 0x. The remaining authoritfes do not set minimuin levels.

only 3 authorftes calculate gearing ratios and these would normally expect to see results of less than 1.0 . although some flexibtlity is allowed.

In most cases the minimuw maximun acceptab le ratio values are set for guidance rather than being appl fed rigidly. The inter-relationsh ip be tween ratios, toge ther with other inforiation given by the acsounts, is examined to assess the significance of any departure from the normally expected levels.

Traditional ratio analys is, as used by the authoritfes responding to th is survey rel les heavtly upon an assessment of 1 lauldite This is to be expected given that a jor jor concern is to avota letting contracts to firms which are i ikely to go out of bus iness. Profftability is a lso seen as important, followed by gearing, with a few authorittes calculating additional rattos as shown in Table 4. However, most authoritfes look not only at the ratios they have calculated but also at the overall financial position as indicated by the accounts. Ratlos are used to focus attention on the salfent points. Therefore, it would not be correct to assume, for examle, that the five authoritles which do not calculate profttability ratfos do not take any acsount of this aspect in their appratsals.

$0627 r$ 
d) Bankers' References

Fourteen of the 25 respondents seek bankers' references in support of applications from potential contractors. Some seek $b$ ankers' references in every case, others use them on a selective bas is depending on the size of the firm, how well known or otherwise it may be and the type of contract.

\section{Financfal Limits on Contract Size}

Twenty two of the 25 authorittes impose some form of 1 imit on the value of contracts which may be awarded. These limits take one of three forms: a) a limit on the maximum total value of contracts which may be awarded to a partfcular contractor in any one year; b) a limit on the value of work which a partfcular contrastor may have outstanding at any one time; $\Rightarrow)$ a 1 imit on the value of individual contracts which may be awarded to particular contractors (but no 1 imit on the number of contracts which may be wonl. The results are broken down as follows:-

Tab le $5(0.3 .1)$

No. Authoritfes

a) Annual Limit on Total Value

12 of Contracts

b) Limit on Value of Work Outstanding at Any One Time $\quad 6$

c) Limit on Value of Individual Contracts (but no Overall Limit)

The following tables show the values used.

Tab le 6 shows the values used by the 12 authorities which set annual ilmits.

\begin{tabular}{|c|c|c|c|c|c|}
\hline \multirow{2}{*}{ Tab le 6} & \multirow{2}{*}{ 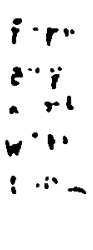 } & a) & \multicolumn{2}{|l|}{ Annual Limits } & No. Authoritie \\
\hline & & (1) & $\begin{array}{l}100 \% \text { turnover } \\
50 \% \text { turnover } \\
25 \%-28 \% \text { turnover } \\
20 \%-25 \% \text { turnover (or }\end{array}$ & less) & $\begin{array}{l}1 \\
4 \\
4 \\
3\end{array}$ \\
\hline & $\therefore$ & & $\because:$ & & \\
\hline & $\begin{array}{l}\because \cdots \\
\cdots 1:\end{array}$ & & + & $\dot{.}$ & $\underline{\sqrt{2}}$ \\
\hline
\end{tabular}

Note (1) 3 authorities use $50 \%$ of the average prevtous 2 years turnover

Tab le 7 (overleaf) shows the 1 imits set by the 6 authorities which control the amount of work outstanding at any one time. 
. 50\% turnover

.25\% turnover

Unknown

c i :

c) Limits Per Contract (zut no Orerall Limit on Number of Contracts

One of the 4 authorfties whith 1 init the value of individual contracts uses 1 imits recommended by Infocheck. (Recommended contract 1 imits do not appear as part of the usual on 1 ine company status reports which Infocheck produce but ma be prov Ided by spectal arrangements). Another uses a limit of $25 \%$ turnover or $50 \%$ turnover depending on the type of contract. The others set 1 imits averaging approximately $15 \%$ depending upon the results of the financtal appra isal.

Irrespective of the type of 1 int applfed, most authorities apply more restrictive I faits to firms with less favourable financtal appraisal results.

\section{Why are Financlal Limfts Used?}

The responses show a broad concensus as to the reasons for applying financial 1 imits. These are summar ised below:-

- firms should not take on work beyond their capacity: authorities do not wish to encourage over-tradina and. consequent recelversh ips.:

- the risk of mid-contract I iquidation or other default should be minimised in order to avold additional costs, administrative inconventence, problems in getting defects remedied etc.

- firms should not be over-rel iant on Council business; if for any reason the council were to cease providing the level of work expested, the firm might suffer financial difficulties wth consequent job losses in the local area, bad Council public.relations image etc.

- the authority should not allor itself to become over-dependent upon a few contractors as this could encourage the formation of cartels and povide the opportunity for collusion between officers and contractors.

- there should be as wide a choice of suttable firms as poss tb le to ensure that tenders are competitive and the authority gets value for maney. 
- the use of financial limits based on standard sriteria ensures that applizants are treated fairly.

Most authorities find it necessary to allow some exceptions to the rules, for example if there is a shortage of firms on the 1 ist for particular types of work. One authority notes that the set i imits ray be exceeded by up to $10 \%$ without consultation to allow some flexibllity. Some authorities require committee approval for limits to be exceeded.

Whilst the use of financial I imits in some form is seen as essential by most authorittes for the reasons mentianed above, most agree that monitoring adherence to those 1 imits is problematic. unless an authority has a computer ised system which can combine both tendering and payments $h$ istortes for individual contractors, it can prove difficult to apply the 1 imits. A few authortties responding to this survey are moving in this direction but as yet none has such a system in full operation. Therefore, the use of annual linits relies to a large extent on keeping running totals of the amount of work awarded to individual contractors. Limits on the amount of work outstanding at any one time also require payments to be checked on a regular bas is so that payments can be subtracted from the value of contracts awarded to determine the avallable linte.

Keeping track of contracts and payments in this way is time-consuming and dffficult given that a number of different departments and even sections with in departments are involved in letting contracts.

4. Use of Financtal Guarantees, Performance Bonds Etc

\subsection{Fin anclal Guarantees}

As shown in Table 1, 21 authorfttes use financial guarantees from parent compantes.

4.2 Performance Bonds.

Table 8 : Are Performance Bonds Used?

No. Authorittes

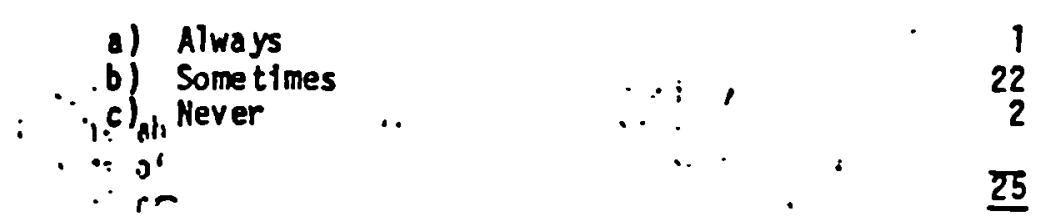

Most of the authoritfes responding to the survey use performance bonds under certa in circumstances, whether for contracts over a certa in value, of a particular type (e.g. all new build works) or for firms which fa il to satisfy the usual financial requirements. Nineteen authoritfes quoted a threshold contract value ab ove whtch performance bonds are usually sought. A wide range of threshold values was quoted as illus trated in Table 9. 
Threshold

f 30,000

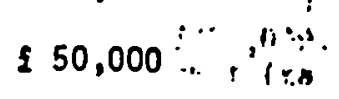

\& $60,000:$ i.....

$£ 100,000$

1. .

$£ 125,000-\$ 150,000$

$\$ 200,000-\$ 250,000$

$£ 500,000 \quad, \cdots i$

Speclal Circunstances
No. Author 1 tles

5. New and Energing Bus Inesses

Nine teen of the $\mathbf{2 5}$ authorities are prepared to give work to new or emerging businesses with ifttle or no financlal track record.

The arguments in favour of using new and emerging bus inesses were as follows:-

- lack of suttable established firms avallab le to do the job

- local economic development issues: e.g. new businesses cannot be expected to develop unless they are given a chance to demonstrate their capabilities; being accepted for local authority contracts acts as a good reference and can help firms secure work from other sources.

If new and emerging businesses are to be offered work, most authorities find it necessary to relax the financial appraisal criter fa normily appl fed. In the absence of audited financial accounts, some authorities seek other forms of $f$ in ancial references such as bankers' and accountants' references, detalls of financlal backing, detalls of prevlous contracts carried out, business plans and financtal forecasts etc. Some authorittes assess such firms on the bas is of technical criteria alone.

Given the degree of $r$ isk assocfated with awarding contracts to new firms, some authorities restrict the types of contracts which may be awarded e.g. to Jobs of a fragmented nature such as painting and decorating or minor landscaping works. Many authorities restrict the value of contracts which may be awarded. Ten authoritles mention specific sums; ranging from $\$ 500$ per contract to $\$ 20,000$ per annum. 
Some respondents menttoned the danger of encouraging new bustnesses to rely too heavily on Council contracts. One authority adopts a sys tem of banding in setting its financlal limits, with the financial limit progresstvely rediced as a proportion of turnover as a firmis size increases. Thus a firm with an annual turnover of less than $\$ 10,000$ would be allowed a contract limit of $150 \%$ of turnover, reducing to $100 \%$ when turnover $r$ ises to $\{10,000-\{50,000$, and $75 \%$ for turnover of $\{50,000-\{100,000$. When turnover $r$ is es above $\$ 100,000$ the authority's normal I imit (maximum of $50 \%$ of turnover) then applites. In this way, firms are encouraged to seek work from other sources.

To minimise the risk involved in giving work to new businesses, many authoritles insist on financfal guarantees or performance bonds. Some authorittes ensure stage payments are made whllst others take the opposite view and only pay on completion. A few authorities require specific comittee approval before firms with no track record can be added to an approved 11st. Other safeguards include regular monttoring of firms both from a financlal and technical point of view with a few authoritfes having formal reporting procedures. 
APPENDIX D-2

VALIDATION OF MULTIPLE REGRESSION SEOOND VERSION MODET

AT LONDON BOROUGH OF CAMDEN 


\section{London Borough of Camden}

Finarice Department

Peter Derrick BA IPFA - Director of Finance

The Town Hall Euston Road London NW1 2RX Telephone: 01-2784444

$$
\text { FAX - 01-860 } 5748
$$

A Abidali Esq ᄀ

Date

7 December 19

Civil Engineering Department Loughborough University of Technology

Loughborough

Leics LEII 3TU

Your reference

Our relerence

FIN/SPO/LP

Inquiries to

Mr I Pardhana.

Ext. 2222

\section{Dear Mr Abidali}

RE: FINANCIAL ȦPPRAISAL OF CONTRACTORS

I am pleased to confirm that this Council has made use of the appraisal model developed by you.

Financial appraisal at this authority is very much in a state of flux and presently we employ a combination of the Altman formula, several 'key' Accounting Ratios, as well as your model to assist us with our appraisal processes. From time to time we also make use of other facilities such as those offered by credit Ratings Ltd, programmes developed by other local authorities, as technical aids in the appraisal process.

Speaking from the point of view of someone who has needed to analyse a number of Annual Reports and Accounts over the past few months, I am able to say that your model with its heavy reliance on the profitability factor has proved discriminating and interesting. Having said this; I am sure you are only too well aware of the potential dangers of relying exclusively upon the results of a single test, which is why we make use of several tests including yours to supplement our judgemental processes.

I hope this letter is useful to you and I would Iike to close by thanking you for your help and to wish you every success for the future.

with kind regards.

Yours sincerely

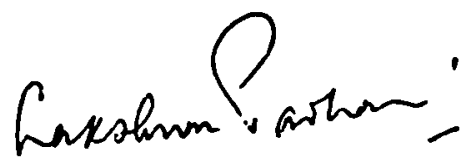

I PARDHANANI SPECIAL PROJECTS OFFICER

All correspondence to be addresse to the Director of Finance 
APPENDIX D-3

Z-SCORE TRENDS 
ABERDEEN CONSTRUCTION PLC

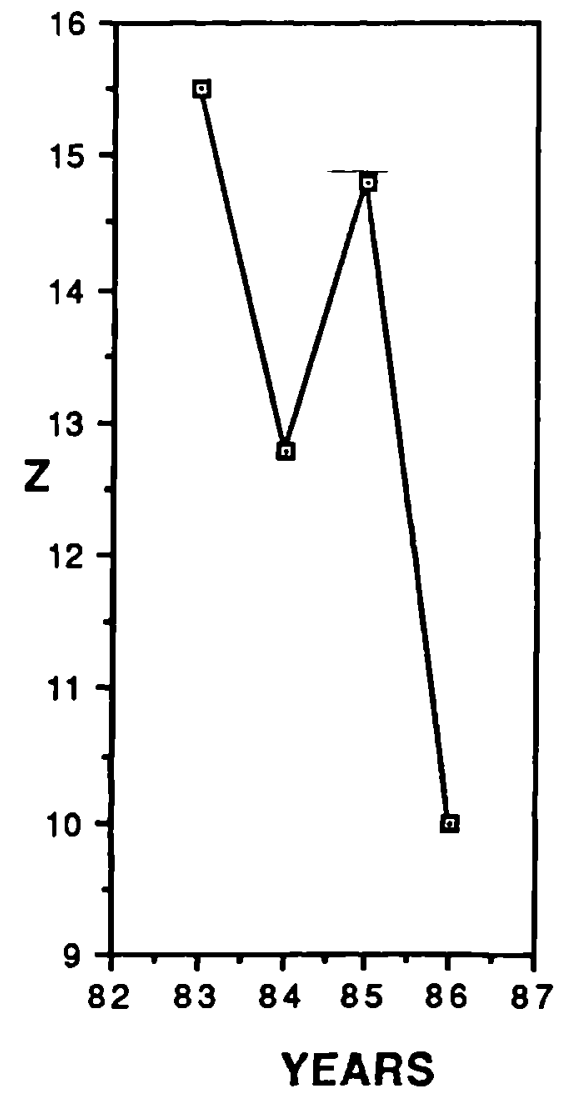

BARRATT DEVELOPMENT PLC

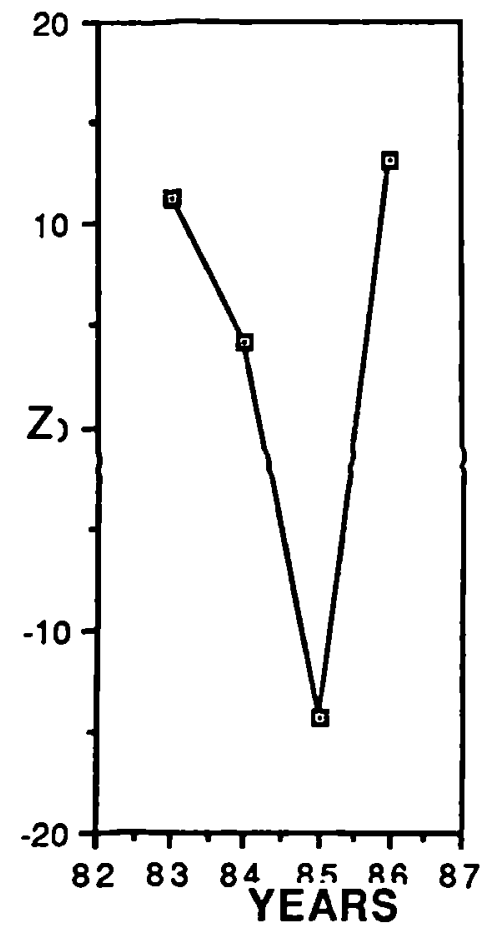

BENBAILY CONSTRUCTION PLC
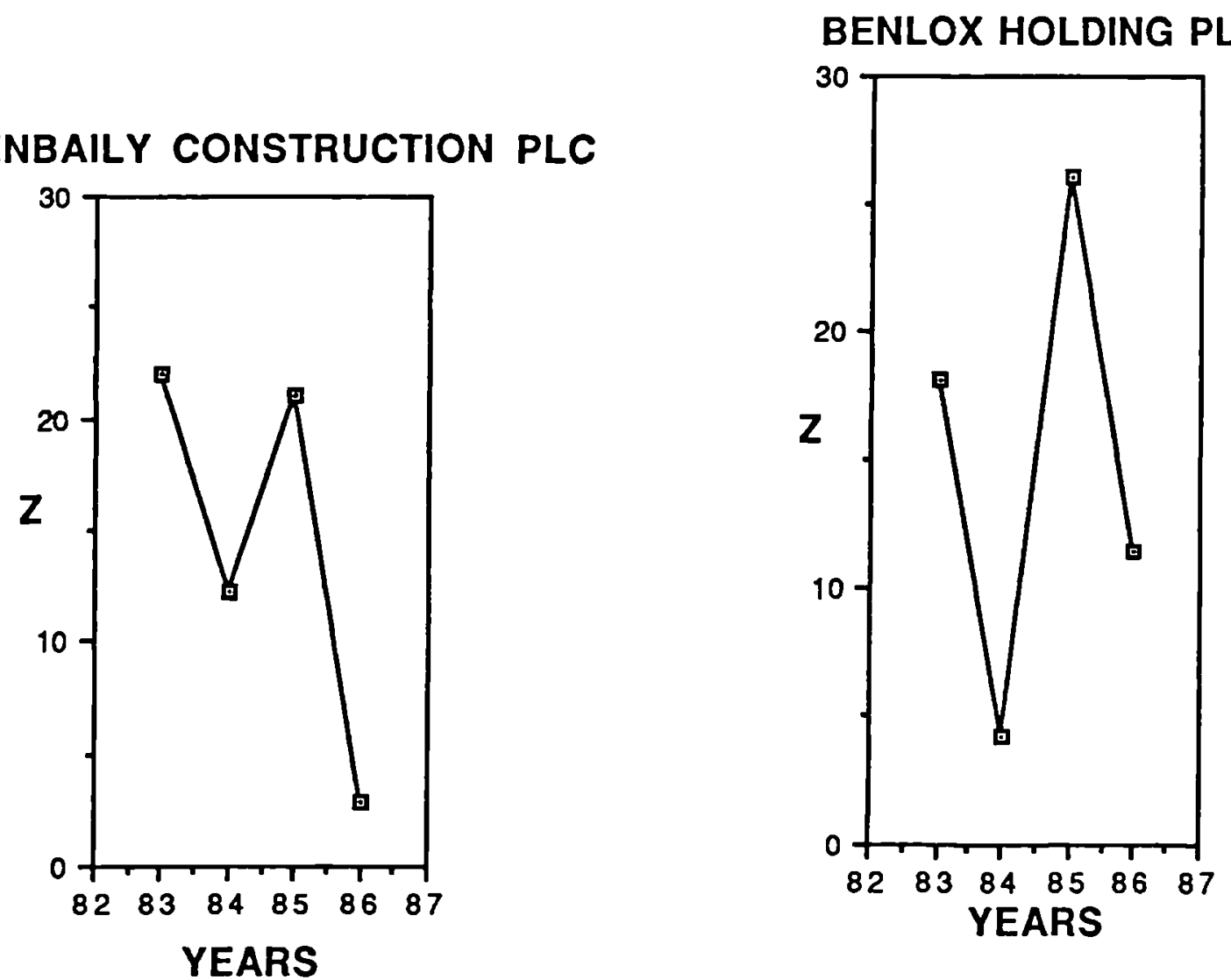

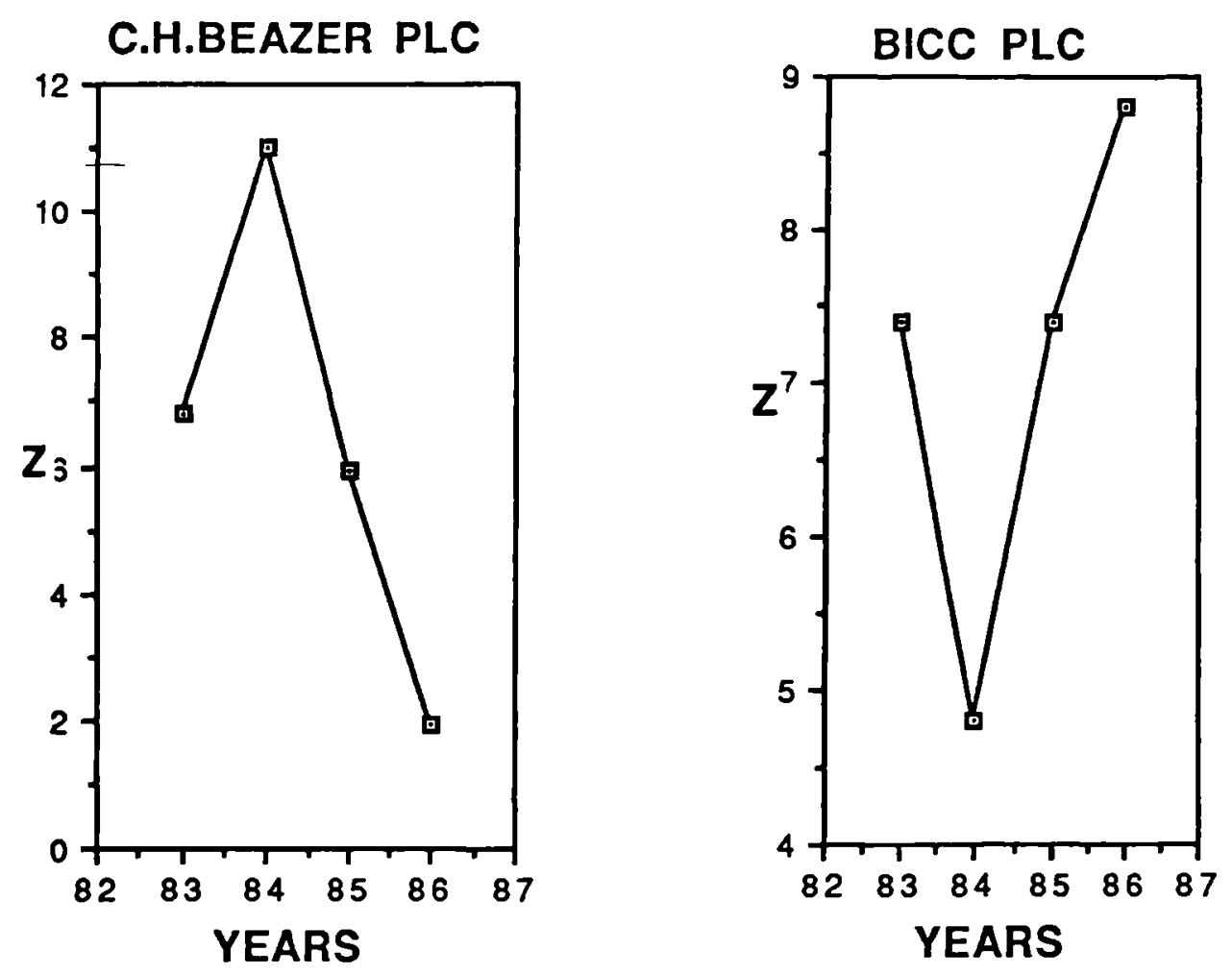

BROWN \& JACKSON PLC
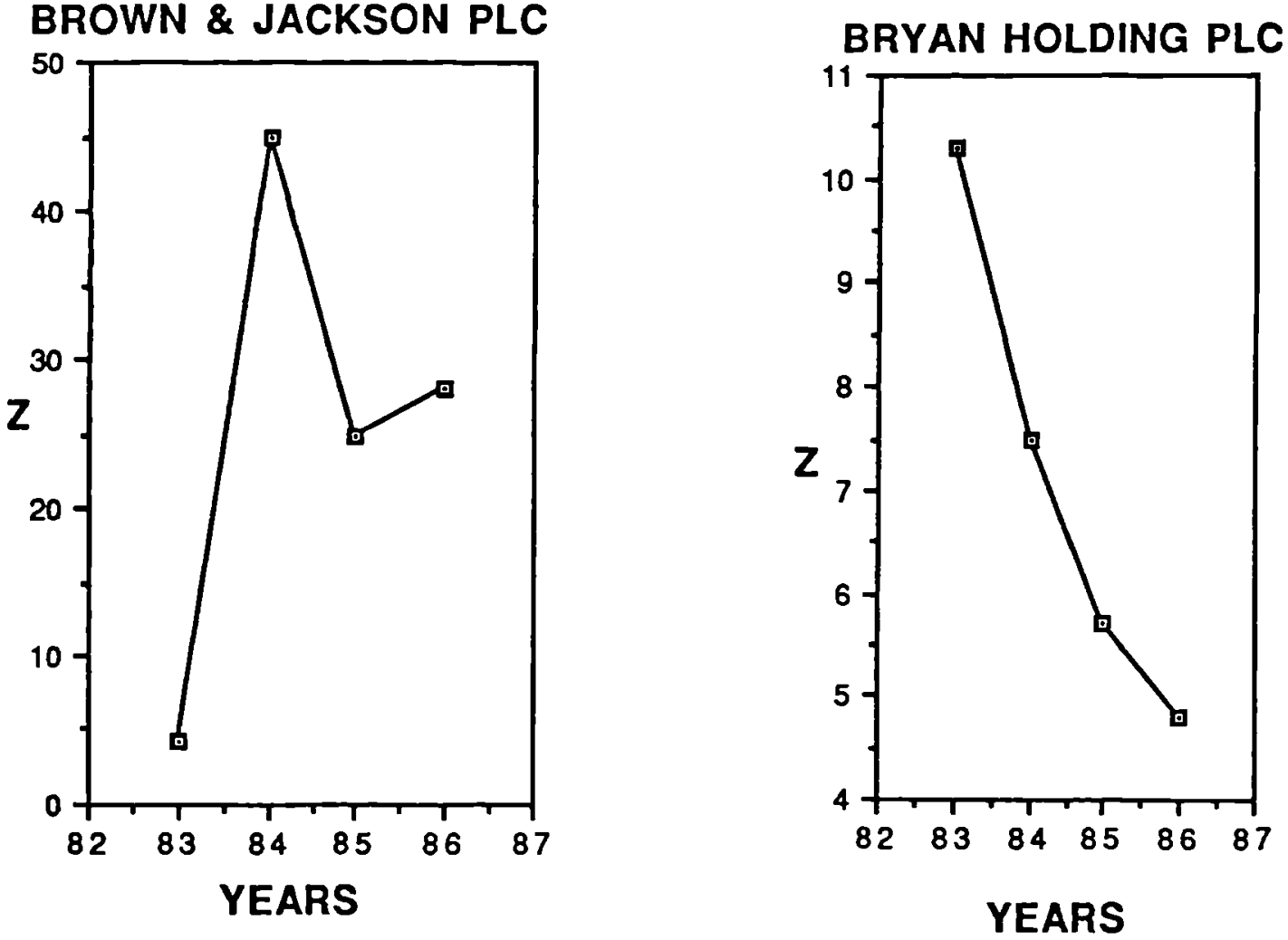
BOULTON \& PAUL PLC
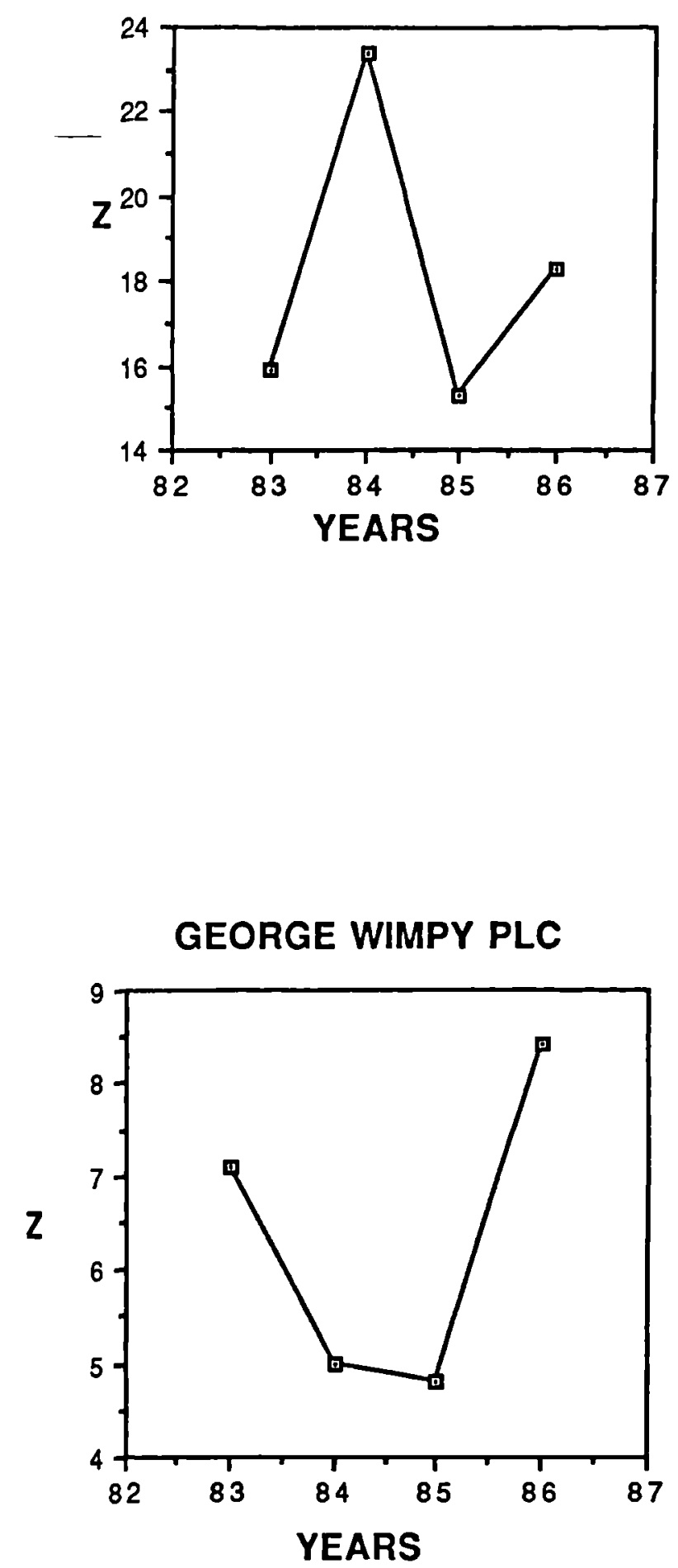
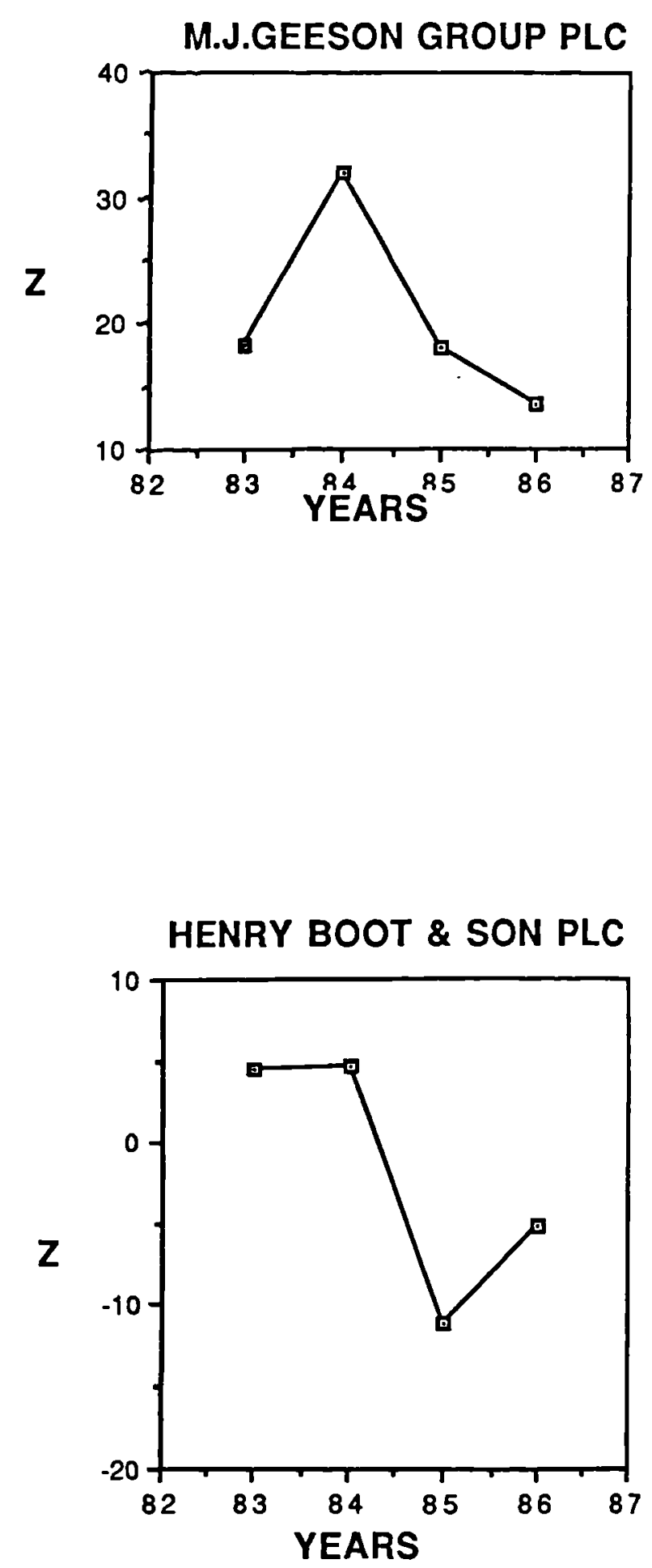

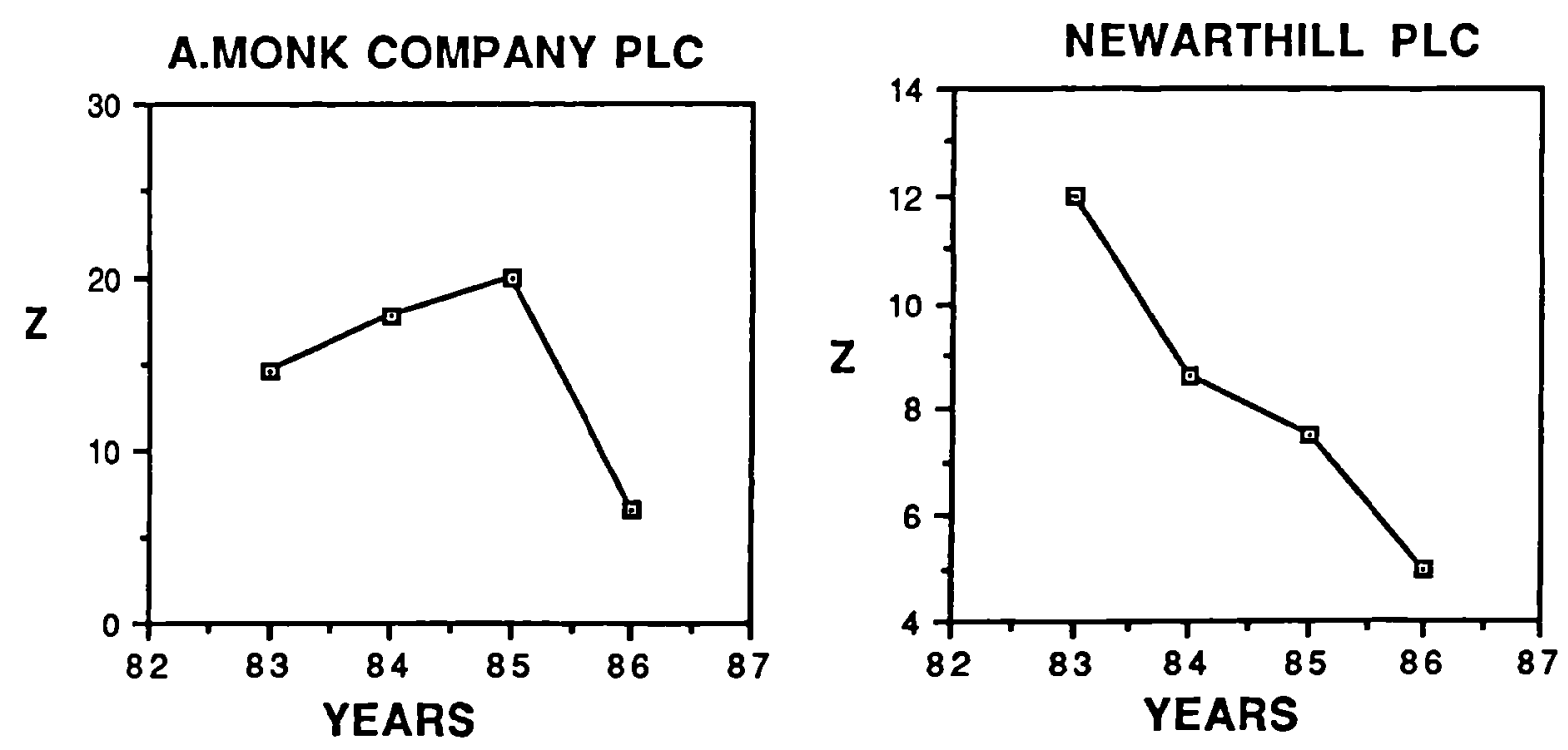

RUSH \& TOMKINGS GROUP PLC
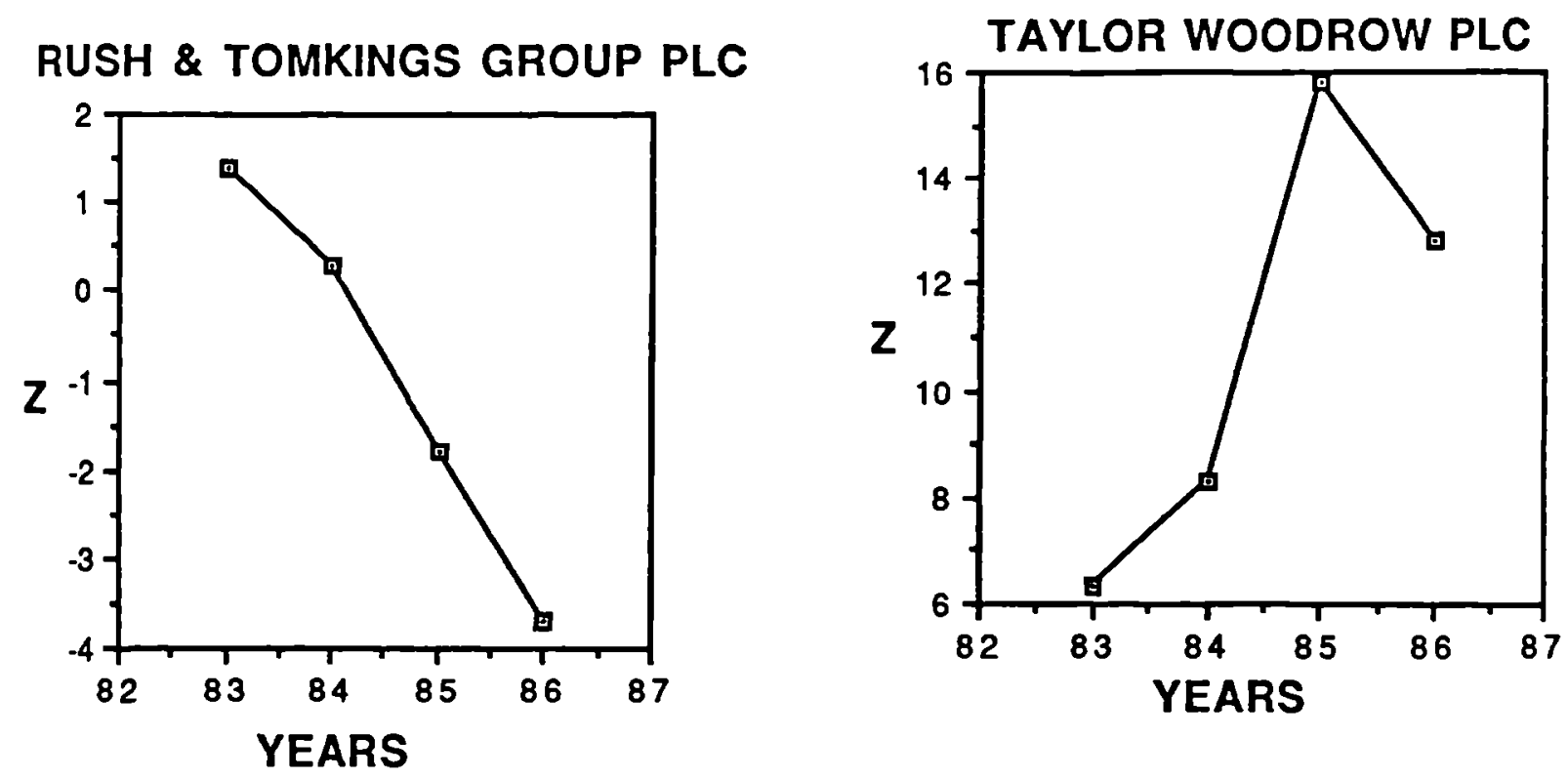

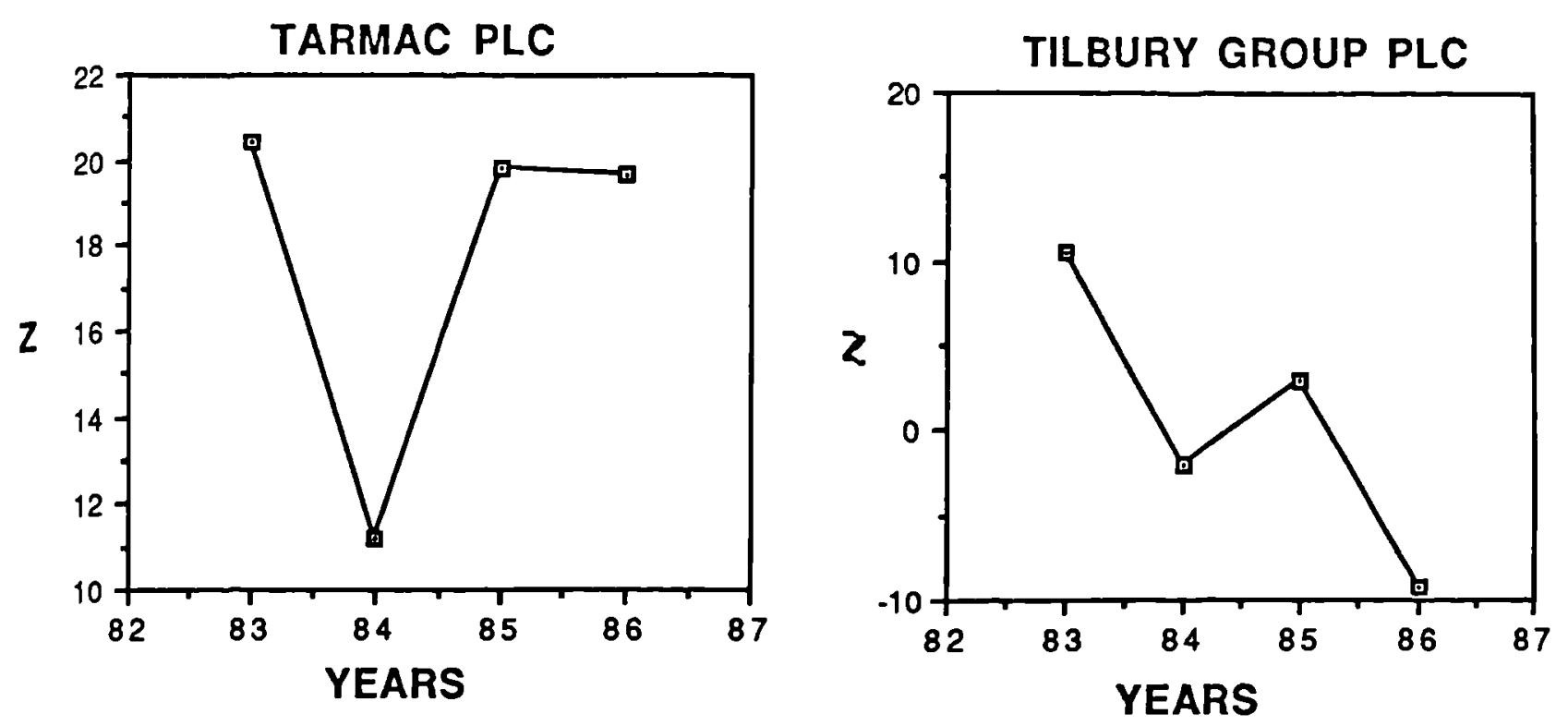

TURRILFF CORPORATION PLC

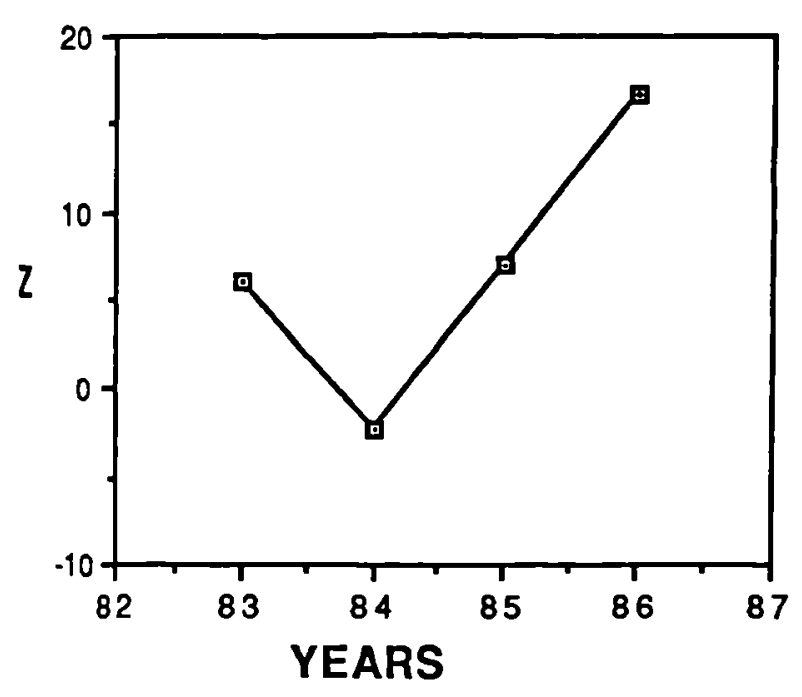

WILSON CONNOLLY HOLDING PLC

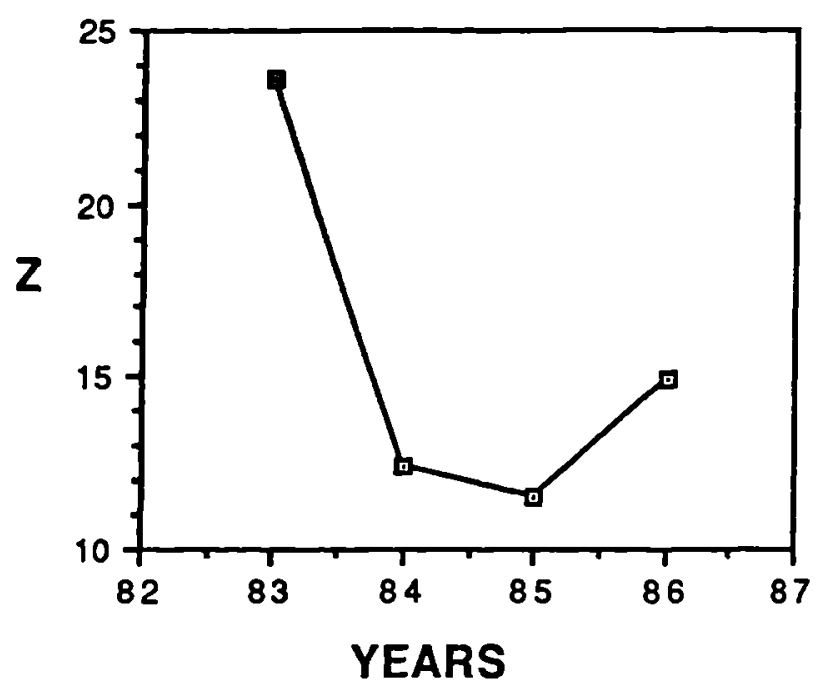



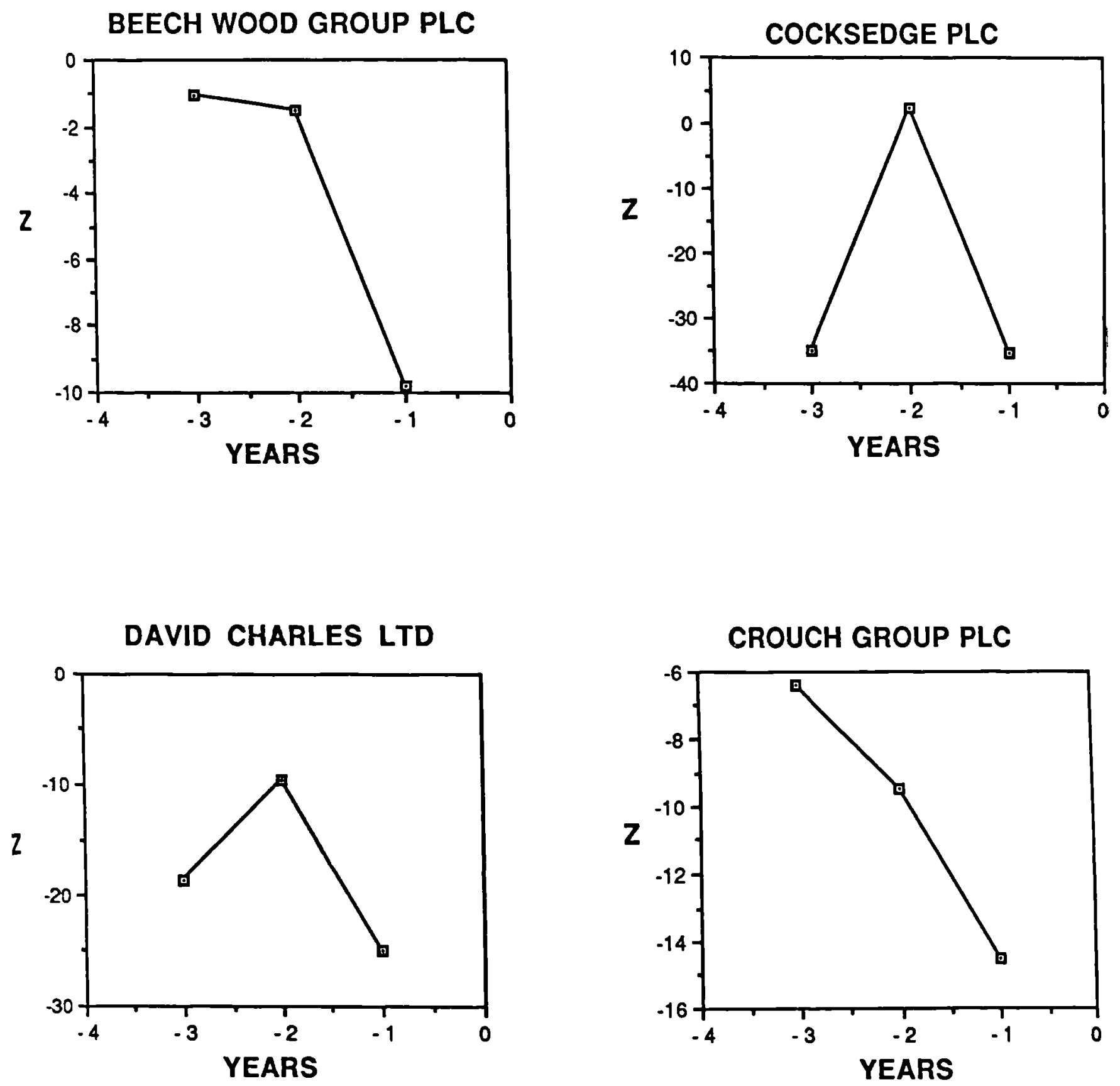

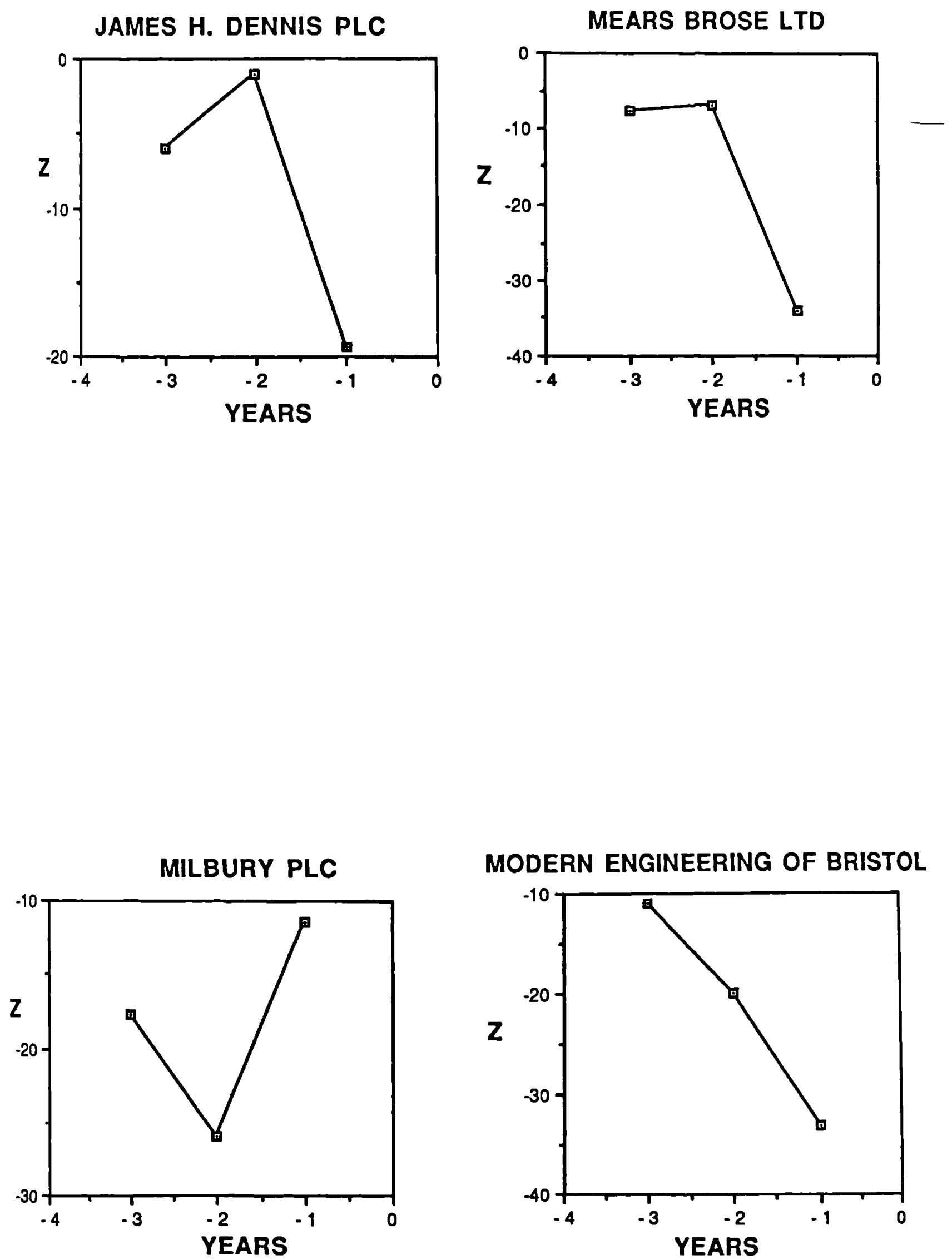

MODERN ENGINEERING OF BRISTOL

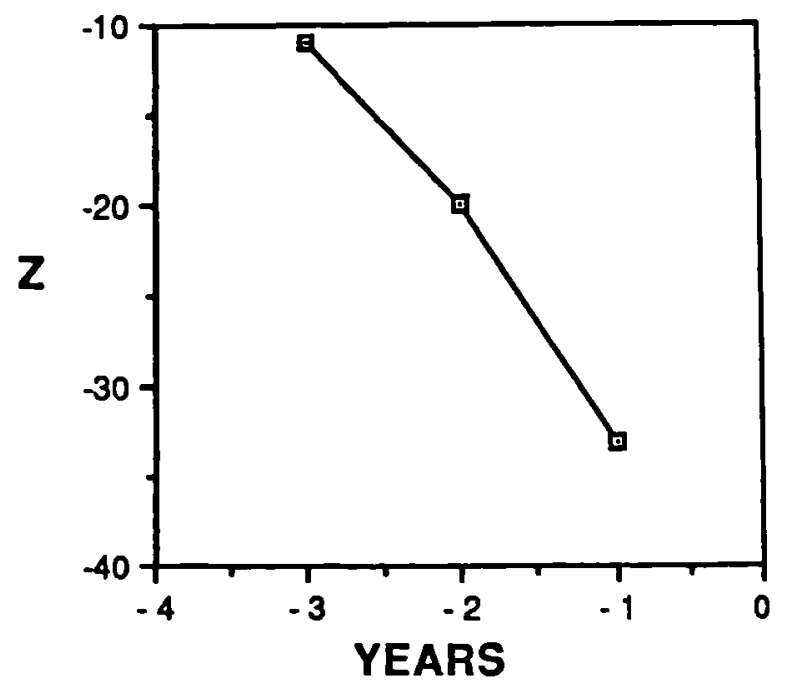



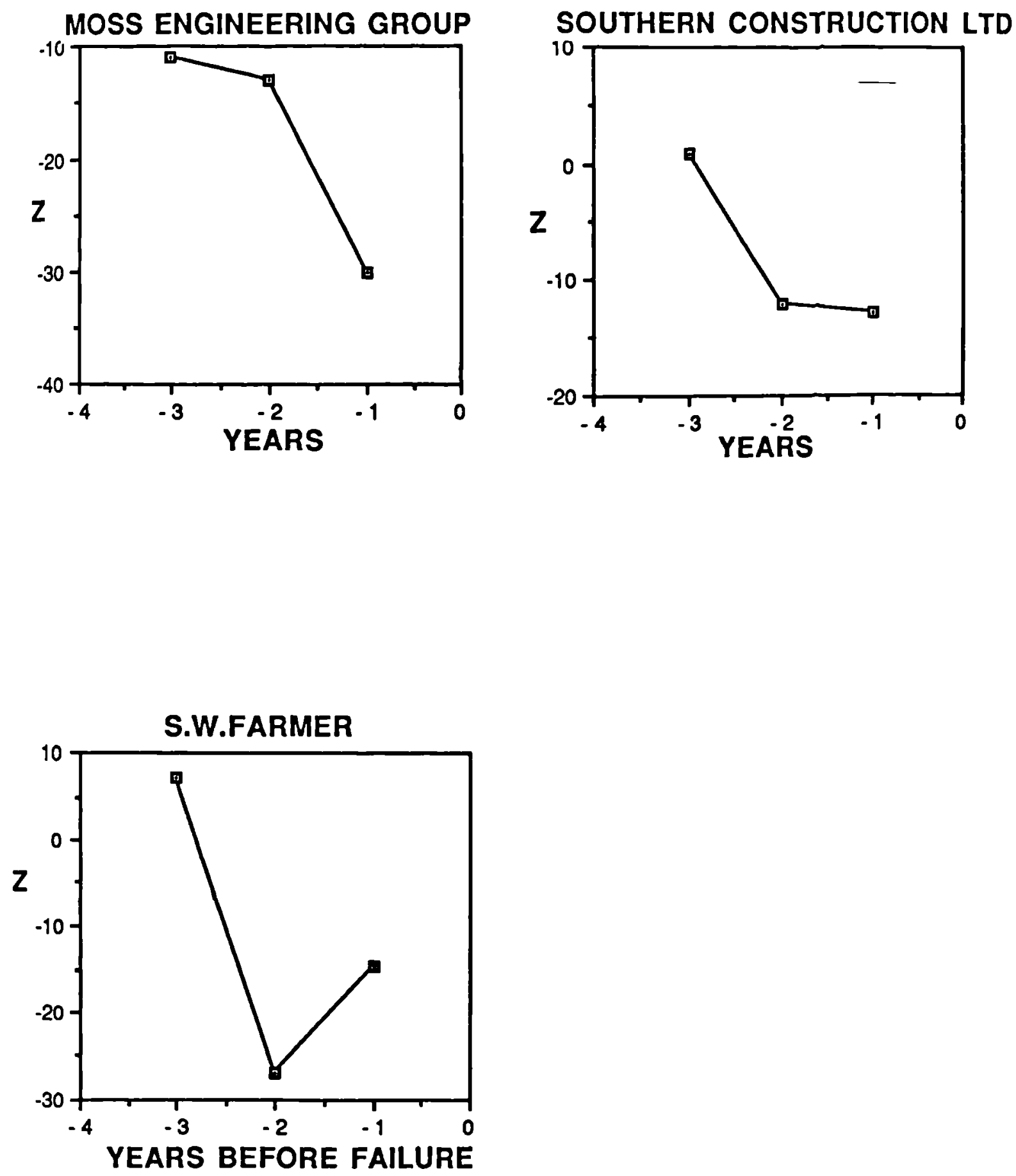
APPENDIX D-4

\section{CASE STUDIES}




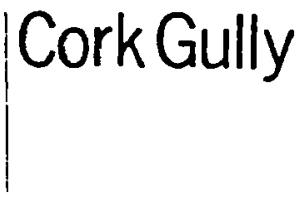

rour relerence
Shelley House 3 Noble Street London EC2V 700

lelephone 01-606 7700 cables Groprovis London

tax groups IInI1 01-606 9887

when telephoning please

ask for

Mr. E. Williams

Ext. 3217

PRIVATE \& CONFIDENTIAL

30th March, 1988.

To the Shareholders and Creditors of Crouch Group Plc

Dear Sirs,

\author{
CROUCH GROUP PUBLIC LIMITED COMPANY \\ (In Receivership \& Liquidation)
}

Trading Address prior to Receivership:

Sutherland House. Surbiton Crescent. Kingston-upon-Thames, KT1 2JU

I write to advise you that meetings of Members and of the Creditors of Crouch Group Plc were duly convened and held pursuant to Section 98 of the Insolvency Act 1986 at these offices on Friday 18th March 1988.

Mr. P.J.H. Meyer, Director of the Company, acted as Chairman.

A summary of the Statement of Affairs as at 18th March 1988, as sworn to by the Director, Mr. Meyer, was presented to the meetings, together with a Group family tree, copies of which are attached.

The meetings were advised that Cork Gully had been instructed by Mr. Meyer on 16th February 1988 to assist in convening the meetings of Members and Creditors and preparation of the Statement of Affairs for presentation thereat for which a fee of $\{5,000$ plus VAT had been voted but not yet paid. It was pointed out that neither I nor my firm had previously acted for the Company or for any of its directors other than in regard to placing certain subsidiaries into creditors' voluntary liquidation.

On 2nd July 1984, the Group's Bankers, Midland Bank Plc, had appointed Mr. D.L. Morgan and Mr. N.H. Russell of Spicer \& Pegler, as Joint Receivers and Managers to Crouch Group Plc and certain of its principal subsidiaries, namely: -

Crouch Homes Limited

Crouch Developments Limited

Crouch Investments Limited

Crouch Group Services Limited

Crouch Civil Engineering Limited

Crouch Painting Limited

Crouch Joinery Limited

Cont. 
Mr. N.H. Russell died on 21st March 1986, since when Mr. Morgan had continued to act as sole Receiver.

The appointments of Joint Receivers to Crouch Group Plc were made by the Bank under the terms of Debentures registered 4th May 1950 and 9th April 1984, granting fixed and floating charges over all assets of the Company.

Prior to the appointment of the Joint Recelvers on 2nd July 1984, one of the principal trading subsidiaries, namely Crouch Construction Limited, was placed by the Members into Voluntary Liquidation on 21st May 1984, and on 12th June 1984 this company went into creditors' voluntary liquidation. The company had suffered substantial losses on two major contracts due to industrial relation problems and it was apparent that further severe losses were being incurred.

Following the appointment of the Joint Receivers on 2nd July 1984, a number of the Group's subsidiaries went into liquidation as follows:-

Crouch Developments Limited

- 4th October 1984 Creditors Vol. Liq.

Crouch Leisure Developments Limited - Compulsory Liquidation 17 th December 1984

Crouch Homes Limited

- Compulsory Liquidation

Crouch Painting Limited 8th February 1985

- Compulsory Liquidation 25 th February 1985

Crouch Investments Limited

- Creditors Vol. Liq. 20 th July 1985

Earlier on $18 \mathrm{th}$ March 1988 , the following dormant subsidiaries were placed in Creditors' Voluntary Liquidation:-

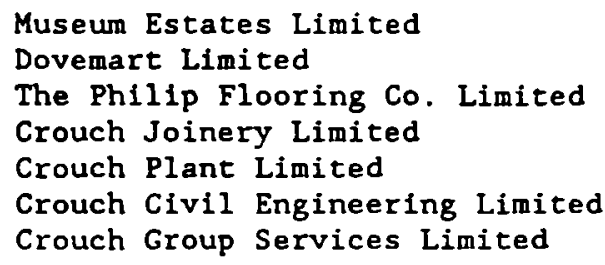

In each case, I was appointed Liquidator for the purpose of the winding - up. 
The meetings were advised that the Company was incorporated in 1931 when it traded in the name, G.T. Crouch Linited, as residential, commercial and industrial property builders and developers. The name was changed to Crouch Group Limited in January 1969 and to Crouch Group Public Limited Company in March 1982.

The Company was converted into a public company on 20th February 1969 when the authorised share capital was increased from $\{35,000$ to $£ 1$ million and the $\varepsilon 1$ ordinary shares sub-divided into ordinary shares of 25 pence each. On the same date, $\{966,667$ of the Company's reserves was capitalised and issued pro-rata to the members as $3,866,668$ ordinary shares of 25 pence each.

The shares in the Company becane quoted on the London Stock Exchange In 1969 being 4 million ordinary shares of 25 pence each.

In June 1981, In order to strengthen the long term capltal base of the Group, certain of the short term borrowings were replaced by the issue of $\{2$ million of 98 Convertible Unsecured Loan Stock 1993/96.

In December 1982, the Company reported a Group loss for the six months ended 30th September 1982 of 11.329 million, the first reported loss incurred by the Group since its shares were listed on the Stock Exchange in 1969. A re-appraisal of the Group's trading and financlal situation took place and it was resolved to reduce the Group's borrowings. At a Board meeting held on 13 th December 1982, Mr. Clempson, who was appointed executive chairman in 1978, was removed fron his executive duties and also removed as Chairman of the Board.

The audited accounts for the year ended 31st March 1983, which were finalised in August 1983, disclosed that provisions of 11.787 million were required to be made in respect of developments and $f 1.889$ million against losses incurred in the U.S.A. As a consequence, the net tangible assets of the Group were shown to have reduced to $\{3.906$ million from $\$ 7.745$ million at 3lst March 1982.

On 28th December 1983, the Board of Crouch Group Plc announced that the Group had entered into conditional agreements with Mr. P.J.H. Meyer who was then (with his family interests) a substantial shareholder.

Detalls of these agreements were set out in a formal circular issued to all shareholders of the Group Company dated 4th January 1984. This circular was issued by the then Board under the chairmanship of Mr. Campailla. 
Group shareholders were reminded in the circular that, in August 1983, the Group Board had resolved to ensure a reduction in overheads and borrowing charges and to bring about an optimum balance of house building, construction and commercial development. Unfortunately, it had not been possible within a short time to find tenants for a substantial part of the completed developments and consequently this had delayed the sale of the properties concerned. Furthermore, difficulties had been encountered in selling the Crouch Group investment properties and in reaching speedy conclusions to the partnership agreements in Florida, and therefore it had not been possible to reduce borrowings quickly. The circular stated that the Group Board was under pressure from its bankers to accelerate disposals which meant that working capital was not available for Crouch Homes to replace its stock of land for private house building purposes.

It was now the Group Board's view, the circular explained, that the continuing shortage of working capital had begun to prefudice the long term viability of Crouch Homes. It was therefore necessary to adopt a new approach if the Group was to survive. The Board had therefore welcomed an approach by Federated Housing Plc, a company controlled by Mr. Meyer who also held 18.58 of the existing ordinary share capital of Crouch Group Plc, whereby a subsidiary of Federated Housing would take over the responsibility for and some of the benefits of, managing and financing the development and sale of the Managed Land Bank of Crouch Group.

This agreement would provide an initial cash injection of $£ 750,000$ into Group and would alleviate the burden of providing working capital to develop the Managed Land Bank. The agreement would also ensure that the Managed Land Bank would realise its current value and thereby provide an uplift to reserves. The terms of the management agreement would not restrict the continuation of house building by the Crouch Group.

It was also proposed, (amongst other things) shareholders were advised, that Crouch Group would acquire 20 per cent of Federated Housing in return for an issue of new ordinary shares.

The Implementation of these proposals, the circular continued, would fundamentally restructure Crouch Group's balance sheet by reducing gearing and give the Group time to reorganise its business within a more reasonable time scale.

Shareholders were advised that upon the agreements detailed in the circular becoming unconditional, Mr. P.J.H. Meyer would be invited to join the Crouch Group Board and become its Chairman. On Mr. Meyer Joining the Board of Crouch there would be a complete review of the operations of the Group in the light of which decisions would be taken as to the Group's future direction. In the meantime the present Directors of Crouch Group believed that the Group had adequate bank facilities for its present requirements.

Cont. 
The proposals were duly approved by shareholders at a meeting held on 27 th January 1984. Subsequently, the Company's authorised share capital was increased from $£ 1,500,000$ to $£ 1,950,000$. The issued share capital was increased from $\{1$ million to $\{1,450,000$, through the issue of $1,800,000$ new ordinary shares at 25 pence each, in exchange for the Company's $\{900,000$ investment in Federated Housing.

The Directors at the time of the re-organisation were:-

Mr. F.D.N. Campailla (Chairman)

Mr. J.M. Blshop (Managing)

Mr. T.M. Hearley

Mr. A. Longman

Mr. D.L. Shaw

Mr. A. Stephenson

On 13th January 1984 shareholders had been advised that the Group's unaudited half year results for the six months ended 30 th September 1983 had resulted in a loss for the period of $E l .171$ million on a turnover of f9.096 million.

No audited accounts had been prepared since 31st March 1983.

Following implementation of the Board's proposals at the Extraordinary General Meeting of the Company on 27th January 1984, Messis. Bishop, Hearley, Longman and Stephenson resigned and Mr. Meyer became Chairman in place of Mr. Campailla.

Notwithstanding the inflow of funds to the Crouch Group arising from the agreements with Federated Housing and the liquidation of Crouch Construction Limited which relieved the Group from pressure from that Company's creditors and continuing losses on contracts, the Group Board found it impossible to continue trading without additional Bank support. The Bank was unable to agree to provide an increased facility in excess of the borrowings which at that time totalled some $53.3 \mathrm{~m}$. , and following legal advice, the Directors considered they had no alternative other than to request the Midland Bank to appoint Receivers to the Group.

Subsequent to the appointment of Joint Receivers on 2nd July 1984 , the remaining Directors (with the exception of $\mathrm{Mr}$. Meyer), together with the Secretary, Mr. Homer, resigned on 13th September 1984.

The Statement of Affairs as at 2nd July 1984, as lodged with the Receivers and Managers, indicated the following assets and estimated realisations as regards Crouch Group Plc:- 


\begin{tabular}{lcc}
$\begin{array}{l}\text { Assets subject to Debenture } \\
\text { Holders fixed charge: }\end{array}$ & $\frac{\text { Book Values }}{\mathbf{f}^{\prime} 000}$ & $\begin{array}{c}\text { Estimated to } \\
\text { Realise }\end{array}$ \\
$\begin{array}{l}\text { Shares in Federated Housing Plc } \\
\text { Amounts owed by Subsidiaries }\end{array}$ & 900 & 720 \\
$\begin{array}{l}\text { Deduct: } \\
\text { Midland Bank Plc } \\
\text { Fixed Charge Security }\end{array}$ & 3,233 & - \\
$\begin{array}{l}\text { Assets subject to Debenture } \\
\text { Holders Floating Charge: } \\
\text { Investments in Subsidiaries }\end{array}$ & 4,133 & 720 \\
\begin{tabular}{l} 
Estimated Total Net Assets \\
\hline
\end{tabular} & 3,318 & - \\
\hline
\end{tabular}

A summary of the Recelvership receipes and payments for Crouch Group Plc covering the period 2nd July 1984 to 18 th March 1988 was provided as follows:-
$£^{\prime} 000$
$£^{\prime} 000$

Receipts: Sale of Federated Housing Shares

720

Less: Expense of Sale

3

Dividend (Net)

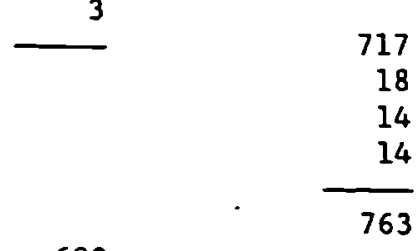

Payments: Debenture Holder

600

Receivers Remuneration

77

Disbursements and VAT

36

Balance in Hand

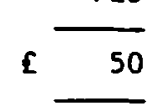

The sumnary of the sworn Statement of Affairs as at 18 th March 1988 , includes the funds in the hands of the Receiver, [50,266, from which there must be provided further costs and expenses, in particular professional charges incurred in dealing with Group taxation affairs, leaving a net realisation estimated at $£ 30,000$ for Statement of Affairs purposes.

Cont. 
The meetings were advised that amounts owing by Subsidiaries were as follows: -

$\begin{array}{lrc} & \frac{\text { Book Value }}{\mathcal{L}} & \begin{array}{c}\text { Estimated to } \\ \text { Realise }\end{array} \\ \begin{array}{lrc}\mathcal{E} \\ \text { Crouch Group Services Limited }\end{array} & 2,522,622 & - \\ \text { Crouch Homes Limited } & 330,000 & 33,000 \\ \text { Crouch Developments Limited } & 134,094 & - \\ \text { Crouch Leisure Developments Limited } & 185,000 & - \\ \text { Crouch Investments Limited } & 1,381 & - \\ \text { The Philip Flooring Co. Limited } & \mathbf{8 , 5 0 0} & \underline{33,000}\end{array}$

It was explained that asset realisations are subject to the subrogation claim of Crouch Homes Limited whose contribution towards settlement of the Debenture Holders' indebtedness entitled it to stand in the place of the Charge Holder. Such was the contribution frow Crouch Homes compared with all other contributories, that inevitably the surplus fixed and floating charge realisations from the Receiverships and Liquidations of the Group companies would require to be passed to the Liquidators of Crouch Homes Limited.

It was stated that the unsecured creditors listed on the sworn Statement of Affairs as at 18th March 1988, were partly based upon those listed in the Statement of Affairs as at the date of receivership, and partly upon claims notified since that date. In this connection, the Trustees for the Holders of the Crouch Group 98 Convertible Unsecured Loan Stock had claimed $£ 2,000,000$ in respect of loan stock outstanding and £684,269 for interest, fees and expenses outstanding at 18th March 1988 .

It would be a matter for the Liquidator to agree unsecured claims in due course, but present indications were that only those creditors who have valid claims in the liquidation of Crouch Homes Limited, have any prospect of receiving a dividend.

It was regretted that no surplus funds were expected to become available for distribution to unsecured creditors of Crouch Group PIc, or to shareholders. Shareholders wishing to make a claim under Section 22 CGTA 1979 should communicate with their own Inspector of Taxes. The estimated deficiency as regards creditors was shown to amount to $[3,277,172$ and as regards members, was estimated at $\{4,727,172$, subject to costs.

Cont. 
In arriving at the overall deficit of approximately 44.7 million, the principal items contributing to the deficiency since the date of the last published and audited accounts, 31st March 1983, when net shareholders funds were shown to amount to $£ 1$ million, were as follows:-

$\varepsilon^{\prime} 000$

(a) Inter-company debts written down 3,149

(b) Investments in Subsidiaries 42

(c) Interest and Expenses outstanding
on Unsecured Loan Stock

(d) Guarantee liabilities re.

Performance Bonds, brought in 291

(e) Loss on sale of Federated Housing

shares

(f) Guarantee Liability of Debenture

Holder settled in Receivership

The Receiver had advised that the total receipts and payments in the eight Group company receiverships were as follows:-

\begin{tabular}{lr} 
Receipts & $\mathcal{E}^{\prime} 000$ \\
Payments & 6,777 \\
\multicolumn{1}{c}{ Balances in Hand } & 6,036 \\
\cline { 2 - 2 } & 741 \\
\hline
\end{tabular}

Settlement of the Debenture Holders' indebtedness plus interest thereon had accounted for $\{3,402,077$. In addition, payments to other secured creditors had accounted for $[1,533,627$.

Action had been taken by the Receiver to protect the interests of Creditors should it be possible to claim from the trustees of the Pension Fund that any surplus therefrom be made available for the benefit of creditors. The trustees were expected to apply to the Court for further instructions in the matter.

The Receiver also advised that the overseas investments owned by Crouch Investments Limited (In Liquidation), in Florida and Phoenix Arizona, in which the Group had invested over 23.8 million at 31 st March 1982 had failed to produce any realisation.

At the Members' meeting, a Resolution for the Company to proceed to Creditors Voluntary Liquidation was passed and I and my partner. Michael Anthony Jordan, were appointed Joint Liquidators of the Company. At the subsequent meeting of Creditors, our joint appointment was confirmed.

Cont.

Cont. 
No Liquidation Committee was appointed.

A formal notice for claims is enclosed and I would be obliged if you would supply a detailed statement of your claim to Crouch Group Plc (In Liquidation), c/o Shelley House, 3 Noble Street, London EC2V 7DQ (Ref: SH501) in order that it may be scheduled.

I also attach duplicate VAT Debt Relief Forms both copies of which should be completed and returned to me if you wish to seek such relief. In that event, your claim in the liquidation must not include the VAT element.

If you require any further information, please do not hesitate to contact me.

\section{Yours faithfully,}

R.M. ADDY

Joint Liquidator of Crouch Group Plc

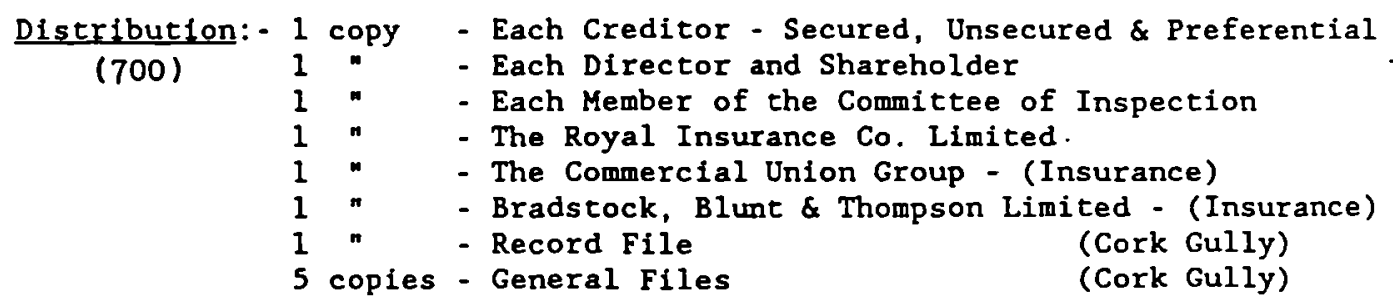


CROUCH GROUP PLC

(In Receivership - 2nd July 1984)

Summary of the Estimated Statement of Affairs as at 18th March 1988

\begin{tabular}{|c|c|c|}
\hline & Book Value & $\begin{array}{l}\text { Estimated } \\
\text { to Realise }\end{array}$ \\
\hline & $\varepsilon$ & $\varepsilon$ \\
\hline \multicolumn{3}{|l|}{ ASSETS: } \\
\hline $\begin{array}{l}\text { Assets not specifically charged: } \\
\text { Funds in the hands of Receiver } \\
\text { Amounts owing by Subsidiaries } \\
\text { Investments in Subsidiaries }\end{array}$ & $\begin{array}{r}50,266 \\
3,181,597 \\
42,010\end{array}$ & $\begin{array}{c}30,000 \\
33,000 \\
-\end{array}$ \\
\hline Estimated total assets, subject to costs & $3,273,873$ & 63,000 \\
\hline
\end{tabular}

\section{LIABILITIES :}

Subrogated Debenture claim of Crouch Homes Limited

Non-preferential claims:

Trustees for the unsecured loan stockholders Preferential creditors in the receivership

Trade and Expense

Performance bonds and insurances

Estimated deficiency as regards Creditors, subject to costs

ISSUED SHARE CAPITAL

Estimated total deficiency as regards Members, subject to costs

Note: The above is a summary of the sworn Statement of Affairs as at 18 th March 1988, which is available for inspection by Members and Creditors. 


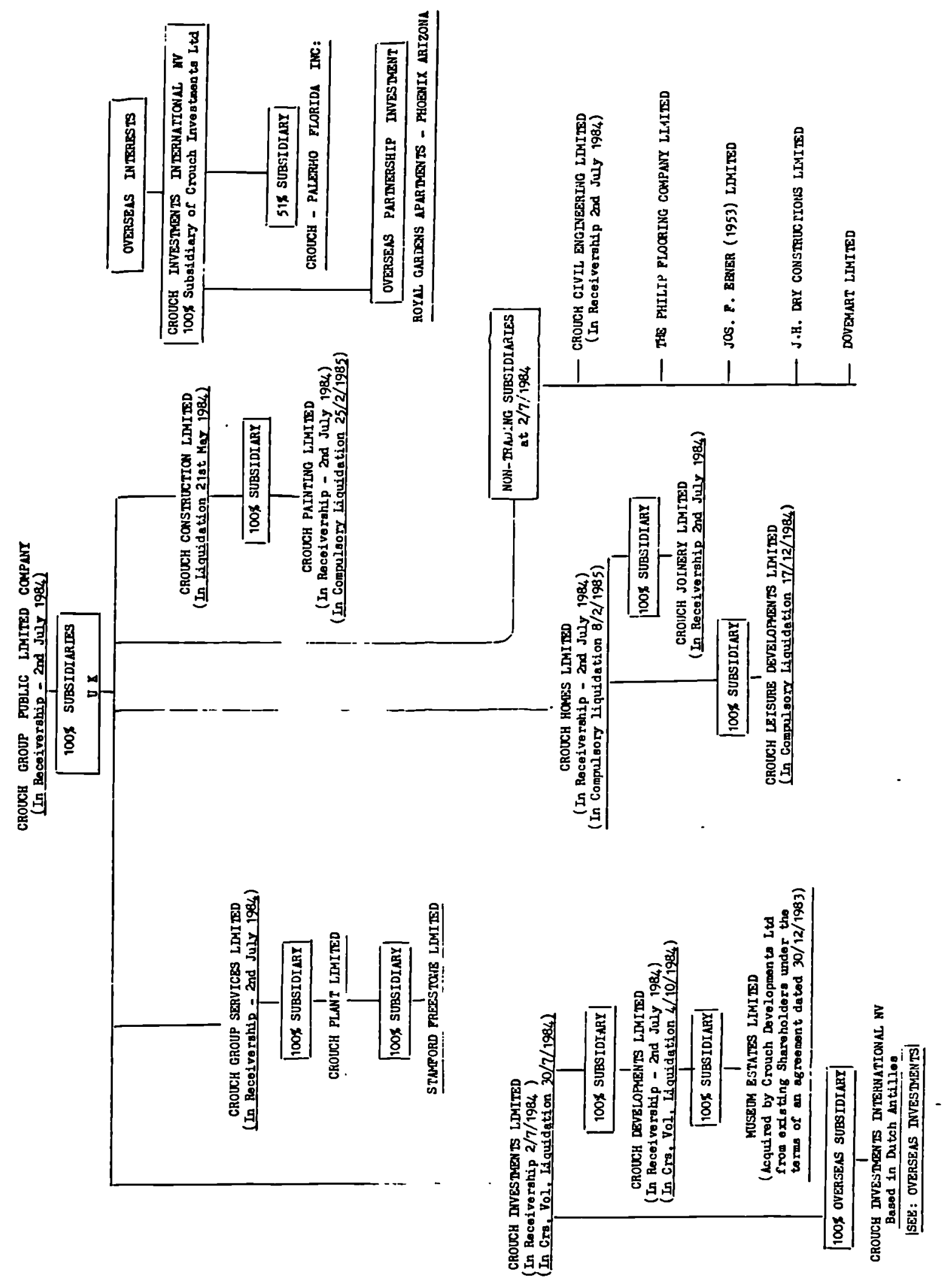


NOTICE to CREDITORS to SEND CLAIMS

\author{
IN THE MATTER Of THE INSOLVENCY ACT 1986 \\ - a n d - \\ IN THE MATTER of CROUCH GROUP PUBLIC LIMITED COMPANY \\ (In Voluntary Liquidation) \\ NOTICE IS HEREBY GIVEN that the Creditors of the above named \\ Company, which is being voluntarily wound up, are required, on or before \\ 13th May 1988 to prove their debts by send to the undersigned R.M. Addy, \\ of Cork Gully, Shelley House, 3 Noble Street, London EC2V 7DQ the said \\ Liquidator of the Company, written statements of the amount they claim \\ to be due to them from the Company and, if so requested, to provide such \\ further details or produce such documentary or other evidence as may appear \\ to the Liquidator to be necessary. A Creditor who has not proved his debt \\ before the declaration of any dividend is not entitled to disturb, by \\ reason that he has not participated in it, the distribution of that \\ dividend or any other dividend declared before his debt was proved.
}

D A T E D this 18 th day of March 1988

R. M. ADDY

Liquidator 
" Covirgully

Your reterence
Shalloy Houso 3 Nobly Streat London EC2V 700

telephomo 01.6067700 telog̣rarns Groprovis Londen telex 884730 Corkgy G

osk for

\title{
Mr Right
}

arrelerence SH 502

Ext. 3257

Dear Sirs,

\author{
Re: Crouch Construction Isimited \\ (In Liquidation) \\ Regiatered Office and Businesa Addregs: \\ Sutherland Houge, Surbiton Crcacent, \\ KIngaton-on-Thames, Surrey. \\ Builders and Contractors
}

We write to inform you that a Neeting of Creditors of the above-named Company convened pursuant to Section 293 of the Companies Act, 1948, was held at the Chartercd Insurance Institute, Aldermanbury, London, EC2 on Tuesday, 12 th June 1984.

An approxinate Statement of Affairs as at the 21 st May 1984 was presented to the Meeting and a copy is attached.

The Meeting was informed that the Company was incorporated as a private limited company on the 16th July 1969 in the name of Cavus Contractors Limited, in which name it traded as bullding contractors until 4th May 1978 when the nane was changed to Crouch Construction Limited. Between 1970 and 1978 the Company traded on a small scale, and during the early years, only two shares of $\delta l$ each were issued; one being held by the founder of the Company, a Mr. Flux, and the cther by $M$ \& J.F. Plant Hire Limited which was a subsidiary of Crouch Group Limited.

Mr. Z.J. Crouch was appointed a Director in November 1970 but he died in February 1973. Although he was replaced with other members of the Group in the ensuing years, the Company traded without any particular success but continue in business.

In April 1978 the Company became a wholly-owned subsidlary of Crouch Group ple when 998 additional Ordinary Shares of 21 each were allotted to Crouch Group for cash at par, and embarked upon a rapid expansion in contract works, maisly in the Southern Counties and particularly involving local authority houging. EAnce that time the Company has continued to trade as a wholly-owned subsidlary nf Crouch Group ple which became a Public Company in Pebruary 1969 anrl has been gunted on the Stock Exchange since that time.

In September 1979 the Company adopted a new set of Articles of Association and 1 ts authorised Share Capital was increased to $£ 10,000$ although the issued capital remained at 51,000 . There had been numerous changes in the Board of !) 1rectors since 1982 but at the preaent time the Directors were as follows:-

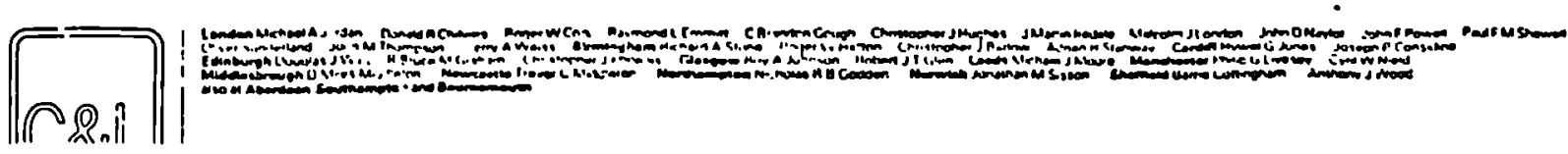


Mr. Peter Meyer

Mr. Leslic Andrews

Mr. Trevor slater

Mr. David Shav

Mr. P.D.N. Campailla
- Appointed 29th February 1984 - Chairman having been appointed to the Group Board on 18t February 1984

- Appointed 29th February 1984 - Managing Director

- Appointed 1at Pebruary 1984 having been appointed Group Managing Director lot February 1984.

- Appointed 18t Auguat 1978

- Surveyor/Non

Execut 1ve

- Solicitor/Non Executive

Mr. Richard Meinertzhagen - Appointed a Director on lat July 1978

The Secretary of the Company and of the Group Companies $18 \mathrm{Mr}$. Barry Homer.

The previous trading results for the four years ending 318t March 1983 extracted from the Company's audited accounts were summarised as follows:-

Year ended 31st March

$$
\varepsilon^{\frac{1980}{1000}} \quad \varepsilon^{\frac{1981}{000}} \quad \varepsilon^{\frac{1982}{1000}} \quad \varepsilon^{\frac{1983}{1000}}
$$

Turnover, being the value

or contracts carried out

$\begin{array}{llll}3,258 & \underline{4,947} & \underline{7,714} & 12,319 \\ (172) & \underline{(62)} \quad \underline{(356)} \quad \underline{102}\end{array}$

Profit/(Lo8B), before taxation

The Profits/(LoBses) have been arrived at after charging or (crediting) the following:-

Depreciation

Plant. Hire

Directors' emoluments

Loss on sale of Pixed Assets

Bank Interest

(Group in overdraft but not Company)

The taxable profits in the years 1982 and 1983 were eliminated by the utilisation of 1088 ses brought forward and by the recelpt of group relief for taxation purposes, for which the Group received no payment.

March 1983.

No audited accounts had been prepared for the Company oince the 31 st

Directors' emoluments for the year to 318t March 1984 amounted to £73,715 made up as follows:-

\author{
Mr. A. Stephenson \\ Mr. R. Meinertzhagen \\ Mr. L. Andrews \\ Mr. R.J. Weavers \\ Mr. A.G. Britton
}

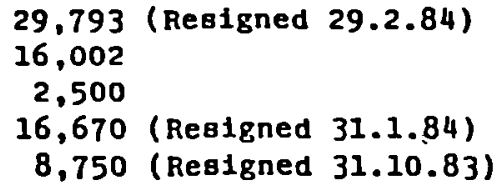

The turnover of the Company for the year ended 31 st March 1984 was est1mated to amount to approximately $111.2 \mathrm{~m}$. Based upon a realistic appraisal of contracts in progress it becomes apparent that the Company had suffered 
oevere 108вes alnce lot April, 1983. All the current contracts were taken on prior to the main board changes, which took place early in 1984. In May of this year the gross value of contracts in progregs amounted to approximately $£ 20 \mathrm{~m}$ of which approximately $\mathrm{ElOm}$ of work remained to be complcted.

On 8th November 1983 the Company granted to Midland Bank ple a Fixed Charge over 1ts Book Debts as additional security for the overdraft (previously secured by a Floating Charge granted in June 1978) and in support of the Long standing Cross-Guarantee liability for the Group indebtcdness to the Bank.

On 28th December 1983, the Board of Crouch Group ple announced that Crouch Group had entered into a conditional agreement with a Mr. P.J.H. Meyer who was then (with his family's interest) a substantial shareholder. Details of these agreements were set out in a formal circular issued to all shareholders of the Group Company and dated 4 th January 1984.

Shareholders were advised that upon the agreements detalled in the circular becoming conditional Mr. P.J.H. Meyer would be invited to join the Crouch Group Board and become its Chairman. Upon Mr. Meyer Joining the Board of the Group Company there would be a complete review of all operations of the Crouch Group in the light of which decisions would be taken as to the Group's future direction. These proposals were approved by the Shareholders of crouch Group plc at a meeting held on the 27 th January 1984.

On 29th February $1984 \mathrm{Mr}$. L. Andrews was appointed Managing Director of Crouch Construction Limited in place of Mr. Stephenson who had resigned on that day.

It was reported that the trading position of Crouch Construction Limited during $1983 / 84$ suffered as a result of two major lose-making contracts at Shirley and Dulwich and also from poor trading on other contracts taken on at tight margins during a period of recession. Problems had also arisen from the numerous changes in directors and senior staff.

Referring to the Approximate statement of Affairs, the meeting was informed that the Midland Bank had a Fixed Charge over all Book Debts and other debts and

- held a Floating Charge over all other assets and the statement of Afrairs was drawn up 80 as to reflect this oituation.

The debtors included completed contract balances relating to some 31 contracts where, according to the Company's records, there were total sums outatanding of approximately $\$ 231,000$ including retention moneys in the region of 5211,000 . These debts exclude ex-contractual claims which have not been agreed. -

After making an appropriate provision for nominated sub-contractors' liabilities, estimated at $£ 2,520$ and a provision for mafntenance and damages of $£ 30,000$ the net book value of the contract debtors amounted to approximately £198,000, est1mated to real1se $\$ 152,000$. The D1rectors, however, were of the opinton that if the ex-contractual claims were to be pursued some additional sums. should be rcalised, but it was difficult to quantify the sums involved at this stage.

Amounts owed by fellow subsidiartes of the Company were estimated to have a book value of $\$ 276,000$ made up as follows:- 


\begin{tabular}{lr} 
Crouch Group Services Limited & 136,000 \\
Crouch Homes Limited & 97,000 \\
Crouch Leisure Developments Limited & 43,000 \\
\hline & $\$ 276,000$
\end{tabular}

The meeting was advised that no significant payments had been made to an other Group Company Bince November 1983. However, receipts received during 19 Included amounts of $£ 50,000$ from Museum Estates Limited and $£ 250,000$ from Crouc Group Services Limited, the latter amount being cash introduced by Mr. P.J.H. Meyer personally to assist Group liquidity.

The Shares in the wholly-owned subsidiary Company, Crouch pinting Limit acquired in April 1978 were shown fin the books at $£ 12,000$. As, :..;ever, this subsidiary suffered losses resulting in a deficiency in net asset:s in excess of E150,000, no realisable value was attributed to the investment.

Stock and work in progress related to 17 contracts outstanding for completion as at $218 \mathrm{~s}$ May, although 4 of the contracts were virtually complete.

It was reported that James R. Knowleg and ABsoclates, Quantity Surveyors had becn ingtructed to carry out an appraisal of each contract and had been actively engaged in endeavouring to arrange possible assignments of the contrac to other contractors with the consent of the employing authorities. However, based on the negotiations which the Surveyors were undertaking it was consider unlikely that any substantial sums would be recelved from the work in progrcss contracts and for this reason the realisable value in the statement of affairs shown at only $£ 53,000$ after making provision for liabilities to nominatcd subcontractors and reservation of titie claims by suppliers to materials on vario of the contract sites.

After taking into account preferential liabilities estimated at $\$ 174,00$ Including a claim by the Bank for moneys advances to pay salaries and wages, 1 was apparent that there was little or no prospect of funds becoming available to enable a dividend to be paid to Unsecured Creditors estimated to total some E2.4m, excluding contingent liabilities under contract performance bonds havin a gross value of $\$ 1.36 \mathrm{~m}$.

The meeting was advised that the deficiency as shown by the statcment 0 Afrairs in the sum of $\$ 2,714,000$ was computed as follows:-

\begin{tabular}{|c|c|c|}
\hline \multicolumn{2}{|c|}{$\begin{array}{l}\text { Amounts written-off from the asgets } \\
\text {. against book values }\end{array}$} & $\frac{E^{\prime} 000}{464}$ \\
\hline Leв8: & $\begin{array}{l}\text { Excess of Assets over Capital and } \\
\text { Llabilities as at } 31.3 .83\end{array}$ & 87 \\
\hline $\begin{array}{l}\text { Balanc } \\
\text { for }\end{array}$ & $\begin{array}{l}\text { e being estimated trading losees } \\
\text { he period } 1.4 .83 \text { to } 21.5 .84\end{array}$ & $\begin{array}{r}377 \\
2,337\end{array}$ \\
\hline & & $\varepsilon 2,714$ \\
\hline
\end{tabular}

The meeting was advised that on 21 st May 1984 the Parent Company, Crou Griup ple, as Shareholders of the Company, passed at short notice a Resolutio Imucdiately placing the Company in liquidation and appointed Mr. M.A. Jordan anl Mr. R.M. Addy of Cork Gully as Jolnt Llquidators. This action had been 
taken on the basis that if fundo were not avallable to pay for materialo and oub-contractors and Indeed to pay to stafr and cmployees of the Company, the security of the contract sites, which represented on the face of 1 the largest asset, would have been put at risk.

Pollowing a considerable amount of discuselon, creditors present at the meeting confirmed the voluntary liquidation of the Company together with the appointment of Mr. Jordan and Mr. Addy as Joint Liquidators with a Committee of Inspection comprising of:-

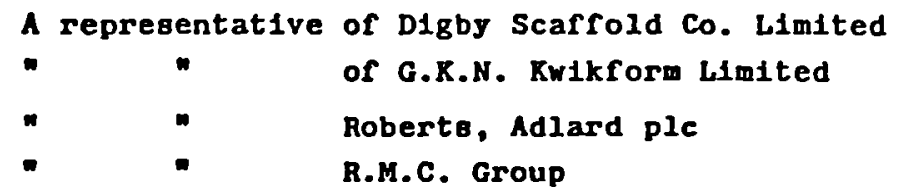

Mr. J. Kelly representing various creditors

A Formal Notice for claims is enclosed and if you have not already done 80, we should be pleased if you would oupply a detailed statement of your claim to Crouch Construction Limited (In Liquidation) c/o Shelley House, 3 Noble street, London, EC2V 7DQ (Ref. SH502) in order that it may be scheduled.

We also attach in duplicate V.A.T. Bad Debt Relief rorms, both copies of which should be completed and returned to us if you wish to seek such relief. In that event your claim against the company must not include the V.A.T. element.

Meanwhile, if there is any further information you require, please do not hesitate to write to this office.

we are,

\section{Yours ratthfully,}

CORX GULLY

. Distribution:-

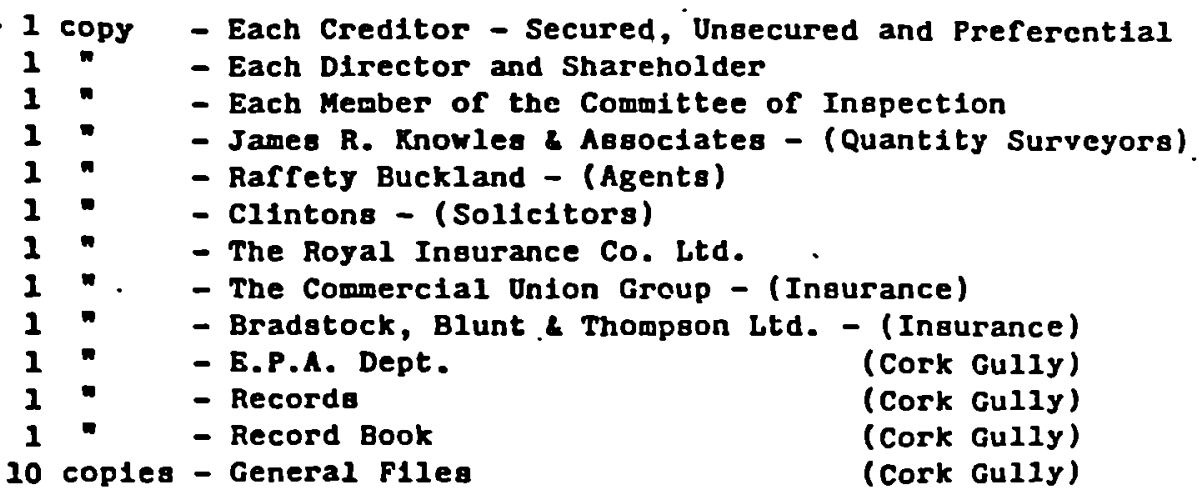


NOTICE to CREDITORS to SEND CLAIMS

TIIE COMPANIES ACTS, 1948 to 1981

CROUCH CONSTRUCTION LIMITED

NOTICE IS HEREBY GIVEN that the Creditors of the above-named Company are required on or before the loth day of Auguat 1984, to send thein names and addresses and the particulars of their debts or claims, and the names and addresses of their Solicitors if any, to ROBIN MICHAEL ADDY of Shelley House, 3 Noble street, London, EC2V 7DQ the Joint Liquidator of the said Company, and, if so required by notice in writing from the said Liquidator, are by their Solicitors, or personally, to come in and prove their said debts or claims at such time and place as shall be specified in such notice, or in defauit thereor they will be excluded from the benefit of any distribution made before such debta are proved.

D A T E D this 218 day of June, 1984.

R.M. ADDY,

Joint Liquidator. 
RE: CROUCH CONSTRUCTION LIMITED (In Llqu1detion)
Resietered orfice and Bueinese hadrese:

Sutherland Howee, Surblton creacent,

Kingoton-on-Thased, Surrer.

\section{APPROXIMATB STATEGENT OF APPAIRS}

- at at -

210t mar 1984

ASSETS

Ancete subject to Plxed Charge:

cospleted contract debtore

Leas: Noainated aub-contractore

Provielon for defecte and danaces

Asounte oved by Crouch oroup cospaniea

Deduct: Midland Bank - rlxed charge escursty

Aesete subject to ploating Charge:

Shares in Subaldiars Company

Purniture, equipent, alte hute ete.

Stock and work-1n-progreet

Leee: Nou1nated eub-contractore

Provieton for remerration of title claine

Excese coet of completion
Approrigate Book Values

$c^{\prime}+00 \quad c^{\prime} 000 \quad 4^{\prime} 000$
Eat loated to Reallse

$c^{\prime} 000 \quad c^{\prime} 000 \quad \varepsilon^{\prime} 000$
231

$\begin{array}{rr}3 & \\ 30 & 33 \\ \end{array}$

$\frac{276}{174}$

174

152

$\frac{276}{128}$

128

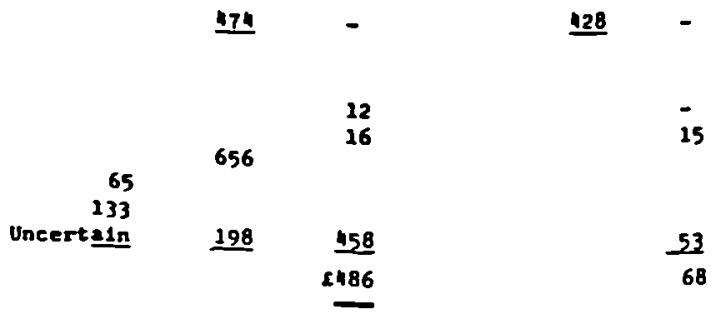

LIA日ILITIES:

Preferential Creditora:

P.A.Y.B. Incone Tax and M.I.C.

Wagee. Salariee and hollday pay

Rates

Mldland Bank ple for adrances of uaged and aalaries

ESTIMATED DEPICIENCY as regarda Preferent1al Creditor eubject to Conta of Realiantion

Debenture-nolder - Mldland Bank plc:

Direct Indebtedneas

Leea: P1xed Charge necurity deducted above

Preforential clalo - (expected to produce)

BSTIMATED DEPICIENCY a regarda Debenture- holder, subject to Contb of Realisation

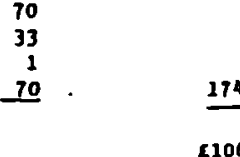

613

128

$\underline{20}$

$\stackrel{48}{\longrightarrow}$

Unuecured Creditora:

Trade and Expense

sub-contractore

Sub-contractorl

Protilion for revervation or title clalas

Anounte oved to Croveh Group compantee

ESTIMATED DEPICIENCY an regarde Uneecured Creditore, subject to Costa of Realisation

ISSUED SHARE CAPITAL

ESTIMATED DEPICIENCY as regarde Contributorteg, subject to Coote of Realleation

NOTES: 1. The above stateaent of arfalre wut be read in conjunction with the verbal report given to the Meeting of Creditore, a sumary or which le lesued to all known Creditore.

2. There ars be contingent habilitied in reapect of uncompleted contracta, the amount of which cannot at prebent be aecertained, but part of uhich mis be eecured by contract perforance bonds.

CORX GULLT.

Chartered Accountante.

shelley woune,

3 Noble street,

Lodon, EC2Y 700 


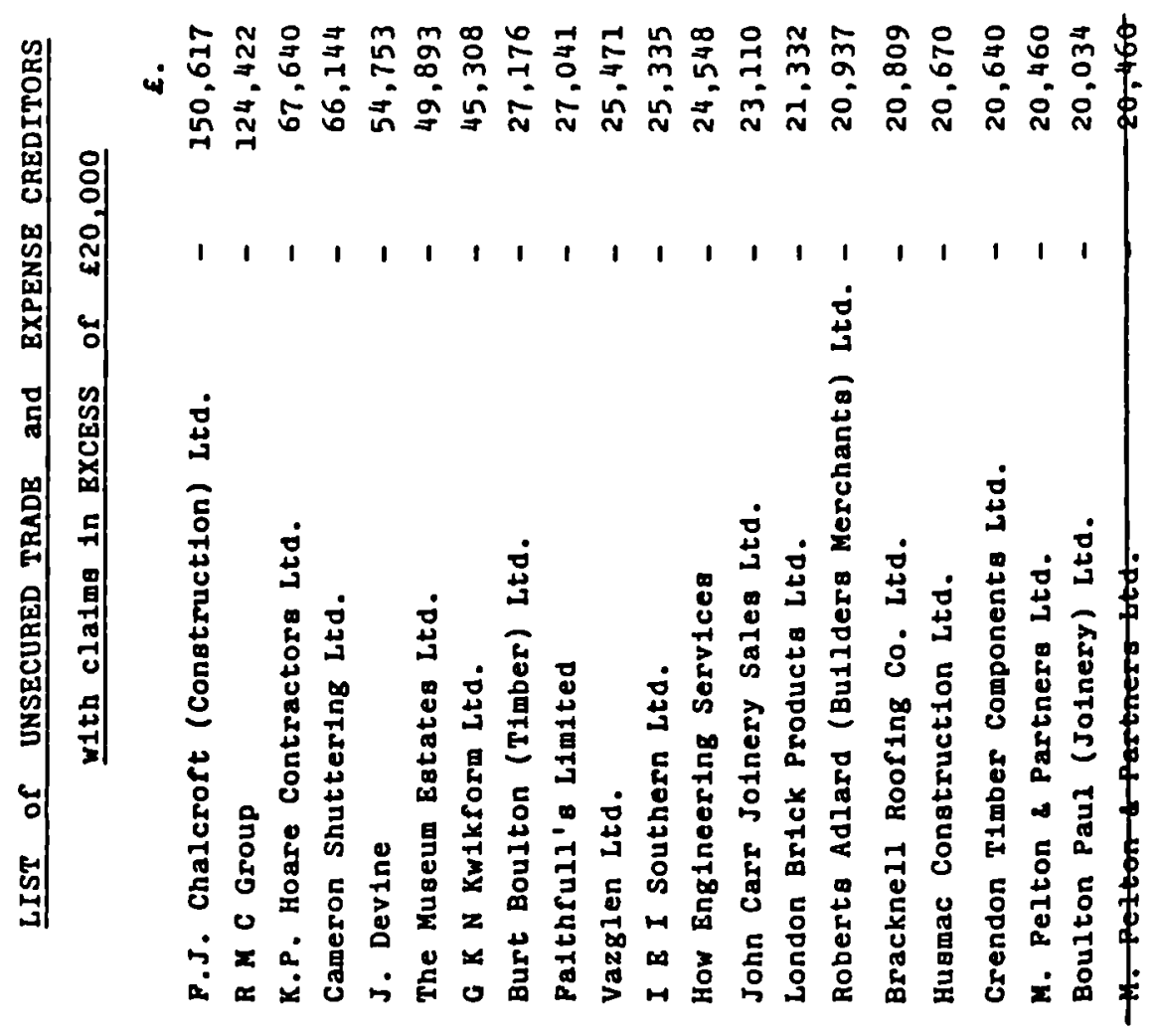

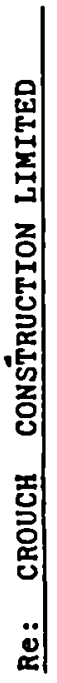
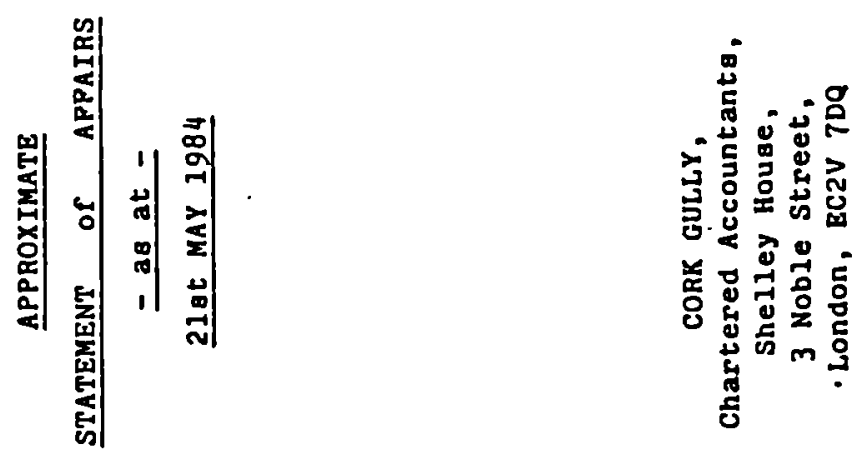


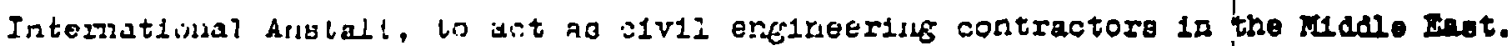

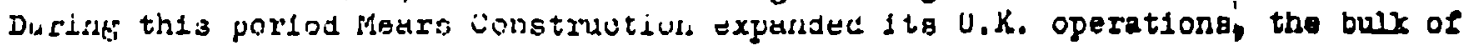
which consigted of alvi! elifiniserl!te worke such ag roads, reserroirp, sea defences,

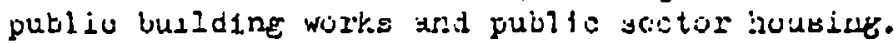

At thie time the Group 2 lso decided to transfor its headquarters from Sydennam to Swindon. When the move was made early in 1978, however, the Qroup' tradlate position sad coteriorated considerably partly due, in the view of the Directore as regards Mears Constmation, to the adverse weather condition in the second half of 1977 ind to the ract that certain major contracti prored to be losemaking. Also in carly 1979 a requegt for subatantially increased overdraft facilities was made to the Group's Banikers who as a condition for granting the increase took Fixod Charpen over the Croup's properties and requented a roport on the Croup's Inanciai josition to he presented by Price Waterhouse Co. This roport showed the need $f_{r}$ additional Group facilitieg and a furthar 1norane to E3.25m. was eranted 1n April 197\%, in exchange for Flxed and Floating Cheribte over aseots of the Long Compenies. As a result of a 10 se of E1,026,000 inourred by Mesro Construction for the ialf year to 31st March 1978, and to tmajng losees elsowhere in the Groug anount:ns to $\varepsilon 470,000$ revised cash-flow projections prepared in

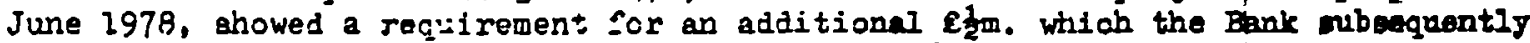
2.-"eed to grant in exchange for the execution on 6th July 1978, of Null Fired and Fipatize Charges by Hears construitior. ard otiner najor Companies in the Group that had not al ready give: pleajing Charese, supported by Cross-Guarantees.

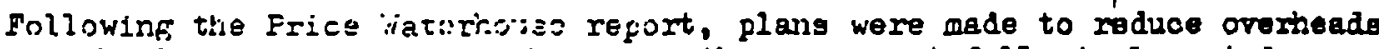
throughout the Group, al t:10ugh in th.e cvent they were not fully implemented. However, Moars In:erma: iorlal ar.d far, of the Long business were sold to third partics ard purchasers wcro 2180 siupht for the Group as a whole or for particular activitieg.

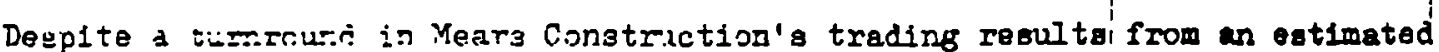
1033 of over $E I, J 00, \ldots)$ in the $3 i x$ months to the 31 et March 1978, to an oatisated 103.3 of only E12, J0J in the six menths to the 30th Septemier 1978, the oxpected isprovement in the sroup overall dil not materialise and negotiations for the sale of the Conpany werc lisucsessif 21 with the result that on the 18th January 1979.

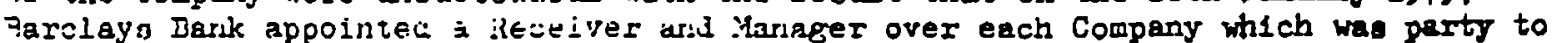
the MASS account.

It was repurtei sha: the iaicure of the Group was attributed by the Directora of Meara Jolitngs ta tire follcwing fictors:

(a) the losses incurres $y$ Mears Sonstruction during late 1977 and the early part of 1978 .

(b) the joiay oy cliersa is the settlement of certain substantial claims on contracts.

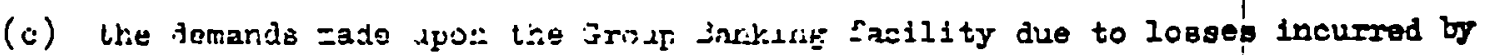
uther Comparies Nitisir : he Group.

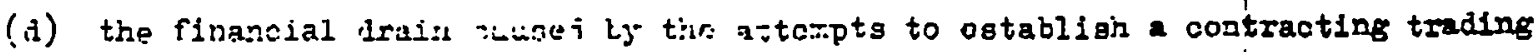
Juao overseas.

(e) the shont terll encis erfes:a if ine rove to Swindon.

Detaila of the tracil:e resilts of Mears Joldings for the three yeara to 30 th Sevtember 1978 were given as colluws: 


30.91976

\section{Exc:eso if Ext,escitinc crer Income \\ Extraordunary : tens}

Dividents recelve:

Dividenda gai:d

Reydlts for yeax

Cioning Gurpias (te: issncy)
E.000

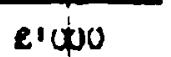

$30,9,19$

i! $\mathbf{5} 000$

\begin{tabular}{|c|c|c|}
\hline$\left(\begin{array}{r}2) \\
267\end{array}\right)$ & $\left\{\begin{array}{l}114 \\
3 \neq 0\end{array}\right\}$ & $\left\{\begin{array}{l}212 \\
327\end{array}\right.$ \\
\hline $\begin{array}{c}(269) \\
510\end{array}$ & (434) & (539) \\
\hline $\begin{array}{r}241 \\
(125)\end{array}$ & $\left\{\begin{array}{l}474 \\
125\end{array}\right.$ & $\begin{array}{c}(539) \\
- \\
\end{array}$ \\
\hline $\begin{array}{l}116 \\
938\end{array}$ & $\begin{array}{c}(559) \\
379\end{array}$ & $\left\{\begin{array}{l}539 \\
160\end{array}\right)$ \\
\hline
\end{tabular}

The Yeetinfe were aryised shat each of the Mass account Compantes 1s, ao vetween Itrelf and tise Jark. respo:sible for the winole of the Mass account orerirait and, tinrourpin Ciss-iuarantees. for other liabilities of the froup Compenies to the Bank, Thic inole iiatility to the Bark was therefore ahown in the' enclosec Itutoment of Affairs The Receivers and Yanagers wero of the opinion that tho

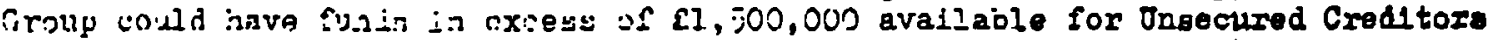
after the diaciaree It Prefcrontial claima and the liatility to the Bank but the

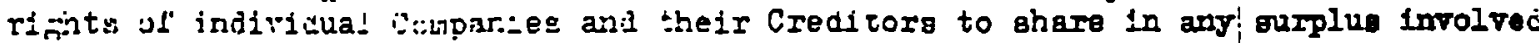
ccmilex logal surut:; inj: $i$ j:lle takc a consideratlc time to resolve.

Whe leftoiers:, es!lentod in the Statement of A:fairs to amount to $24,517,000$ jad jeen conpulct ae is:-16.is:

Surplus ( : asset:i jvet liajilities as at 1.10 .1975

$\varepsilon^{\prime} 000$

21000

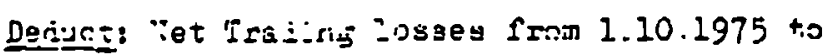
1.j. I ?97\%

DEvile:is paid durias perzod

822

I.esa: Dirilenis rec ived

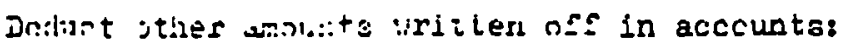

Acvance 0 - Toration lax irrocoverable

Amoints :rit:or. :if Isvest-ants in Jubsidiaries

Deri.inzer per serounts as at 10. 1.1979

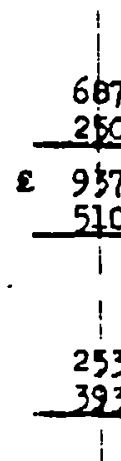

667

250

- 957

510

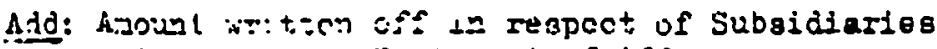
in preparison slatesent of iffairs Contirisent ilajilities MAj'J ÂLisur:

Estimated quta Deficiensy

At lise Extrasrainary General Meeting of Merjerg it was resolved that the Cionpany be sisnd ip : 21.0 larily and Mr. M.A. Jordan of W.H. Cork, Cully \& Co. end

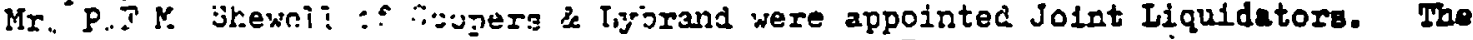
Brarehaljers alg; r.:oinal=al to the Coamittee of Irapection:

$$
\begin{array}{lll}
M r & \text { H.N. Apiin } \\
\text { isr II. . Lester } \\
\text { Mr. P M. Trmer }
\end{array}
$$

The lizeditors at taeis ilecti:2s contined the voluntary liquidation and

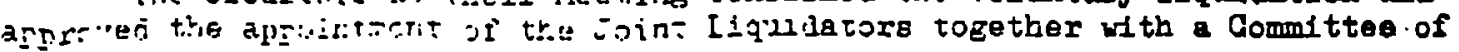




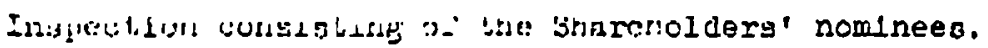

Shareholdrire are advised that the share Register will remais closed lexcept Sor ire Refistration of irer.ty of Probate. It lo rot necessery for them to

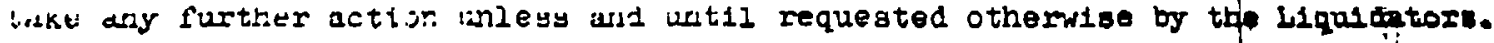

In accordanco with the attacred Notice, Creditors are requeted to sorrad ti: cuopers \& Lybrand at ihe alaress shown above a detailed statement of thair iaiz:s arrinat Kear's 3roz. Foldines ilmited tofether with detaily of any gecursty trela. We would draw joir actention to the legislation relating to Value ddded. Tar rolief un vad dehts. Creditors who wish to claim such rellef shauld doduct tho mojint af Valie Added Jax frow tho claim to be submitted to tho Iiquidatora and sirous 1 inform the Livilidalors accorainfly that their claim in the ilquidation 1o net U: V.A.T.

Pinage quote the aane of Meara 3ros. Holdinga Iirited (In Iflquidation) in al correapondence relatias to thi a Company.

Yours fat thfully,

P. F. N. SEEWELL,

M. A. JORDAN, as Joint Liquidetorg of Mears Bros. Eoldings Limited.

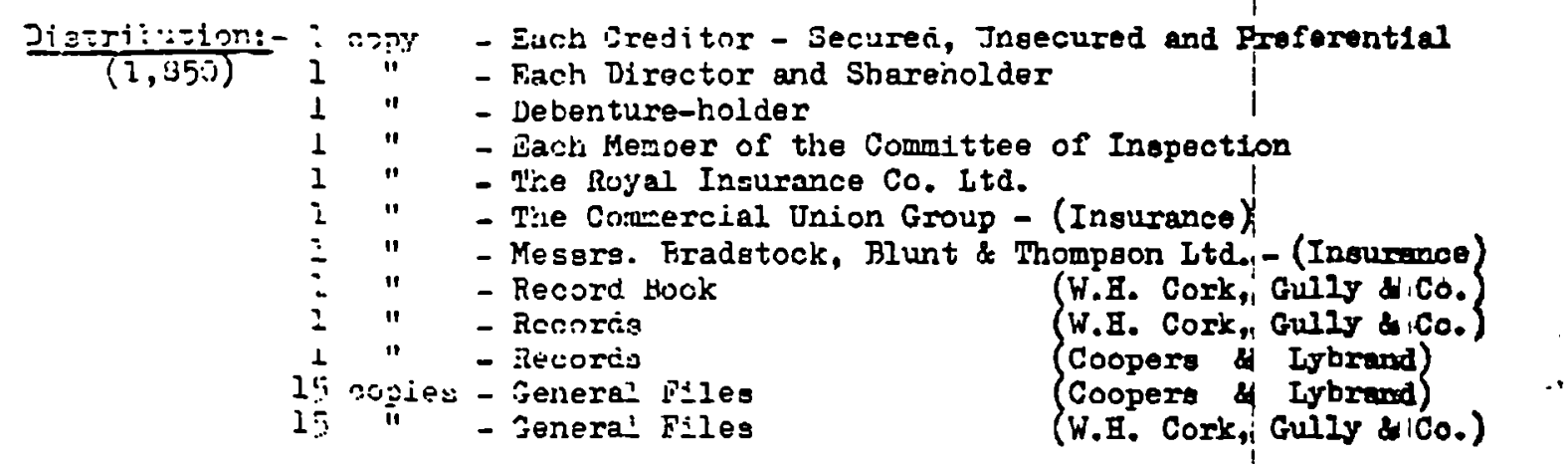




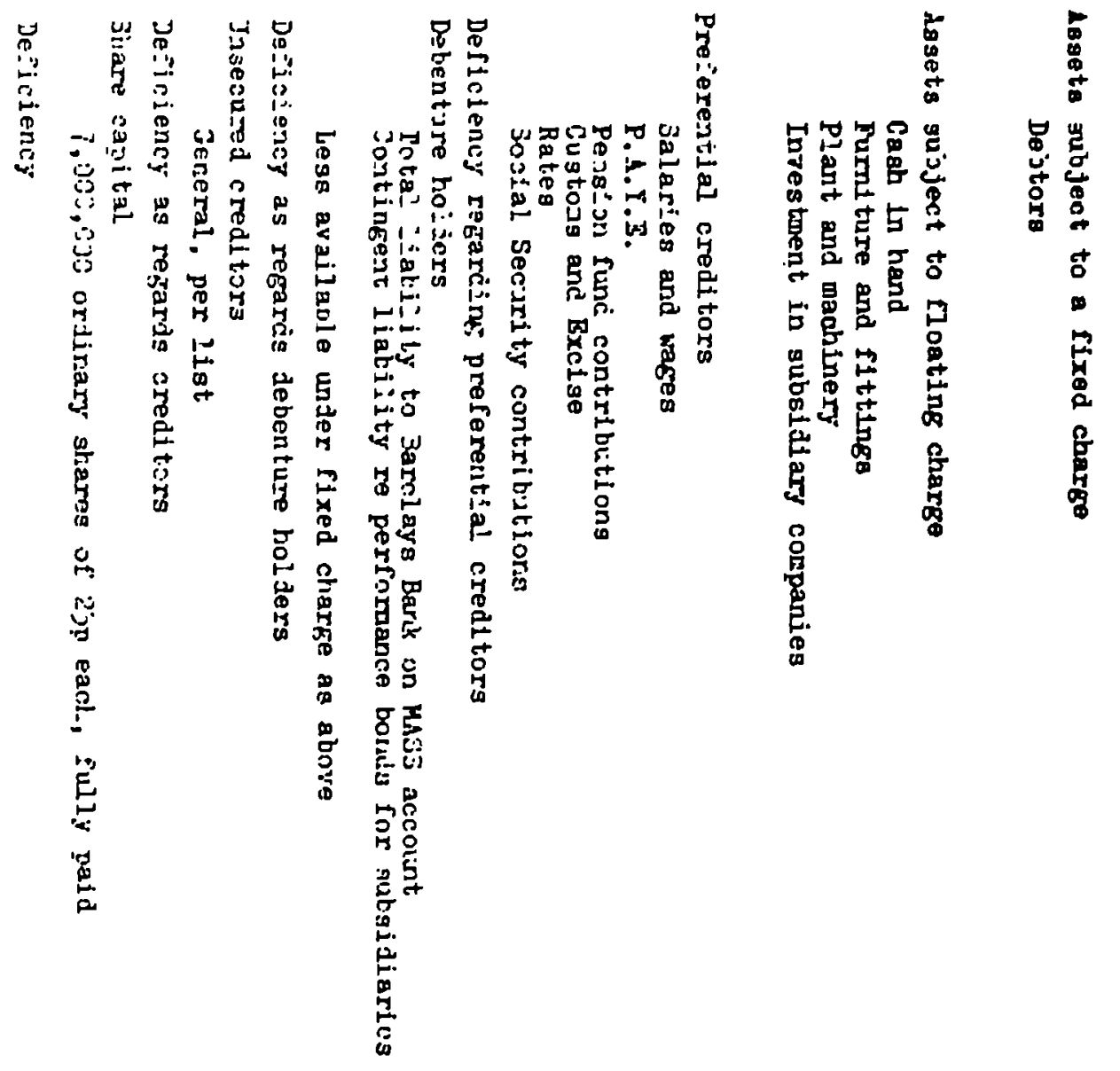

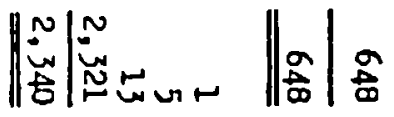

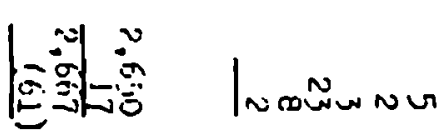

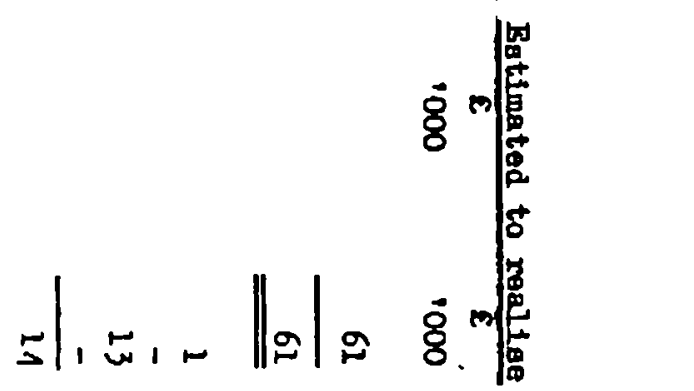

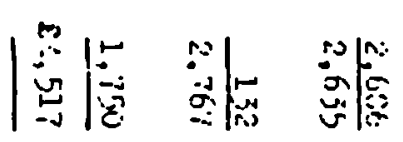

ot to

$\therefore \quad$ 都 


\section{Noteg to D1 rec:us' Eullinated Statoment of Affolrd}

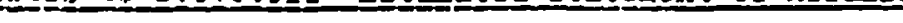 \\ 1. This estinate. wich -8 oubject to the costs of recaitrershis \\ and liquidutior. skould ie read in conjunction with the roparte to \\ the stareholdere and croittors. \\ ?. \\ It hen veer. asgmed that the flxed charge orer debtors giron \\ by the debentise 'B valit. This point will orly be relevant if the \\ bank seeks to or:"eze IIs Jwr subrogated claln in competition with \\ other preferertial cacilicts. \\ 3. \\ The aeturs inelude er,87,000 from other group compandes \\ in reccivoratip ar.1 considered irrecoverable. Dobte due to and from \\ 5T5:is companics na; hijever altor sujotantially as a rogult of the \\ claise nade afjirst tic es yanies oy the bank and any aubsequent \\ payserts ur:ist ti:e iciserture. At this stago the amounts involred \\ cannut be snuenri ar.1 ti.e -ejal rights ilikely to arise therefrom are \\ une] teas \\ 1. The preferential $32 i$ ariea and wages do not include any

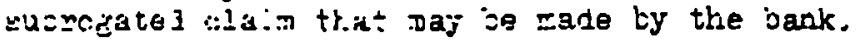 \\ 5. The exppary has guaranteed performance bonds, hlse plurchase and \\ bank and otter -eans li: $: t .3$ zlosaldiarles. For the purposes of the \\ staierent of afl'izrs th.c jirnctore have not attempted to asaess any \\ cortingert -iajs?il: sirce thcy are unaware of any clesim which hes been \\ ilade anter this :-eajis:- \\ i. \\ Xn pretisioy sas seez made for possible rodundancy playments.
}


Autumali: gleunisfi Eervicey Ltd.

Burc!ayn Bank (Londur \& Intermational) Itd.

Baring Srog. \& Lo. Ltd.

Coward Chance \& Co.

Coys of Kensinetun (Motors) Ltd.

9,777

Deinitte Haskins \& Seilo

564

East-ilest Europe

10,480

IBOS 'ir:unce Lti.

1,464

45,000

Inlarijl Revenue

1,712

3.: Lcigifield \& Sons Ltd.

17,795

Lexterten Ltd.

Lombari IJoret Centra] T.t.d.

1,558

Meare Properties Lt..

3.749

Sel sors Hurat $\&$ So.

3,344

liew Opportunily Prese Itj.

Ponc Ofrice

1,042

Price watemruse an.

Thames Nater kutizor: ty

widter Jon \& Pacicuas

A.3. Wrate

Jnclaimed dividencis

Sundry Cresiters unier E5,30 


\section{Souther. Counties Construction Co. Limited}

The first Meeting of Creditors of the above-named Company, convened pursuant to provisions of Section 293 of the Companies Act, 1948, took place at Centre Hotel, Portsmouth, on Friday 30th January, 1981. The Chairman of the Meeting was Mr. R.A. Boyce who was accompanied by Mr. Michael Andrews, the Chairman of the Board of Southerr. Constructions (Boldings) Ltc. (the Bolding. Company of the Group), and Mr. Richard Stone of Messrs Cork Gully who was appointed Joint Receiver by the Debenture Holder on the 12th May, 1980. A cony of the Statement of Affairs and list of principal Creditors which was submitted to the Meeting is enclosed herewith.

The Meeting was adiressed bv Mr. Michael Radford of Messrs Radford, Sons \& Co., whe reforted that he had recently been instructed by the Directors of the Company to assist them with the Conalities for winding-up the Company. He outlined the history of the Company, which was inccronrated in 1036 and continued trading until March, 10,1, whe it ciosed down because of the war. It re-commenced in 1946 and expanded steadily. In 1956 the shares were acouirec by the holding company, Southern Constructions (Holdings) Limited which later became $a$ publicly quoted Company. There were many changes of Directors and, at the late of the Meeting, those who remaines in office were:-

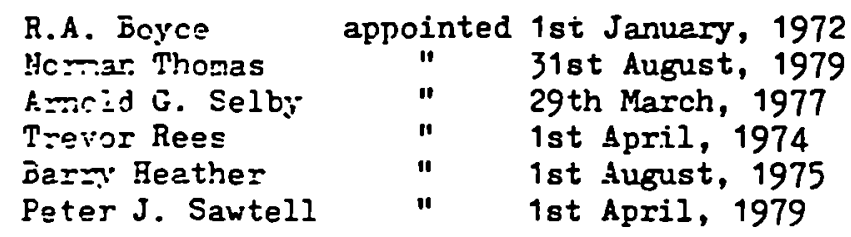

Mr. Michael J. Stallard was appointed Secretary on 1st September, 1977, but, arter assisting the Receivers for several months, he took a post abroad and Mr. Boyce was appointed Secretary on 30 th December, 1980.

Over the years additional businesses were acquired to work with the Company and parts of the Company's activities were separated into individual limited liability Companies, as subsidiaries of the Holding Company. Certain of these Companies ceased trading and, at the date of the appointment of the Receivers, there were four other actil subsidiaries, as follows:-

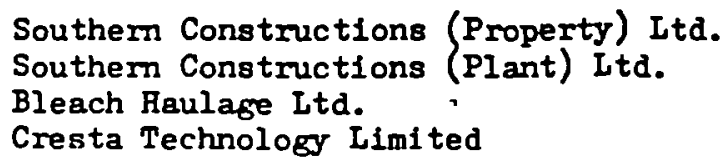

The bulk of the business carried on by other subsidiary Companies was on behalf of Southern Counties Construction Co. Ltd., which was the principal trading Corpany within the Group. The Companies were inter-dependent and, in considering the trading results, it is more relevant to refer to the Group results rather than those of the Company solely The following are the summarised tradinf results for the 5 years ended 31 st January, 1978

$$
2 / \ldots \ldots+\ldots
$$




\begin{tabular}{|c|c|c|c|c|c|}
\hline - & $\underset{\text { C }}{1978}$ & $\underset{\varepsilon}{1977}$ & $\underset{\mathbf{E}}{1976}$ & $\underset{\mathbf{E}}{1975}$ & $\underset{\mathbf{E}}{1971}$ \\
\hline Turnover & 12,221 & 13,709 & 10,737 & 9.929 & 7,363 \\
\hline Profit (108s) before taxation & (293) & $(1,452)$ & 160 & 554 & 223 \\
\hline Taxation & (9) & $(765)$ & 85 & 316 & \\
\hline Net profit (loss) after tax & $(284)$ & $(687)$ & 75 & 238 & \\
\hline
\end{tabular}

The interim results for the six months ended the 30 th June, 1979 were published in October 1979 and showed the following:-

$\begin{array}{rr}6 \text { months to 30th June } & \text { Year } \\ 1978 & 1979\end{array}$

$\begin{array}{lrrr}\text { Turnover } & 6,858 & 4,663 & 12,221 \\ \text { Profit (Loss) } & 33 & (398) & \text { (293) }\end{array}$

As will be seen the Company's turnover had fallen substantially compared to 1978, and this trend continued in the latter part of 1979 as the Company re-organised its affairs. The accounts for the year have not been completed, but the turnover was approximately E10 million, and the estimated trading loss was nearly $£ 800,000$.

The summarised figures above show that the Company had been very prosperous up to 1975, but suffered a gradual deterioration thereafter. In March, 1977, following the collapse of the Emest Ireland Group of Companies the Company acquired the Caffin Divisior of that Group, including its offices at Riclomanoworth and various employees, and it took an assignment of a number of contracts. Onfortunately the activities did not fit in well with the existing business, and it is estimated that losses on the contracts taken over amounied to $\mathrm{E}$ million.

Regulax management accounts were prepared and, although these showed a continuing trend of losses througthout 1979, the Directors were confident that the Group was solvent, and due to the remedial steps that had been taken, it would overcome its difficulties. Finance was provided by National Westminster Bank Itd. with an overdraft limit of 2765,000 but with a "bounce-up" facillty of $£ 300,000$ to cover periodic pressures due to delays in obtaining certificates on contracts and payments thereunder. There vere various cash flow crises in early 1980, and the Directors realised that the Company would need addi tional finance, and Bonds totalling $£ 600,000$ in reopect of contracts amounting to 27 million that had been secured. An approach was made to the Bank for assistance and the Bank insisted that the Group's affairs be Inveatigated by an independent firm of lccountants, and this exercise was carried out at the end of April and the first week of May. The contracts were examined by an independent firm of Surveyors, and the properties valued. The reports that went to the Bank showed that, on a going concern basis, the assets of the Group exceeded 1ts llabilities by E577,081, al though on a break-up there would be a substantial. defleieng. The Directors were optinistio that, in the light of the report, the Bank would accept their request for further aselstance but, when the Bank refused, the Directors had no alternative but to formally request the Bank to appoint Receivers.

The Receiverg continued trading for a ahort whlle attempting to finioh off a small job and to aseign contracts. AB a regult of the termination of certain contracts and losse oustalned through the assigment of others, the value of debts and work in progress has bee

$$
3 / \ldots \ldots
$$


reduced by approximately 21.4 million. The deficiency account can be summarised as foll

\begin{tabular}{|c|c|}
\hline $\begin{array}{l}\text { Deflciency at } 318 t \text { December, } 1978 \\
\text { Amount written off debts and work in progress } \\
\text { Contingent liabilities under perfomance bonds } \\
\text { Redundancy pay, holiday pay and notice payments }\end{array}$ & $\begin{array}{r}273,121 \\
1,419,694 \\
386,753 \\
114,721\end{array}$ \\
\hline $\begin{array}{l}\text { Balance being estimated trading lose for } \\
\text { the perlod 1st Jamuary, } 1979 \text { to lat May, } 1980\end{array}$ & $\begin{array}{l}2,194,289 \\
1,236,578\end{array}$ \\
\hline Deficiency per Statement of Affairs & $\varepsilon 3,430,867$ \\
\hline
\end{tabular}

At the date of the appointment of the Receivers the total indebtedness to the Bank wes E815,353, and there wes a contingent liability of 2226,867 in respect of Bonds. The funds at present held by the Receivers from the realisation of the assets of Southern Counties Construction Ltd., are quite small, but they estimated that approximately $\Sigma 500,000$ remains to be realised, principally in respect of final accounts and claims on completed contracts.

Onfortunately the Receivers have not yet succeeded in disposing of any of the Group's properties and the funds held by them at present from the realisation of the assets of the associated Companies is in the region of $\varepsilon 400,000$, and thus interest continues to accrue on the overdraft. The estimated value of the Company's properties is $£ 750,000$ and thus, provided the debts and retentions realise the amount estimated by the Beceivers and their Surveyors, a fund should be available for the Creditors of the Group in due course.

The Statement of Afsairs shows that there are no assets available for Unsecured creditors. Cther Companies within the Group however show substantial surpluses. Mr. Radford expressed the view that, when the assets of all the Companies had been realised and it is known what funds (if ang) are available for Creditors, consideration should be given to combining the assets and liabilities and equating the dividends payable across the Companies within the Group. Onderstandably objections to the proposal might be received from Creditors of the other Companies but, bearing in mind that the Iiabilities. of Southern Counties Construction Cu. itd., constitute $90 \%$ of the liabilities of the Group and, moreover, the other Companies where there are substantial assets would not have existed but for the fact that those assets were hived off from Construction, the proposal has the merit of equity. When the position is clearer, Creditors will be asked to express their riews, and it may be necessary even to make an application to Court.

The Meeting resolved that Michael G.V. Radford.F.C.A. be appointed Ilquidator, with a Comittee of Inspection consisting of the respresentatives of:-

The Devrm Steel Co. Itd.

H. \& J. Gloogup Itd.

Beady Mlled Concrete Group

Tarmac Roadstone (Southern) Itd.

Shell UK 011

Would those Creditors who did not submit claims in response to the sotice of the leeting of Creditors plesee be sood enough to do so, and where approprlate submit the forms of acknowledgement for V.A.T. purposes. Forms previously eubmitted are returned jerewith.

\section{Yours faithfully}

RADFORD, SONS \& CO. 
亲
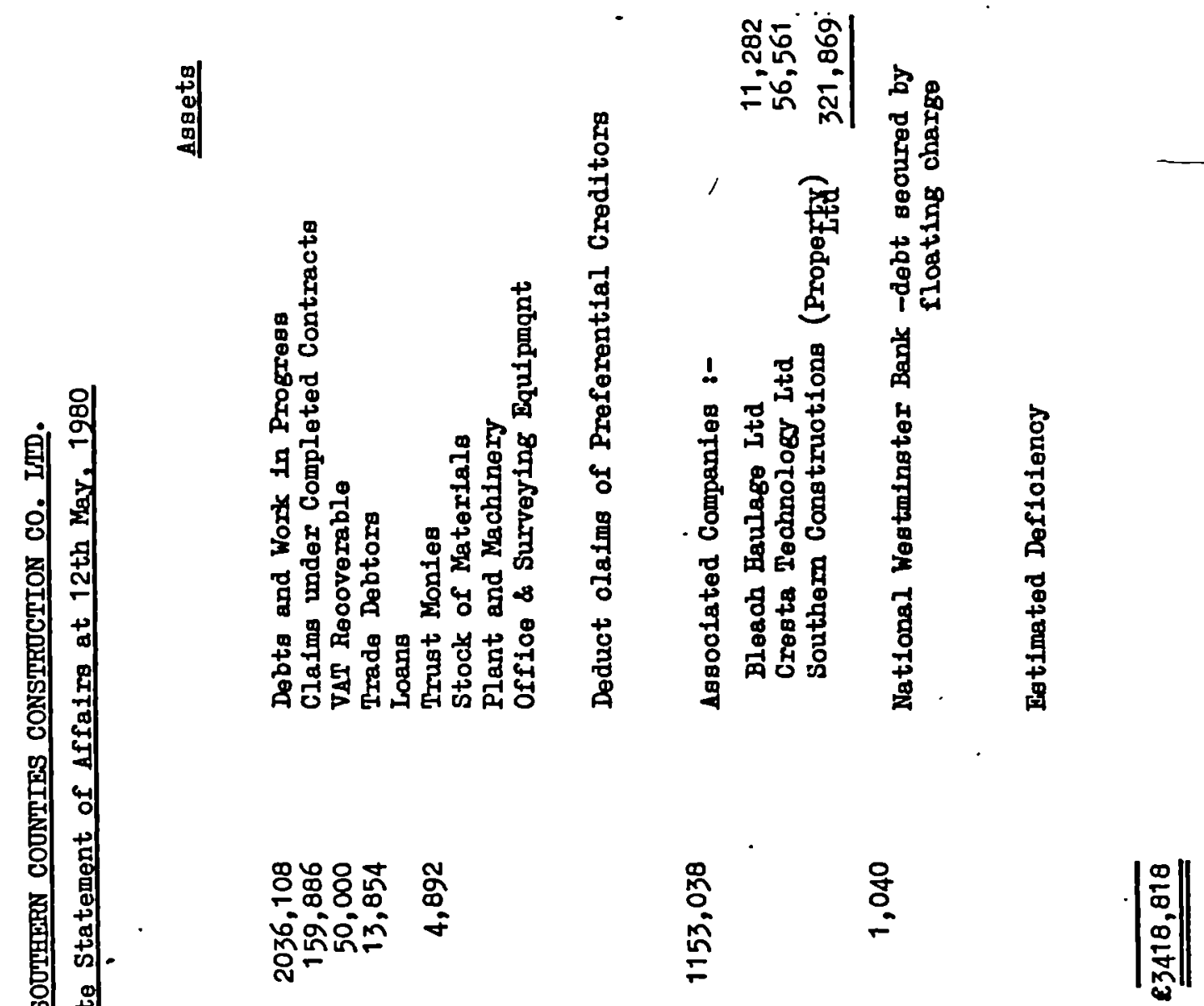

弯

ํํำ
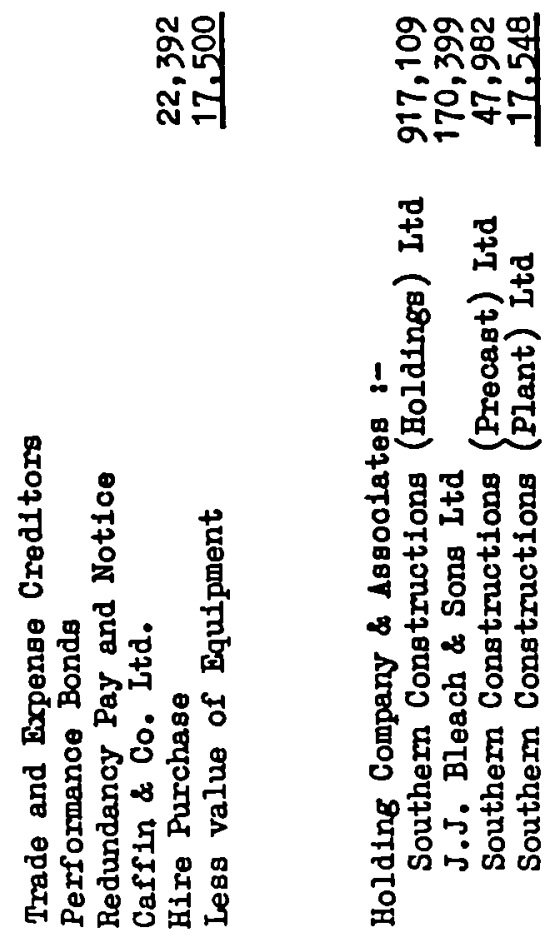

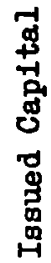


RADFORD, SONS \& CO.

Chartered Stecountants

MICHAEL G. V. RADFORD

12 PORTLAND STREET.

Consultans :

Gordon E. Radford SOUTHAMPTON SO1 OEB

Telephone (0703) 330703

Facsimile (0703) 330099

Our ref. MR/CJ/C. GEN

Your ret.

PRIVATE AND CONF IDENTIAL

26 th August, 1988

Dear Sirs,

Southern Constructions (Holdings) Limited

The first Meeting of Creditors of the Company convened pursuant to the provisions of Section 98 of the Insolvency Act 1986, took place at the Southamptoa Park Hotel, Southampton, on Wednesday, the 17th August, 1988.

The Chairman of the Meeting was Mr. J.M.G. Andrews. The Statement of Affairs sworn by Mr. Boyce, one of the Directors, showed that the only assets of the Company are certain claims against subsidiary Companies, which are also in the course of being wound-up.

The Receiversip of the principal trading subsidiary, Southern Counties Construction Co. Ltd., will not be completed for several months. However, it is anticipated that when the Receiver has completed his work, certain funds will flow back to the Holding Company which might result in a dividend being payable to the Creditors whose claims appear to amount to the following:-

$\begin{array}{lr}\text { Trade and Expense fccounts } & 59,871 \\ \text { Subsidiary Companies } & 105,793 \\ \text { Guarantee Liability } & 140,073 \\ \text { Claims from Directors and Ex-Directors } & 18,930 \\ \text { Ex-employees } & 9,100\end{array}$

The Meeting resolved that Mr. Michael G.V. Radford, FCA, be appointed Liquidator. Mr. Radford is also Liquidator of the subsidiary Companies.

Would those Creditors who did not submit claims in response to the Meeting of Creditors, please be good enough to do so and where appropriate submit forms of acknowledgement for V.A.T. Bad Debt Relief purposes.

Yours faithfully,

RADFORD, SONS \& CO. 
APPENDIX D-5

\section{QUESTIONNAIRE}




\section{QUESTIONNAIRE}

Please tick the appropriate box for question 1-10 and Yes or No for questions 11-17.

1 - Please state whether the chief excutive is the sole authority or has an assistant or deputy in the company.

Sole authority

Assistant or deputy with

authority

[ ]

[ ]

2- Please state whether the chief executive is the same person acting as both chief executive and chairman of the company.

Chief executive and chairman same person
Chief executive and chairman not same person

3- Please state whether the Company Board comprises persons not working in the company.

Comprises only members

working in the company
Comprises of members

not working in the company 
4- Please state the average exeperience in years of the majority of the company's site Engineers up to section Engineers.

Over 10 years

Less than 10 years

5- State whether the financial director has sole authority for financial decisions or shared by other senior managers.

Sole acting person

Shared authority

with authority

6- State the average experience years of the majority of the company's management staff (site and service manager including at Head office).

Over 10 years

Less than 10 years

[ ]

7- State whether the company produces cash flow plans.

Cash flow plan prepared No cash flow plan and reviewed periodically 
8- State whether the company has a budgetery control system.

Budgetery control system

avialable in the company
No budgetery control system

avialable in the company

9- State whether the senior management staff carry all the responsibility for tendering.

Senior management staff

Bidding decision not taken

experienced in bidding at middle management level

and taking bidding decisions

[ ]

[ ]

10-State how your company responds to market changes.

Quick response

Fair response

\section{[ ]}

[ ]

11- Did the company issue debentures before $1986 ?$ 
12-Did the company expand its business before 1986 and did this result in over trading?

13-Did the company under-take a specific project before 1986 which caused significant losses?

14-Did the company take over an other firm before 1986 which resulted in significant losses?

15- Did the company diversified its business before 1986? If Yes does it relate to the same line of your business?

16-Did the company under-take a specific project including contract claims before 1986 which caused significant losses?

17- Did the company under-take a specific overseas projects before 1986 which caused significant losses? 


\section{APPENDIX E}

E.1 Introduction

E.2 Test the Goodness of Fit

E.3 The F-Test

E.4 Test of Model 2

E.5 Test on Financial Ratios

E.6 Test on A-Soore Model

E.7 Test on Relationship Between $\mathrm{z}$-Score and A-Score

E.8 Appendix References 


\section{APPENDIX E}

\section{STATISTICAL TESTS}

\section{E.1 INTRODUCTION}

One of the main objectives of statistical analysis in a situation of uncertainty, unavailable mathematically, or otherwise to produce the right answer, is that the information derived from samples drawn acoording to specific criteria can be used to make estimates of and inferences about the characteristics of populations.

Statistical analysis can do no more than help to assess the level of risk involvement. This idea is central to the whole concept of statistical analysis, which is cancerned not with the impossible task of finding the right answer but with measuring the level of uncertainty. This inevitably throws the final decision back on the researcher's judgement.

\section{E.1.2 CHOOSING A SAMPLE}

A sample, of whatever size, should be randamly chosen. In practice it is not easy to meet this condition so that various devices are used to keep the sample as close to the ideal as possible. Despite much effort, few data were collected with sufficient information.

The rules for choosing an appropriate size of sample in this research were based on:

- availability of data

- qualitative analysis. 
Unfortunately, due to lack of information available only 22 failed companies have been collected. Eleven were used to develop the model and 11 used to test the model. Also 20 continued companies were used to develop the model and 70 companies were used to test the model.

The selection criterion adopted for the "non-fatled 20" group was as follows:

- continuing in business for at least four years and also had to have continued in operation for two years after the focal year 1986

- has not been exposed to continuous losses for the last four years in business, same of them may have made losses over one or two years

- finally, appearing solvent, but not necessarlly considered healthy companies.

While the selection criterion for the "failed 11" group consisted of those declaring bankruptcy and into receivership between 1978 through 1986, a period of 8 years.

\section{E.1.3 TEST ON NORMALTTY OF DATA}

The standard discriminant analysis procedures assume that the variables used to describe or characterise the member of the groups being investigated are multivariate normally distributed.

In practice, deviations from the normality assumption in finance appear more likely to be the rule rather than the exception [see Deakin, 1977]. 
Violations of the normality assumption may bias the test of significance and estimated error rates.

In the applied literature, the problem of testing for the appropriateness of the distributional assumption has been largely ignored, This is cue in part, one would presume, to the fact that most available normality tests are for univariate and not multivariate normality [1]. In our case a reasonable approximation nomality has been taken by calculating the financial ratios for four years for the "non-failed 20" groups and the last three years for the "failed 11" group, and averaging the ratios in order to smooth the means. Also logarithmic and reciprocal transfomation is adopted to improve normality.

\section{E.1.4 TEST ON REIATIONSFIP BETWEDN VARTABLES}

Correlation between varlables were tested. Previous studies (2)(3) suggested that any ratio highly correlated with other ratios that describe similar aspects of the company's financial structure should be discretised for example, correlation between any two variables 0.7 or greater, one of them should be selected for inclusion in the analysis. This research adopted similar concepts as shown in Figure E.1.

\section{E.2 TEST THE GOODNESS OF FIT}

In order to test the goodness of fit of the nomal distributions characterised by the mean and standard deviations of the two samples, the Kolmogorov-smironu test is employed. The hypothesis tested is that the nomal distribution fits the data. 
If the computed value of the greatest absolute difference between the distribution functions exceeds the tabular value, the hypothesis is rejected.

The " $\mathrm{Z}$ " values for the "non-falled 20 " and "falled 11" groups are shown in Table E.1. The range of " $Z$ " values is divided into segment 3 units, and the frequency indicated on the graph is the number of " $\mathrm{Z}$ " values failing within that particular segment.

The histograms closely resemble the superimposed normal curve as shown In Figure 6.2 (see Chapter 6). The greatest difference between actual proportion and expected proportion is shown in Tables E-2 and E.3.

The hypothesis is not rejected at the 0.05 level of significance for either group, as the tabular value for the samples size of twenty and eleven are 0.26 and 0.36 respectively, and the assumption of nomality is presumably satisfied. 
TABLE E-1

\begin{tabular}{|c|c|c|c|}
\hline Rank & "Non-failed" Group z Values & "Failed" & Group Z-Values \\
\hline 1 & 13.27 & & \\
\hline 2 & 3.59 & & \\
\hline 3 & 14.9 & & \\
\hline 4 & 14.53 & & \\
\hline 5 & 6.4 & & \\
\hline 6 & 7.1 & & \\
\hline 7 & 3.52 & & \\
\hline 8 & 7.07 & & \\
\hline 9 & 18.22 & & $\mu_{1}=9.6$ \\
\hline 10 & 20.4 & & \\
\hline 11 & 6.32 & & \\
\hline 12 & -1.85 & & \\
\hline 13 & 14.74 & & \\
\hline 14 & 8.25 & & \\
\hline 15 & -0.96 & & \\
\hline 16 & 10.8 & & \\
\hline 17 & 17.7 & & \\
\hline 18 & 5.7 & & \\
\hline 19 & 6.8 & & \\
\hline 20 & 15.6 & & \\
\hline 21 & & -4.1 & \\
\hline 22 & & -11.53 & \\
\hline 23 & & -22.6 & \\
\hline 24 & & -18.8 & \\
\hline 25 & & -10.13 & $\mu_{2}=-14.3$ \\
\hline 26 & & -8.8 & \\
\hline 27 & & -16.0 & \\
\hline 28 & & -18.3 & \\
\hline 29 & & -21.3 & \\
\hline 30 & & -18.0 & \\
\hline 31 & & -7.66 & \\
\hline
\end{tabular}




\begin{tabular}{cccccccc}
\hline Range & $\begin{array}{l}\text { Actual } \\
\text { Frequen- } \\
\text { cies }\end{array}$ & $\begin{array}{l}\text { Actual } \\
\text { cumula- } \\
\text { tive }\end{array}$ & $\begin{array}{l}\text { Expected } \\
\text { Propor- } \\
\text { tion }\end{array}$ & $\begin{array}{l}\text { Expected } \\
\text { ammala- } \\
\text { tive }\end{array}$ & $\begin{array}{l}\text { Actual } \\
\text { Propor- } \\
\text { tion }\end{array}$ & $\begin{array}{l}\text { Expected } \\
\text { Propor- } \\
\text { tion }\end{array}$ & $\begin{array}{l}\text { Diffe- } \\
\text { rences }\end{array}$ \\
\hline $0-(-3)$ & 1 & 1 & 0.76 & 0.76 & 0.05 & 0.053 & 0.003 \\
$0-(+3)$ & 2 & 3 & 0.06 & 0.82 & 0.15 & 0.057 & 0.093 \\
$3-(6)$ & 0 & 3 & 0.25 & 1.07 & 0.15 & 0.075 & 0.075 \\
$6-9$ & 3 & 6 & 2.835 & 3.905 & 0.3 & 0.274 & 0.026 \\
$9-12$ & 5 & 11 & 3.78 & 7.685 & 0.55 & 0.539 & 0.011 \\
$12-15$ & 1 & 12 & 0.76 & 8.445 & 0.6 & 0.593 & 0.007 \\
$15-18$ & 4 & 16 & 5.67 & 14.115 & 0.8 & 0.99 & -0.19 \\
$18-21$ & 2 & 18 & 0.06 & 14.17 & 0.9 & 0.995 & -0.095 \\
$21-24$ & 2 & 20 & 0.06 & 14.23 & 1.0 & 1.0 & 0 \\
& & & & & & & \\
\hline
\end{tabular}

TABLE E-2: SHOWS DIFFERENCES BETWEEN ACTUAL AND EXPECTED PROPORTIONS IN "NONFAILED 20" GROUP (Kolmogrov Sinimov Test)

\begin{tabular}{lccccccc}
\hline Range & $\begin{array}{l}\text { Actual } \\
\text { Frequen- } \\
\text { cies }\end{array}$ & $\begin{array}{l}\text { Actual } \\
\text { tive }\end{array}$ & $\begin{array}{l}\text { Expected } \\
\text { tion } \\
\text { tion }\end{array}$ & $\begin{array}{l}\text { Expected } \\
\text { ammia- } \\
\text { tive }\end{array}$ & $\begin{array}{l}\text { Actual } \\
\text { Propor- } \\
\text { tion }\end{array}$ & $\begin{array}{l}\text { Expected } \\
\text { Propor- } \\
\text { tion }\end{array}$ & $\begin{array}{l}\text { Diffe- } \\
\text { rences }\end{array}$ \\
\hline$(0)-(-6)$ & 1 & 1 & 0.76 & 0.76 & 0.09 & 0.062 & 0.028 \\
$(-6)-(-12)$ & 4 & 5 & 5.67 & 6.43 & 0.454 & 0.526 & 0.068 \\
$(-12)-(-18)$ & 2 & 7 & 0.06 & 6.49 & 0.636 & 0.537 & 0.103 \\
$(-18)-(-24)$ & 4 & 11 & 5.67 & 12.16 & 1.0 & 1.0 & 0 \\
\hline
\end{tabular}

TABLE E-3: SHOWS DIFFERENCES BETWEEN ACTUAL AND EXPECTED PROPORTIONS IN "FAILED 11" GROUP (Kolmogrov Smirnov Test) 


\section{E-3 THE F-TEST}

F-test: It enables us to compare two estimates of the same variance to give the likelihood that discrepancy would arise for the size we have got, the test depends vitally on degrees of freedom.

By establishing null hypothesis that all the figures come from the same distribution and then estimates are made of the varlance of this distribution in a variety of ways. Comparison of these estimates allows a decision to be made on whether they are so different that the null hypothesis should be rejected.

The mean of the $\mathrm{Z}$-value for the "non-failed 20 " group is 9.60 and the sums of squares of differences:

$$
\begin{aligned}
& s_{1}{ }^{2}=\left(z-\bar{z}_{1}\right)^{2}=760 \\
& \text { s.d. }=\sqrt{ } \frac{\sum\left(z-\bar{z}_{1}\right)^{2}}{n-1}=6.324
\end{aligned}
$$

and the variance is the square of standard deviation. Hence variance for the "non-falled" group = 39.9.

Similarly, the mean of the Z-value for the "failed 11" group is 14.30 and the sums of squares of differences

$$
\begin{aligned}
& s_{2}{ }^{2}=\Sigma\left(z-\bar{z}_{2}\right)^{2}=375 \\
& \text { s.d. }=\sqrt{ } \frac{\Sigma\left(z-\bar{z}_{2}\right)^{2}}{n-1}=6.123
\end{aligned}
$$

and the variance is 37.49 .

The best estimate of s.d. of whole populations: 


$$
\begin{aligned}
& \text { s. } \overline{d .}=\sqrt{\frac{\Sigma\left(z_{1}-\bar{z}_{1}\right)^{2}+\Sigma\left(z_{2}-\bar{z}_{2}\right)^{2}}{n_{1}+n_{2}-2}} \\
& \text { s.d. }=\frac{759.38+375.25}{20+11-2}=6.253
\end{aligned}
$$

Variance of whole population $=39.1$.

Estimate sums of square for whole population:

$$
39.1 \times 29=1133.9 \text { with DF1. }
$$

2. Estimate of variance for each column and averages:

$$
\begin{aligned}
& \frac{37.79+39.9}{2}=38.69 \text { with } 29 \text { degrees of freedom } \\
& \frac{39.1}{38.69}=1.010
\end{aligned}
$$

Now we use the F-test to enable us to compare two estimates of the same variance to give the likelihood that discrepancy would arise fram the size of samples we have got. There are two ways of making estimates of the variance: 


\section{1) Estimating variance group by group}

On the basis of null hypothesis, the "non-falled" group is a sample sized 20 from the overall population. For this group the average $\mathrm{Z}-$ score is 9.6, the sum of the squares of the difference from this average is 759.4 .

So the population variance is

$$
\frac{759.9}{19}=39.97
$$

We can do the same with the "failed " group where the average is 14.30, the sum of squares of the differences from this average is 375.25 and the estimate of varlance is:

$$
\frac{375.25}{10}=37.52
$$

So that the best estimate of population variance is:

$$
\frac{39.97+37.52}{2}=38.75, \text { call this estimate "A" }
$$

\section{1i) Estimating variance using group averages}

The averages for each group are 9.6 and -14.3 respectively and this is a sarmle size of 2 of what might be a large number of averages.

We can make an estimate of the variance of this large number of averages from the two we have got. Average of the two:

$$
\frac{9.6+(-14.3)}{2}=-2.35
$$


Sum of squares of differences:

$$
[9.6-(-2.35)]^{2}+[-14.3-(-2.35)]^{2}=285.6
$$

Estimate of variance, by using 2 degrees of freedom:

$$
\frac{265.6}{2}=142.8
$$

Now, the central limit theorem tells us that for sample size "n" out of a full population with standard deviation ' $S$ ' the averages will form a new distribution whose standard deviation will be $S / \sqrt{ } \mathrm{n}$. The variance is the square of standard deviation so that:

$$
\text { Variance of average }=\text { variance of population } / \mathrm{n}
$$

If we considered the sample size the lowest is 11 instead of 20 . In order to get lower estimates so that our final estimate of the overall variances $142.8 \times 11=1570.8$, call this estimate "B".

\section{THE TEST}

We now have two estimates of the variance of the $\mathrm{z}$-scores on the assumption (null hypothesis) that there is no difference between two groups, these estimates are:
A. Estimating variance group by group and averaging
38.75
B. Estimating variance using groups averages
1370.8

Before we must consider "degrees of freedom" again because the test depends vitally an this. Firstly when we used each group we got 19, 10 
degrees of freedom respectively. Using both groups gives $20+11-2=$ 29 degrees of freedam. Secondly, when we used the averages of each group, there were only two figures. We are therefore comparing:

\subsection{5 with 29 degrees of freedom 1750.8 with 2 degrees of freedam}

The ratio $1570.8 / 38.75=40.5$

The tabular value of $F$ is 5.42 where $D F_{1}=2$ and $D F_{2}=29$ at the 18 significance level while the computed value of $F$ is 40.5. Therefore the computed F-statistic for the overall function is good.

An F-ratio is the ratio between two variances and is used to test for homogeneity of variance and equivalence of two groups.

A value of ' $F$ ' larger than the tabular value for the degrees of freedom in the numerator $\mathrm{DF}_{1}$, and the degrees of freedom in the denominator $\mathrm{DF}_{2}$ at an indicated level of significance leads to the rejection of the hypothesis that the two groups are samples from the same population with a confidence level of 998 or 18 level of significance.

Therefore, we can conclude that an increase in differences between means of the variables or decrease in the variability of variables improves the ability of discriminant models to differentiate between groups.

An alternative, and equally valid approach is to use the student $t$ test to compare the $\mathrm{z}$-scores of two groups. 
The average $z$-scores of group $1+9.6$

The average Z-scores of group $2-14.3$

The best estimate for the standard deviation of common population

$$
=\checkmark \frac{s_{1}^{2}+s_{2}^{2}}{N_{1}+N_{2}-2}=6.253
$$

The null hypothesis regards the two samples as samples from the same population. Therefore no difference in the averages of the populations from which the samples are taken have to be extended to include the assumption that the standard deviations are also the same.

The formula for different sized samples is:

$$
\begin{aligned}
t & =\frac{\text { difference in averages }}{\text { best estimate of s.d. }} \div \sqrt{1 / n_{1}+1 / n_{2}} \\
t & =\frac{9.6+14.3}{6.253} \div \sqrt{1 / 11+1 / 20} \\
& =\frac{3.822}{0.374}=10.219
\end{aligned}
$$

The number of degrees of freedan $=11+20-2=29$.

Tabular value of $t=2.462$ at 18 significance level. 


\section{E.4 TEST OF MODEL 2}

Each variable in the multiple regression second version model is tested for significant contribution to the coefficlent of determination $\left(R^{2}\right)$ which is a measure of the proportion of the variance of the dependent variable accounted for by the independent variables.

The amount of variance explained by the model is 898 of the total variance. The adjusted $\mathrm{R}$-squared is $91 \%$. The higher level of variance explained indicates the power of the model and that the most discriminant variables are included in the model.

Also, the $t$ value of the model tested indicates that the calculated value (3.45) is greater than the tabular value (2.75) at 0.01 significance level.

\section{E.5 TEST ON FINANCIAL RATIOS}

The statistical method used to obtain the most correct predictor ratios was based on criteria that an increase in difference between means of the ratios or decrease in variability of ratios improves the ability of discriminant ratios to differentiate between groups.

The student $t$-test is employed to compare the financial ratio means of two groups for example. The means of current ratio for failed and nonfailed groups were 1.16 and 1.66 respectively. The best estimate for the standard deviation of common population:

$$
\text { s.d. }=\sqrt{\frac{\Sigma\left(r_{1}-\bar{r}_{1}\right)^{2}+\Sigma\left(r_{2}-\bar{r}_{2}\right)^{2}}{n_{1}+r_{2}-2}}=0.511
$$


The formula for $t$ for different sized samples is:

$$
\begin{aligned}
& t=\frac{\text { difference in averages }}{\text { best estimate of s.d. }} \div \frac{1}{n_{1}}+\frac{1}{n_{2}} \\
& t=\frac{1.66-1.16}{0.51} \div \sqrt{ } \frac{1}{20}+\frac{1}{11} \\
& t=2.6
\end{aligned}
$$

The number of degrees of freedom $=11+20-2=29$. The tabular value of $t=2.46$ at 18 significance level, therefore we can reject the hypothesis that the two groups are samples from the same population with a confidence level $99 \%$ or 18 level of significance.

Similarly, the $t$-values for $N A / C L$ and EBIT/INT ratios are 5.16 and 2.56 respectively which are greater than the tabular value 2.46 at 18 level of significance. 
TABLE E-4: SHOWS THE MEANS OF FINANCIAL RATIOS USED IN THE ANALYSIS

\begin{tabular}{|c|c|c|c|c|c|}
\hline$C A / C L$ & & NA/CL & & $\mathrm{T} / \mathrm{INT}$ & \\
\hline $\begin{array}{l}1.06 \\
2.74 \\
1.32 \\
1.67 \\
2.24 \\
1.36 \\
2.29 \\
1.65 \\
2.55 \\
1.097 \\
1.69 \\
1.09 \\
1.6 \\
1.39 \\
1.27 \\
1.38 \\
1.317 \\
1.42 \\
1.25 \\
3.4\end{array}$ & 1 & $\begin{array}{l}1.675 \\
1.91 \\
1.177 \\
1.11 \\
1.7 \\
0.947 \\
1.75 \\
1.36 \\
2.38 \\
0.937 \\
1.47 \\
6.7 \\
1.01 \\
1.92 \\
1.44 \\
2.07 \\
1.35 \\
1.25 \\
0.74 \\
3.37\end{array}$ & & $\begin{array}{c}3.82 \\
4.4 \\
6.65 \\
1.7 \\
4.4 \\
6.35 \\
4.4 \\
8.2 \\
2.1 \\
3.5 \\
2.92 \\
3.18 \\
2.15 \\
5.65 \\
1.05 \\
9.1 \\
7.47 \\
33.0 \\
5.1\end{array}$ & \\
\hline \multirow[t]{2}{*}{1.66} & & 1.765 & & 4.7 & \\
\hline & $\begin{array}{l}1.47 \\
0.5 \\
1.72 \\
0.59 \\
1.01 \\
1.25 \\
1.34 \\
1.22 \\
1.28 \\
1.06 \\
1.36\end{array}$ & & $\begin{array}{l}1.34 \\
0.49 \\
1.13 \\
1.08 \\
1.02 \\
0.68 \\
0.64 \\
0.92 \\
0.79 \\
0.58 \\
0.46\end{array}$ & & $\begin{array}{l}0.90 \\
3.07 \\
1.64 \\
1.42 \\
0.85 \\
1.34 \\
0.71 \\
0.19 \\
2.15 \\
1.43 \\
2.2\end{array}$ \\
\hline 1.16 & & 0.816 & & 1.44 & \\
\hline
\end{tabular}




\section{E.6 TEST ON A-SCORE MODEI}

The A-scores for the "at risk 7" and "solvent 7" groups are shown in Figures 10.1 and 10.2 as follows:

$$
\begin{aligned}
& 62,72,62,96,50,69,50 \\
& 31,45,41,29,47,28,43
\end{aligned}
$$

\section{i) Testing by Using t-Test}

In order to deal with the mull hypothesis that there is no difference in the averages of both populations it has to be extended to include the assumption that the standard deviations are also the same.

The average of the first group is 65.85 and the average of the second group is 37.7 .

For the first group the sum of the squares of the differences from the average is:

$$
\begin{aligned}
(62-65.85)^{2} & +(72-65.85)^{2}+(62-65.85)^{2}+(96-65.65)^{2} \\
& +(50-65.85)^{2}+(69-65.85)^{2}+(50-65.85)^{2}
\end{aligned}
$$

Therefore the sum of squares of differences $=1488.78$.

For the second group the sum of the squares of the differences from the average is:

$$
\begin{aligned}
(31-37.7)^{2} & +(45-37.7)^{2}+(41-37.7)^{2}+(29-37.7)^{2} \\
& +(47-37.7)^{2}+(28-37.7)^{2}+(43-37.7)^{2}
\end{aligned}
$$


i.e. the sum of squares of differences $=393.25$.

The best estimate of the standard deviation is given by:

$$
\checkmark s_{1}^{2}+s_{2}^{2} / 2(n-1)
$$

where $n$ is the size of the sample. Therefore

$$
\begin{gathered}
V(1488.78+393.25) / 2(7-1)=\underline{12.52} \\
t=\frac{(\text { difference between sample average })}{\text { best estimate of standard deviation }} \times \sqrt{\text { sample size } / 2} \\
t=\frac{65.85-37.7}{12.52} \times \sqrt{7 / 2}=4.2
\end{gathered}
$$

The tabular value of $t$ with 12 degrees of freedom is 2.681 with 18 significance level. We are therefore justified in saying that there is a significant difference between the groups.

An alternative approach is to use the wilcoxan (rank sum) test. The wilcoxon test, starts by putting all the results in rank order, lowest first:

$\begin{array}{rrrrrrrrrrrrrr}28 & 29 & 31 & 41 & 43 & 45 & 47 & 50 & 50 & 62 & 62 & 69 & 72 & 96 \\ \text { A } & \text { A } & \text { A } & \text { A } & \text { A } & \text { A } & \text { A } & \text { B } & \text { B } & \text { B } & \text { B } & \text { B } & \text { B } & \text { B } \\ 1 & 2 & 3 & 4 & 5 & 6 & 7 & 8 & 9 & 10 & 11 & 12 & 13 & 14\end{array}$


The sum of the A rankings is:

$$
1+2+3+4+5+6+7=\underline{28}
$$

The sum of the B rankings is:

$$
8+9+10+11+12+13+14=\underline{67}
$$

We test to see whether this difference is too great. The table shows that with 7 in each sample the tabular value is 39 [see page 130 (4)]. Therefore, we can reject the null hypothesis at the $5 \frac{8}{8}$ level of significance.

\section{E.7 TEST ON RELATIONSHIP BETWEEN Z-SCORE AND A-SCORE}

In order to test the relationship between the Z-score and A-score, the correlation test is employed.

The ' $\mathrm{Z}$ ' and ' $A$ ' values for the "At risk 7" and "Solvent 7" groups are shown in Table and their average $\mathrm{Z}$ - and A-values are 1.92 and 51.75 respectively.

The standard deviation of $\mathrm{Z}-$ and A-scores is calculated as follows:

$$
\begin{aligned}
& S_{Z}=\sqrt{\frac{\Sigma(Z-\bar{Z})^{2}}{n-1}}=14 \\
& S_{A}=\sqrt{\frac{\Sigma(A-\bar{A})^{2}}{n-1}}=18.9 \\
& S_{A Z}=\sqrt{ } \frac{\sum(Z-\bar{Z})(A-\bar{A})}{n-1}=179.18
\end{aligned}
$$

where $n=14$. 
The correlation coefficient is now given by:

$$
r=\frac{S_{Z A}}{S_{Z}-S_{A}}=\frac{179.18}{14 \times 18.9}=67.78
$$

and the equation of the regression line is

$$
\begin{gathered}
A=\left(\frac{S_{Z A}}{S_{Z}^{2}}\right)(Z-\bar{Z})+\bar{A} \\
A=\frac{179}{196}(z-1.92)+51.75 \\
A=0.9 Z-1.75+51.75 \\
A=0.9 Z+50
\end{gathered}
$$

where $\mathrm{Z}=0, \mathrm{~A}=50$.

Clearly, the value of $r=0.677$ which indicates that a real correlation exists, but is not strang enough, as usually a correlation coefficient of more than 0.7 indicates a strong relationship. However, the Z-score value of zero corresponded to an A-score cut-off value of 50 , these being critical values in both models. 


\begin{tabular}{lrrrrrr}
\hline$Z$ & $A$ & $(\mathrm{~A}-\bar{A})$ & $(\mathrm{Z}-\overline{\mathrm{Z}})$ & $(\mathrm{A}-\overline{\mathrm{A}})^{2}$ & $(\mathrm{Z}-\overline{\mathrm{Z}})^{2}$ & $(\mathrm{~A}-\mathrm{A})(\mathrm{Z}-\mathrm{Z})$ \\
\hline-8.1 & 62 & 10.3 & -10.02 & 106 & 100 & -105 \\
-6.5 & 72 & 20.3 & -8.42 & 412 & 70.9 & -170.9 \\
-4.47 & 96 & 44.3 & -6.39 & 1962 & 40.8 & -283 \\
-8.23 & 50 & -1.7 & -10.17 & 2.89 & 103.4 & +17.3 \\
-26.3 & 69 & 17.3 & -28.22 & 299 & 796.3 & -488 \\
-6.5 & 50 & -1.7 & -8.42 & 2.89 & 70.7 & +14.3 \\
-11.7 & 62 & 10.3 & -13.67 & 106 & 186.8 & -140.8 \\
16.15 & 31 & -20.7 & +14.23 & 429 & 202.5 & -294.5 \\
14.0 & 43 & -8.7 & 12.08 & 75.7 & 145.9 & -105 \\
7.6 & 41 & -10.7 & 5.68 & 114.5 & 32.2 & -60.7 \\
10.5 & 29 & -22.7 & 8.58 & 515.3 & 73.6 & -194.7 \\
23.2 & 47 & -4.7 & 21.28 & 22 & 452.83 & -100 \\
10.0 & 45 & -6.7 & 8.08 & 44.9 & 65.2 & -54 \\
17.3 & 28 & -23.7 & 15.38 & 561.7 & 236.5 & -364.5 \\
26.88 & 725 & & & 4654 & 2577 & -2329.4 \\
& & & & & & \\
\hline & & & & & & \\
\hline
\end{tabular}

$$
\overline{\mathrm{Z}}=1.92, \overline{\mathrm{A}}=51.75
$$

TABIE E.5 


\section{E.8 APPENDIX REFERENCES}

1. Deakin, E.B. (1976). Distribution of financlal accounting ratios, some empirical evidence. The Accounting Review, Vol. 51, No. 1 (January 1970), pp 90-06.

2. Taffler, R.J. 1976. Finding those firms in danger using discriminant analysis and financial ratio data. A comparative UK-based study City University Business School Working Paper No. 3 (September 1977).

3. Troy, D. PhD Thesis, Alabama University, USA (1967).

4. Foundation of Statistics, 1980. Philip Mantagnon, Stanley Thornes Publishers Ltd. 